\title{
LA ONTOLOGÍA DE LO SOCIAL
}

\author{
Una aproximación a partir de John Searle
}




\section{Índice general}

5 Introducción

$\begin{array}{ll}6 & \text { I } \\ 8 & \text { II } \\ 9 & \text { III } \\ 10 & \text { IV } \\ 12 & \text { V } \\ 13 & \text { VI } \\ 15 & \text { VII }\end{array}$

17 Capítulo 1: Sobre el realismo externo

17 Introducción

18 Realismo y antirrealismo

23 Hechos dependientes e independientes del observador

23 Sobre las versiones múltiples

26 La construcción de los mundos goodmanianos

28 Sobre el realismo externo. Una defensa

38 Capítulo 2: Conciencia y lenguaje

38 Introducción

39 Sobre el significado

46 Linguistic turn y pragmatic turn. El aporte de Apel

55 Filosofía tradicional y filosofía analítica. El aporte de Tugendhat

61 Conciencia y lenguaje. El aporte de Dummett

63 A modo de conclusión

65 Capítulo 3: Los actos de habla 
65 Introducción

66 El aporte de Searle I

68 1. Tipos de actos de habla

72 2. Reglas

73 3. Actos de habla y significado

77 4. Retornando a los hechos en bruto e institucionales

78 5. Los actos ilocucionarios: el ejemplo de las promesas

81 La profundización de Searle

84 Conclusión

85 Capítulo 4: Lenguaje y sociedad

85 El lenguaje como fenómeno natural

87 Lenguaje y sociedad

91 Representación y expresión

95 Condiciones de satisfacción

97 Composición sintáctica

100 Deontología

102 Lenguaje e instituciones: una aproximación

104 Conclusiones

108 Capítulo 5: Un enfoque antropológico

108 Introducción

108 El enfoque antropológico de Searle

111 La antropología filosófica de Ernst Tugendhat

113 Sobre la comprensión humana

118 El lenguaje proposicional

121 Los términos singulares

124 El decir "yo"

129 Observaciones finales

132 Capítulo 6: La intencionalidad colectiva 
132 Planteamiento del problema

134 ¿Intencionalidad colectiva versus intencionalidad individual?

137 El cooperativismo en Tomasello. Una aproximación

144 La cognición y la comprensión del infante

149 Sobre el "nosotros"

150 Palabras finales

151 Capítulo 7: Asignación de función

151 Introducción

153 Asignación de función. Sus tipos

157 La prioridad de los hechos en bruto

159 El trinquete cultural

162 Lenguaje y realidad institucional

169 Sobre el contexto $C$

172 A modo de conclusión

173 Capítulo 8: El problema de las normas

173 Introducción

173 Los actos de habla y sus reglas

181 La realidad institucional y sus reglas

183 Sobre " $X$ cuenta como $Y$ en $C$ "

190 Críticas a Searle y conclusión

192 Capitulo 9: Los conceptos institucionales. Una aproximación

192 Planteamiento del problema

193 Teoría cúmulo y realidad institucional

195 Designadores rígidos y conceptos institucionales

195 I 
197 II

199 Palabras finales

\section{Conclusiones}

205 Bibliografía consultada 


\section{Introducción}

El presente trabajo es el producto de una serie de inquietudes y problematizaciones referidas a dos grandes ámbitos del pensamiento, la teoría social por un lado, y la filosofía del lenguaje por otro. A partir de allí, hemos desarrollado la presente tesis en torno a la obra de John Searle, autor muy difundido y discutido en los países de habla inglesa, pero muy poco trabajado en nuestras latitudes (aunque el tratamiento que ha tenido una de sus obras, Actos de habla, constituye una genuina excepción). La intención de la presente obra es contribuir a edificar una teoría de la sociedad o, como se la suele llamar en el mundo anglosajón, una filosofía de la sociedad. Si hemos elegido centrarnos en la obra de Searle es porque consideramos que ha sabido escoger los problemas adecuados y, más allá de algunos distanciamientos, su teoría de la sociedad es efectiva. Pero, ¿qué significa que una teoría sea efectiva? Searle propone una formalización lógica de la sociedad; ese es su mayor logro, poder dar cuenta en una fórmula del funcionamiento de todas las relaciones sociales. Si, de todas. Todo hacer social se ajusta a la formulación "Un $X$ en el contexto $C$ es un $Y$ ". Y Searle lo lleva a cabo de un modo satisfactorio.

Nuestro interés, como decíamos, vincula el problema del lenguaje y el problema de las relaciones sociales; y partimos de la siguiente afirmación: todo lo que no es lenguaje es naturaleza; el mundo social o, para usar la terminología de Searle, los hechos institucionales, tienen una estructura lingüística. Esta tesis no es original en absoluto, todos los teóricos del lenguaje -tanto los analíticos como los continentales, lo han advertido; la arena sociológica, sin embargo, se ha mostrado hostil a abordar el problema del lenguaje como un problema central. ¿Por qué eso ocurre? No lo sabemos, posiblemente se debe a un cierto prejuicio: el apego de la disciplina a los autores clásicos (o a una lectura particular de ellos). Los autores clásicos de la sociología, Durkheim, Marx, Weber y Simmel, no tematizaron, salvo en casos excepcionales, el problema del lenguaje como un problema central. Y la razón es que todos ellos son autores previos al giro lingüísticos, son autores que no se han podido nutrir de las obras de Frege, Russell, Wittgenstein, Gadamer, Heidegger, por citar algunas figuras destacadas. Lo curioso es que los autores contemporáneos que abordan los temas referidos a la teoría social, tampoco se interesan por el lenguaje de un modo central. La excepción es Habermas quien, gracias a Apel, aborda el problema de lenguaje como una problema fundamental para la teoría social. Con la pretensión de salvar este descuido al interior de las 
reflexiones sobre las relaciones sociales, hemos delineado una tesis sobre Searle; autor formado dentro de la tradición analítica del lenguaje y que, poco a poco, se ha interesado por cuestiones más generales, hasta elaborar una teoría de la realidad social, una ontología de lo social.

Antes de pasar al análisis de la obra propiamente, consideramos necesaria una digresión más. Estimamos que suele subestimarse la obra de Searle, acusándolo de "simplista"; por el contrario, entendemos que muchas veces se confunde la sencillez con la profundidad. Esto es un error; el teórico (de la sociedad, del lenguaje, de lo que fuere) debe tratar de exponer sus ideas y argumentos del modo más sencillo posible. Las teorizaciones deben ser lo más transparentes posibles porque, de ese modo, se observan los errores y las fallas; el exceso de complejidad y de sofisticación suele desembocar en puntos oscuros y en perplejidades que inhiben la reflexión. La teoría de Searle es sencilla. Y ese es uno de sus puntos fuertes. Todo lo que se quiera decir, debe ser dicho de un modo claro, esa es la única manera de progresar, tanto en el derrotero del pensamiento, como en la vida en general.

Hecha ya la aclaración, a continuación desplegaremos una breve síntesis de todas las problemáticas que hemos abordado a lo largo de la presente obra; ello es necesario porque nuestra tesis analiza, desmenuza y critica la obra de Searle punto por punto, lo cual podría generarle al lector poco familiarizado con la obra de Searle, una ausencia del sentido de unidad que ha tenido su obra a lo largo de los años. Si bien Searle es un autor prolífico y se ha inmiscuido en distintos problemas, tales como la filosofía del lenguaje, la intencionalidad, la filosofía de la mente, y la teoría de la realidad social, entendemos que su esfuerzos han estado dirigidos al problema de la ontología social. Nosotros, aclaramos, no hemos tematizado todos los problemas por los que Searle se ha interesado desde hace cincuenta años; no sería posible un trabajo tal en una tesis; se hubieran necesitado varias. Aquí nos hemos enfocado, arbitrariamente, por supuesto, en su filosofía del lenguaje y en su teoría de la realidad social. Pero es hora de terminar con los preámbulos y pasar al análisis de la obra de Searle.

I.

Como decíamos, la obra de Searle se centra en el carácter ontológico del mundo social; es decir, en el modo en que las acciones epistémicamente subjetivas, dependientes del 
observador, constituyen estructuras ontológicas independientes del observador. Las preguntas rectoras de la presente investigación podrían resumirse del siguiente modo: ¿cuál es la especificidad del ser humano?, ¿qué nos diferencia de los primates y del resto de los animales de nivel superior?, ¿por qué estos últimos no son capaces de leer diarios, casarse, elegir gobernantes, hacer guerras o salir de compras?, ¿por qué unos forrajean y otros van a los supermercados? Podríamos resolver éstos problemas teniendo en cuenta que los seres humanos, a diferencia del resto de los animales, poseemos un cerebro con un nivel de desarrollo increíble. Sin embargo, la neurobiología es capaz de explicar algunas, pero no todas las complejas relaciones que los seres humanos entablan entre sí y con la naturaleza. Los humanos hacemos algo más que vivir y realizar tareas juntos (hechos sociales); hemos dado el paso hacia la creación de hechos institucionales -tales como el dinero, los gobiernos, las universidades, los casamientos, la elección de presidentes.

Acordamos en sostener que la realidad social es un esfuerzo colectivo tendiente a cumplir ciertas metas y objetivos, a través de un seguimiento de reglas (Wittgenstein, 2008; Searle, 1994; Winch, 1990). Cómo es posible lograrlo y cuál es la especificidad del ser humano, aquello que lo distingue del resto de los animales de nivel superior, son nuestras preguntas fundamentales. Por eso mismo, aquello que aquí nos interesa es dar cuenta de una porción del mundo; nos referimos al mundo social. Los seres humanos no viven en un medio ambiente en bruto; por el contrario, lo moldean, lo constituyen y tienen la capacidad de realizar enunciados respecto de sus vidas y entorno; así, existen ciertas diferencias entre los humanos y el resto de los animales de nivel superior.

Llegados a este punto, es preciso hacer referencia a un elemento que es central en la obra de Searle; hay una cierta porción de la realidad que es dependiente del observador, y otra que es independiente del observador. Para abordar esta diferenciación, Searle elabora su teoría del realismo externo. En el primer capítulo analizaremos la diferencia entre los hechos en bruto, es decir, de los hechos que no dependen del observador, como por ejemplo, que haya nieve en la cima del Monte Aconcagua; y los hechos sociales e institucionales, que sí dependen del punto de vista del actor, como por ejemplo, la existencia de Estados, matrimonios, presidentes y dinero.

Podríamos decir, a riesgo de ser un tanto tajantes (y simplistas), que las ciencias naturales se ocupan de la porción del mundo que no depende del observador, y las ciencias sociales estudian la otra porción que sí depende del observador. Sin embargo, un mismo objeto puede ser analizado desde ambas perspectivas. Así, por ejemplo, una 
mesa es un conjunto de partículas, moléculas y átomos que en absoluto dependen de la intencionalidad o de la capacidad predicativa del observador; pero se trata, a la vez, de un objeto creado por el hombre, un objeto cultural que no ha comenzado a existir a la par de los ríos, las montañas y los mares.

Lo interesante es observar que ciertas características relativas al observador (la realidad social e institucional) tienen una existencia epistémicamente objetiva aunque dependan ontológicamente de observador, es decir, aunque sean ontológicamente subjetivas. Por eso mismo, su posición realista es externa; este realismo, como veremos, se diferencia del realismo interno de Putnam y de posiciones anti-realistas, como la desarrollada por Nelson Goodman.

II.

En la actualidad, los biólogos utilizan el término cultura para cuando se produce un aprendizaje social en el que los distintos grupos de la especie hacen cosas de manera distinta. Los seres humanos representan el caso paradigmático dentro de las especies animales, porque se han diseminado por todo el planeta y donde quiera que vayan, inventan herramientas y técnicas comportamentales para adaptarse al medio ambiente. Pero los animales humanos no sólo son únicos en términos cuantitativos; los seres humanos son capaces de crear un mundo institucional y eso se debe básicamente, a cuatro elementos. El primero de ellos y más importante es el lenguaje. Tan importante es, según trataremos de demostrar, que abarca tres de los ocho capítulos del presente trabajo. En el capítulo dos, damos cuenta de la prioridad metodológica que tiene el lenguaje respecto de la conciencia intencional, haciendo girar la discusión en torno a las diferencias entre el paradigma del lenguaje (representado de Apel) y el de la conciencia, paradigma que comienza con Descarte y encuentra en Husserl a su último gran exponente; extrañamente, Searle, a partir de su obra Intencionalidad de 1983 se ubica entre las filas de esta última tradición. Decimos que esto es extraño porque con su obra Actos de habla del año 1969, parecía ubicarse dentro de la tradición analítica del lenguaje.

El capítulo tres es un capítulo atípico; si bien en el resto de los capítulos contrastamos la posición de Searle con la de otros autores para, finalmente, sacar nuestras propias conclusiones que, unas veces le dan la razón a Searle y otras no (por eso mismo, el 
presente se trata de un estudio crítico-constructivo), en este capítulo haremos meramente una exposición de la teoría de los actos de habla que Searle ha desarrollado a lo largo de los años. La razón por la cual optamos por no entrar en discusiones es que, justamente, este es el tema que más se ha trabajado y discutido de la amplia obra de Searle (tanto en el mundo anglosajón como en nuestro país). El material al respecto es sumamente extenso y el propósito de nuestra tesis es abordar problemáticas que no se encuentran en las discusiones que los académicos de nuestro país suelen sostener. El Searle que a continuación analizamos es el Searle "desconocido", el que se ha leído muy poco, el que ha pasado casi desapercibido para los teóricos no sólo argentinos, sino para los de habla castellana en general. Muestra de ello es la baja cantidad de material que han producido los teóricos de habla hispana al respecto. Nuestro trabajo, modestamente, intenta saldar esa deuda.

A partir del capítulo cuarto, comenzamos a adentrarnos en la vinculación entre el lenguaje y el resto de los aspectos sociales y culturales. Si bien el lenguaje, y la posibilidad misma de adquirir un lenguaje, tienen un componente biológico, la impronta cultural es fundamental; tal es así que, un infante humano aislado del contacto con el resto de su especie, sería incapaz de convertirse en un hablante competente. Pero si bien tenemos una disposición natural, biológica, para adquirir el lenguaje proposicional, jamás podríamos adquirirlo sin las enseñanzas del resto de la comunidad de hablantes. A partir de éste capítulo comenzamos a dar cuenta de la normatividad y del resto de la realidad institucional, una realidad que tiene la forma, " $U n X$ en un contexto $C$ cuenta como un $Y$ ". El lenguaje, como le gusta decir a Searle, is like a glue. Es un "pegamento" que mantiene unida a la realidad social e institucional; sin él, viviríamos en la mera animalidad; es él, junto a otros elementos, aquello que nos permite a los seres humanos desarrollar un medio ambiente que logra trascender (en el sentido de ir más allá) la realidad en bruto, estrictamente natural.

III.

En los capítulos seis, siete y ocho, analizaremos esos otros elementos que posibilitan la existencia de los hechos institucionales; nos referimos a la intencionalidad colectiva, las funciones de estatus, y las normas constitutivas. Pero antes de eso, en el capítulo cinco, daremos cuenta de un problema que es central tanto para una filosofía del lenguaje, 
como para una teoría de la sociedad, nos referimos a ciertas problemáticas referidas a la antropología filosófica; aquí adoptaremos la perspectiva desplegada por Ernst Tugendhat. Entendemos que todo planteo, toda pregunta sobre el lenguaje o sobre las instituciones humanas debe edificarse sobre un planteo más fundamental en el sentido de más básico. Esa pregunta más básica que debe actuar como un punto de partida es, “¿qué es el hombre?" Y ello es así porque es el hombre quien adquiere el lenguaje; es el hombre el que constituye una realidad institucional; es el hombre el que declara la guerra, se casa, crea y usa el dinero, crea universidades, estados y presidentes. Una pregunta por todos esos aspectos debe incluir a la pregunta fundamental, “¿qué es el hombre?”. Estimamos que el planteo de Tugendhat nos brinda una respuesta y un planteo completamente pertinente para nuestro trabajo y, por eso mismo, consideramos pertinente tomar su respuesta a esa pregunta fundamental en el corazón de nuestro trabajo. La antropología debe actuar como filosofía primera porque incluye a todas las otras preguntas filosóficas y a todas las disciplinas filosóficas, como así también a todos los planteos referidos a las relaciones sociales e institucionales.

Recién tras haber aclarado las diferencias entre los hechos que dependen del observador, de los hechos que no dependen del observador, después de haber tematizado las cuestiones referentes al lenguaje, y haber aclarado que la antropología humana es excepcional, estamos en condiciones de seguir profundizando los puntos en los cuales los animales humanos nos diferenciamos del resto de los animales de nivel superior. A pesar de que gran parte de nuestro material genético es exactamente igual al de los simios, existen ciertas características que nos permiten construir un mundo institucional que ellos no poseen. Todo ello es posible gracias al lenguaje, y es éste uno de los aspectos fundamentales pero, repetimos, no es el único.

En el capítulo seis analizaremos otro componente de la realidad institucional: la intencionalidad colectiva.

IV.

Searle sostiene que existen dos formas de intencionalidad, la primera es del tipo, "tengo la intención de", "creo", "espero"; la segunda tiene la forma "tenemos la intención de", "creemos", "esperamos". La tradición filosófica ha supuesto que el segundo tipo de intencionalidad -la intencionalidad colectiva o del "nosotros"- es reductible a la primera - 
la intencionalidad individual o del "yo"-. Por ejemplo, para que juguemos un partido de futbol es preciso, ante todo, que yo tenga la intención, el deseo, la voluntad de jugarlo. Si los veintidós yo no tuvieran la intención de jugar el partido, no habría partido posible. Pero si la intencionalidad está en la cabeza de cada uno de nosotros, ¿cómo es posible algo así como la intencionalidad colectiva? Gran parte de la tradición entiende a la intencionalidad individual o del "yo" como una protointención; Searle, por el contrario sostiene que la intencionalidad primitiva o protointención no es la individual o del "yo", sino la colectiva o del "nosotros". La mayoría de los filósofos reducen el "tenemos la intención de", "creemos", "esperamos", al "tengo la intención de", “creo", "espero".

Para aclarar ciertos puntos recurriremos al planteo de Michael Tomasello; tanto Searle como Tomasello critican a la tradición porque generalmente se ha supuesto que, cuando dos personas tienen una intencionalidad colectiva, es decir, cuando intentan hacer algo juntas (o lo hacen efectivamente), cada una de ellas tiene la intencionalidad del tipo, "tengo la intencionalidad de hacer tal y tal cosa" y a la vez "creo que tú también tienes esa misma intención”. Además, tengo que creer que tú crees que yo creo que tú tienes esa intención; eso a su vez, genera una regresión no viciosa del tipo, "creo que tú crees que yo creo que tú crees que yo creo", etcétera; mientras que por tu parte, "tú crees que yo creo que tú crees que yo creo que tú crees", etcétera. A estas creencias iterativas sobre creencias de dos o más personas, se las denomina creencias mutuas. Searle sostiene que todo este enfoque, que reduce la intencionalidad colectiva a la intencionalidad individual más la creencia mutua, está equivocado. Tanto para Searle como para Tomasello, en nuestras cabezas existe la intencionalidad colectiva de un modo primitivo.

De éste modo, "tenemos la intención de" está en mi cabeza individual. Cuando dos o más personas hacen algo juntas, cada una de ellas, individualmente, tiene la forma "tenemos la intención de". Ello tendrá consecuencias para lo que yo creo y para lo que yo tengo intención de hacer. Existe intencionalidad colectiva cuando hay gente cooperando, cuando comparten sus deseos, sus pensamientos, sus intereses, etcétera. La intencionalidad colectiva es el fundamento de todas las actividades sociales.

Pero existen ciertas diferencias entre ambos autores, y esa disonancia es, precisamente, la que pretendemos destacar. A diferencia de Searle, Tomasello $\left(2007,2010,2010^{a}\right)$ sostiene que el resto de los animales de nivel superior no poseen un sentido del nosotros; no tienen, por lo tanto, intencionalidad colectiva. El sentido exclusivamente humano del nosotros puede ser observado, no sólo en el mundo institucional de los supermercados, las tarjetas de crédito y los gobiernos, sino que está presente en ejemplos mucho más 
simples. A diferencia de los chimpancés, los humanos se plantean metas conjuntas con sus compañeros y lo hacen a temprana edad, muy poco después de cumplir un año. Searle, no realiza esta distinción conceptual y sostiene que cuando dos o más agentes "hacen algo juntos", tienen ya intencionalidad colectiva; cuando ello ocurre, Searle habla de hecho social. Los hechos sociales, dentro de su perspectiva, no son privativos de los seres humanos; los animales que cazan juntos, los pájaros que se agrupan para confeccionar sus nidos, las hormigas y las abejas que trabajan conjuntamente también poseen intencionalidad colectiva.

Más allá de las discusiones divergentes, lo que nos interesa es dejar constancia del problema de la intencionalidad colectiva como uno de los pilares que posibilitan el desarrollo de aquello que denominamos, la realidad institucional. En el capítulo siete, por su parte, daremos cuenta de otro elemento fundamental de la realidad institucional; nos referimos a la asignación de función.

v.

Los seres humanos tenemos la capacidad de asignarle a ciertos elementos una serie de funciones que no tiene una vinculación directa con sus características físicas. Tanto los seres humanos como el resto de los animales de nivel superior pueden usar un palo, por ejemplo, para golpear a un animal o para bajar un plátano; de esta manera se estaría haciendo algo así como usar el palo como la "extensión de la mano". Muchos simios, de hecho, usan ramas para bajar frutos que se encuentran a una altura considerable. Pero ningún simio utiliza un trozo de madera como, por ejemplo, una barrera. $Y$ no pueden hacerlo porque las barreras de los ferrocarriles no actúan como barreras gracias a sus exclusivas capacidades físicas. Muy por el contrario, nosotros los seres humanos, le asignamos a ese trozo de madera una función determinada: prohibir la circulación de peatones cuando el tren se acerca, a los fines de prevenir cualquier tipo de accidente fatal. De lo que se trata es de una capacidad exclusivamente humana de asignarle funciones a los objetos; esas funciones sobrepasan sus propiedades estrictamente físicas. A ese tipo de funciones Searle las denomina, funciones de estatus; y tienen la forma lógica, "Un $X$ en un contexto $C$, es un $Y$ ". Así, un trozo de madera en un contexto en particular y bajo ciertas condiciones, actúa como una barrera. Esa forma lógica tiene la 
capacidad de dar cuenta de todos los hechos institucionales. Y es ese el gran logro de Searle.

Además, el enunciado " $X$ cuenta como $Y$ en el contexto $C$ ", expresa un tipo de normas que también son centrales para la construcción de la realidad social. Nos referimos, tal como lo veremos en el capítulo ocho, a las normas constitutivas. Existen ciertas normas que regulan formas de comportamiento previamente existentes; tales como, por ejemplo, las normas de tránsito. La norma que indica que "se debe sobrepasar a otro auto por el lado izquierdo de la calzada", da cuenta de un comportamiento previo: la gente se moviliza en autos; y ello necesita cierta regulación. A este tipo de normas, Searle las denomina normas regulativas; ellas son las que regulan actividades que existen con independencia de las normas; son del tipo "hágase esto o hágase esto otro", y tienen generalmente la forma, "Haz $X$ " o, "Si $X$ entonces $Y$ ". Por otro lado, contamos con normas que constituyen o hacen posible la actividad que regulan. El ejemplo característico son las reglas de los juegos. Las mismas, no tienden a mejorar las características del juego sino que, por el contrario, lo constituyen, lo hacen posible. La posibilidad misma de jugar requiere que existan normas; estas reglas constituyen el modo en que se juega el juego. Por ello, Searle habla de normas constitutivas. Lo que Searle sugiere es que la distinción entre hechos brutos y hechos institucionales sólo puede ser cabalmente comprendida teniendo en cuenta la noción de normas constitutivas; los hechos institucionales sólo existen dentro del sistema de normas de ese tipo.

\section{VI.}

Cabe preguntarnos finalmente, ¿cómo puede ser posible que la realidad institucional sea tan poderosa?; la fórmula general " $X$ se considera como $Y$ en $C$ ", ¿no es demasiado simple como para representar la complejidad institucional? Aquí Searle (1997) introduce dos mecanismos sumamente simples que posibilitan aclarar el problema. En primer lugar, la estructura " $X$ se considera como $Y$ en $C$ " puede iterarse. Las funciones de estatus se acumulan sobre otras funciones de estatus. El término $X$ en un determinado nivel, puede actuar como $Y$ en un nivel anterior; así, pueden convertirse los términos $Y$, en $X$. En las sociedades complejas, además, el término $C$ suele ser un término $Y$ de una fase anterior. Grafiquemos esto mediante ejemplos. Profiero ruidos por la boca. Ese es un hecho bruto, hacer ruidos no tiene nada de institucional. Pero yo soy, sin embargo, un hablante 
competente del castellano que me dirijo a otro hablante competente de mi lengua madre; por tanto, esos ruidos se consideran como la expresión de una frase castellana. Este es un ejemplo de la fórmula " $X$ se considera como $Y$ en $C$ ". Ahora, en una expresión de esa frase castellana, el término $Y$ del nivel previo funciona como un término $X$ en un nivel superior. La expresión de esa frase castellana, con una intencionalidad y en un contexto determinado funciona, pongamos por caso, como la formulación de una promesa. Ahora la promesa, considerada como $Y$, funciona como término $X$ en un nivel superior. Formular ese tipo de promesas en un contexto determinado, se considera como suscribir un contrato. El planteo de Searle, como vemos, es el siguiente, ha partido de un hecho en bruto -los ruidos proferidos por la boca-, y ha acumulado posteriores términos $Y$ por la aplicación repetida de la fórmula. $Y 1$ se convierte en $X 2$, que se considera como $Y 2$, la cual se convierte en $X 3$, y así sucesivamente hasta llegar al punto de la subscripción del contrato. En un nivel superior, podemos suponer que ese contrato funciona como casarse. A su vez, casarse se considera como estar sujeto a una serie de derechos, deberes, obligaciones, beneficios, responsabilidades, etcétera. De este modo se van creando y reconfigurando estructuras cada vez más complejas; solo basta con iterar el mecanismo una y otra vez. En muchos casos, además, el término $C$ es producto de una asignación previa de función de estatus. Por ejemplo, en Argentina, para casarse es necesario estar en presencia de un funcionario autorizado. Ser un funcionario autorizado es el resultado de una función de estatus. Los seres humanos no sólo heredan genes biológicos sino también una historia cultural que se modifica y transmite a las generaciones siguientes. Para decirlo con Tomasello, los seres humanos poseemos una "doble herencia" [biológica y cultural]; esto es propio y exclusivo de nuestra especie animal.

Otra característica central para comprender el funcionamiento de las instituciones humanas es que los hechos institucionales no existen aisladamente, sino en interrelaciones recíprocas complejas. Veámoslo con un ejemplo. Tengo dinero porque lo he ganado como empleado de la Nación Argentina; me lo depositan en mi cuenta bancaria y lo utilizo para pagar los impuestos y las facturas que debo a las compañías de luz, gas, teléfono. Observamos así que las palabras destacadas obedecen a términos institucionales, hacen referencia a la interconexión de la realidad social e institucional. A los fines de aclarar el modo en que se interrelacionan los hechos brutos con la realidad institucional, Searle da un paso más y sostiene que no debemos pensar los hechos en bruto independientemente de los institucionales; no se trata de dos grupos de hechos 
separados y excluyentes. La finalidad de los hechos institucionales es lograr el control de los hechos en bruto. Recientemente he proferido una serie de ruidos y he intercambiado algunos trozos de papel con un grupo de desconocidos; como resultado de ello, pude subirme a un micro y, al recorrer largas distancias he modificado en bruto mi situación geográfica. Gracias a las funciones de estatus, vivo en un departamento y en una localidad que de otro modo no me sería posible. Gracias a la asignación de estatus, la gente va a la guerra, es encarcelada y ejecutada, entre otras cosas.

VII.

Finalmente, realizaremos un último aporte a la teoría de la realidad social desplegada por John Searle. Este aporte tendrá la peculiaridad de ser tentativo e introductorio; no será aquí pertinente desarrollarlo in extenso, sino que más bien, lo tematizaremos y lo desarrollaremos con un escaso nivel de complejización y detalle. Searle sostiene que su teoría de los nombres propios, conocida por la tradición como "teoría cúmulo" resulta útil para comprender conceptos institucionales tales como, "dinero", "Historia", "capitalismo", "presidente", "Estado"; por nuestra parte, sin embargo, consideramos que un tratamiento tal es insatisfactorio y, por ello mismo, será conveniente analizar esos conceptos institucionales a la luz de la teoría de los designadores rígidos desarrollada por Saúl Kripke en las conferencias agrupadas en Naming and Necessity, del año 1981.

Recientemente, en una obra del año 2011, Philosophical Troubles, Kripke aplica su noción de designador rígido, que había sido diseñada para analizar los nombres propios, con el objetivo de comprender el uso de la primera persona. Del mismo modo, aquí sostendremos que resulta completamente pertinente utilizar su teoría de los designadores que operan rígidamente, para desplegar un tratamiento y una mayor comprensión de dichos conceptos institucionales. Consideramos que de este modo se posibilita un mejor desarrollo de la teoría de la realidad social de Searle, y puede ser legítimamente considerada como un avance en el camino de la clarificación conceptual de los problemas que aquí nos interesan.

Tras esta breve introducción, estamos en condiciones de adentrarnos en un análisis un poco más detallado de la teoría de la realidad social (o de la ontología de lo social) propuesta por John Searle. Nuestra intención es dar cuenta de aquellos elementos que 
nos distinguen del resto de los animales de nivel superior, sin olvidar que nosotros mismos somos animales y que las diferencias con nuestros parientes más cercanos, los chimpancés, no son tan amplias como generalmente creemos; lo único que nos diferencia son un puñado de características que desarrollaremos con mayor precisión a continuación. 


\section{Cap. 1: Sobre el Realismo Externo}

\section{Introducción}

La noción de realismo es aplicable a una vasta cantidad de dominios, desde la ética y la estética, hasta las ciencias, la modalidad, la semántica, las matemáticas, y los objetos cotidianos que podemos observar a través del microscopio. De éste modo, se puede sostener una posición realista en un campo, y una anti-realista en otro; así también, la línea divisoria entre realismo y anti-realismo, en relación a un campo específico, puede permanecer borrosa o confusa. La Stanford, distingue dos aspectos generales del realismo. En primer lugar, aquello que se refiere a la existencia. Las mesas, las rocas y el sol, por ejemplo, tienen una existencia determinada: las mesas son cuadradas, las rocas son de granito y el sol es amarillo. Todas estas cualidades son independientes del observador, se ubican más allá de su conciencia, de su mente y de su capacidad predicativa. Aquí se podría objetar que, si bien las rocas y el sol no dependen de las creencias de los sujetos (de hecho, las rocas y el sol existen con anterioridad al animal humano), con las mesas no sucede lo mismo, puesto que éstas sí han sido creadas por los seres humanos. De todos modos, el realista no se refiere a esta distinción; aquello que le interesa argumentar, por el contrario, es que los objetos del mundo cotidiano y sus propiedades, no dependen de nuestras prácticas lingüísticas o esquemas conceptuales. El anti-realismo, por su parte, adquiere diversas formas. Entre ellas, las teorías del error, el anti-constructivismo, el instrumentalismo, el nominalismo, ciertos tipos de reduccionismo y el eliminativismo típico.

Es posible diferenciar, según Searle, al menos dos posiciones anti-realistas que se oponen a la noción de existencia defendida por los realistas. En primer lugar, aquellos que rechazan la dimensión de existencia; en segundo lugar se encuentran quienes no niegan la existencia de los objetos, pero niegan la instanciación de sus características distintivas. La oposición clásica a la noción de independencia planteada por el realismo, ha sido el idealismo. El idealismo supone que los objetos cotidianos son, en algún sentido, objetos mentales. Tal como Berkeley clásicamente afirma, las rocas, las montañas y los lagos, no son más que ideas en la mente de los espíritus. Si bien el idealismo filosófico ha caído en desgracia, no ha faltado quien ha dudado de la noción de independencia defendida por el 
realismo. Nos referimos a Michael Dummett. Dummett, en su clásico artículo, El realismo ${ }^{1}$, plantea la disputa entre los realistas y los anti-realistas, no en relación a una clase de entidades o a una clase de términos, sino en relación a una clase de enunciados. Estos enunciados poseen un valor de verdad objetivo, es decir, independiente de nuestros medios para conocerlos; la realidad que los hace verdaderos o falsos es independiente de nosotros.

\section{Realismo y antirrealismo}

En el presente apartado nos centraremos en la noción que John Searle defiende respecto a la disputa entre realismo y anti-realismo. Para Searle, existen dos tipos de hechos, unos dependen de nosotros, y los otros no. Mientras que a los primeros los denomina hechos sociales e institucionales; a los segundos, hechos en bruto. Esta posición filosófica (altamente controvertida) sostiene que existe una realidad totalmente independiente de nuestras representaciones (a ello Searle lo denomina realismo externo, es decir, "externo" a nuestras representaciones); ello se emparenta con (pero no es idéntico a) la aceptación de una realidad ontológicamente objetiva (objetividad ontológica). Algunos estados mentales -como los dolores, son ontológicamente subjetivos, pero no son representaciones; si bien son independientes de la representación, no son independientes de la mente. De éste modo, la objetividad ontológica implica el realismo externo, pero no a la inversa (Searle, 1997, p. 161).

Lo que Searle remarca es que, si nunca hubieran existido seres humanos, el grueso del mundo existiría tal y como ahora lo conocemos, excepto una pequeña porción que es construida o se ve afectada por nuestras representaciones. Del mismo modo, cuando nuestra especie animal deje de existir (especie que cuenta con sólo dos millones de años de existencia), el mundo seguirá su curso inalterado. El monte Aconcagua, por ejemplo, más allá de lo que yo y el resto de los humanos enunciemos o pensemos al respecto, seguirá existiendo tal como lo conocemos. Así, el enunciado, "El Aconcagua es el pico más alto de Sudamérica" implica una serie de representaciones ${ }^{2}$ que no afectan en nada al Monte mismo. Searle afirma que la realidad no depende de las representaciones que

\footnotetext{
${ }^{1}$ En, Michael Dummett, La verdad y otros enigmas, FCE, México, 1990.

${ }^{2}$ Para Searle, el término "representaciones" es más amplio que, e implica a, los enunciados, las creencias, las percepciones, los pensamientos, el lenguaje.
} 
los seres humanos llevan a cabo sino que, por el contrario, es externa, se encuentra por fuera de sus creencias, deseos y lenguaje. Por eso mismo es que denomina a su posición realismo externo. La realidad está desligada de quién representa y de cómo lo hace.

Dentro de la concepción de Searle, el realismo es una teoría de la ontología, pero no es necesariamente una teoría de la verdad. El realismo no implica ni es idéntico a la teoría de la verdad como correspondencia; tampoco es una teoría semántica. Tampoco el realismo es una tesis epistémica; si bien gran parte de la tradición -desde el siglo XVII-, que ha atacado al realismo suponía que, "aquello que podemos conocer son los datos de nuestros sentidos"; pero ello no ofrece una crítica válida a la posición realista. Más adelante volveremos sobre ello.

Suele suponerse, por otro lado, que el realismo está comprometido con la teoría que supone que sólo hay un léxico óptimo para describir la realidad, que es la realidad misma la que determina cómo hay que describirla. Sin embargo, nada de esto está implicado con una posición realista; es perfectamente consistente aceptar el realismo y, a la vez, sostener la tesis de la relatividad conceptual, tesis que sugiere que para describir diversos aspectos de la realidad, pueden utilizarse diferentes léxicos que hasta pueden llegar a ser inconmensurables. En La construcción de la realidad social (1997), Searle sostiene que,

\begin{abstract}
El realismo, según yo uso el término, no es una teoría de la verdad, no es una teoría del conocimiento y no es una teoría del lenguaje. Y si se insiste en encasillarlo, podría decirse que el realismo es una teoría ontológica: dice que existe una realidad totalmente independiente de nuestras representaciones (p. 164).
\end{abstract}

En sentido estricto, el realismo no es una tesis sobre cómo es el mundo. Podríamos equivocarnos en cuanto al modo en que describimos el mundo y, aunque todos nuestros enunciados y representaciones fuesen falsas, no por ello la tesis realista sería una tesis falsa. El realismo sólo se remite a decir que las cosas tienen una manera de ser lógicamente independiente de todas las representaciones, pero nada dice sobre cómo las cosas son. Una cosa son las representaciones; otra, la realidad representada. Searle sostiene (1997, pp. 166-167) que al antirrealista le resulta imposible sostener que existe una realidad por fuera de nuestras representaciones, de nuestra mente; para el realista, aún si no hubiera objetos materiales, existiría, de todos modos, una realidad 
independiente, pues la no existencia de objetos materiales sería una característica de la realidad independiente de nuestras representaciones. Pero en este punto hay un error. El antirrealismo no niega la existencia de un mundo externo a nuestras representaciones, a nuestra conciencia o lenguaje. Lo que está en cuestión, tal como la cita de Dummett refería más arriba, es que podamos conocer (o siquiera hablar con sentido) de una realidad completamente independiente de nuestras representaciones, conciencia o lenguaje.

Es preciso recordar en éste punto, la proposición 5.6 del Tractatus: "los límites de mi lenguaje significan los límites de mi mundo"3. No quiero detenerme aquí a considerar la concepción figurativa del lenguaje que se encuentra en éste primer Wittgenstein. Tan sólo pretendo llamar la atención del pronombre personal posesivo mí. El lenguaje actúa como límite de mi mundo, de mi estructura de sentido. Actúa como un delimitador, imponiendo su estructura. Hacia esa misma dirección se edifica el andamiaje conceptual de Nelson Goodman, desde Hecho, ficción y pronóstico (1955) en adelante. Veamos.

El irrealismo goodmaniano no afirma que todo (o siquiera algo) sea irreal, sino que considera que existen distintas versiones del mundo, y esas versiones hacen mundos. La ontología, de ésta manera, es evanescente. Así, por ejemplo, que dentro de un sistema La Tierra esté en reposo, y dentro de otro, esté en movimiento, nada dice respecto de La Tierra en sí, sino de las versiones que dan cuenta de ella. Ante ello Goodman afirma que ambas visiones son verdaderas. Cada versión debe ser ubicada en su mundo. Las versiones que no se aplican al mismo mundo no entran en conflicto. Una versión sólo es verdadera en algunos mundos; una versión falsa lo es en ninguno. Es así como Goodman explica la multiplicidad de mundos: hay versiones verdaderas en conflicto, y ellas no pueden ser verdaderas en el mismo mundo (1995). No es posible hablar de las versiones del mundo y "el mundo"; éste último se evapora porque no hay ningún rasgo independiente de la versión. Nuestra pretendida versión neutral del movimiento se asienta en una serie de prejuicios; la distancia entre objetos, la velocidad y la aceleración son relativas al observador y a un marco de referencia ${ }^{4}$. Las versiones estructuran mundos. El

\footnotetext{
${ }^{3}$ Wittgenstein, Ludwig; Tractatus lógico-philosophicus, ed. Alianza, Madrid, 2009. La cursiva le pertenece al autor.

${ }^{4}$ En este punto (como en casi todos) Searle estaría plenamente en desacuerdo. No todos los hechos del mundo son relativos al observador. Sí lo son los hechos institucionales (el dinero, las Universidades, los Estados), pero no los hechos en bruto (las montañas, los ríos, las estrellas). Estos conjuntos de hechos presentan importantes diferencias en términos ontológicos. Si bien dentro de una investigación filosófica la diferenciación puede ser menor, decididamente no lo es dentro del marco de una investigación sociológica.
} 
mundo depende de la versión pero no es la versión misma ${ }^{5}$. Nelson Goodman, en De la mente y otras materias (1995) lo expresa del siguiente modo,

...Cuando afirmo que hacemos mundos: hacemos versiones y las versiones verdaderas hacen mundos (p. 64).

La idea central de Goodman es que mediante la creación verbal podemos hacer "que las estrellas bailen"; somos nosotros quienes hacemos las cosas mismas. Esto parece absurdo; solo a simple vista. Es preciso tener en cuenta que sólo las versiones verdaderas son capaces de hacer cosas (1995, p. 65). Goodman no sostiene que podamos hacer mundos a voluntad, libre y caprichosamente. En la obra citada (pp. 65, 66), Goodman pone un ejemplo interesante. Supongamos que me encuentro en una atestada sala en la que hay un equipo de sonido con placas de video y altavoces empotrados en una estantería; un receptor y un plato giratorio en un mueble situado en una esquina y un control remoto ubicado en una mesa estilo francés. Todo estaba allí antes de advertirlo; pero, ¿lo estaba para mí? Tras poder otorgar un contenido proposicional a todos y cada uno de los elementos de la sala, puedo descubrirlos, distinguirlos. Otro visitante, proveniente de una jungla inhóspita de la que nunca ha salido, no podría descubrir nuestro equipo de sonido y toda su parafernalia. Pero, ¿por qué no puede? Porque no posee los medios para conocerlos y descubrirlos. Carece de conceptos. Tampoco puede descubrir los libros y las plantas que nos rodean, pero puede descubrir lo que yo no: combustible y alimento para subsistir.

Otro ejemplo que Goodman propone (1995, pp. 66-67) es el de las constelaciones. ¿Han existido desde el momento en que existen las estrellas, o surgieron gracias a una selección y agrupación más o menos arbitraria? Decir que la constelación ha existido siempre, previamente a cualquier versión, significa que todas las configuraciones de estrellas son siempre, y en cualquier caso, constelaciones. Goodman sugiere que, afirmar que todas las configuraciones son constelaciones equivale a afirmar que ninguna lo es. Ahora bien, del mismo modo en que hacemos constelaciones seleccionando y agrupando ciertas estrellas y no otras, también hacemos estrellas trazando unas ciertas fronteras en lugar de otras. Si las estrellas han existido con anterioridad a todas las versiones, es por medio de una versión que ubica a las estrellas mucho antes que a sí misma. Como

\footnotetext{
${ }^{5}$ Al contrario de lo que sugiere Searle, hasta una posición tan radicalmente antirrealista como la de Goodman no niega la existencia de una realidad externa al lenguaje, la conciencia, la simbolización.
} 
vemos, al hacer mundos, el significado de la verdad no reside en aquellos mundos, sino en nosotros mismos, en nuestras versiones y en lo que hacemos con ellas.

Goodman, al contrario de lo que Searle le hace decir en La construcción de la realidad social (2004, pp. 166-167), reconoce la diferencia entre una versión correcta y su mundo. Lo uno y lo otro no son idénticos. Por ejemplo, una versión que afirme que las estrellas están allí, lejanas e imperturbables, no es ella misma lejana e imperturbable; las versiones no se hacen con letras. Por otro lado, si bien viene a ser superficialmente lo mismo decir que hay una estrella allí, lejana e imperturbable, y el enunciado verdadero, "Hay una estrella allí, lejana e imperturbable", una afirmación parece hacer referencia a una estrella mientras que la otra, a un enunciado. Por último, pero no por ello menos relevante, ningún rasgo-del-mundo es independiente de las versiones. En palabras de Goodman,

Todo lo que se puede decir con verdad de un mundo depende de la acción de decir -no del hecho de que lo que digamos sea verdadero, sino de que lo que decimos con verdad (o bien aparece como correcto) participa de y es relativo, no obstante, a un lenguaje o a otro sistema de símbolos que utilicemos- (1995, p. 74).

Ante la pregunta, ¿es posible trazar una clara frontera entre los rasgos-del-mundo que dependen del discurso y aquellos que no dependen de él? La respuesta de Goodman es, ciertamente no. Si bien debemos tener presente que no es lo mismo una versión del mundo, y el mundo, la distinción es sólo formal; en la práctica -según su posición-, carece de sentido. En De la mente y otras materias (1995, p. 75) advierte que existen dos complejos que permiten oponerse a la creación de mundos. El primero es el complejo según el cual, el-mundo-es-tan-maravilloso-que-yo-no-podría-haberlo-hecho-tan-bien, también conocido como el complejo, según el cual, sólo-Dios-puede-hacer-un-árbol. El segundo es el complejo que sostiene que el mundo-es-tan-terrible-que-no-quiero-ser-suresponsable. Ambos descansan en la misma falacia: suponer que podemos hacer cualquier cosa a nuestro antojo. Cierta porción de la realidad (fundamentalmente, la realidad social) puede crearse con cierto grado de capricho y poco nivel de conocimiento: una mesa, un adorno, la imitación de un cuadro, un libro, y cosas por el estilo. En éste punto Searle podría preguntarle al señor Goodman, si podemos fabricar, del mismo modo, estrellas, planetas y océanos. Por curioso que parezca, Goodman diría que sí es posible 
hacerlo. Tanto las estrellas, como los planetas y los océanos, son producto de versiones es cierto-, pero poseen un distinto estatus ontológico. Aquí es pertinente la diferenciación que Searle establece entre hechos que dependen del observador, y hechos que no dependen del observador.

\section{Hechos dependientes e independientes del observador}

No negamos aquí que los seres humanos elaboramos versiones que crean mundos, pero el punto central es que no todos los elementos o porciones de esos mundos se encuentran en el mismo nivel en términos ontológicos; quizás sí en términos epistémicos, pero decididamente distintos ontológicamente. Goodman insta a Scheffler $(1995$, p. 75$)$ a que demuestre qué rasgos de las estrellas no han sido hechos por nosotros y lo desafía a que explique cómo estos se diferencian de aquellos que dependen del lenguaje. El mismo reto podría solicitárselo a Searle; tanto éste como Scheffler sostienen que nosotros no hacemos las estrellas, ni los Cerros Aconcagua. Goodman tiene parte de la razón porque, como expusimos más arriba, lo que hace el lenguaje es crear una estructura, todo lo que se encuentra fuera de sus límites es incognoscible. Fuimos nosotros, los seres humanos, quienes en un tiempo pretérito "creamos" las estrellas y todas sus características; pero, ¿es posible equiparar esa creación con otra porción de la realidad, con la realidad social e institucional, conformada por dinero, Estados, Universidades y Bancos crediticios? Cierta y decididamente, no. La diferencia radica, no en el aspecto epistémico sino en el ontológico. El dinero y las estrellas son una creación epistémica porque para conocerlos es preciso imprimirles el sello del lenguaje pero, por otro lado y en términos ontológicos, hay una diferencia sustancial. Tenemos máquinas que crean dinero, y los gobiernos pueden fabricarlo siguiendo ciertos pasos burocráticos y con ciertas limitaciones. ¿Podemos hacer lo mismo con las estrellas? Ante ésta pregunta, y para decirlo una vez más, hay dos respuestas. Sí y no. Sí, en términos epistémicos; no, en términos ontológicos.

\section{Sobre las versiones múltiples}


Goodman utiliza otro ejemplo -el de los colores-, para referirse al error que implica aceptar una posición realista. Herbert Hochberg ${ }^{6}$ sostiene que el hecho de que "blanco" se aplique a una serie de cosas, no las hace blancas; más bien, se las nombra "blancas" porque son blancas. Este planteo, según Goodman, está equivocado. Es evidente que no puedo hacer, por mero capricho, que los términos denominados "blanco" sean rojos -al aplicarles el término "rojo". Pero, no es menos cierto que la lengua castellana los hace blancos cuando, precisamente, les aplica el término "blanco". A algo, lo que fuere, se lo denomina "blanco", no porque sea blanco independientemente de lo que pudiera significar. En palabras de Goodman:

Un lenguaje que les aplica el término "blanco" las hace blancas; un lenguaje las hace rojas si alguien les aplica el término "rojo" (1995, p. 85. El destacado me pertenece).

De éste modo, Nelson Goodman entiende que los predicados, más que nombrar propiedades, o denotar clases o secuencias, clasifican 0 , mejor dicho, hacen, ordenan individuos. Las cosas no son blancas porque son blancas sino, por el contrario, porque reciben esa denominación dentro de una versión en particular. Así, por ejemplo, dentro de las versiones del mundo al que pertenecen los esquimales, se diferencian alrededor de treinta tonalidades del color blanco; ello les permite diferenciar la existencia de animales polares, observar los distintos grosores de hielo para evitar pisar una capa fina de hielo, advertir dónde se ubican las crías de foca y los blancos de peces.

Este planteo no se refiere a la existencia de mundos posibles (posición que Goodman no sólo critica, sino también ridiculiza); se trata, por el contrario, de múltiples mundos reales. En Maneras de hacer mundos (1990), Nelson Goodman considera dos enunciados igualmente verdaderos aunque opuestos entre sí. El primero reza, "el sol se mueve siempre"; el segundo, "el sol no se mueve nunca". Quizás debiéramos considerarlos no como enunciados completos, sino como elipsis parciales de otros enunciados. De éste modo, podríamos afirmar que, "en el marco de referencia A, el sol se mueve siempre", y, por otro lado, "en el marco de referencia B, el sol no se mueve nunca". Sin embargo, la idea de marco de referencia parece apuntar a los marcos de descripción mismos, más que a aquello que éstos describen. Pero, si dejamos de lado todo marco de referencia,

\footnotetext{
${ }^{6}$ Ver al respecto, "Mapping, Meaning, and Metaphysics", en Midwest Studies in Philosophy 2, 1997, pp. 191211. Citado por Nelson Goodman, De la mente y otras materias, 1995, p. 85.
} 
¿cómo sería el mundo? Goodman observa de ésta manera, que nuestro universo consiste en esas formas de descripción. Tanto las ciencias, como las distintas obras de escritores y pintores, como nuestras propias percepciones -que se han ido modificando a lo largo del tiempo gracias a las circunstancias, intereses, intuiciones y estados anímicos, nos suministran una amplia variedad de versiones y concepciones del mundo. El pluralismo de Goodman (y el de Cassirer) se opone típicamente al materialismo y al fisicalismo monopolista de Searle -al que aquí adscribimos-, sostiene que existe sólo un sistema preeminente (la física) que incluye a todos los demás; así, cualquier otro sistema, a la larga o a la corta, debe reducirse a él. Si así no lo hiciere, se lo rechazaría por falso o sin sentido. No aceptar el primado de la física, según Goodman, no significa desestimar el rigor; se trata, por el contrario, de reconocer que se requieren criterios diferentes de los aplicados en las ciencias, criterios no por ello menos exactos o más vagos, que permiten analizar distintas versiones perceptivas, sean pictóricas o literarias. En palabras de Goodman,

En la medida en que seamos proclives a la idea de que existe una pluralidad de versiones correctas, que son irreductibles a una sola y que entran en mutuo contraste, no deberemos buscar su unidad tanto en un algo, ambivalente o neutral, que subyace a tales versiones cuanto en una organización global que las pueda abarcar a todas ellas (1990, pp. 22-23. El destacado le pertenece a Goodman).

Se torna muy difícil comprender este punto; ¿cómo es posible asumir que sobre una misma cosa hay distintas versiones, todas ellas correctas? Si así fuera, estaríamos habilitados a decir cualquier cosa sobre algo. Pero eso va en contra de los intereses y de los objetivos de la ciencia y de la filosofía. Si fuera cierto el planteo de Goodman, ¿para qué escribir libros de filosofía? Se escribe para convencer a otros (o al menos para intentarlo). Si usted quiere saber por qué llueve en nuestro planeta, no hable con el cura de su parroquia, consulte a un astrónomo; si quiere saber por qué existen los seres humanos, no lea la biblia, lea a Darwin. La ciencia demuestra sus argumentos empíricamente; y no ocurre lo mismo con otras versiones del mundo (el arte, la religión, la música). No pretendemos decir con esto que el resto de las versiones no tienen valor alguno, pero del problema de lo verdadero, se ocupa la ciencia. 
Prosiguiendo con el análisis goodmaniano, es preciso aclarar que el modo en que aborda la problemática (distinto, por ejemplo, al de Cassirer, quien asumía la tarea por medio de un estudio transcultural del desarrollo del mito, la religión, el lenguaje, la ciencia y el arte) se centra en el estudio analítico de los símbolos y sistemas simbólicos. De éste modo, tanto los universos que están hechos de mundos, como los mundos mismos, pueden construirse de muchas maneras.

Es aquí, precisamente, donde retomamos (aunque nunca abandonamos por completo) nuestra problemática de las estructuras. Es contradictorio, según Goodman, hablar de hechos desnudos, en bruto -como hace Searle-, inestructurados, no conceptualizados. Pero, ¿por qué? Porque esa misma manera de hablar impone estructuras, propiedades, y conceptualizaciones. Si es el caso que podamos concebir palabras sin un mundo, no lo es pretender concebir un mundo carente de palabras u otros símbolos (Goodman, 1990, p.24). Pero no es esto lo que Searle sostiene. Es cierto que nosotros, los seres humanos, solo tenemos acceso al mundo, a nuestro mundo, mediante conceptualizaciones; pero el punto de Searle es que hay una parte del mundo que no necesita del lenguaje humano, ni de los seres humanos, para existir.

\section{La construcción de los mundos goodmanianos}

Ahora bien, es posible preguntarse, en este punto, cómo se lleva a cabo la construcción de un mundo tal como lo entiende Goodman; ¿cómo se realiza este proceso? En Maneras de hacer mundos (1990), Goodman identifica cinco elementos (advirtiendo que el listado no es ni completo ni definitivo): i) Composición y descomposición, ii) Ponderación, iii) Ordenación, iv) Suspensión y complementación, y por último, v) Deformación. Veamos uno por uno. i) Cuando hacemos mundos separamos y conjuntamos. ¿Cómo lo hacemos? Poniendo etiquetas, nombrando, conceptualizando, aplicando predicados, gestos, imágenes; todo ello consolida los procesos de composición o descomposición. Podemos reunir, por ejemplo, bajo un único nombre propio distintos sucesos, identificándolos como partes de "un objeto" o "una persona"; el ejemplo del color blanco para los esquimales es aquí completamente pertinente; si de hablar sobre la naturaleza se trata, es preciso comprender que tanto al maravillarnos de su uniformidad, o al enfurecernos por su imprevisibilidad, siempre se trata de un mundo que es de nuestra hechura (1990, p. 28). Este punto, tal como advertimos anteriormente, es aceptado en parte desde la posición 
del realismo externo; es cierto en lo relativo a los hechos sociales e institucionales porque tienen una estructura lingüistica, pero no ocurre lo mismo con los hechos en bruto. ii) Tal como hemos visto en los ejemplos anteriores, en algún mundo faltan algunos géneros que, por el contrario, son pertinentes en otro. Quizás sería más preciso afirmar que no es cierto que algunos géneros no estén presentes en un mundo pero sí en otro; quizás podríamos sostener que de lo que se trata es de la importancia, de la significación de un género en un mundo en particular; de éste modo, algunas de las diferencias que hay ente los mundos no se refieren a la cantidad de entidades que hay en cada uno de ellos, sino a los énfasis o acentos existentes. iii) En ciertas ocasiones, diversos mundos no se diferencian respecto a la cantidad de entidades que los componen, ni por los acentos o perfiles, pero sí lo hacen en base a sus respectivas secuencias de ordenación. No hay nada que sea un hecho primitivo o anterior en el orden de la derivación, por fuera de un sistema constructivo. De esta manera, por ejemplo, la ordenación del tiempo en milenios, siglos, décadas, meses, semanas, horas, minutos y segundos, no se encuentra "en el mundo", sino que somos nosotros quienes los construimos y los ponemos en el mundo (Nelson Goodman, 1990, p. 33) ${ }^{7}$. Esto es totalmente cierto porque la ordenación de la temporalidad es netamente social. iv) Cuando un mundo se construye a partir de otros mundos, generalmente intervienen procesos de eliminación y complementación, de rechazo de viejo material y aportaciones novedosas. Los seres humanos tenemos una ilimitada capacidad de pasar cosas por alto; tal como atestigua la psicología, encontramos aquello que estamos dispuestos a encontrar, mientras que permanecemos ciegos a aquellas otras cosas que ni ayudan ni obstaculizan nuestros propósitos. Tal como ocurre al admirar a un mago habilidoso, se nos escapan las cosas que están ahí, y vemos cosas que no estaban en ningún lugar. La ciencia -sostiene Goodman- no escapa a esta lógica; muy por el contrario, la tarea del científico es construir un mundo que obedezca a sus leyes universales y que sea congruente con los conceptos por él seleccionados. Esto es cierto, la ciencia, como toda creación humana, no es infalible. Pero no debemos olvidar que la ciencia toma sus conclusiones a partir de procesos medibles y contrastables a nivel empírico, y ello no sólo puede realizarlo un científico sino, potencialmente, toda la comunidad de hablantes, y en términos prácticos, toda la comunidad científica. v) Existen,

\footnotetext{
${ }^{7}$ La diferenciación que Searle establece entre hechos en bruto y hechos sociales e institucionales, no es empero, banal. Con todas las dificultades teóricas que acarrea la noción de "hecho" es perfectamente cuestionable que no es lo mismo hablar -como en éste caso hace Goodman, de la construcción del tiempo, que de las montañas o los ríos. Si bien en ambos casos hay mediaciones y construcciones simbólicas, en términos ontológicos (tal como explicamos líneas arriba) no se trata de la misma "construcción". No construimos una temporalidad determinada del mismo modo que una montaña o un árbol.
} 
por último, algunos cambios que son deformaciones o reconfiguraciones. Estos cambios podrán considerarse, dependiendo el punto de vista, como procesos de corrección o de distorsión. Aquí, Goodman ofrece una serie de ejemplos, como el efecto de nuestra vista al ver dos monedas de distinto tamaño y valor; tendemos a ver más grande a la de menor valor aunque sea más pequeña. Estos cinco elementos señalados por Goodman conforman algunas de las maneras en las que construimos mundos.

No sería exagerado sostener que gran parte de las diferencias que Searle y Goodman sostienen respecto del realismo radica en la diferenciación (en el caso de Searle) de dos tipos ontológicamente distinto de hechos, los institucionales por un lado, y los hechos en bruto por otro. Gran parte -aunque no todas, de las consideraciones antirrealistas de Goodman se aplican a la formación de los hechos institucionales que Searle distingue. Para ambos, esta porción de la realidad posee una estructura lingüística y está mediada por formas simbólicas o por algún tipo de intencionalidad humana (como luego sostendrá el Searle II). Pero no ocurre lo mismo respecto a los hechos en bruto. Jamás Searle podría aceptar -y nosotros tampoco lo hacemos-, que nuestras versiones del mundo hayan creado los mares, las estrellas y los montes. Los seres humanos jamás podríamos lograr "que las estrellas bailen". Los hechos en bruto son externos al punto de vista del observador; no dependen ni de la intencionalidad, ni del lenguaje de los seres humanos. Sostener que esos hechos necesitan que se les imprima el lenguaje para asegurar su comprensión, no implica suponer que su existencia dependa del lenguaje. Defendemos aquí la posición realista de Searle. Pero, ¿qué es lo distintivo de su concepción del realismo?

\section{Sobre el realismo externo. Una defensa}

Tras este recorrido, estamos en condiciones de volver nuevamente a la concepción de Searle acerca del realismo externo. Searle sostiene que del hecho de que nuestra concepción del mundo esté constituida por cerebros humanos que interactúan, no se sigue que la realidad concebida sea producto de la interacción de cerebros humanos. Este es un caso de non sequitur, de falacia genética. Muchos teóricos posmodernos ${ }^{8}$ han

\footnotetext{
${ }^{8}$ Como es sabido, el principal foco de ataques era el deconstructivismo de Derrida, autor que Searle detesta y con el cual confrontó hasta el hartazgo durante la década del 80. Ver al respecto, Jesús Navarro Reyes, Cómo hacer filosofía con palabras, FCE, España, 2010.
} 
argumentado que, debido a que nuestro conocimiento está socialmente construido, y es susceptible de arbitrariedad y voluntad de poder, el realismo queda socavado o, al menos, debilitado. Para comprobar su tesis realista, Searle considera tres argumentos (aunque son más bien tesis): el argumento de la relatividad conceptual, el argumento verificacionista y el argumento de la Ding an sich. Veámoslos uno por uno.

La tesis de la relatividad conceptual se refiere a que es posible tener un número distinto y diverso de representaciones para representar la misma realidad. Ello, se supone, refuta directamente cualquier argumento realista. Aquí Goodman afirmaría que es el lenguaje quien impone estructuras. Pero Searle, por su parte, está de acuerdo con la tesis de la relatividad conceptual; el punto es que ella no invalida ni se opone al realismo externo. Cualquier sistema de clasificación y demarcación es una creación humana y, en ese sentido, es arbitraria. El mundo se divide según lo dividamos y siempre será posible algún otro modo de clasificación. Cualquier descripción verdadera se hace siempre utilizando un sistema de conceptos que nosotros hemos creado arbitrariamente para describir el mundo. La tesis del realismo externo no es en absoluto inconsistente con la tesis del relativismo conceptual.

La tesis del realismo externo es como sigue:

RE: La realidad existe independientemente de nuestras representaciones de ella.

La tesis del relativismo conceptual es:

RC: Todas las representaciones de la realidad son relativas a algún conjunto de conceptos seleccionados arbitrariamente.

Como vemos, mientras que la primera sentencia dice que hay algo fuera que ha de ser descrito, la segunda dice que tenemos que seleccionar un conjunto de conceptos y simbolizaciones para describirla.

Ciertos filósofos -Putnam por ejemplo-, han tendido a suponer que si aceptamos el relativismo conceptual y lo conjugamos con el realismo, generamos inconsistencias. Veámoslo con un ejemplo ideado por el propio Putnam (1994, pp. 60 y ss.). Imaginemos que hay una parte del mundo como muestra la siguiente figura: 


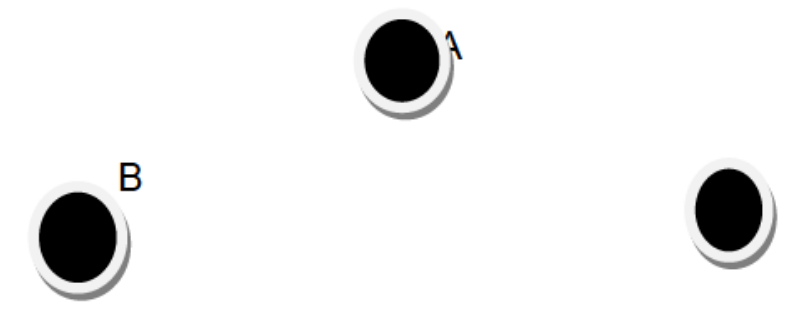

¿Cuántos objetos hay en éste mundo? De acuerdo con el sistema carnapiano de la aritmética, hay tres objetos, pero de acuerdo con ciertos lógicos polacos como Lesniewski, hay siete objetos, contados del siguiente modo:

$$
\begin{gathered}
1=A \\
2=B \\
3=C \\
4=A+B \\
5=A+C \\
6=B+C \\
7=A+B+C
\end{gathered}
$$

Ahora bien, cabe preguntarse una vez más, ¿cuántos objetos realmente hay en éste mundo? ¿Hay tres o siete? No hay ninguna respuesta absoluta a éstos interrogantes. E enunciado, "Hay tres objetos en el mundo" será verdadero dentro de un marco categorial, y el enunciado, "Hay siete objetos en el mundo" será verdadero dentro de otro esquema categorial. El argumento de Putnam (según Searle) es que, debido a que es posible sostener, a la vez, enunciados inconsistentes, el realismo externo también lo es ${ }^{9}$.

Un relativista convencido, afirmará que en nuestro mini-mundo del ejemplo, realmente hay tres objetos teniendo en cuenta el primer sistema de clasificación para contar objetos, y realmente siete, de acuerdo al segundo criterio. Lo central en el planteamiento de Searle es que,

\footnotetext{
${ }^{9}$ En la obra que Searle cita, Las mil caras del realismo, Putnam no dice nada de lo que Searle le hace decir; así, afirma que, "el realismo interno es, en el fondo, únicamente la insistencia en que el realismo no es incompatible con la relatividad conceptual. Se puede ser al mismo tiempo un realista y un relativista conceptual (1994, p. 61). Como vemos, Putnam no elabora una negación del realismo. Estimo que el realismo interno o pragmático de Putnam, no se diferencia grosso modo, de aquello que Searle denomina realismo externo.
} 
El mundo real no se ocupa de cómo lo describimos, y sigue impertérrito su curso, indiferente a varias descripciones que damos de él (1997, p. 172).

Los distintos ejemplos de relativismo conceptual que la bibliografía ofrece, muestran que diferentes sistemas conceptuales generan descripciones diferentes e inconsistentes en apariencia, a la hora de dar cuenta de la misma realidad. De todos modos, ninguna de estas argumentaciones hace que el realismo externo se desplome. La aparente inconsistencia no es más que una ilusión. Para graficar, una vez más, la relación entre relativismo conceptual y realismo, Searle propone el siguiente experimento mental. Pensemos en una porción del mundo, el Cerro Aconcagua, tal como era antes que existan los seres humanos. Imaginemos ahora que aparecen los humanos en el mundo, se hacen representaciones y elaboran enunciados respecto de esta formación rocosa; imaginemos, finalmente, que los humanos dejan de existir de un momento a otro, y con ellos, todas las representaciones y enunciados. ¿Qué ocurre con la existencia del Aconcagua y con todos los hechos relacionados con el Aconcagua, acontecidos a lo largo de todo este periplo? Searle respondería: absolutamente nada. Las descripciones van y vienen, pero los objetos, los hechos, continúan inalterados. Pero aquí podríamos plantear lo siguiente: si no existieran seres humanos, ¿el Cerro Aconcagua sería un cerro?, ¿tendría el nombre Aconcagua? La respuesta es, evidentemente, no. Sin lenguaje, sin conceptualizaciones no podríamos referirnos a él como "monte", ni con el nombre propio "Aconcagua". Pero, asi y todo, eso seguiría existiendo.

Searle sostiene, además, que al utilizar el relativismo conceptual contra una posición realista, lo único que se logra es caer en la falacia de uso-mención.

Del hecho de que una descripción sólo pueda hacerse en relación a un conjunto de categorías lingüísticas, no se sigue que los hechos/objetos/estados de cosas/etc., que se describen puedan existir sólo en relación a un conjunto de categorías (1997, p. 174. El destacado le pertenece a Searle). 
Al contrario de lo que Goodman sostiene, para Searle, no hay distintas maneras de hacer mundos porque nosotros no "hacemos" mundos, sino tan sólo descripciones que pueden o no casar con el mundo real.

Pasemos ahora a la segunda tesis contra el realismo que Searle analiza; nos referimos al argumento verificacionista. Ante la pregunta, ¿qué puedo conocer?, es posible afirmar cosas tales como, conozco que estoy sentado en mi sillón de escritorio frente a mi computadora, que vivo en cierta localidad de un país determinado, y cosas por el estilo. Para el verificacionismo (al menos para la versión que Searle presenta), aquello que podemos conocer es aquello que podemos experimentar; de éste modo, cuando afirmamos que conocemos las sillas, las computadoras y nuestra localidad, o bien estamos hablando de nuestras experiencias, o bien estamos hablando de algo que no conocemos. El mundo, según el verificacionismo, se conoce a través de nuestras experiencias; de ello se concluye que la experiencia es constitutiva de la realidad ${ }^{10}$. Así, para Berkeley, los objetos son colecciones de ideas; para Mill, son posibilidades permanentes de sensación.

Según Searle, la tesis verificacionista consta de dos supuestos. El primero es que todo lo que podemos llegar a percibir son nuestras propias experiencias. Si es cierto que hay una realidad más allá de nuestras experiencias, ésta sería incognoscible o ininteligible. El segundo argumento es una extensión del primero; sostiene que la única bese para hacer afirmaciones sobre el mundo real son nuestras experiencias. Por ello, si los asertos sobre el mundo real van más allá de nuestras experiencias, estamos postulando algo sin fundamento epistemológico. Searle, por su parte, entiende que los dos supuestos se encuentran errados. Por un lado, es completamente cierto que al percibir conscientemente algo, tenemos ciertas experiencias. Por ejemplo, para cualquier percepción auditiva, hay una experiencia auditiva que le corresponde. Afirmar, "escucho música" implica, "tengo cierto tipo de experiencia auditiva". Si bien es cierto que la experiencia auditiva es un componente esencial de la precepción auditiva, de ello no se sigue que lo percibido sea la experiencia auditiva ${ }^{11}$. Así, en La construcción de la realidad social (1997), Searle afirma que,

\footnotetext{
${ }^{10}$ Non sequitur. Del hecho de que el mundo se conozca a partir de nuestras experiencias, no se sigue que la experiencia sea constitutiva de la realidad. De todos modos, el verificacionismo no es una tesis acerca de los límites del conocimiento, sino acerca de los límites del significado.

${ }^{11}$ Tampoco se sigue, de todos modos, que sea un fenómeno externo.
} 
No se sigue, en una palabra, que uno no tenga acceso directo al mundo real cuando uno se sirve, para percibirlo, del aparato perceptivo (p. 178).

Para Searle, ha quedado demostrado que el primer argumento es erróneo. Con el segundo supuesto ocurre algo similar. Mis experiencias me dan acceso a algo que está por fuera de mis experiencias. Del hecho que conozcamos a través de la experiencia, no se sigue que aquello que conozcamos sean meras experiencias. Aún cuando todas nuestras consideraciones respecto al mundo anduvieran erradas, la referencia de todas las equivocaciones sería un mundo que está por fuera de mis percepciones, de mi mente, de mi lenguaje. Aunque todos mis asertos fueran producto de alucinaciones, o por la obra de un genio maligno empecinado en confundirme y engañarme, así y todo, mis asertos serían sobre un mundo que se ubica, digamos, de la piel hacia afuera ${ }^{12}$. Searle sostiene que,

\begin{abstract}
Aún si el escepticismo anduviera en lo cierto, y yo anduviera sistemáticamente errado, yo andaría errado respecto de los rasgos del mundo real. La posibilidad de andar sistemáticamente errado acerca de esos rasgos no prueba que mis afirmaciones sobre ellos sean meros sumarios de enunciados sobre las experiencias de mis sentidos (p. 180. El destacado le pertenece a Searle).
\end{abstract}

Pasemos ahora al último argumento en contra del realismo. El argumento de la "cosa en si" [Ding an sich], el cual es una combinación de los anteriores. Si es cierto que cuando lidiamos con el mundo, siempre lo hacemos dentro de un marco conceptual determinado, el acceso a la "cosa en si" kantiana no es posible ${ }^{13}$. Si bien es cierto que no es posible salir de todos los estados y sistemas cognitivos para contemplar las relaciones entre ellos y la realidad, de ello no se sigue que no sea posible conocer una realidad que se encuentra por fuera de la cognición. Searle concluye que,

\footnotetext{
${ }^{12}$ Tomo la expresión de Antonio Blanco Salgueiro (2004), Palabras al viento. Ensayo sobre la fuerza ilocucionaria, ed. Trotta, Madrid.

${ }^{13}$ Cabe destacar que para Kant tampoco lo es. No es posible conocer el nóumeno.
} 
Sólo podemos representar la realidad desde un punto de vista, pero la realidad ontológicamente objetiva no tiene punto de vista (p. 184).

Tras haber dado cuenta de las tesis en contra del realismo, Searle pasa a esbozar los argumentos a su favor. Demostrar que existe un mundo por fuera de nuestras representaciones, sostiene, es similar a demostrar la racionalidad humana. Si somos capaces de dar razones, de discutir e intercambiar argumentos es porque somos sujetos racionales. En éste punto, Searle supone algo altamente controvertido: si discutimos acerca de la existencia del mundo externo es porque ese mundo existe. El realismo externo opera en Searle no como una tesis o hipótesis, sino como la condición para que existan ciertas hipótesis o tesis. La base sobre la que Searle se apoya en última instancia para sostener y defender el realismo externo, son los logros de la ciencia moderna. Debido a que diferentes investigadores en distintas épocas y lugares han arribado a similares conclusiones y apreciaciones sobre el mundo, el mundo por fuera de nuestras representaciones existe. Si hay convergencia o falta de convergencia es porque estamos presuponiendo el realismo. Todo enunciado del tipo "la ciencia converge", sea verdadero o falso, tiene que ver con una realidad que es independiente de ese enunciado o de cualquier otro. La tesis de Searle es que,

El realismo externo es un presupuesto del trasfondo para la
comprensión normal de una clase muy amplia de
expresiones $^{14}(1997$, p. 192).

El presupuesto del trasfondo posee dos características: es perdifuso y es esencial. Es perdifuso porque vale para una clase muy amplia de expresiones; es esencial porque si

\footnotetext{
${ }^{14}$ Se torna aquí necesario hacer una breve aclaración de los que Searle entiende por "trasfondo". Las capacidades del trasfondo son aquellas que posibilitan los estados intencionales, pero no consisten ellas mismas en estados intencionales. El significado literal de una sentencia cualquiera, sólo puede determinar sus condiciones de satisfacción, gracias a un trasfondo de capacidades, disposiciones, habilidades, que no son ellas mismas parte del contenido semántico de la sentencia. Todos los hablantes competentes del castellano sabemos que la sentencia "Corta el césped" debe ser interpretada de un modo distinto a "Corta el pastel"; si ante la primer sentencia alguien trae un cuchillo, o ante la segunda, alguien trae una cortadora de césped, hay un sentido muy cotidiano en el que puede decirse que esa persona no entendió lo que se le pedía. Entendemos cada sentencia en la que el verbo cortar se mantiene constante, de un modo diferente porque en cada caso nuestra interpretación depende de las capacidades de trasfondo. Gran parte del trabajo del último Wittgenstein, y de lo que Bourdieu denomina "habitus", se emparentan con lo que Searle denomina "trasfondo".
} 
prescindimos de él no podemos preservar la comprensión normal de esas expresiones. Respecto a su perdifusividad, se observa que vale para un amplio espectro de expresiones, tales como:

El monte Aconcagua tiene nieve y hielo en su cima.

Mi perro tiene garrapatas.

Cada átomo de hidrógeno contiene un electrón.

Observamos que es esencial porque las sentencias, cuyo significado es público, son entendidas del mismo modo por cualquier hablante y oyente competente del castellano. La comprensión normal de las sentencias requiere una comprensión idéntica por parte del hablante y del oyente, y la identidad de comprensión requiere que la referencia de las oraciones sea una realidad públicamente accesible, ontológicamente objetiva. La condición de accesibilidad pública, precisamente, requiere que la manera de ser de las cosas no dependa de mis representaciones o de las suyas. Nosotros podemos comprender las oraciones consignadas más arriba de un modo idéntico, porque versan sobre una realidad que es accesible públicamente. $Y$ esto vale también para las sentencias que fallan porque no existen las entidades a las que nos referimos. Aunque se revelara que el Monte Aconcagua jamás ha existido, como así tampoco mi perro maltrecho o los átomos de hidrógeno, así y todo, entendemos las oraciones gracias a una realidad que es externa. El mundo tiene una manera de ser independiente de nuestras representaciones; ese es el requisito del realismo externo. En palabras de Searle,

Los esfuerzos para comunicarse en un lenguaje público requieren que presupongamos un mundo público. $\mathrm{Y}$ el sentido de "público" en cuestión requiere que la realidad pública exista independientemente de las representaciones de esa realidad (p. 193).

La idea de Searle no es que para comprender una expresión tenemos que presuponer un objeto referencial específico, por el contrario, aún en el caso en que ninguno de esos objetos existiera, las condiciones de inteligibilidad quedan preservadas. Si bien la 
existencia del Monte Aconcagua es una condición de verdad del enunciado, la existencia de una manera de ser de las cosas que se ubica por fuera (independientemente) de nuestras representaciones sobre ellas, no es una condición de verdad; muy por el contrario, se trata de una condición de inteligibilidad que poseen los enunciados ${ }^{15}$. Como observamos, la tesis en cuestión no es una tesis epistémica; se centra en las condiciones de inteligibilidad más que en las condiciones de conocimiento. Tanto vale para los enunciados conocidos como para los no conocidos, verdaderos o falsos. Searle sostiene que,

El RE, así construido, es una restricción puramente formal. No dice cómo son las cosas, sino sólo que las cosas tienen una manera de ser que las hace independientes de nuestras representaciones (p. 194).

La tesis se limita a afirmar que cuando proferimos un enunciado tal como, "El Monte Aconcagua tiene nieve y hielo en su cima", se asegura la comprensión porque se supone que hay (aunque no se sigue que hay) una realidad públicamente accesible. La existencia de una realidad independiente de la mente, que presupone una realidad independiente de las representaciones es, precisamente, lo que Searle denomina realismo externo.

Tras haber abordado el problema del realismo, y haber adoptado una posición afín a la de Searle, en el próximo capítulo nos centraremos en otro de los temas abiertamente discutidos por Searle y Apel principalmente; nos referimos al problema del significado y de la prioridad metodológica o bien del lenguaje, o bien de la conciencia intencional. Si hemos comenzado nuestro trabajo a partir de la diferenciación entre hechos en bruto y hechos sociales e institucionales, es porque dicha demarcación pretende delimitar los problemas que a nosotros (siguiendo a Searle) nos interesan abordar. Diferenciar el estatus ontológico de unos y otros hechos es la tarea central requerida para analizar lo que aquí nos interesa, es decir, la realidad social.

\footnotetext{
${ }^{15}$ Davidson, en Interpretación radical, tiene muy buenos argumentos para sostener lo contrario. Argumentos que aquí no serán presentados. Ver, Donald Davidson, De la verdad y de la interpretación, ed. Gedisa, Barcelona, 2001, pp. 137 y ss.
} 
A continuación nos detendremos en el problema del significado porque es allí donde se observa el viraje de Searle hacia una tradición filosófica que se encuentra por fuera del linguistic turn, marcando el pasaje de aquello que denominaremos el Searle I (afín a la filosofía del lenguaje) al Searle // (más cercano al paradigma de la conciencia). La clarificación de estas problemáticas son los pasos previos que nos permitirán esclarecer en los capítulos finales-, los elementos constitutivos de la realidad social e institucional. 


\section{Cap. 2: Conciencia y lenguaje}

\section{Introducción}

La pregunta que guía nuestra reflexión en el presente apartado es la siguiente: ¿cuál es el fundamento del significado, la conciencia intencional o el lenguaje? Parte de la tradición filosófica que inauguran Frege, Russell y el primer Wittgenstein, sostuvo que el significado de los signos se fija, fundamentalmente, mediante convenciones lingüísticas. Otra tradición filosófica, aquella que comienza con Descartes y encuentra su último gran exponente en Husserl, sostuvo por el contrario, que es el elemento prelingüístico de nuestra conciencia -las cogitatio en Descartes, y la intencionalidad en Husserl- el elemento fundamental en cuanto a la fijación del significado. Dentro de la tradición analítica de la filosofía del lenguaje se observan dos fases, la filosofía del lenguaje formal o semántica y la filosofía del lenguaje ordinario. La primera hizo abstracción del modo en que el usuario utiliza el lenguaje y, consecuentemente, de aquello que Austin (2008) denominó fuerza ilocucionaria. La segunda fase -el giro pragmático al interior del giro lingüístico, rescató la dimensión pragmática como función integradora del lenguaje natural; así lo hicieron la teoría de los "juegos de lenguaje" del Wittgenstein tardío y la teoría de los "actos de habla" que se encuentra en Cómo hacer cosas con palabras de Austin (2008), y en Actos de habla de Searle (1994).

La posición fuertemente externista y convencionalista, propia del pragmatic turn, si bien ha sido celebrada por unos -Habermas y Apel por ejemplo, no ha contado con una aceptación total (como suele ocurrir). Han aparecido, junto a la teoría de Austin, teorías del significado que intentan reducir el significado lingüístico a intenciones mentales de carácter prelingüístico. Ente las teorías del significado intencionalista, Apel (2002) distingue la posición de Paul Grice, desarrollada principalmente en Meaning (1957) y la de John Searle en su obra Intencionalidad, del año 1983. Aquí nos ocuparemos principalmente de esta última obra. La teoría del significado que John Searle desarrolla en Intencionalidad, se encuentra emparentada en cierto modo con la de Edmund Husserl -no en todos, pero sí en algunos de sus aspectos. Tanto Searle como Husserl desacoplan la intención significativa de la intención comunicativa. Es aquí donde, según Apel, Searle se retrotrae a una posición anterior al linguistic turn, produciéndose un distanciamiento 
respecto a los lineamientos generales desplegados en Actos de habla ${ }^{16}$. Catorce años después de haber publicado Actos de habla, en Intencionalidad, Searle asume que los estados intencionales diferenciados -tales como las creencias, las intenciones, los deseos-, son la base necesaria para explicar tanto los distintos significados de los actos de habla, como la posibilidad misma de las distintas clases de actos de habla.

A continuación haremos una exposición de las nociones generales que Searle desarrolla en Intencionalidad para, posteriormente, someterlas a un contrapunto crítico a partir de las conceptualizaciones desplegadas por Apel, Tugendhat y Dummett.

\section{Sobre el significado}

Tanto para Searle como para Husserl, y para toda filosofía anterior al linguistic turn, la pregunta fundamental respecto al significado lingüístico es la siguiente:

El problema del significado es: ¿cómo la mente impone Intencionalidad sobre entidades que no son intrínsecamente intencionales? ¿Cómo es posible que meras cosas puedan representar? (Searle, 1999, p. 175).

El enfoque de la Intencionalidad que Searle adopta en Intencionalidad (1999) es naturalista. Searle sostiene que los estados Intencionales, al igual que la digestión, el crecimiento y la secreción de bilis, son procesos que forman parte de nuestra historia biológica (1999, p. 168). Evolutivamente, el significado y el lenguaje aparecen tardíamente en la historia del ser humano. Si bien hay otras especies -como los primates-, que cuentan con creencias, intenciones y deseos, la especie humana tiene la distintiva forma de Intencionalidad que solemos asociar al lenguaje y al significado. Según Searle (a diferencia, como veremos, de Apel) estas formas de Intencionalidad tienen un basamento

\footnotetext{
${ }^{16}$ Cabe resaltar en éste punto que, al contrario de los comentarios de Apel, Searle siempre ha negado ese "retroceso" en sus planteamientos teóricos. La diferencia entre Actos de habla y sus posteriores obras se justifican por una dimensión de alcance explicativo. Si en Actos de habla se preocupa principalmente (aunque no únicamente) por problemáticas referidas al lenguaje, en sus obras posteriores su interés es más general, centrándose en la constitución de la realidad social e institucional. En su última obra, Making the social Word (2010) hay una revalorización de su posición originaria respecto al lenguaje. De todos modos, no es menos cierto que, a partir de Intencionalidad, Searle entiende a la filosofía del lenguaje como parte de la filosofía de la mente.
} 
biológico. En éste punto, sin embargo, Searle sostiene que la Intencionalidad "difiere de otras clases de fenómenos biológicos en que tiene una estructura lógica..." (p. 168). De éste modo, se considera al significado como un desarrollo especial de formas más primitivas de Intencionalidad. Esas formas de Intencionalidad, precisamente, no son intrínsecamente lingüísticas. De acuerdo con este enfoque, Searle, -el Searle ${ } I^{17}$ - toma a la filosofía del lenguaje como una rama de la filosofía de la mente. Este punto es el que ha dado lugar a innumerables controversias. Aquí, pareciera que el esfuerzo de Searle va a contramano del de Frege y Husserl; lo que Searle pretende es analizar ciertas nociones semánticas fundamentales -tales como el significado-, en términos de nociones psicológicas.

En la realización de actos ilocucionarios, Searle distingue un doble nivel de Intencionalidad. Un nivel del estado Intencional expresado en la realización del acto y un nivel de la intención al realizar el acto. Así, por ejemplo, cuando expresamos el enunciado "está lloviendo", por un lado expresamos la creencia de que está lloviendo y, por otro, realizamos un acto intencional de enunciar que está lloviendo. Las condiciones de satisfacción del estado mental expresado en la realización del acto de habla son idénticas a las condiciones de satisfacción del propio acto de habla. Por ello mismo,

Un enunciado será verdadero si y sólo si la creencia expresada es verdadera, una orden se obedecerá si y sólo si el deseo expresado se cumple, una promesa se guardará si y sólo si la intención expresada se lleva a cabo. Estos paralelismos no son accidentales y cualquier teoría del significado tiene que explicarlos. (Searle, 1999, p. 172).

El punto central, sostiene Searle, es ver que en la realización del acto de habla, la mente impone intencionalmente las mismas condiciones de satisfacción sobre la expresión física del estado mental expresado, que el estado mental en sí mismo. Allí está la clave del significado. Si focalizamos únicamente en las condiciones de satisfacción del estado Intencional expresado, o sólo en las condiciones de satisfacción del acto de habla, el análisis será incompleto. Además de los fenómenos físicos -la producción de sonidos,

\footnotetext{
${ }^{17}$ Adoptaremos la convención propuesta por Apel. Al Searle de Actos de habla (1969) lo llamaremos Searle I, mientras que al Searle de Intencionalidad (1983), Searle II. La distinción pretende dar cuenta de su quiebre teórico.
} 
marcas, etc.-, deben analizarse los estados mentales que producen los fenómenos físicos.

Searle distingue al respecto, cuatro condiciones de adecuación; a saber:

1- Hay dos niveles de intencionalidad en la realización del acto de habla: uno es el nivel del estado psicológico expresado al realizar el acto, y el otro es la intención con la que el acto se realiza que hace que sea un acto determinado. Al primero lo denomina "condición de sinceridad" y al segundo "intención de significar".

2- Ambas condiciones de satisfacción son idénticas. Aquello que una explicación de la intención de significar debe mostrar es cómo es posible que ello ocurra, aún cuando las condiciones de satisfacción de la intención de significar sean diferentes tanto de las condiciones de satisfacción del acto de habla como de las condiciones de sinceridad.

3- Es preciso realizar una clara distinción entre representación y comunicación. De éste modo, cuando una persona hace un enunciado tiene la intención de representar algún hecho o estado de hechos y la de comunicar esa representación a sus oyentes. Pero no por ello debemos confundir su intención de representar con su intención de comunicar. Al comunicar producimos ciertos efectos en nuestros oyentes; nada de ello ocurre al representar. Se puede hacer un enunciado sin por ello tener la intención de producir convicción o creencia alguna en los oyentes; o sin pretender que lo comprendan o crean en lo que dice. Así, Searle distingue dos aspectos de las intenciones de significar: la intención de representar y la intención de comunicar. El error de la tradición, sostiene Searle, es no haber dado cuenta de esta distinción y suponer que la explicación total del significado puede darse en términos de intenciones comunicativas. Primero debo representar y luego comunicar; la intención de representar es previa a la intención de comunicar. Nunca a la inversa, pues parte de lo que se comunica es el contenido de las propias representaciones. Se puede tener la intención de representar sin tener la intención de comunicar, pero no se puede tener la intención de comunicar sin tener la intención de representar.

4- En Una taxonomía de los actos ilocucionarios $(1975)^{18}$, Searle enumera cinco categorías básicas de actos ilocucionarios: los aseverativos, les dicen a nuestros oyentes (verdadera o falsamente) cómo son las cosas; los directivos, mediante los

\footnotetext{
${ }^{18}$ En, Luis MI. Valdés Villanueva (ed), La búsqueda del significado, ed. Tecnos, Madrid, 1991, pp. 449-476.
} 
cuales intentamos que nuestros oyentes hagan ciertas cosas; los comisivos, con los cuales nos comprometemos nosotros mismos a hacer las cosas; los declarativos, donde generamos cambios con nuestras emisiones; y los expresivos, donde comunicamos nuestros sentimientos y actitudes. Al escribir Intencionalidad (ocho años más tarde respecto al artículo citado), Serle mantiene la misma taxonomía pero sostiene que esos cinco tipos de objetos ilocucionarios son "empíricos", porque el modo en que el lenguaje representa el mundo es una extensión y realización del modo en que la mente representa el mundo, estos cinco tipos de actos deben derivarse de algún tipo de acto más fundamental de la mente.

Searle entiende que es la Intencionalidad de la mente aquello que, además de crear la posibilidad del significado, limita su forma. Utilizamos los actos de habla realizativos para pedir disculpas, enunciar, ordenar, felicitar, pero no existe un realizativo que nos permita freír un huevo. ¿Por qué no? El análisis del significado debe plantearse como objetivo mostrar las posibilidades y limitaciones de la Intencionalidad de la mente. Dummett por su parte, en Origins of the Analytical Philosophy (1993), sostiene que "la única ruta hacia el análisis de los pensamientos es a través del análisis del lenguaje" (p. 128); a ello lo denomina el axioma fundamental de la filosofía analítica. Como vemos, el Searle de Intencionalidad (Searle II) se separa del axioma fundamental, afirmando que la vía para el análisis del significado no debe ser el análisis del lenguaje sino el de la Intencionalidad de la mente. Mientras que el Searle de Actos de habla (Searle I) parecía trabajar a partir del axioma fundamental de la filosofía analítica, Searle II rompe con el axioma fundamental, retrocediendo hacia el terreno de la filosofía de la conciencia, hacia una filosofía mentalista. Sobre este cambio en los argumentos de Searle han llamado la atención, principalmente, Apel $(1994,2002)$ y Habermas $(1991,2007,2011)$.

Lo curioso del planteo de Searle es el modo en que es ejemplificado. En este punto introduce un ejemplo en torno al gesto de una señal convenida convencionalmente:

Supongamos que usted y yo estamos de acuerdo de antemano en que si yo levanto mi brazo ese acto cuenta como una señal de que tal y tal es el caso. Supongamos, en un contexto militar, que le señalo a usted una colina mientras que yo estoy en otra de la que el enemigo se ha 
retirado, y por un acuerdo previo señalo esto levantando mi brazo. (1999, pp. 174 y 175).

El problema del significado para Searle, tal como citamos más arriba, es el siguiente: “¿Cómo la mente impone Intencionalidad sobre entidades que no son intrínsecamente Intencionales? ¿Cómo es posible que meras cosas puedan representar?” (p. 175). La respuesta de Searle es que el acto de emisión se realiza con la intención de que la emisión tenga condiciones de satisfacción. Las condiciones de satisfacción de la creencia (en éste caso, que el enemigo está en retirada) se transfieren a la emisión por medio de un acto Intencional. El significado, según éste planteo, se origina en la mente para materializarse posteriormente, en un acto de habla. En el ejemplo de Searle, es la intención lo que provoca que mi brazo suba y dé la señal. El paso de la intención de representar a la intención de comunicar es, asegura, muy simple. La intención causa que mi brazo suba. Se tiene la intención de que la emisión tenga la dirección de ajuste mente (o emisión)-a-mundo ${ }^{19}$. Searle sostiene que el paso de la intención de representar a la intención de comunicar es simple porque la intención de comunicar consiste en que el oyente reconozca que el acto se realizó con la intención de representar. Así, cuando hago las señales levantando la mano, mi intención es conseguir que mi compañero reconozca que le estoy señalando que el enemigo se ha retirado y puede avanzar. En palabras de Searle,
Esta intención en la acción causa que mi brazo suba, y el que mi brazo suba tiene como condiciones de satisfacción con la dirección de ajuste mente (o emisión)-a-mundo que el enemigo se esté retirando, y mi auditorio reconoce tanto que mi brazo está subiendo como que su subir tiene esas condiciones de satisfacción (1999, p. 176).

Ahora bien, cabe preguntarnos una vez más, ¿cómo es esto posible? ¿No se ha comprendido el significado porque la señal misma presupone ya convenciones lingüísticas? Veamos el problema a partir de otro ejemplo. Si yo pretendo pasar por entre

\footnotetext{
${ }^{19}$ Lo que Searle denomina dirección de ajuste, da cuenta del modo en que nuestra mente (o nuestras emisiones) se relaciona o modifica la realidad (mundo). Esta dirección de ajuste puede ser de mente-amundo, o de mundo-a-mente. Más adelante hablaremos de ello.
} 
una muchedumbre, puedo enunciar algo parecido a: "permiso, quisiera pasar", o "córranse de mi paso", o cosas por el estilo. Por supuesto que también podría dar empujones; las personas también se correrían me mi camino y así, mi objetivo estaría cumplido (pasar por ente la muchedumbre). Si bien el presente ejemplo -a diferencia de lo que ocurría con el ejemplo de la colina de Searle, no cuenta con una convención lingüística previa, también se entiende el acto meramente físico (levantar el brazo o, en nuestro ejemplo, empujón). Pero, ¿qué significa aquí que el empujón se entiende? Significa que es posible otorgar un contenido proposicional a la acción y ceder el paso ante el contacto físico (o bien no cederlo y propinarle un golpe por haber sido descortés). Algo similar ocurre con el ejemplo de la colina; lo que hacemos es otorgarle un contenido proposicional a la acción. Por eso la entendemos y la seguimos (o no, y ello tendrá sus consecuencias dentro de un juego de lenguaje en particular).

Llegados a éste punto, retomamos la pregunta que al principio del apartado habíamos planteado; se trata, sin lugar a dudas, de una de las cuestiones más disputadas del siglo XX. Apel plantea el problema del siguiente modo:

¿Qué es más fundamental (more basic) para la fundamentación de una teoría del significado: el significado de los signos fijado en el sentido de convenciones lingüísticas, o el significado que prestamos a los signos en virtud de la intencionalidad prelingüística de nuestra conciencia, al otorgarle vehículos sígnicos físicos? (Apel, 2002, p. 92).

Como hemos visto, la argumentación de Searle II toma el segundo camino, el de la intencionalidad prelingüística de nuestra conciencia. No es esa la posición que aquí adoptaremos sino que trabajaremos teniendo en cuenta el primer camino, el de las convenciones lingüísticas. Para ello, analizaremos la problemática a partir de Apel, Tugendhat y Dummett.

El problema de Searle II, para decirlo de otro modo, es el de la relación entre la Intencionalidad prelingüística y la institución del lenguaje. Searle ilustra la problemática del siguiente modo, 
Supongamos que hubiese una clase de seres que fuesen capaces de tener estados Intencionales como creencias, deseos e intenciones pero que no tuviesen un lenguaje, ¿qué más necesitarían para ser capaces de realizar actos lingüísticos? (1999, p. 184).

Esto es altamente curioso porque, según parece, incluso ciertos animales de nivel superior como los delfines y las abejas, al comunicarse presuponen un código lingüístico condicionado por el instinto. Es muy difícil siquiera imaginar algún tipo de criaturas que tengan estados intencionales diferenciados -tales como los que nosotros denominamos "creencias", "deseos" o "intenciones" sin poseer, a la vez, algún tipo de lenguaje, ya sea uno convencional (como es el caso de los animales humanos) o un código de signos instintivos. Teniendo en cuenta el caso de la evolución humana, es posible suponer que la diferenciación de los estados intencionales y de las intenciones significativas posibles, por un lado; y la diferenciación de los significados convencionales, por otro, se han condicionado recíprocamente. Esa suposición, precisamente, no nos habilita a reducir unilateralmente los significados lingüísticos posibles a la intencionalidad no lingüística de la conciencia (Apel, 2002, pp. 97, 98). Lo que se pretende poner en duda en este apartado, es tanto la independencia de las intenciones significativas de la intención comunicativa, cuanto su independencia del lenguaje; para ello se adoptará el punto de vista del linguistic turn de la filosofía contemporánea. El caso de Searle es especialmente sugestivo porque en su ya clásico libro de 1969, Actos de habla, aparecía enteramente como un representante del linguistic turn. En esa obra parecían integrarse, en el sentido de una pragmática del lenguaje, la semántica de las oraciones con la pragmática de los actos de habla que se producen al enunciar las oraciones; así, el significado lingüístico puede ser entendido a partir de la doble estructura performativo-proposicional de toda oración lingüística explícita. Por otro lado, la función representativa del significado y la función comunicativa performativa indicada están ya siempre -y por principio-, codeterminadas por un lenguaje desarrollado (diferenciado) usado en la comunicación (Apel, 2002, pp. 98, 99). Cuando catorce años más tarde, en 1983, apareció el libro Intencionalidad, la philosophy of language se había retrotraído a una philosophy of mind. Antes de continuar debemos aclarar qué se entiende por el linguistic turn de la filosofía del siglo veinte. Además, debemos analizar en qué medida la filosofía del lenguaje se ha 
convertido en rival de la filosofía de la conciencia con respecto a la prioridad metodológica.

\section{Linguistic turn y pragmatic turn. El aporte de Apel}

Apel (2002) toma al Wittgenstein del Tractatus como el auténtico fundador del linguistic turn puesto que sugiere que las oraciones proposicionales en tanto que representaciones de hechos son a la vez las condiciones de posibilidad de los hechos descriptibles. En las Vermischte Bemerkungen (1977), Wittgenstein sostiene que,

Los límites del lenguaje se muestran en la imposibilidad de describir los hechos que se corresponden con una proposición [...], sin repetir exactamente la proposición. (Tenemos aquí que ocuparnos con la solución kantiana del problema de la filosofía. $)^{20}$

Según Apel, esta interpretación filosófico trascendental del Tractatus coincide con el esquema de definición de Tarski (1972) para la explicación semántica del concepto de verdad, la cual dice, "El enunciado "p" es verdadero si y sólo si p". De éste modo, "El enunciado "el gato está sobre el felpudo" es verdadero si y sólo si el gato está sobre el felpudo"21. Podríamos seguir preguntando, de todos modos, ¿bajo qué condiciones comprobables podemos decir que éste es el caso?, ¿a qué otro elemento podemos apelar para saber si el gato esta o no está sobre el felpudo? La respuesta de Wittgenstein y Tarski sería: “a ningún otro". Y ello porque no podemos describir la situación sin repetir la oración proposicional en la que se describe el hecho como tal. En Semiótica trascendental y filosofía primera (2002), Apel afirma que,

La representación del mundo por medio del lenguaje -más exactamente en este caso: por medio de oraciones

\footnotetext{
${ }^{20}$ L. Wittgenstein, Vermischte Bemerkungen, Fráncfort, Suhrkamp, 1977. Citado por K.-O. Apel, Semiótica trascendental y filosofía primera, ed. Síntesis, Madrid, 2002, p. 100.

${ }^{21}$ Ver al respecto, A. Tarski, La concepción semántica de la verdad y los fundamentos de la semántica, ed. Nueva Visión, Bs. As., 1972, y D. Davidson, De la verdad y de la interpretación. Fundamentales contribuciones a la filosofía del lenguaje, ed. Gedisa, Barcelona, 2001.
} 
proposicionales- es precisamente irrebasable. En ello se muestra el primado metodológico del a priori del lenguaje (Apel, pp. 100, 101) 22 .

Un fenomenólogo husserliano que defendiese el primado de la conciencia de los fenómenos dados objetaría lo siguiente: yo puedo convencerme a través de la percepción respecto a mi opinión de que el gato está sobre el felpudo, y no sobre la estufa, se corresponde con un hecho fenoménicamente dado; incluso este hecho fenoménico podría ser fotografiado para demostrar -mediante la fotografía-, que mi opinión se correspondía con un hecho. Esa percepción fenoménica operaría como un criterio objetivo de verdad puesto que trasciende la mera descripción verbal del hecho en una oración proposicional. Pero, ¿es posible mediante éste argumento refutar la tesis de la irrebasabilidad metodológica de la representación lingüística del mundo?

Aquello que el argumento fenomenológico muestra es que la representación descriptiva del hecho por medio de la oración proposicional puede ser sobrepasada; así, el fenómeno dado es identificado perceptivamente, proporcionándole a mi conciencia la evidencia de la correspondencia entre el hecho meramente afirmado y el hecho dado fenoménicamente. Apel afirma y acepta (a diferencia de los representantes del linguistic turn) que la evidencia para la conciencia es un medio indispensable para la confirmación o falsación de hipótesis científicas por medio de juicios perceptivos ${ }^{23}$. La evidencia para la conciencia, además, permite abrir una escapatoria fenomenológica al círculo vicioso entre una proposición verdadera y un hecho abstracto: una proposición verdadera es lo que se corresponde con un hecho, y un hecho es lo que se corresponde con una proposición verdadera. En palabras de Apel,

La representación proposicional del mundo de la experiencia puede ser trascendida en el sentido de la identificación perceptiva de evidencia fenoménica; y, en este sentido, el a

\footnotetext{
${ }^{22}$ Tal como Apel observa, Ernst Tugendhat en sus Vorlesungen zur Einführung in die sprachanalytische Philosophie (Frankfort, Suhrkamp, 1976) ha puesto de relieve el a priori del lenguaje como a priori proposicional; ello marca una diferencia con el a priori de la representación del objeto de la conciencia que tanto Kant como Husserl defendían. Más a delante desarrollaremos éste punto.

${ }^{23}$ En éste punto Apel se distancia de Popper. Para Apel la evidencia para la conciencia no es una mera causa -psicológicamente relevante de la aceptación subjetiva de enunciados básicos de la ciencia-; se trata más bien, de una razón epistemológicamente relevante, de su aceptación relevante. Ver K. Popper, Lógica de la investigación científica, ed. Tecnos, Madrid, 1990.
} 
priori irrebasable de la experiencia no es el lenguaje, sino la conciencia de la evidencia perceptiva (2002, p. 102, cursivas del autor).

Hay un aspecto, sin embargo, que no puede ser refutado por la teoría fenomenológica de la evidencia; ese aspecto es el elemento principal de la explicación wittgensteiniana del linguistic turn, esto es, la explicación del a priori lingüístico de la descriptibilidad de hechos experimentables (Apel, 2002, p. 102). En el capítulo anterior sobre el realismo, citamos un ejemplo de Nelson Goodman que es pertinente para este caso. Mientras que en una sala yo podría ser capaz de distinguir un equipo de audio, el poblador de una selva inhóspita, no podría. En éste caso, nuestro amigo de la selva puede comprobar la confrontación perceptiva con un fenómeno dado cualitativamente, pero le falta, por otro lado, la determinación interpretativa del fenómeno dado como algo; lo que le falta es la posibilidad de una descripción lingüístico-proposicional. Apel entiende que éste punto puede ser esclarecido con más detalle utilizando una teoría semiótica del conocimiento. Charles $\mathrm{S}$. Peirce, el fundador de la semiótica pragmática y de la faneroscopia, habla -en consonancia con Husserl-, de evidencia fenomenológica (a esto lo denomina Primeridad), de encuentro entre el yo y el no-yo (Segundidad), y explica la objetivación y la capacidad intencional de hacer presente de la evidencia fenomenológica por medio de la función icónica del signo. A diferencia de Husserl, Peirce no habla de verdad en el sentido de conocimiento; es necesario, por el contrario, una interpretación válida intersubjetivamente del significado del fenómeno en cuestión, en el sentido de la mediación de la donación inmediata del fenómeno a través de la universalidad conceptual de los símbolos lingüísticos (Terceridad) ${ }^{24}$. Peirce tuvo la capacidad de conjugar el a priori del lenguaje propio de la filosofía del linguistic turn, con la evidencia perceptiva en el sentido del a priori de la conciencia (Apel, 2002, p. 103). Ello abre paso a una mediación epistemológicamente relevante entre fenomenología y filosofía del lenguaje.

En Semiótica trascendental y filosofía primera (2002), Apel sostiene que,

La filosofía analítica del lenguaje se orientaba en su primera fase, la lógico-semántica, a las oraciones proposicionales, y

\footnotetext{
${ }^{24}$ Ver al respecto, K.-O. Apel, El camino del pensamiento de Charles S. Peirce, ed. Visor, Madrid, 1997. Recientemente los hablantes hispanos contamos con una traducción de los Collected Papers, editados por FCE.
} 
no a los actos de habla. Esto significa, hacía abstracción de la dimensión pragmática, tal como más adelante fue denominada por Charles W. Morris, del uso intencional e interpretativo de oraciones por parte de hablantes y oyentes en el contexto de una situación (2002, p. 104. Cursivas de Apel).

En Semiótica filosófica (1994), Apel distingue tres etapas al interior de la filosofía analítica del lenguaje: i) el giro lingüístico y la falacia abstractiva del semanticismo trascendental; ii) el giro pragmático como superación de la falacia abstractiva del semanticismo trascendental; iii) el repliegue del giro pragmático a través de la reducción del significado a intenciones prelingüísticas y la posibilidad de una refutación de esta reducción. En la primera fase de la historia representada por Apel, se destacan el Tractatus de Wittgenstein y también la semántica lógico-constructiva de Carnap y Tarski. Apel entiende que en el Tractatus ya se produce el giro lingüístico de la prima philosophia en tanto que giro semántico-trascendental, caracterizado por la aplicación de conceptos lingüísticos en lugar de los conceptos mentalistas inaugurados por la filosofía moderna desde Descartes hasta Husserl -conciencia, juicio, pensamiento, intencionalidad-. Ello se observa en la proposición 4: "El pensamiento es la proposición con sentido". Otro rasgo característico del giro lingüístico realizado por Wittgenstein es, según Apel, la sustitución del "principio supremo de los juicios sintéticos" de Kant (las condiciones de posibilidad de la experiencia son las condiciones de posibilidad de los objetos de la experiencia) por un postulado de las condiciones lógico trascendentales del lenguaje puro como condiciones de posibilidad de hechos en tanto que elementos de un mundo descriptible (Apel, 1994, p. 193). A este principio Apel lo llama de la autonomía onto-semántica y de la no-trascendibilidad metodológica del lenguaje. Apel juzga este principio como el parámetro irreversible de la filosofía del siglo XX y como el criterio a partir del cual debe ser definido el giro lingüístico. Este principio, como vemos, está en consonancia plena con el axioma fundamental de Dummett.

Como es sabido, Apel toma la estructura triádica o trivalente-relacional de la función de los signos o semiosis desarrollada por Charles S. Peirce ${ }^{25}$. A partir de allí, ya en la

\footnotetext{
${ }^{25}$ Ch. S. Peirce, y posteriormente Ch. W. Morris en sus Fundations of the Theory of Signs (1938), desarrolla una concepción de la semiótica que descansa en una relación triádica de la semiosis, es decir, una relación entre el signo mismo, sus referentes reales, y su usuario o intérprete.
} 
segunda etapa, resultan dos aspectos o direcciones necesarias para la superación de la falacia abstractiva del semanticismo: uno se relaciona con la dimensión semántica de la referencia de los signos; el otro con la dimensión pragmática del uso de los signos.

Ante todo, Apel sostiene que el concepto de intencionalidad referencial no puede separarse del concepto de significado público en cuanto intensionalidad de nombres (sean propios o genéricos). Husserl, en tanto que representante de la tradición del trascendentalismo mentalista que precedió al giro lingüístico, suponía que la conciencia trascendental del yo, que en la "revolución trascendental" sobreviviría a la puesta entre paréntesis fenomenológica (epojé) del mundo, del lenguaje y de la comunicación con otros sujetos, sería capaz de constituir atemporalmente todos los significados a través de su intencionalidad. Para presuponer su autocomprensión o sus autocomprensiones como "yo", sin embargo, los sujetos deben contar, a su vez, con significados públicos intensionales que son siempre ya portadores de signos lingüísticos y comunicables. Los sujetos de intencionalidad participan del significado público a través de la interpretación de los signos y contribuyen a los significados públicamente participables a través de sus intenciones de significado (Apel, 1994, p. 206). De éste modo, Apel sostiene que,

\section{La función trascendental de sujeto de cada sujeto particular de la intencionalidad reside exactamente en la presentación de tales pretensiones de significado -por ejemplo, en el contexto del discurso argumentativo- cuya validez intersubjetiva podría ser realizada por una comunidad ilimitada de la interpretación de los signos (1994, p. 206. Cursivas del autor).}

Por eso mismo Apel, en coincidencia con Charles S. Peirce y Josiah Royce, sostiene que la comunidad ilimitada de la interpretación de los signos es el sujeto trascendental definitivo de las intenciones de significado y -por ello, del conocimiento intersubjetivamente válido ${ }^{26}$-. A diferencia de Tugendhat por ejemplo, Apel sostiene que la intencionalidad es necesaria para la realización pragmática de la dimensión semántica de la referencia de los signos ${ }^{27}$. Este problema -o al menos una parte de él, la que aquí nos

\footnotetext{
${ }^{26}$ Ver especialmente los capítulos 4 y 5 de La transformación de la filosofía, ed. Taurus, Madrid, 1985.

${ }^{27}$ No trataremos aquí este vasto problema, sólo nos remitimos a mencionar la posición de Apel. Apel desarrolla minuciosamente éste problema en el tercer capítulo de Semiótica filosófica, op. cit.
} 
interesa- se aclarará cuando nos adentremos a continuación en la tercer etapa de la filosofía analítica del lenguaje.

En la segunda mitad del siglo pasado ha surgido una nueva corriente del giro psicologista de la mano de la teoría "intencionalista" del significado de Paul Grice. Apel entiende que la estrategia principal de esta corriente es minimizar la institución lingüística de los significados "atemporales" públicamente compartibles, reduciendo los significados a las intenciones de los hablantes. Searle II da un paso más que Grice y retorna al paradigma precomunicativo y prelingüístico del significado en el sentido de la representación de los estados psíquicos (Apel, 1994, pp. 250 y ss.). A parir de su obra Intencionalidad, Searle ha pasado a suponer (al menos esta es la interpretación de Apel y Habermas que aquí defendemos) que la "intencionalidad" en sentido estricto, esto es, los "estados intencionales" tales como los "deseos", las "convicciones" y las "intenciones" son más fundamentales en relación al significado que las convenciones lingüísticas de significado que regulan las expresiones de las intenciones de significado. Lo que Searle II pretende, en palabras de Apel es, "fundamentar la filosofía del lenguaje dentro de una filosofía del espíritu" (1994, p. 251); y ello por dos razones. En primer lugar porque Searle II adopta un punto de vista cuasi-husserliano según el cual las expresiones del lenguaje no portarían absolutamente ningún significado si no fuera por nuestras intenciones prelingüísticas. En segundo lugar, porque las "condiciones de cumplimiento" ligadas a los actos ilocucionarios son "condiciones de cumplimiento" en relación con los "estados intencionales del espíritu". De éste modo, una oración será verdadera si la creencia expresada es correcta; una orden será obedecida si se concreta. Apel no niega el importante papel que cumple la intencionalidad ${ }^{28}$; para Apel se trata de una condición necesaria y esencial del uso del lenguaje, tal es así que, "una adecuada filosofía del lenguaje debe ser al mismo tiempo una adecuada filosofía del espíritu" (1994, p. 252). Aquello que Searle II -junto a toda la filosofía anterior al giro lingüístico- no tiene en cuenta es que no pueden tomarse a las entidades físicas como entidades lingüísticas sin presuponer ya una estructura que se corresponda con una estructura lingüística del significado. Searle supone que las intenciones de significado no tienen por qué suponer

\footnotetext{
${ }^{28}$ Quizás esta sea una de las diferencias más importantes entre Searle y Tugendhat; éste último, como veremos más adelante, no le otorga una importancia central a la intencionalidad de la conciencia.
} 
una estructura de significado ligada convencionalmente a las estructuras lingüísticamente relevantes de las entidades físicas. ${ }^{29}$

Veamos ahora, ¿a qué se denomina "pragmatic turn" al interior del "linguistic turn"? Se habla de "pragmatic turn" para referirse a la corriente de la "ordinary language philosophy" orientada al uso del lenguaje, introducida por el último Wittgenstein. También se alude al mérito de la teoría de los actos de habla fundada por J. L. Austin ${ }^{30}$. Bajo el "pragmatic turn" de la filosofía del lenguaje también se suele entender una estrategia que intenta reducir el sentido (meaning) articulado lingüísticamente a las intenciones de acciones teleológico racionales (Apel, 1994, p. 291). El origen de esta estrategia no lo encontraremos en la Teoría de los actos de habla de Austin, sino más bien en la teoría intencionalista de base pre-lingüística de Paul Grice. También Searle por su cuenta, a partir de Intentionality (1983), ha intentado fundamentar su propia teoría de los actos de habla mediante una teoría de la intencionalidad. Acordamos con Apel en sostener que esta radicalización del "pragmatic turn" es un paso desafortunado, puesto que con ello lo único que se logra es sacrificar el gran logro del "linguistic turn" de la filosofía analítica:

...el haber destacado la relevancia del logos semántico del lenguaje como condición de posibilidad del sentido intersubjetivamente válido- en aras del retroceso a las posiciones del solipsismo metódico ligado a puntos de vista prelingüísticos. Me parece sin embargo que el tener en cuenta las posiciones subjetivas de significados en una teoría de las acciones del decir, o actos de habla, no tiene por qué conducir necesariamente a un abandono del "linguistic turn" de la filosofía contemporánea (1994, p. 291, 292. Los destacados le pertenecen a Apel).

Apel sostiene (y aquí defendemos su posición) que el hecho de tematizar las intenciones subjetivas de significación no implica necesariamente, una reducción del significado

\footnotetext{
${ }^{29}$ Y ello es curioso porque el Searle I defendía la importancia de las reglas convencionales del lenguaje para la constitución de los significados públicamente válidos (Apel, 1994, pp. 255 y ss.) Esa importancia analítica que tienen las reglas queda evidenciada en la distinción entre reglas regulativas y reglas constitutivas. Este problema la analizaremos en el Capítulo 8.

${ }^{30}$ También se habla de "pragmatic turn" en teoría de la ciencia. Se sostiene, dentro de ésta perspectiva, que no es posible hacer abstracción de la dimensión pragmática del sentido, incluso para la comprensión de las teorías y las explicaciones científicas. No trataremos aquí éste problema.
} 
lingüístico a las intenciones de acciones prelingüísticas; debiera llevarse a cabo, más bien, una ampliación pragmáticamente integrada del concepto de la semántica lingüística. Con estas consideraciones previas estamos en condiciones de realizar un análisis más minucioso de la teoría intencionalista del significado que Searle II nos propone. Para decirlo brevemente, Searle entiende que los estados intencionales de la conciencia tales como creencias, deseos, temores, esperanzas e intenciones, establecen las condiciones de cumplimiento mediante las cuales puede ser entendido el significado de los actos de habla. De éste modo, a una constatación le corresponde un estado de cosas de cuya existencia el hablante está convencido; a una orden le corresponde un estado deseado por el hablante; a una promesa, un estado deseado por el oyente. En el caso de la constatación, la condición de satisfacción se determina por la creencia del hablante; en éste caso, la correspondencia de la emisión se corresponde con el estado de cosas en el mundo; a ello Searle lo denomina word to world dirección of fit. En los casos de las ordenes y promesas, por el contrario, el ajuste debe ser producido activamente, la dirección de ajuste en este caso será del mundo a la emisión (world to word direction of fit). En Intencionalidad, Searle sostiene que,

...la clave al problema del significado es ver que en la realización del acto de habla la mente impone intencionalmente las mismas condiciones de satisfacción sobre la expresión física del estado mental expresado, que el estado mental tiene en sí mismo (1999, p. 172).

Ya hemos hecho referencia anteriormente a una confrontación entre el a priori del lenguaje proposicional de Wittgenstein y la defensa fenomenológica del a priori de la conciencia. La propuesta de Apel dista de ser una propuesta radical; su posición se ubica en un in between entre el planteamiento husserliano y el wittgensteiniano. La propuesta de la fenomenología husserliana se emparenta grosso modo con la posición de Searle II en lo siguiente: existe una prioridad del a priori de la conciencia respecto a la evidencia perceptiva de los estados de cosas que son afirmados en una proposición. Es el sujeto consciente quien tiene la tarea activa de comprobar si la intencionalidad de su creencia acerca de la existencia de un estado de cosas es cumplida por el fenómeno dado. Searle también sostiene que el estado intencional de la conciencia determina las condiciones de cumplimiento del acto de habla de la afirmación de ese estado de cosas (Apel, 2002, p. 
107). Lo anterior, sin embargo, no contradice el punto central de Wittgenstein; el a priori lingüístico proposicional de la descriptibilidad de hechos de la experiencia, no queda refutado. De éste modo, Apel afirma,

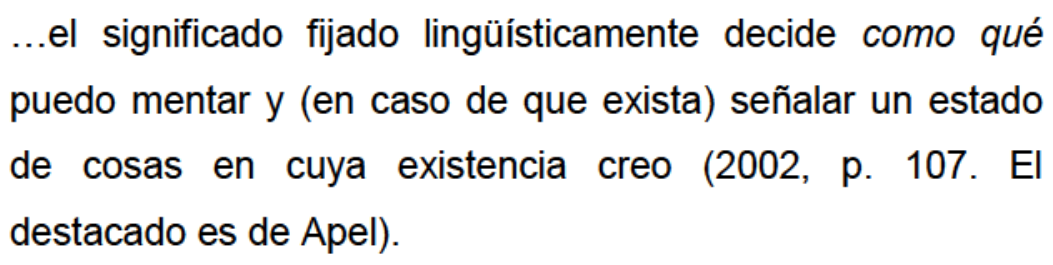

En lo tocante a la evidencia puramente fenomenológica, el estado intencional de la conciencia impone las condiciones de cumplimiento del acto de habla de la afirmación; de éste modo, es mi creencia la que decide qué fenómeno soy capaz de reconocer como condición de cumplimiento de esa misma afirmación. Hasta ahí Apel está de acuerdo con Searle. A partir de aquí comienzan las divergencias porque en lo referente a la interpretabilidad intersubjetivamente válida de la evidencia fenomenológica (y previo a la creencia del contenido intencional de la creencia), las condiciones de cumplimiento son dependientes de la oración proposicional del lenguaje con que el estado de cosas mentado puede ser descrito. Por eso mismo, y como se observa en la anterior cita, aquello que decide cómo y qué puedo mentar (pensar) es el uso de los signos. En nuestro ejemplo del capítulo anterior del habitante de la zona selvática que se topa con un equipo de audio, el sujeto podría orientarse pre-lingüísticamente como supone Husserl; pero en contra de Husserl (y de Searle II), no podría manifestarlo de una forma pública o intersubjetivamente comprensible. Para decirlo con Peirce, el mentar intencional y las condiciones de satisfacción, determinadas por nuestro habitante de la selva lejana, serían explicitables sólo en el sentido de la "Primeridad" (el ser-así de las cualidades sensibles) y de la "Segundidad" (encuentro del yo con el no-yo), pero decididamente no, en el sentido de la "Terceridad" (interpretabilidad como algo). Así, la dependencia unilateral del significado lingüístico respecto la intencionalidad de la conciencia, que Searle la presume como más fundamental, está descaminada.

A continuación proseguiremos con el análisis de la Intencionalidad en Searle a partir de un autor que tiene una propuesta más radical que la de Apel, un autor que, formado dentro de la tradición fenomenológica se posiciona fuertemente dentro de la tradición de la filosofía del lenguaje. Nos referimos a Ernst Tugendhat. 


\section{Filosofía tradicional y Filosofía analítica. El aporte de Tugendhat}

La filosofía trascendental o "tradicional" -como Tugendhat la denomina en Traditional and analytical philosophy (2009)-, se refiere a los objetos de un modo enteramente distinto al de la filosofía analítica. Esa referencia es pre-lingüística. Esa referencia pre-lingüística se piensa como un tener-ante-sí. El concepto que la filosofía moderna ha utilizado para referirse a éste tener-ante-sí es el de representación. La conciencia puede referirse a los objetos, se supone, porque "se los representa". Este punto es el que viene a criticar la filosofía analítica del lenguaje.

La teoría-objeto de Husserl es una teoría representacional; la intencionalidad no es lingüística. Pero Husserl, sostiene Tugendhat, siguió a Frege al sostener que las descripciones son semánticamente más fundamentales que los nombres propios (2009, p. 285). Para Husserl, todos los objetos espaciales se presentan ante las representaciones perceptuales y esa síntesis de objetos-conscientes, como conciencia intencional, es ella misma comprendida como una representación. Aquí Husserl se mueve claramente dentro de la tradición kantiana. Según Kant, la representación de un objeto depende de una "regla" que realiza una "síntesis" de distintos tipos de representaciones. Pero no pretendemos aquí detenernos en la epistemología de Kant. Volvamos a Husserl y a las críticas que pueden hacerse desde el campo de la filosofía analítica.

Lo que Husserl denomina objetos se corresponde exactamente con aquello que junto a Tugendhat podríamos denominar el soporte de ciertas expresiones lingüísticas (2009, p. 286). Pero la relación con los objetos, en la perspectiva de Husserl, se sostiene gracias a la intencionalidad; esto sólo puede ser interpretado -sostiene Tugendhat-, en un sentido metafórico. Ocasionalmente Husserl distingue al objeto como tal de sus determinaciones predicativas; al objeto como tal lo denomina "la $X$ pura en abstracción de todos los predicados"31. Aunque hubiera definido los objetos como sujetos a una posible predicación, nunca se detuvo en un análisis del empleo de los términos singulares ${ }^{32}$ para la explicación de la relación-objeto. Aquello que diferencia un modo y otro de hacer filosofía es que la filosofía tradicional entiende la relación-objeto sin tomar la función del signo como su starting-point (Tugendhat, 2009, p. 288). De este modo,

\footnotetext{
${ }^{31}$ Aquí Tugendhat se refiere específicamente al §131 de Husserl, Ideas I (1992).

${ }^{32}$ Más adelante, en el capítulo 5 nos detendremos en los términos singulares.
} 
El análisis del lenguaje no critica que la filosofía trascendental se haya guiado por la conciencia, sino que haya pensado la conciencia de objetos de una manera demasiado sencilla, sin tener en cuenta que nos referimos lingüísticamente a los objetos con expresiones que, en tanto que términos singulares, forman parte de una estructura lógica determinada (semántico-formal). (Tugendhat, 2003, p, 95).

Quien defienda el punto de vista de la filosofía de la conciencia podría asegurar que puede pensarse perfectamente una referencia prelingüística de los objetos prescindiendo de una estructura lógica. ¿De qué manera? Como representación. En el uso lingüístico habitual, Tugendhat distingue dos significados de la expresión "representarse algo". El primero se corresponde con una frase nominal tal como, "él se representa que ahora llueve en Buenos Aires". En éste ejemplo se entiende "representarse algo" en el sentido de imaginarse que algo es de un modo particular. En el otro significado se completa "él se representa..." con una expresión que figura por un objeto; por ejemplo, "él se representa el Monte Aconcagua", o "ya no puedo representarme el rostro de aquella novia". Estos casos se refieren a una imagen de fantasía, una imagen interior que se pone visualmente ante sí. Con éste segundo modo de empleo se enlaza la terminología filosófica, aún cuando la filosofía trascendental (en especial la de Husserl) renunció a la teoría de la representación y dejó en claro que la conciencia se refiere a los objetos de una manera directa y no a través de representaciones interiores. De éste modo, el término "representar" se ha convertido en el concepto general para la referencia consciente hacia los objetos. Para Tugendhat este concepto es absurdo. Lo que se produce es una transferencia de algo que forma parte de una relación visual a una relación lógica. Aquello que caracterizó a la filosofía desde sus orígenes griegos hasta Husserl fue la ausencia de reflexión desde el análisis del lenguaje ${ }^{33}$.

\footnotetext{
${ }^{33}$ En la filosofía griega encontramos numerosas referencias al lenguaje, al uso de las palabras, a relaciones y diferenciaciones de los animales humanos y el resto de animales. En la Política, Aristóteles afirma: “La razón por la cual el hombre es un ser social, más que cualquier abeja y cualquier animal gregario, es evidente: la naturaleza, como decimos, no hace nada en vano, y el hombre es el único animal que tiene palabra." (2007, p. 31). Así también, en Ética Nicomáquea afirma: “[El hombre] debe también tener conciencia de que su amigo existe, y esto puede producirse en la convivencia y en la comunicación de palabras y pensamientos, porque así podría definirse la convivencia humana, y no, como el caso del ganado, por pacer en el mismo lugar. (2007a, p. 202). Pero éstas reflexiones son del lenguaje; no, a partir del lenguaje.
} 
Ahora bien, se podría sin embargo objetar lo siguiente, alguien podría decir que, aunque nos refiramos lingüísticamente a un objeto, tenemos que representárnoslo. Si alguien utiliza un término singular como "Juan" no le preguntamos, "¿a quién te representas como "Juan"?", sino más bien, "¿a quién te refieres con "Juan"?". Los objetos no son representados por la conciencia, sino que nos referimos a los objetos. ¿Pero qué significa aquí conciencia?, ¿dónde se encuentra?, ¿es algo que tenemos que buscarlo en nuestro interior, algo así como una visión interior? Lo interior es la conciencia, dirán los defensores de la filosofía trascendental; ahí no puede llegar la observación ni la visión. Pero Tugendhat aclara,

Tal vez ustedes digan: "Pero ya sé sin dudas que tengo conciencia de esto y aquello, así que ésta conciencia tiene que estarme dada interiormente de alguna manera". ¿Tiene que estarlo? Es una deducción precipitada decir que lo que no sabemos sobre la base de la observación exterior lo sobemos sobre la base de la observación interior (2003, p. $101)^{34}$.

De lo único que estamos seguros es del hecho que hablamos sobre las cosas. La clarificación llega entonces, a través del análisis del lenguaje. Para Tugendhat, el análisis del lenguaje debe ocupar el lugar metodológico que había ocupado la fenomenología descriptiva porque sostiene que los campos de la visión (visión interior, visión del mundo) presupuestos por la fenomenología, son una ficción.

Edmund Husserl distingue en las Investigaciones lógicas (1976), dos nociones de conciencia. Una surge cuando se dice que alguien tiene conciencia de algo, o que se refiere concientemente a algo. A esta noción de conciencia Husserl la denomina intencionalidad o vivencia intencional -esta noción es determinante para Husserl-. La conciencia entendida como vivencias intencionales se enmarca en un género más amplio de vivencias en general. En cada ser humano, las vivencias se encuentran en la unidad de un torrente de vivencia; también a este torrente de vivencia Husserl lo denomina conciencia. En este segundo concepto de conciencia, el basamento es el concepto de "vivencia". Lo determinante para Husserl son las nociones de vivencia e intencionalidad,

\footnotetext{
${ }^{34}$ Para un análisis más profundo respecto a lo externo y lo interno, ver L. Wittgenstein, Investigaciones filosóficas. Especialmente §305-308.
} 
las cuales son abordadas y analizadas de un modo fenomenológico mediante el método de la visión interior. Lo que Tugendhat pretende es demostrar que la visión interior no entra en juego en ninguno de los dos casos y que lo único decisivo son los criterios lingüisticos. Recordemos que Husserl tiene in the back of his mind, no a Kant, sino a la esfera cartesiana de la certeza interior. A lo que Husserl denomina vivencias, Descartes lo llama cogitaciones; abarca a todos los estados que tiene una persona; cuando los posee, la persona tiene un saber indudable de que los tiene. Cuando digo: "tengo este estado de ánimo", "mis temores son tales y cuales", "estoy deprimido o angustiado", la pregunta, "¿cómo lo sabes?" carece de sentido, es inoportuna. Así, Husserl sostiene que, si no puedo dudar de un estado mío, es porque me está dado de un modo inmediato, lo percibo de manera inmediata. Wittgenstein llamó la atención respecto a éste tipo de planteos que asimilan, sin razón, los enunciados sobre lo interior a los enunciados sobre lo exterior. Los enunciados sobre las "vivencias" no se basan en la observación exterior, eso es evidente; pero de ello no se sigue -como hizo Husserl-, que esos enunciados se basan en la observación interior. Más arriba planteábamos que las preguntas del tipo, “¿cómo sabes que tengo dolores, estoy angustiado o triste?" carecen de sentido. Para Husserl sin embargo, esas preguntas son plenas de sentido y la respuesta sería algo así como: "lo sé mediante la percepción interior". Wittgenstein $(2007,2008)$ sostiene -con acierto- que la diferencia radica en que, mientras la tercera persona del presente puede verificarse mediante la observación, la primera $\mathrm{no}^{35}$. Cuando siento dolor y grito, o enuncio una oración, esa oración no se basa en la observación del dolor, sino que expresa el dolor (Investigaciones filosóficas, 2008, § 244). Yo pronuncio ese enunciado como tal enunciado que puede ser percibido por otros y que puede verificarse mediante la observación. Si ese no fuera el caso, jamás podríamos comprender ni enseñar frases como, "tengo miedo" o "estoy preocupado". En palabras de Tugendhat:

Las dos cosas, que una frase en primera persona del presente no se puede verificar y que una frase en tercera persona se puede verificar mediante la observación, forman parte esencialmente del modo de empleo de esa frase (2003, p. 104. El destacado es de Tugendhat.).

\footnotetext{
${ }^{35}$ Ver específicamente el abordaje de los conceptos psicológicos en las Investigaciones filosóficas (2008), § 244 y ss., y Zettel (2007), § 472 y ss.
} 
Al mostrar esta bilateralidad en el empleo de las frases vivenciales, Wittgenstein abrió camino a una comprensión de lo interior que se distingue tanto del conductismo como del introspeccionismo.

Volvamos ahora a Husserl y a su concepto determinante de conciencia, la conciencia entendida como vivencia intencional. Estas vivencias tienen la particularidad de estar dirigidas a un objeto. De éste modo, la conciencia es conciencia de algo, el fantaseo es fantaseo de algo. Husserl constata la dirección de un objeto mediante la evidencia de la intuición de la esencia. Tugendhat sostiene por el contrario que, de lo que se trata, es de un criterio lingüístico. Husserl constata que los verbos tales como "percibir", "odiar", "amar", "enunciar", son transitivos, hay que añadirles un objeto como complemento gramatical; así es posible, "amar algo", "percibir algo", etcétera. La intencionalidad, de éste modo, es una relación. Pero, ¿en qué se diferencia este tipo de relación de otras?, ¿en qué se diferencian los verbos transitivos intencionales de los no intencionales? Esto Husserl no lo aclara. La respuesta que Tugendhat nos presenta es que la mayor parte de estos verbos no son términos singulares que figuran por objetos concretos, sino que se trata de frases nominalizadas, expresiones nominalizadas de la forma "que p", que figuran por estados de cosas. Cuando Husserl dice en sus ejemplos que percibimos, amamos, odiamos algo, ese "algo" no se refiere a un objeto sino a un estado de cosas. El planteo de Husserl tamizado por las conceptualizaciones provenientes del linguistic turn, sería el siguiente:

\section{La filosofía inglesa, que emplea el término proposition en vez de "estado de cosas", llama propositional attitudes a estos modos de conciencia. Podemos hablar de "modos proposicionales de conciencia" (2003, p. 107. Los destacados le pertenecen a Tugendhat).}

No todos los modos intencionales de conciencia -y Tugendhat no lo niega-, pertenecen a estos modos proposicionales de conciencia. Así, en algunos casos como "amar", "ver", "admirar", "contemplar", puede aparecer como complemento transitivo un término singular que figura por un objeto concreto. Se puede decir "veo que el sol sale", como también "veo el sol"; se puede decir "admiro que la gente sea buena", tanto como "admiro la bondad". Por ello mismo, tendríamos dos clases fundamentales de modos intencionales de conciencia: proposicionales y no proposicionales; los que se refieren a estados de 
cosas y los que se refieren a objetos concretos. Aún debemos preguntarnos en qué se distinguen éste tipo de relaciones de todas las demás. Husserl sostiene que lo común a todos los estados de conciencia es que están dirigidos a algo. Pero, ¿qué significa esto? Como sugerimos más arriba, los cañones y las pistolas también están dirigidos a, y eso no los convierte en estados de conciencia. El uso "estar dirigido a", sólo puede ser comprendido en términos metafóricos. Cuando percibimos un objeto, cuando lo vemos, cuando lo amamos o le tememos, aquello que tenemos a nuestra disposición no es nuestra visión interior, sino sólo el uso del lenguaje.

Tugendhat da un paso más y afirma que "todos los modos de conciencia intencionales no proposicionales implican modos proposicionales" (2003, p. 108). Ello es así porque la referencia a un objeto mediante un término singular forma parte de la comprensión de las frases predicativas. La referencia a un objeto no debe entenderse como una parte que puede depender o no de una conciencia proposicional, sino que reposa en una conciencia proposicional, en el hecho de que consideremos verdadera a una frase existencial. De eso se sigue que toda conciencia intencional es, tanto implícita como explícitamente, conciencia proposicional. Lo particular de la relación intencional consiste en que se basa en la comprensión de frases. De éste modo,

\begin{abstract}
El intento de superar desde la filosofía analítica el concepto "enfático" de conciencia de Husserl nos ha conducido a un resultado inesperado: constatamos que no hay conciencia de algo que no se base en el hecho de considerar verdadera a una frase existencial y que la "cualidad" especial de la consciencia a la que Husserl llamaba "intencionalidad" y que caracterizó como "estar dirigido a algo" resulta ser la comprensión de frases (2003, p. 112. Los destacados le pertenecen a Tugendhat).
\end{abstract}

Con lo anterior también se desploma el modo de hablar, tan arraigado en la filosofía trascendental, de la conciencia en términos de una relación sujeto-objeto. Esta relación no 
existe. Cuando un sujeto se refiere a un objeto, ésta relación nunca es simple y directa, siempre se encuentra mediada por la comprensión de frases ${ }^{36}$.

Hemos visto que, el lugar preponderante que conceptualmente Apel le otorgaba a la noción de intencionalidad, fue sometido por Tugendhat a un análisis estrictamente lingüístico. Para concluir el presente apartado, y defender la posición radical característica del linguistic turn, sólo nos resta hacer referencia al tratamiento que Dummett le otorga a la relación conciencia-lenguaje.

\section{Conciencia y lenguaje. El aporte de Dummett}

Al referirse al giro lingüístico, Dummett tampoco vacila en ubicar al Tractatus de Wittgenstein (1922) como un paso fundamental. Tampoco hay que dejar de lado los trabajos de Frege y Russell; Frege fue el primer filósofo en llevar a cabo una investigación plausible de la naturaleza de los pensamientos y su estructura. Si bien su principal interés no fue el estudio del lenguaje, éste fue una vía para analizar aquello que realmente lo preocupaba: el análisis de la conciencia. El paralelismo entre lenguaje y conciencia fue para él fundamental. Por eso mismo, según aclara Dummett, su estrategia para analizar los pensamientos fue centrarse en el análisis de las expresiones lingüísticas o simbólicas. Más allá de las dificultades analíticas que Dummett observa (1996), aquello que aquí nos interesa es resaltar que cuando los filósofos retomaron el camino que Frege había hilado, el giro lingüístico se había tomado definitivamente. $Y$ una vez consolidado el giro lingüístico, el axioma fundamental de la filosofía analítica resultó irresistible: "la única ruta hacia el análisis de los pensamientos es a través del análisis del lenguaje" (Dummett, 1996, p. 128).

Ciertos filósofos de la tradición analítica, tales como Evans y algunos de sus seguidores Peacocke en particular-, han empero rechazado el axioma fundamental y han ubicado a la filosofía de la conciencia como a una filosofía fundacional. Este también, aunque Dummett no lo menciona, es el caso de Searle II. La filosofía de la conciencia, a la cual Frege le dedicó su principal atención, es aquella rama de la filosofía que se ocupa de los problemas referidos a la conciencia, la estructura de los pensamientos y sus

\footnotetext{
${ }^{36}$ Estimo que en la sociología actual, este esquema sujeto-objeto es aún preponderante. La sociología no se ha apropiado (aunque hay casos excepcionales como Habermas y el propio Searle) de las conceptualizaciones provenientes de la filosofía analítica del lenguaje.
} 
componentes. Entonces, como podemos imaginar, la pregunta "¿qué es un pensamiento?" ha sido abordada tanto desde el punto de vista de la filosofía de la conciencia como desde el punto de vista de la filosofía del lenguaje. Para los filósofos del lenguaje, de lo que se trata es de explicar el significado de una palabra para determinar la contribución que una palabra hace al significado de una oración que la contiene; no se requiere más que eso. Desde la filosofía de la conciencia, el principio que rige es aquel que ubica a la conciencia por sobre sus sentidos constitutivos. Es mérito de Frege haber percibido que un pensamiento completo califica como verdadero o como falso; la conexión ente sentido y valor veritativo es fundamental para obtener una respuesta a la pregunta “¿qué es un pensamiento?” Lo central aquí es que esa respuesta exige una respuesta sustantiva, no-psicológica.

Si los pensamientos no son contenidos de la mente, tal como Bolzano había demostrado, deben ubicarse entonces en un compartimento distinto tanto del mundo físico como del mundo interior de las experiencias privadas. La metáfora del tercer reino, le sirve tanto a Frege como a Husserl, para oponerse al psicologismo que ambos rechazan. De ésta manera, aclara Dummett,

\begin{abstract}
Si, ahora, nuestra capacidad de pensar se iguala con, o al menos se explica en términos de, nuestra habilidad para usar el lenguaje, el baluarte tal [la metáfora del "tercer reino"] no es requerido: porque el lenguaje es un fenómeno social, de ninguna manera privativo de un individuo, y su uso es públicamente observable (1996, p. 131. Traducción propia).
\end{abstract}

Lo que nos permite el giro lingüístico es acceder a una vía que nos aleja de las explicaciones internistas (mentalistas), y nos otorga la posibilidad de tratar a los pensamientos en términos objetivos. Revertir la prioridad del lenguaje, puede conducirnos, según Dummett, a recaer en el psicologismo. Para éste último, según afirma Frege, los pensamientos son subjetivos y así mismo, incomunicables. Este fue el principal pecado del psicologismo. En palabras de Dummett,

...no puede hablarse de los conceptos como proviniendo de la mente como se hace con las imágenes mentales que no 
pueden ser descritas en términos de contenidos de la conciencia; y es precisamente esto lo que otorga el terreno más sólido para creer en el axioma fundamental de la filosofía analítica, esto es, que el análisis de los pensamientos pueden y a la vez deben dirigirse vía el análisis de las expresiones lingüísticas (1996, pp. 133-134. Traducción propia).

Al explicar los significados lingüísticos, estamos en condiciones de explicar los contenidos de conciencia, pero no al revés. Ya nos hemos referido a la prioridad metodológica del lenguaje por sobre la conciencia de la mano de Apel. Aquí Dummett estaría de acuerdo también en reprocharle a Searle su retroceso hacia la filosofía de la conciencia en cuanto a la determinación del significado. Searle II no hace sino renunciar al axioma fundamental; axioma que parecía ser la pieza central de Actos de Habla.

\section{A modo de conclusión}

El presente capítulo y los próximos dos, giran en torno a una preocupación que es central, se trata sin más de pensar la creación de hechos institucionales a partir del lenguaje, tomando al lenguaje como punto de partida, pero entendiendo que para poder analizar un fenómeno tan complejo como las instituciones humanas, es preciso dar cuenta de otros elementos fundamentales (de los cuales daremos cuenta en los capítulos finales). En términos teóricos, nuestra posición se encuentra estrechamente ligada -y parte del-, axioma fundamental; a lo largo de todo nuestro trabajo sostendremos que la única vía para acceder a los pensamientos es a través del lenguaje, porque el pensamiento es lenguaje. ${ }^{37}$ No descartamos la importancia, sin embargo, de la evidencia fenomenológica a la que Apel hace referencia, pero para los fines del presente trabajo nos centraremos en el lenguaje proposicional, que nos permite a los seres humanos construir un mundo que no sólo es natural, sino que trasciende a los hechos en bruto, siendo éste el rasgo característico de nuestra especie animal.

Por otro lado, es preciso entender a los significados en términos públicos y transmisibles; la importancia de este análisis es relevante no sólo en términos filosóficos sino también

\footnotetext{
${ }^{37}$ Filósofos del continente, tales como Gadamer y Heidegger, también han defendido esta posición.
} 
sociológicos, porque lo que estamos haciendo (o pretendemos hacer) podría caracterizarse -como bien se hace en el mundo anglosajón- en términos de una filosofía de la sociedad. En los próximos capítulos iremos viendo más en detalle cómo a partir del lenguaje (junto a otros elementos, como hemos aclarado) es posible que construyamos instituciones. 


\section{Capítulo 3: Los actos de habla}

\section{Introducción}

En el presente capítulo nos centraremos en los lineamientos generales desplegados por John Searle en Actos de habla, una de sus obras fundamentales -del año 1969-, y que corresponde a los planteos de lo que hemos denominado el Searle I, es decir, el Searle más apegado a la filosofía analítica del lenguaje (y al axioma fundamental). Este, precisamente, es el Searle más conocido, el más leído y discutido; por eso mismo no nos detendremos en un análisis detallado de esta obra y de los problemas que de ella se deducen; más bien se expondrán los lineamientos generales sin entrar en discusiones, con la finalidad de informar al lector no familiarizado con la tradición, de qué se trata la teoría de los actos de habla.

Ante todo, es preciso aclarar que no debe extrañar que una obra tan vasta como la de Searle, tropiece con ciertas contradicciones; al contrario de lo que muchas veces se estima, estas modificaciones al interior de la perspectiva de los autores, da cuenta del continuo y renovado interés por las problemáticas analizadas; las teoría cambian y eso es sinónimo de una profundización en el estudio de la materia. No debiera extrañar, por ejemplo, que el Searle I, en la década del 60, le haya otorgado una importancia central a la filosofía del lenguaje, mientras el Searle II, el de los años 80 , se vea interesado en una filosofía de carácter mentalista. Ese tipo de modificaciones son entendibles. Lo llamativo de "el caso Searle" es que a mediados de los 80 haya virado hacia el paradigma de la conciencia y, en esos mismos años, haya escrito junto a Daniel Vanderveken, una obra de filosofía del lenguaje como, Fundations of Illocutionary Logic (1985). En el presente capítulo, también nos centraremos en los puntos centrales de esa obra.

La teoría de los actos de habla de Searle -tal como aclaramos en el capítulo anterior-, se inscribe en la segunda fase de la tradición de la filosofía analítica del lenguaje, la filosofía del lenguaje ordinario, cuyo concepto central es el de fuerza ilocucionaria (Austin, How to do Things with Words, 1962). De lo que se trata es de rescatar el aspecto pragmático del lenguaje; es decir, su uso. Los orígenes de esta tradición se encuentran en "el segundo Wittgenstein", el de Philosophische Untersuchungen (1958), quien ya había puesto de relieve la importancia del uso del lenguaje que los hablantes llevan a cabo, mediante su teoría de los juegos de lenguaje. 


\section{El aporte de Searle I}

Searle comienza Speech Acts (1969), preguntándose por el modo en que las palabras se relacionan con el mundo. Cómo es posible que, en un contexto y ante un auditorio adecuado, las sentencias que un hablante prolifera puedan convertirse en órdenes, promesas, pedidos y cosas por el estilo. ¿Cómo es posible que cuando digo "Ignacio tiene mil novias" quiero significar que mi amigo Ignacio tiene muchas novias y no que Pedro viajó a Brasil por tercera vez?, ¿qué cosas están en juego cuando, al enunciar una maraña de ruidos, digo significativamente una cosa y no otra? ¿Cuál es la relación entre lo que quiero decir cuando digo algo, y lo que verdaderamente significa más allá de mis intenciones expresivas?; ¿cómo representan las palabras a las cosas?, ¿qué es para algo ser verdadero o falso? Estas son algunas de las preguntas centrales dentro de la filosofía del lenguaje. Estas preguntas tienen sentido porque efectivamente las personas se comunican, elaboran enunciados con significados específicos, dicen cosas queriendo decirlas y, en ciertas ocasiones, se entienden, forman acuerdos, dan y piden argumentos, y discuten. También dan órdenes, hacen preguntas, promesas, dejan legados, piden disculpas; sus emisiones pueden ser tenidas por verdaderas o falsas, ridículas, sin sentido o profundas.

Como dijimos, Searle hace filosofía del lenguaje, lo que no es igual a (aunque suele confundirse con) la lingüística. Mientras esta última se refiere al nombre de un método, aquella es el nombre de un tema. La filosofía lingüística pretende resolver problemas filosóficos específicos atendiendo al uso ordinario del lenguaje; la filosofía del lenguaje, por su parte, intenta proporcionar descripciones filosóficamente iluminadoras de ciertas características generales del lenguaje -la verdad, la referencia, el significado, la necesidad-. Su interés principal no son los elementos particulares de un lenguaje particular. La filosofía del lenguaje no se ocupa de los lenguajes, sea inglés, francés, castellano o rumano; sino sobre el lenguaje (Searle, 1994, pp. 13-14).

Dominamos un lenguaje porque vivimos en una comunidad de hablantes; tomamos parte en una compleja forma de conducta dominada por reglas $\mathrm{y}$, precisamente, para vivir un lenguaje tenemos que ser capaces de dominar esas reglas. La problemática del lenguaje, como vemos, es tanto filosófica como sociológica porque tiene la capacidad de explicar el aspecto social de los seres humanos. Lo central aquí es que cuando un hablante nativo 
del castellano -como es mi caso-, hace caracterizaciones lingüísticas, no realiza informes o describe la conducta de un grupo, sino que más bien lo que hace es describir aspectos del dominio de una habilidad dominada por reglas. Además, y tal como lo ha trabajado en detalle el Wittgenstein tardío, esas mismas caracterizaciones lingüísticas están hechas, ellas mismas, en base a un seguimiento de reglas. Para aclarar éste punto, Searle recurre a la analogía que Wittgenstein había hecho entre el lenguaje y los juegos. Sabemos que en el fútbol se realiza un tanto cuando la bola ingresa al arco y los jugadores están en una posición determinada (no se encuentran en posición adelantada). Ahora, ¿sobre qué se basa ese conocimiento?, ¿cómo es posible? La pregunta no se refiere al desempeño de un jugador de fútbol en particular, sino a la práctica del deporte en general. Si sé cómo jugar al fútbol es porque he interiorizado un conjunto de reglas. Lo que muestra el ejemplo es que algo similar ocurre con el conocimiento de las caracterizaciones lingüísticas. Si alguien preguntara cómo sabes que "Las mujeres son hembras", se podría responder que "se le llama mujer a la hembra humana adulta" o, simplemente "lo sé porque hablo castellano". De todos modos, no se pretende afirmar con esto que las caracterizaciones lingüísticas son siempre infalibles; los hablantes cometen errores.

La hipótesis de Searle, como hemos dicho, es que hablar un lenguaje es tomar parte de una forma de conducta gobernada por reglas (1994, p. 25). La forma en que esta hipótesis toma forma es que hablar un lenguaje consiste en realizar actos de habla; actos tales son, hacer enunciados, dar órdenes, hacer preguntas, promesas, exclamaciones de deseos y cosas por el estilo. Envuelve actos tales como referir y predicar. Debido a que toda comunicación lingüística incluye actos lingüísticos, es preciso centrarse en el estudio de los actos de habla; ellos son la unidad mínima del lenguaje. Por eso mismo, se ubican antes (en el sentido de more basic) que la palabra, el símbolo o -según la posición de Frege-, la oración elemental. Lo característico de la teoría de los actos de habla es que se ubica en el punto de intersección entre una teoría del lenguaje y una teoría de la acción; una teoría del lenguaje forma parte de una teoría de la acción porque el simple hecho de hablar es una forma de conducta gobernada por reglas, y constituye una de las actividades fundamentales de los seres humanos.

Es cierto, por otro lado, que un lenguaje puede no ser lo suficientemente rico como para decir lo que se pretenda decir; sin embargo, no existen barreras, en principio, para decir lo que se quiera decir en uno más rico. Por eso mismo, no hay dos estudios semánticos distintos: un estudio de los significados de las oraciones por un lado, y un estudio de las realizaciones de los actos de habla por el otro -langue y parole en términos 
saussureanos-. De la misma manera que la noción de significado de una oración requiere una emisión literal de esa oración con ese significado en un contexto determinado para constituir la realización de un acto de habla particular, así también la noción de acto de habla requiere una oración (al menos) posible, su emisión en un contexto y su significado, para la realización del acto de habla. El hablante puede querer decir más de que efectivamente dice pero, en principio, siempre es posible decir lo que se quiere decir. Por estas razones, Searle afirma que,

...un estudio del significado de las oraciones no es distinto en principio de un estudio de los actos de habla. Propiamente interpretados son el mismo estudio (1994, pp. 27 y 28$)$.

Y ello porque, para decirlo una vez más, toda oración significativa puede ser usada para realizar un determinado acto de habla, y ya que a todo acto de habla puede dársele una formulación exacta en una oración (u oraciones), el estudio de los significados de las oraciones y el estudio de los actos de habla no son dos estudios que marchan por distintas vías, sino un mismo estudio desde dos ópticas distintas.

Existen, como sabemos, dos tendencias generales en la tradición de la filosofía analítica, por un lado se ubican aquellos que se centran en el uso de las expresiones en las situaciones de los actos de habla y, por otro lado, quienes trabajan en el significado de las oraciones. Suele suponerse que estos caminos son inconsistentes, irreconciliables; quizás la historia de la tradición se la responsable, basta tener en cuenta, por ejemplo, que el "segundo" Wittgenstein se inclinó por el primer camino, mientras que el "primero", por el significado de las oraciones. Muy por el contrario, Searle entiende (atinadamente, agregamos) que estos dos enfoques no compiten entre sí sino que se complementan mutuamente. ¿Por qué? Porque para todo posible acto de habla existe una posible oración, y su emisión literal en un contexto particular constituye la realización de ese acto de habla.

\section{Tipos de actos de habla}


Anteriormente habíamos dicho que, en principio, puede decirse cualquier cosa que quiera ser dicha. A ello Searle lo denomina, principio de expresabilidad. Al emitir una oración, generalmente queremos decir más cosas de las que decimos. Si alguien me pregunta, "¿vas a correr?", yo podría responderle simplemente con un "si”. Pero queda claro, según el contexto, que lo que quiero decir es "si, voy a correr", o "si, esta mañana de domingo es perfecta para ejercitarse", o "si, después de una ajetreada jornada laboral necesito despejarme". De un modo similar, también puedo decir "iré" queriendo significar la promesa de que iré a correr, es decir, queriendo decir algo así como, "te prometo que iré". Los casos anteriores demuestran que incluso si no digo exactamente lo que quiero decir, siempre me es posible hacerlo. Searle expresa éste principio diciendo que para cualquier significado $X$ y para cualquier hablante $H$, siempre que $H$ quiera decir, transmitir, comunicar $X$, entonces es posible que exista alguna expresión $E$ tal que $E$ sea una expresión exacta de, o una formulación de $X$. Su formalización es la siguiente:

$(\boldsymbol{H})(\boldsymbol{X})(\boldsymbol{H}$ quiere decir $\boldsymbol{X} \rightarrow \boldsymbol{P}(\exists \boldsymbol{E})(\boldsymbol{E}$ es una expresión exacta de $\boldsymbol{X}))$.

Tal como dijimos más arriba, la hipótesis central de Actos de habla es que hablar consiste en realizar actos conforme a reglas. Existen distintos géneros de esos actos. Imaginemos que un hablante emite alguna de las oraciones que siguen:

1. David no trabaja.

2. ¿No trabaja David?

3. ¡David no trabaja!

4. ¡Desearía que David no trabaje!

Ahora bien, ¿cómo podríamos caracterizar o describir éstas emisiones?, ¿qué está haciendo el hablante cuando las enuncia? Algo que podríamos decir es que nuestro hablante está profiriendo oraciones del idioma castellano; pero además de esa evidencia, también podríamos decir que el hablante está haciendo algo. En 1 el hablante está realizando una aserción; en 2 está planteando una pregunta; en 3 está dando una orden; y en 4 está expresando un deseo o anhelo. Pero hay un elemento común en las cuatro oraciones. En cualquiera de éstas oraciones el hablante se refiere a, menciona o designa un objeto determinado: "David", y predica la expresión "no trabaja". Así, en la emisión de las cuatro oraciones, la referencia y la predicación son las mismas. A éstos actos de habla completos Austin, en How to do things with words (1962), los había bautizado actos 
ilocucionarios. Searle retoma esa misma terminología pero rechaza la distinción que Austin había hecho entre actos locucionarios e ilocucionarios ${ }^{38}$. Algunos verbos castellanos que denotan actos ilocucionarios son: "argumentar", "solicitar", "considerar", "objetar", "prometer", "aprobar", "dar la bienvenida", "censurar", "pedir disculpas", "criticar", "pedir", "ordenar", "mandar", "comendar", "observar", "legar", "aconsejar", "aseverar", "enunciar", "describir", entre otros (Searle, 1994, p. 32).

Un primer resultado de lo precedente es que al emitir cualquiera de las cuatro emisiones del ejemplo anterior, un hablante se encuentra realizando tres tipos de actos: a) emite palabras; b) refiere y predica; y c) enuncia, pregunta, ordena, anhela. Bajo la rúbrica general de actos de habla, Searle le asigna nombres a éstos actos:

a) Emitir palabras = realizar actos de emisión.

b) Referir y predicar $=$ realizar actos proposicionales.

c) Enunciar, preguntar, mandar, prometer, etc. = realizar actos ilocucionarios.

Lo que Searle pone de manifiesto es que al realizar un acto ilocucionario se realizan característicamente actos proposicionales y actos de emisión (1994, p. 33). De todos modos, se pueden emitir palabras sin decir nada; por ello, pueden realizarse actos de emisión sin realizar un acto proposicional o un acto ilocucionario. También, puede emitirse lo siguiente:

5. David nunca se hizo amigo del trabajo.

En 5, se emitió el mismo acto proposicional que en 1-4 -la referencia y la predicación son las mismas-, el mismo acto ilocucionario que en 1 -se trata del mismo enunciado o aserción-, pero se trata de un acto de emisión completamente distinto a los cuatro anteriores; la oración 5 no contiene ninguna de las mismas palabras y solo alguno de los mismos fonemas. La misma oración puede usarse para hacer dos enunciados diferentes. Junto a la noción de actos ilocucionarios se encuentra la noción de consecuencias o efectos que tienen tales actos sobre las acciones, deseos, creencias de los oyentes. Por ejemplo, mediante una aserción yo puedo asustar o persuadir a alguien, al dar un consejo puedo convencerlo o asustarlo, al hacer un pedido puedo lograr que él haga algo, al informarlo puedo instruirlo, elevarlo espiritualmente. A ello Austin lo denomina actos perlocucionarios (son las cursivas de nuestros ejemplos anteriores). Los actos

\footnotetext{
${ }^{38}$ Ver al respecto, J. L. Austin, How to do things with words, Oxford, 1962 y J. R. Searle, "Austin on locutionary and illocutionary acts", en Philosophical Review, vol. LXXVIII, núm. 4, octubre, 1968.
} 
proposicionales no pueden ocurrir sin plantear una pregunta, hacer una aserción o realizar algún otro acto ilocucionario. Tal como Frege observó en Die Grundlagen (1884), no son las palabras, sino las oraciones, aquellas que se usan para referir objetos. En la terminología de Searle, el portador de la referencia es el acto ilocucionario, cuya estructura gramatical es la oración elemental. Una emisión es una expresión referencial, sólo si se dice algo mediante ella.

Searle sostiene que, en los casos en que dos actos ilocucionarios tengan la misma referencia, la misma predicación y el significado de la expresión referencial sea el mismo, la expresión expresada es la misma. De éste modo, las expresiones 1 a 5 expresan la misma proposición. Y así también las siguientes:

6. David no trabaja porque se cansa.

7. La proposición de que David no trabaja es irrelevante.

En estos últimos ejemplos la proposición expresada es la misma, aunque aparezcan como parte de una proposición más general. Sólo en 1 y en 5 se asevera; las aseveraciones deben distinguirse de las proposiciones. Las aseveraciones son actos, pero las proposiciones no lo son. Una proposición es lo aseverado en el acto de aseverar, es lo que se interroga en el acto de interrogar, lo que se desea en el acto de desear. Es el contenido, y es por eso que hablamos de contenidos proposicionales. Cuando se expresa un contenido proposicional, se expresa siempre al realizar un acto ilocucionario. Searle distingue de este modo, el acto ilocucionario y el contenido proposicional del acto ilocucionario. No por ello debemos suponer que todo acto ilocucionario tiene un contenido proposicional; así lo demuestran expresiones tales como: “jHey!”, “¡Hurra!”, “¡Ouch!” Así llegamos a la tan conocida formalización de los actos ilocucionarios; su forma general es:

\section{$F(p)$}

La variable " $F$ " refiere a la fuerza ilocucionaria, y " $p$ ", a las expresiones que representan proposiciones $^{39}$.

\footnotetext{
${ }^{39}$ Searle formaliza los distintos géneros de actos ilocucionarios, pero en el presente capítulo no ahondaremos en esos detalles. Consideramos que se ha discutido y tratado el tema durante unas cuatro décadas y no pretendemos agregar nada más a la discusión. Sólo se pretende dar cuenta de los lineamientos generales y de algunos matices que resultan significativos dentro del contexto general del presente trabajo.
} 


\section{Reglas}

En Speech Acts (1969), Searle realiza una distinción entre tipos de reglas que mantendrá hasta su última obra, Making the Social World (2010). Searle habla de reglas regulativas y de reglas constitutivas. Si bien este punto será problematizado en el octavo y último capítulo, basta aquí con decir que la característica central de las reglas regulativas es que regulan actividades que existen con anterioridad a, y son independientes de, las reglas; la función de las reglas constitutivas por su parte, no es solamente regular una conducta previa sino que, además crean o definen nuevas formas de conducta. Por ejemplo, las reglas de etiqueta que regulan las relaciones interpersonales son reglas regulativas; las reglas del fútbol o del ajedrez en cambio, son constitutivas porque crean ellas mismas la posibilidad de jugar el juego. Si no hubiera reglas para jugar el ajedrez, simplemente no habría juego de ajedrez. Mientras que las reglas regulativas suelen ser imperativas, "Llévate un abrigo", o "Para la cena hay que vestirse con traje"; las reglas constitutivas, por su parte y siguiendo a Searle, no tienen ese tono y hasta pasan desapercibidas como reglas; así por ejemplo, "Se produce jaque-mate cuando el rey no puede hacer ningún movimiento más", o "Cuando el balón ingresa dentro del arco, se considera un tanto". Estas últimas reglas tienen un carácter casi tautológico puesto que la regla se asemeja a la definición de "jaque-mate" en ajedrez o de "gol" en futbol. Las reglas regulativas tienen la forma "Haz $X$ " o "Si $Y$ haz $X$ ". Las reglas constitutivas en cambio, suelen tener la forma " $X$ cuenta como $Y$ en $C$ " donde $C$ es el contexto.

Con la noción de reglas constitutivas Searle entiende que se resuelven ciertos problemas filosóficos. La pregunta, “¿cómo una promesa puede crear una obligación?" sería similar a preguntar, "¿cómo un gol suma un tanto?" Ambas preguntas pueden responderse utilizando la fórmula " $X$ cuenta como $Y$ en $C$ ". Las reglas constitutivas posibilitan la creación de nuevas formas de conducta (1994, p. 42 y ss.). Searle grafica la diferencia entre unas reglas y otras mediante un par de ejemplos (pp. 45 y 45). Veamos. Supongamos que en mi círculo social rige una regla de etiqueta según la cual, para una reunión debe enviarse la invitación con, al menos, dos semanas de anticipación. La acción de enviar la citación con dos semanas de anterioridad puede darse exista o no la regla. Pensemos ahora en un juego de fútbol. La aserción, "Ellos jugaron al fútbol" no puede darse si no existen ciertas reglas -las reglas del fútbol-. Nada impide, sin embargo, que veintidós personas puedan llevar a cabo los mismos movimientos físicos que realizan los equipos que juegan fútbol, pero sin reglas de fútbol convenidas con anterioridad, la 
conducta no podría ser descripta como una instancia de jugar al fútbol. Sin reglas de juego no hay juego. En palabras de Searle,

En general, la conducta social podría recibir las mismas especificaciones, incluso si no hubiese reglas de etiqueta.

Pero las reglas constitutivas, tales como las de los juegos, proporcionan las bases para especificaciones de conducta que no podrían darse en ausencia de la regla (p. 45).

La hipótesis de Searle en Actos de habla, como antes habíamos mencionado, es que hablar un lenguaje implica realizar actos conforme a reglas. Ahora estamos en condiciones de agregar un elemento y refinar el análisis. De éste modo, la estructura semántica de un lenguaje es un conjunto de reglas constitutivas subyacentes; los actos de habla son actos realizados de acuerdo con esos conjuntos de reglas constitutivas. De ahí la analogía con los juegos. Hablar un lenguaje es parecido a jugar al fútbol; hablar un lenguaje no implica una mera emisión de ruidos. Puesto que los diferentes lenguajes humanos son intertraducibles, es posible considerarlos como plasmaciones convencionales diferentes de las mismas reglas subyacentes. Que pueda hacerse una promesa en lengua francesa con la expresión "Ja promets", y en alemán con la expresión "Ich verspreche" es cuestión de convención. Pero el que una emisión de un dispositivo de prometer (en un contexto y bajo condiciones apropiadas) cuente como la asunción de una obligación, es enteramente asunto de reglas y no de convenciones.

\section{Actos de habla y significado}

Los actos de habla se realizan al emitir sonidos o al producir marcas. Los actos ilocucionarios se diferencian de la emisión de sonidos y de la realización de marcas, en dos aspectos centrales: por un lado, aquellos tienen significado y, por otro lado, se dice que una persona quiere decir algo mediante esos sonidos o marcas. Cuando una persona habla quiere decir algo mediante eso que dice, y lo que se dice tiene un significado. Encontramos aquí una diferencia respecto a los juegos. En el fútbol, por ejemplo, no se dice, característicamente, que los jugadores o el balón tengan un significado, o cuando se 
hace una jugada no se dice que esa jugada tuvo un significado o que alguien haya querido decir algo mediante esa jugada.

En Meaning (1957), Grice había analizado la noción de "significado no-natural" del siguiente modo: decir que un hablante $H$ quiere decir algo mediante $X$, equivale a decir que $H$ intentó que la emisión $X$ produjese algún efecto en $O$, al reconocer esa intención. Aunque posteriormente a Searle II no le hubiera desagradado esta explicación, en Actos de habla le realiza básicamente, dos críticas. En primer lugar, este análisis no logra mostrar el punto que a Searle I más le interesa, que el lenguaje es asunto de reglas y convenciones; en segundo lugar, al definir el significado por los efectos que produce en el oyente confunde los actos ilocucionarios con los actos perlocucionarios. Analicemos ambos puntos con algún detalle. Para ilustrar el primer punto, Searle propone un experimento mental (1995, p. 53 y ss.). Supongamos que yo soy un soldado americano de la segunda guerra mundial y que, desafortunadamente, caigo en manos de las tropas alemanas; para poder escapar se me ocurre hacerme pasar por soldado italiano o alemán. Lo que me gustaría es poder decirles en alemán o en italiano que soy un soldado italiano. Pero supongamos que no tengo un buen manejo de esos idiomas y me resulta difícil decirles que soy un soldado italiano. Se me ocurre entonces montar una pantomima y recitarles un refrán que mi madre me narraba en italiano cuando era un niño. Así, me dirijo a mis captores alemanes con la siguiente oración: Asino vecchio non prende lezioni. Ahora bien, interpretemos la situación en términos griceanos. Mi intención es producir un efecto en mis captores, el efecto de que crean que soy un soldado italiano; por eso intento producir en ellos ese efecto por medio de su reconocimiento de mi intención. Intento que piensen que soy un soldado italiano. Ahora bien, el problema es el siguiente: ¿se sigue de ésta explicación que cuando digo, Asino vecchio non prende lezioni, lo que quiero decir es "Soy un soldado italiano"? No solo no se sigue; además, cuando emito el proverbio italiano no quiero decir "Soy un soldado italiano", ni tampoco "Sono un soldato italiano"; muy por el contrario, lo que las palabras significan es que, "El burro viejo no aprende". Es evidente que mi intención es engañar a mis captores de manera que entiendan que lo que quiero decir es que "Soy un soldado italiano"; parte de lo que se incluye en el engaño consiste en inducirlos a pensar que es eso lo que significan en italiano las palabras que emito. Wittgenstein, en $§ 510$ de las Investigaciones filosóficas escribe, "Di "Aquí hace frío" y significa "Aquí hace calor". ¿Lo puedes hacer?" (2008, p. 335). La razón por la cual no lo podemos hacer radica en que lo que podemos querer es una función de lo que estamos 
diciendo (Searle, 1994, p. 54). El significado, afirma Searle, no sólo es cuestión de intención, sino también de convención ${ }^{40}$. Searle afirma entonces,

Podríamos decir que, según la explicación de Grice, parecería que cualquier oración puede emitirse con cualquier significado, dado que las circunstancias hacen posibles las intenciones apropiadas. Pero esto tiene como consecuencia que el significado de la oración se convierte entonces precisamente en otra circunstancia (1994, p. 54).

Volviendo a nuestro ejemplo, para producir mi pretendido engaño a las tropas alemanas, utilizo un dispositivo basado en convenciones y en reglas que gobiernan su uso, con el objetivo de producir efectos ilocucionarios totalmente diferentes. Cuando una persona emite una oración queriendo decir algo, su contenido está relacionado con lo que la oración significa en el lenguaje en que esa persona está hablando; su significado no es azaroso. El análisis que Searle I realiza respecto a los actos ilocucionarios, involucra tanto a los aspectos intencionales como de los convencionales, y su mutua implicación. La vinculación entre intenciones por un lado, y convenciones y reglas por el otro, es el nudo central del análisis que Searle despliega en Actos de habla; de éste modo sostiene que,

Al realizar un acto ilocucionario, el hablante intenta producir un cierto efecto haciendo que el oyente reconozca su intención de producir ese efecto; y además, si está usando las palabras literalmente, intenta que ese reconocimiento se logre en virtud del hecho de que las reglas para el uso de las expresiones que emiten asocian la expresión con la producción de ese efecto. Es ésta combinación de elementos la que necesitamos expresar en nuestro análisis del acto ilocucionario (1994, p. 54. El destacado es de Searle).

\footnotetext{
${ }^{40}$ Como hemos visto, el Searle de Intencionalidad se muestra más preocupado por el problema de la intencionalidad que por las convenciones y reglas presentes en el lenguaje ordinario. Allí cobra valor, por ejemplo, la crítica de Apel que hemos visto en el capítulo anterior.
} 
Pasemos ahora a la segunda objeción que Searle plantea. Grice sostiene que decir algo queriendo decir lo que significa consiste en realizar un acto perlocucionario. Searle, por el contrario, sostiene que al decir algo queriendo decir lo que significa, se realiza produce un acto ilocucionario. En primer lugar, generalmente ocurre que las emisiones de los hablantes no tienen efectos perlocucionarios. Muchos de los géneros de oraciones usadas para realizar actos ilocucionarios no tienen efectos perlocucionarios asociados a su significado. No hay efectos perlocucionarios asociados a los saludos; si digo, por ejemplo, "Buenas noches" queriendo decir lo que significa, no produzco en el oyente ningún estado o acción que exceda los límites del contenido proposicional. Mi oyente reconoce el saludo porque comprende lo que he dicho, no hay ninguna respuesta o efecto adicional. Ciertas emisiones, sin embargo, cumplen con los requisitos de Grice; cuando se dice "iAndate ya!", el significado está ligado al hecho de provocar un efecto perlocucionario específico: lograr que el oyente se vaya. El efecto sobre el oyente no es ni una creencia, ni una respuesta; se logra mediante la comprensión de la emisión del hablante. A este efecto Searle lo denomina "efecto perlocucionario ${ }^{41}$ ". La formulación sería la siguiente: el hablante $H$ intenta producir un efecto ilocucionario $E l$ en el oyente $O$, haciendo que $O$ reconozca la intención por parte de $H$ de producir $E l$.

Searle (1994, p. 58) resume su postura y la de Grice del siguiente modo:

1. Análisis de Grice:

El hablante $H$ quiere decir $n n$ algo mediante $X=$

(a) $H$ intenta ( $i-I)$ que la emisión $E$ de $X$ produzca ciertos efectos perlocucionarios $P E$ en el oyente $O$.

(b) $H$ intenta que $E$ produzca $P E$ por medio del reconocimiento de $i-$ I.

2. Análisis revisado de Searle:

$H$ emite la oración $R$ queriendo decir lo que significa (esto es, quiere decir literalmente lo que dice) $=$

(a) $H$ intenta ( $i-I)$ que la emisión $E$ de $R$ produzca en $O$ el conocimiento (el reconocimiento, la consciencia) de que se dan los estados de cosas

\footnotetext{
${ }^{41}$ Si bien Searle parece apropiarse del concepto, éste le pertenece a Austin. Ver Austin (1962), How to do things with words.
} 
especificados por (alguna de) las reglas de R. (Llamemos a éste efecto, el efecto ilocucionario $(E I)$.

(b) $H$ intenta que $E$ produzca el $E l$ por medio del reconocimiento de $i-I$.

(c) $H$ intenta que $i-I$ se reconozca en virtud de (por medio de) el conocimiento que $O$ tiene de (algunas de) las reglas que gobiernan (los elementos de) $T$.

Ahora bien, en el primer capítulo hemos aclarado en qué consiste la distinción entre hechos en bruto y hechos institucionales. Aquí es necesario retomar esa distinción para ubicarla en el presente contexto, pues nos resultará útil. Veamos.

\section{Retornando a los hechos en bruto e institucionales}

Basta aclarar aquí que, tanto los hechos en bruto como los hechos institucionales se encuentran, digamos, entremezclados. Vemos a diario en las noticias de los diarios o los canales de TV oraciones tales como: "Racing perdió 2 a 0", "Falleció el presidente de Venezuela", "El señor Pérez contrajo matrimonio con la señorita García". Acciones tales como correr, morir o unirse a otra persona son hechos naturales; los seres humanos tenemos la facultad biológica de realizar todas esas actividades y más. Hasta ese nivel, de lo único que podemos dar cuenta es de la existencia de hechos en bruto, hechos naturales o meramente biológicos. Pero, por otro lado, los partidos de fútbol, los cargos de presidentes y los matrimonios no son -en absoluto-, hechos en bruto; se trata más bien, de instituciones o, para adoptar el vocabulario de Searle, hechos institucionales. Cuando más arriba decíamos que los hechos en bruto y los hechos institucionales se encuentran entremezclados, nos referíamos a que los hechos institucionales suponen hechos en bruto. Para que exista un Estado es preciso que exista una geografía, los matrimonios requieren seres humanos, los billetes de cien dólares se fabrican con la corteza de los árboles, etc. Las cursivas de nuestros ejemplos hacen referencia a los hechos en bruto.

Además, estas instituciones son sistemas de reglas constitutivas, puesto que todo hecho institucional tiene como base un sistema de reglas de la forma: " $X$ cuenta como $Y$ en el contexto $C$ ". Con todo, la hipótesis de Searle es que, cuando una persona realiza un acto de habla como, por ejemplo, una promesa, nos encontramos frente a un hecho institucional. Así, el análisis de los actos de habla no se desarrolla meramente en el 
terreno de los hechos en bruto. Las descripciones de los hechos en bruto pueden explicarse en términos de hechos institucionales, pero los hechos institucionales pueden explicarse solamente en términos de reglas constitutivas subyacentes. Volviendo una vez más a la analogía de los juegos, Searle sostiene (1994, p. 61) que el lenguaje posee regularidades brutas (los ruidos que realizan los humanos en contextos determinados y bajo ciertos estímulos) se deben a que los hablantes de un lenguaje participan en una forma de conducta intencional gobernada por reglas; esas reglas dan cuenta de las regularidades de la misma manera que las reglas del fútbol dan cuenta de las regularidades en el fútbol. Sin reglas pareciera no haber manera de dar cuenta de esas regularidades en cuestión. A continuación veremos la aplicación del análisis en torno a un caso: el acto de prometer.

\section{Los actos ilocucionarios: el ejemplo de las promesas}

Para llevar a cabo un análisis sistemático de los actos ilocucionarios, Searle comienza por los actos de prometer, porque son bastante formales y bien articulados; además, las lecciones que pueden aprenderse de estos actos son de aplicación general (1994, p. 62). Searle admite que existen varias clases posibles de defectos en los actos ilocucionarios; estos defectos, de todos modos, no son suficientes como para vaciar el acto en su totalidad. Puede llegar a ocurrir en algunos casos que una condición pueda ser verdaderamente intrínseca al acto en cuestión pero no ser satisfecha en un caso dado y, así y todo, el acto se habrá realizado. Como vemos, la noción searleana de defecto de un acto ilocucionario se asemeja a la noción austiniana de infelicidad ${ }^{42}$.

A diferencia de lo que ocurre con el resto de los juegos, hemos aprendido las reglas del juego de los actos ilocucionarios, en general, sin una formulación explícita de esas reglas. Enunciar lo implícito es la tarea filosófica por excelencia. En su análisis, Searle se refiere únicamente a las promesas explícitas por completo, e ignora las promesas hechas por medio de giros elípticos, insinuaciones, metáforas y cosas por el estilo; también ignora las promesas hechas en el curso de la emisión de oraciones que contienen elementos irrelevantes a la hora de llevar a cabo una promesa. Trata las promesas categóricas más

\footnotetext{
${ }^{42}$ Ver principalmente los casos de infortunio que Austin analiza en la segunda conferencia de How to do things with words (1962). Allí hace especial hincapié en el contexto y en las condiciones de enunciación, con lo cual quedan invalidadas ciertas críticas con un alto nivel de prejuicio sociológico. Me refiero puntualmente a las críticas que Bourdieu elabora en ¿Qué significa hablar? (2008).
} 
que las hipotéticas, pues la correcta explicación de aquellas será útil para éstas. Como vemos, la tarea de Searle será construir un modelo idealizado de análisis, un modelo tan idealizado como el que utilizan los economistas para realizar análisis económicos, como los utilizados, por ejemplo, por Max Weber para analizar las formas de dominación; o, dentro de la astronomía, las explicaciones del sistema solar que consideran a los planetas como puntos. Toda sistematización requiere idealización y abstracción (Searle, 1994, pp. 64, 65).

Así, toda promesa tiene para Searle la siguiente estructura:

Dado que un hablante $H$ emite una oración $T$, en presencia de un oyente $O$, entonces, al emitir literalmente $T, H$ promete sincera y no defectivamente que $p$ a $O$ si y sólo si se dan las siguientes condiciones (1994, p. 65).

Y las condiciones que Searle menciona son las siguientes:

1. Condiciones normales de input $y$ output: "Output" se refiere a las condiciones para hablar inteligiblemente; "input" son las condiciones de comprensión. Cuando se dan ambas condiciones, tanto el hablante como el oyente saben cómo hablar el lenguaje.

2. H expresa la proposición de que $p$ al emitir T: Lo que hace esta condición es aislar la proposición del resto del acto de habla con el objetivo de particularizar el análisis sobre las peculiaridades del prometer.

3. Al expresar que $p, H$ predica un acto futuro $A$ de $H$ : En una promesa, el acto que predica el hablante no puede ser un acto pasado. No se puede prometer haber hecho algo y tampoco se puede prometer que otra persona hará algo. A las condiciones 2 y 3 Searle las denomina condiciones de contenido proposicional.

4. O preferiría que $H$ hiciese $A$, a que no hiciese $A$, y $H$ cree que $O$ preferiría que él hiciese $A$, a que no hiciese $A$ : lo que distingue una promesa de una amenaza es que una promesa es una garantía de que se hará algo por ti, y no contra ti. Una promesa, además, requiere una clase de ocasión o situación que origina la promesa (ello la diferencia, por ejemplo, de una 
invitación). Lo que caracteriza a las promesas es que la persona a la que se le promete quiere, necesita, o desea, que se le haga algo determinado; el que promete, por su parte, es consciente de ese deseo o necesidad.

5. No es obvio ni para $H$ ni para $O$, que $H$ hará $A$ en el curso normal de los acontecimientos: el acto debe tener un objeto. Si pido a alguien que haga algo que ya hizo o está por hacer independientemente de mi petición, ese pedido no tiene objeto y, por ello, es defectivo. Está fuera de lugar prometer algo que yo, de todos modos, voy a hacer. Searle denomina a las condiciones 4 y 5 , condiciones preparatorias; sin ellas no hay promesa feliz.

6. H tiene la intención de hacer $A$ : aquello que distingue a las promesas sinceras de las insinceras es que, mientras que en las primeras el hablante tiene intención de cumplirla, en las segundas no existe tal intención. A ésta condición Searle la denomina condición de sinceridad.

7. H intenta que la emisión de $T$ le coloque a él la obligación de hacer A: lo característico de una promesa consiste en asumir la obligación de realizar cierto acto. Debe tenerse la intención de realizar la promesa. Ésta, según Searle, es la condición esencial.

8. H intenta (i-I) producir en $\mathrm{O}$ el conocimiento (C) de que la emisión de $T$ cuenta como el hecho de colocar a $\mathrm{H}$ bajo la obligación de hacer $\mathrm{A}, \mathrm{H}$ intenta producir $C$ por medio del reconocimiento de i-l, y tiene la intención de que i-l se reconozca en virtud de (por medio de) el conocimiento que $O$ tiene del significado de $T$ : aquí nos encontramos nuevamente con el análisis griceano corregido. El hablante tiene la intención de producir un efecto ilocucionario determinado haciendo que el oyente reconozca ese mismo efecto; él también tiene la intención de que se consiga ese reconocimiento en virtud de que el significado que emite se asocia convencionalmente con la producción de ese efecto. Las reglas, precisamente, posibilitan que se logre el objeto de la intención expresada en la condición esencial 7.

9. Las reglas semánticas del dialecto hablado por $\mathrm{H}$ y por $\mathrm{O}$ son tales que $T$ se emite correcta y sinceramente si y sólo si se dan las condiciones de 1 a 
8: esta regla clarifica que la oración emitida se usa para hacer una promesa.

Todas estas condiciones, según Searle, garantizan que $O$ comprende la emisión; el efecto ilocucionario $C$ se produce en $O$ porque reconoce la intención que $H$ tiene de producirlo. Este reconocimiento se logra gracias al conocimiento que $O$ tiene del significado de $T$. Mediante el ejemplo de las promesas, se plasma el modo en que funcionan los actos ilocucionarios y las reglas contenidas.

A continuación nos detendremos en otro momento de la evolución del pensamiento de Searle; a éste momento lo denominaremos "la fase del semanticismo lógico de Searle". Como habíamos hecho referencia en la introducción del presente capítulo, en Fundations of Illocutionary Logic, obra del año 1985 y coescrita junto a Daniel Vanderveken, Searle se concentra en construir una teoría formalizada de los actos ilocucionarios, tomando los recursos de la lógica moderna (1985, p. ix). A continuación daremos cuenta de algunos de los rasgos centrales de dicha obra.

\section{La profundización de Searle}

En Fundations of Illocutionary Logic (1985), Searle y Vanderveken despliegan una profundización de la semántica lógica de la teoría de actos de habla. Ello es interesante porque suele suponerse que dicha teoría es una teoría pragmática en sentido puro. Pero si bien el lenguaje es una actividad (fundamental para los seres humanos) $\mathrm{y}$, por eso mismo, el aspecto pragmático es relevante, Searle se empeña en destacar la relevancia del aspecto semántico lógico de los actos de habla. De este modo, Searle sostiene que,

La lógica ilocucionaria es la teoría lógica de los actos ilocucionarios. Su objetivo principal es formalizar las propiedades lógicas de la fuerza ilocucionaria. Las fuerzas ilocucionarias se realizan en la sintaxis de los lenguajes naturales actuales de maneras variadas (...) la tarea de la lógica ilocucionaria, por otro lado, es estudiar el rango entero de fuerzas ilocucionarias posibles por más que ellas 
sean realizadas en lenguajes naturales particulares (1985, p.

1. Traducción propia).

De este modo vemos cómo, así como la lógica proposicional estudia las propiedades de todas las funciones de verdad, la lógica ilocucionaria estudia las propiedades de la fuerza ilocucionaria. Searle sostiene (p. 2) que el método debe prestarle especial atención a los hechos de los lenguaje naturales ${ }^{43}$.

A cualquier elemento de un lenguaje natural que se lo utiliza para indicar una fuerza ilocucionaria determinada, Searle lo denomina, illocutionary force indicating device. Algunos ejemplos de ese dispositivo que indica la fuerza ilocucionaria son, i) "¿Dejarás el departamento?”, ii) “Dejarás el departamento”, iii) “Deja el departamento”, iv) “¡Si tan solo dejaras el departamento!" En estos ejemplos, la presencia de ciertos dispositivos sintácticos, expresan la fuerza ilocucionaria $F$; y algunos dispositivos sintácticos $p$, expresan el contenido proposicional $P$. Para una teoría de los actos de habla que expresa actos de habla elementales de la forma $F(P)$, es $f(p)$. De este tipo son las oraciones elementales; un tipo especial de esas oraciones, son las oraciones performativas. Estas últimas están conformadas por un verbo performativo en la primera persona del singular en modo indicativo, utilizada de la manera adecuada (1985, pp. 2 y ss.). Algunos ejemplo de oraciones performativas son, v) Te prometo que iré mañana; vi) Me disculpo por lo que he hecho; vii) Te ordeno que abras la puerta; viii) Admito que he roto el jarrón. Los verbos que están en itálica, son los verbos performativos.

Pero lo que Searle junto a Vanderveken sostiene en, Fundations of Illocutionary Logic (1985), es que no todos los actos ilocucionarios tienen la simple forma $F(p)$; existen formas más complejas y, a los casos más complejos se los denomina, actos ilocucionarios complejos, y las oraciones que los expresan, oraciones complejas. A su vez, las oraciones complejas están compuestas por oraciones simples usando conectivas, que Searle y Vanderveken los denominan conectivos ilocucionarios. Estos conectivos son del tipo "y", "pero", que le permiten al hablante conjugar distintos actos ilocucionarios en una misma

\footnotetext{
${ }^{43}$ Suele sostenerse (y Searle parece indicarlo) que mientras el pragmatic turn se apega al análisis del lenguaje natural, el linguistic turn parecía desvincularse de él, prestando atención únicamente a las formalizaciones lógicas. Intuyo que esta manera de ver las cosas esta descaminada (y digo “intuyo" porque no soy un especialista de la lógica). Cuando tratamos con formalizaciones, tenemos derecho a preguntar, “¿qué cosa se formaliza?” Aquello que se formaliza es el lenguaje natural; ¿qué otra cosa si no? Suponer que el linguístic turn se había divorciado de los lenguajes naturales es, según mi punto de vista, un error. Sí es posible indicar que no contempla el uso que hace el hablante de lenguaje, es decir, lo que Searle y Austin, denominaron fuerza ilocucionaria. Y ello es, precisamente, aquello que estamos analizando en el presente capítulo.
} 
oración. En un contexto determinado es posible decir, ix) "Voy a proponerle matrimonio, ¿pero ella aceptará?" El hablante, en la misma oración hace una aserción y elabora una pregunta; este tipo de actos ilocucionarios complejos tienen la forma,

$$
(\mathrm{F} 1(\mathrm{p} 1) \& \mathrm{~F} 2(\mathrm{p} 2))
$$

Searle y Vanderveken (1985, p. 4) advierten, sin embargo, que no todos los pares de oraciones admiten gramaticalmente todos los conectivos ilocucionarios. Así por ejemplo, $x$ ) “¿Cuándo te disculparás por lo que has hecho y prometo que iré mañana?”, están sintácticamente mal construidas en castellano.

Existe, además, otro tipo de actos ilocucionarios complejos, éstos involucran la negación de la fuerza ilocucionaria y se los llama actos ilocucionarios negados. Un caso es, por ejemplo, xi) "Te prometo no ir a la fiesta", o xii) "No te prometo ir". Mientras xi) es un acto ilocucionario con un contenido proposicional negativo, y se formaliza $F(\sim p)$; xii) es el típico acto ilocucionario negado, y tiene la forma $\neg F(p)$. Este tipo de actos ilocucionarios hacen explícito que el hablante no pretende ejecutar un acto ilocucionario determinado. Los condicionales también juegan un papel importante. "Si", y "Si...entonces", son utilizados como conectores ilocucionarios. Los actos de habla condicionales tienen la forma, "Si $p$ entonces $F(q)$ ", y "Si $p, F(q)$ ". Algunos ejemplos son, "Si sales antes del trabajo entonces ven a verme", y "Si llueve, prometo llevarte en auto".

La presente teoría general de la forma lógica de los actos ilocucionarios, tiene como objetivo -según señalan Searle y Vanderveken (pp. 5 y 6)-, dar una respuesta coherente a las siguientes problemáticas, 1) ¿Cuáles son los componentes de la fuerza ilocucionaria, y cuáles son las condiciones (suficientes y necesarias) para que un acto ilocucionario sea exitoso?; 2) ¿Cuál es la estructura lógica de todas las fuerzas ilocucionarias?; 3) ¿Cuál es la relación lógica entre los distintos tipos de actos ilocucionarios? ${ }^{44}$

Una teoría de la lógica ilocucionaria, es esencialmente una teoría de los compromisos ilocucionarios determinados por la fuerza ilocucionaria. La lógica ilocucionaria es parte de un proyecto más general de construir una lógica del lenguaje; eso es así debido, al menos, a dos razones (1985, pp. 7 y ss.):

\footnotetext{
${ }^{44}$ Como dijimos, no profundizaremos en estos puntos porque sólo realizaremos una mención de la complejidad que reviste la teoría de los actos de habla. Su análisis detallado no conforma el nudo central de nuestras preocupaciones.
} 
I. La fuerza ilocucionaria es un componente del significado.

Parte del significado de una oración elemental, es que su pronunciación en un contexto dado constituye el desempeño (al menos tentativamente) de un acto ilocucionario, de una fuerza ilocucionaria particular. Por ejemplo, es parte del significado de la oración castellana, “¿Está lloviendo?”; su correcta pronunciación constituye la pregunta en cuanto si está lloviendo. Toda oración completa tiene al menos un indicador de fuerza ilocucionaria; por eso mismo, ninguna teoría semántica del lenguaje podría estar completa sin el componente ilocucionario. La lógica ilocucionaria es parte de una teoría del significado, porque provee el aspecto ilocucionario del significado de una oración.

II. Una lógica ilocucionaria adecuada es esencial para una gramática universal adecuada (en el sentido de "gramática universal" de Montague).

El lenguaje ideal de una gramática universal debe contener constantes lógicas y operadores que sean capaces de generar nombres para todas las fuerzas ilocucionarias posibles de ser pronunciadas. Cualquier oración de cualquier lenguaje natural debe poder traducirse a oraciones del lenguaje ideal de la gramática universal; y esas oraciones deben reflejar la potencialidad ilocucionaria de las oraciones del lenguaje natural. Hasta ahora, sostienen Searle y Vanderveken, la gramática universal ha estado más interesada en proposiciones; pero debe incluir en sus análisis un registro de fuerzas ilocucionarias.

\section{Conclusión}

En el presente capítulo, como hemos aclarado, no hemos pretendido presentar un desarrollo exhaustivo de la teoría de los actos de habla de Searle; nuestra intención fue más bien, dar cuenta de la importancia que para Searle tiene la semántica al interior de su teoría pragmática. Suele suponerse que la pragmática se desentiende de la semántica -y más aún de sus formalizaciones lógicas-. Hemos visto como Searle, principalmente en la obra escrita junto a Daniel Vanderveken, Fundations of Illocutionary Logic (1985), da cuenta de la necesidad de desarrollar la semántica lógica con el objetivo de clarificar su teoría de los actos de habla, la cual es, esencialmente, una teoría de la actividad humana. 
Es notable, por otro lado, que Searle retome este análisis en un momento de su producción teórica en el cual, y tras la aparición de Intentionality (1983), parecía desentenderse del punto de vista de la filosofía del lenguaje para acercarse a un tipo de filosofía de corte mentalista. Con la publicación de Speech Acts en 1969, Searle había adoptado el punto de vista del pragmatic turn al interior del linguistic turn; en 1983 había retrocedido (utilizo la expresión de Apel) hacia el punto de vista de la filosofía de la conciencia para, dos años después (en 1985) desarrollar los aspectos de la lógica semántica al interior del pragmatic turn. ¿Cómo interpretar estas idas y vueltas? Estimamos que la adopción de un punto de vista no es algo inamovible; muy por el contrario, todo depende de lo que se pretenda abarcar y trabajar. Para ciertos problemas es preferible adoptar el punto de vista de la filosofía del lenguaje, y para otros el de la filosofía de la conciencia. Eso parece querer transmitirnos Searle. Nosotros, por nuestra parte, intentamos expresar que, tanto para analizar los problemas que refieren estrictamente al lenguaje, como aquellos orientados a problematizar la realidad social, es preferible adoptar el punto de vista de la filosofía del lenguaje. Con el objetivo de materializar esa preferencia, en el próximo capítulo analizaremos la vinculación entre las formas simbólicas y las relaciones sociales que nos servirá de preludio para el análisis concreto de las instituciones humanas. 


\section{Capítulo 4: Lenguaje y sociedad}

\section{El lenguaje como fenómeno natural}

En un escrito reciente, Searle $(2007)^{45}$ afirma que es un error no entender el lenguaje como una continuidad, una extensión de nuestra herencia biológica específicamente humana. Ello se debe a que la filosofía del lenguaje se ha desarrollado junto a la lógica matemática. Frege, en efecto, inventó la filosofía del lenguaje y la lógica moderna. Posteriormente, la filosofía de lenguaje se desarrolló (junto a Russell y el primer Wittgenstein) como una aplicación de la lógica matemática. Si bien el Wittgenstein tardío y Austin protestaron contra ese excesivo logicismo, tampoco tuvieron en cuenta el componente biológico del lenguaje ${ }^{46}$. Pero, lo que aquí nos interesa es comprender, ¿qué significa abordar la problemática del lenguaje en términos naturalistas?

En primer lugar, según Searle, ello implica entender el significado lingüístico como una extensión de las formas más fundamentalmente biológicas de la intencionalidad -tales como las creencias, los deseos, la memoria y la intención-, como una evolución del desarrollo de unas formas de intencionalidad más fundamentales; Searle se refiere especialmente a la percepción y a la acción intencional. De éste modo, ubica a la percepción y a la intención-en-la-acción entre las formas más primitivas en términos biológicos; las ubica junto al apetito, la sed y el deseo sexual. Así, Searle entiende que debe observarse la fundación biológica del lenguaje en la intencionalidad prelingüística ${ }^{47}$. La pregunta de Searle es acerca de la relación lógica y conceptual entre las formas prelingüísticas de conciencia e intencionalidad y las formas lingüísticas evolucionadas.

La posición de Searle es opuesta, por ejemplo, a la de Davidson. Mientras éste último sostiene que únicamente un ser dotado de lenguaje puede ser capaz de poseer estados intencionales diferenciados, tales como creencias, intenciones y deseos, Searle afirma que,

\footnotetext{
${ }^{45}$ Nos referimos al artículo What is language: some preliminary remarks, editado por Salvas Tsohatzidis en John Searle, Philosophy of Language. Force, Meaning and Mind, Cambridge, 2007.

${ }^{46}$ Searle mismo tampoco lo tuvo en cuenta en Actos de habla.

${ }^{47}$ El interés de Searle por problemáticas referidas a la filosofía de la conciencia (nos referimos específicamente al problema de la intencionalidad) comenzó, como hemos dicho anteriormente, a partir de la publicación de Itentionality en 1983.
} 
Many species of animals have perceptions, perform actions and are capable of acquiring beliefs, desires and intentions, though they have no language. Furthermore, several species are capable of prelinguistic thought processes. I suggest that think of human language as an extension of these prelinguistic capacities $(2007$, p. 16$)$.

Según su punto de vista, no sólo los seres humanos estamos en posesión de estados intencionales diferenciados; los animales de nivel superior también los poseen. Además, Searle se propone analizar el rol de la sociedad y de las convenciones, un rol que, según entiende, siempre se ha tendido a subestimar. Searle asume que el lenguaje es esencialmente social, no en el sentido de suponer que la sociedad humana es esencialmente lingüística. La llave que conecta al lenguaje con la sociedad es la noción de deontología (p. 17); una noción que implica compromisos de distinto tipo. El lenguaje requiere una deontología; y es la deontología, a través del lenguaje, aquello que hace posible que se desplieguen las formas de vida específicamente humana, la civilización humana.

Es posible realizar una teoría de la sociedad de muchas maneras y contemplando distintas variables y problemáticas. Tendemos a creer, junto con Searle y otros filósofos naturalistas -como Tomasello, por ejemplo- que una posible vía de acceso es comparar la forma de vida humana con la de otros animales. ¿Qué tenemos los animales humanos que nos permite hacer lo que el resto de los animales no pueden? ¿Cómo se construye el mundo de la cultura? Estas son preguntas sociológica y filosóficamente relevantes a la hora de elaborar una teoría de la sociedad. Lo anterior se torna más relevante cuando constatamos que más del $99 \%$ de nuestro material genético es idéntico al de los simios (Tomasello, 2010).

\section{Lenguaje y sociedad}

Ni la lingüística, ni la filosofía, ni mucho menos la sociología han dado, según Searle, una problematización satisfactoria del lenguaje. Los estudios de las sociedades desde Aristóteles hasta nuestros días, según su entender, misconceive the rol of language (2007, p. 18) pues dan por sentada la existencia del lenguaje y luego se preguntan cómo 
se construye la sociedad ${ }^{48}$. Los teóricos, continúa, no se preguntan ¿qué es el lenguaje? puesto que asumen su existencia. Un ejemplo son los teóricos del Contrato social; ellos asumen la existencia de un grupo de seres dotados de lenguaje que realizan un contrato. Searle, por el contrario, supone que en una sociedad con un lenguaje común ya hay contrato.

Searle propone una argumentación genética. Imaginemos que existe una especie de seres como nosotros, con plena conciencia prelingüística, acciones voluntarias y procesos prelingüísticos de pensamiento, pero sin lenguaje. ¿Qué capacidades extra necesitarían para crear un lenguaje por ellos mismos? ${ }^{49}$ Decíamos más arriba que los simios comparten con nosotros, los animales humanos, alrededor del $99 \%$ de su material genético; una diferencia crucial es que nosotros hablamos (poseemos un lenguaje proposicional orientado no por el instinto sino por convenciones públicas); ellos no poseen ese tipo de lenguaje. La interrogación acerca del mundo de la cultura entonces, debe referirse a ese $1 \%$ que nos diferencia del resto de los animales. El planteo de Searle no es histórico ni empírico sino conceptual; no se pregunta por la evolución del lenguaje humano, sino por las condiciones en que se adquiere un lenguaje. Searle intenta desplegar un análisis lógico comparando las capacidades cognitivas prelingüísticas y el lenguaje, para resolver el problema del lenguaje (2007, p. 19).

En primer lugar, Searle entiende que un correcto análisis del lenguaje debe ser capaz de abordar tanto las funciones y los usos, como su naturaleza. No podemos explorar los dispositivos estructurales que creemos son fundamentales o esenciales, explorando el uso que hacen los seres humanos de esas estructuras. Searle especifica su análisis a partir de las siguientes problematizaciones,

\footnotetext{
${ }^{48}$ Estimo que Searle exagera un poco. En la nota 14 del capítulo anterior citamos un par de pasajes donde Aristóteles daba cuenta de la importancia del lenguaje; por otro lado, dentro de la tradición judeo-cristiana, el Génesis, al relatar La creación del mundo y la caída del hombre, comienza con las siguientes frases: "dios dijo...", "Dios dijo...", “Dios dijo...” y a medida que Dios decía Dios hacía, hacía la luz, hacía el firmamento, las aguas, etc. Si bien no soy un especialista en teología, es posible observar en estos pasajes la importancia del lenguaje para la tradición católica, tradición sin embargo, que durante la edad media y según Gadamer, evitó abordar el problema del lenguaje. En el siglo pasado han sido muchos los filósofos que han abordado el problema del lenguaje y su importancia para la construcción de una teoría de la sociedad: desde Wittgenstein hasta Habermas, pasando por Austin, Davidson y Apel. Quizás sea cierto, de todos modos, que el lenguaje no ha recibido un adecuado tratamiento en el terreno estrictamente sociológico; sin embargo Habermas, como siempre, constituye un caso excepcional.

${ }^{49}$ Tal como argumentamos con Apel en el capítulo anterior, esto no sería posible. Davidson tampoco estaría de acuerdo con la posibilidad de que existan unos seres con estados intencionales diferenciados pero carentes de lenguaje (sea guiado por convenciones lingüísticas o por el mero instinto). De todos modos, vamos a continuar con el análisis que Searle nos propone; ello nos levará hacia otra problemática que nos interesa abordar.
} 


\begin{abstract}
¿Qué características del lenguaje se encuentran ya presentes en la conciencia prelingüística? ¿Qué características del lenguaje no se encuentran en la conciencia prelingüística? ¿Qué características específicas de la conciencia no aparecen en el lenguaje? ¿Qué funciones necesitan los humanos para realizar el lenguaje, dada la conciencia prelingüística? (2007, p. 21. Traducción propia).
\end{abstract}

Los simios tienen percepción consciente y acciones intencionales junto con procesos conscientes de pensamiento. Todo ello implica, según su posición, que los animales tienen creencias $^{50}$, deseos, intenciones y algún tipo de memoria que les permita reconocer objetos, personas y situaciones. Un animal, por ejemplo, tiene deseo de comer; tiene la capacidad de reconocer cuando ese deseo se ha satisfecho o no. Todo animal, en estado normal, debe ser capaz de reconocer cuándo sus condiciones de satisfacción están realmente satisfechas. Si está sediento, debe ser capaz de advertir que debe beber; si está hambriento, debe ser capaz de advertir que debe alimentarse. Los animales tienen representaciones; Searle aborda el análisis desde un punto de vista lógico, no ontológico. Con el término "representaciones", Searle se refiere a algo que determina las condiciones de satisfacción e implica la capacidad de distinguir el éxito del fracaso.

Otra característica de la conciencia prelingüística que Searle enumera, es que todos los animales que tienen un aparato primitivo biológicamente intencional, cuentan con una vasta cantidad de categorías filosóficas. Los animales poseen las nociones de tiempo,

\footnotetext{
${ }^{50}$ Estimamos que sería conveniente no hablar de creencias sino de instintos. Estamos de acuerdo con Searle en que los animales no tienen una conducta ciega; por el contrario la conducta está dirigida, pero no por creencias (al menos no en el sentido usual del término). Los animales, de seguro, poseen algún tipo de conciencia, tienen estados mentales; los perros, por ejemplo, ante la ausencia de su dueño se entristecen, se excitan sexualmente, atacan y cosas por el estilo pero, parafraseando a Wittgenstein, un perro puede esperar a su dueño, pero no puede esperarlo hasta el miércoles, no puede mentir y tampoco ser sincero; eso es porque no tiene lenguaje (guiado por convenciones). Sabemos que Searle II no estaría de acurdo con nosotros (ni con Davidson, ni con Apel y Habermas) y esa discusión ya la hemos abordado en otra parte. Aquí nos interesa, fundamentalmente, la posición naturalista de Searle y haremos a un costado la ya tematizada problemática de la prioridad metodológica del lenguaje respecto de la conciencia intencional. De todos modos, cuando Searle habla de "creencias" hace referencia a algún tipo de representación que tienen los animales; ellos pueden representarse a un gato sobre el techo, pero no pueden representarse el hecho de que mi tía viajó a Roma. Este comentario (como tantos otros) se lo debo a mi colega y amigo, Ignacio Mazzola.
} 
espacio, causa, agencia, objeto, identidad, individuación, propiedad y relación (2007, p. 23). Con esto Searle no sugiere que los animales tengan un concepto para cada categoría, a lo que se refiere es a lo siguiente. Los animales tienen la capacidad de advertir que un objeto tal y tal se encuentra a la derecha de, o sobre otro objeto. No poseen el concepto, pero se ubican (y ubican a los objetos) en un espacio; reconocen que se alimentan en una secuencia temporal; que si hacen algunas cosas, ocurren otras; que un objeto esta igual que antes pero es distinto a otro. También se dan cuenta cuando una persona se acerca a otra, y advierten si un objeto es rojo; pueden reconocer objetos del mismo tipo pues son capaces, por ejemplo, de reconocer a otro animal de su misma especie o advertir que pertenece a otra.

Llegados a este punto podemos preguntarnos, ¿qué le falta a la conciencia prelingüística para ser lingüística? Searle sugiere que lo que falta es una estructura interna y controlable en el proceso de pensamiento. Un perro puede distinguir e incluso pensar (en el sentido de representarse) que alguien se está acercando a la puerta pero, a diferencia nuestra, no puede usar nuestra sentencia verdadera, "Alguien se está acercando a la puerta", ni distinguirla de la sentencia falsa, "La puerta se está acercando a alguien". Nuestra especie animal no es muy distinta de las otras, pero tiene sin embargo algunas especificidades que deben ser puestas de relieve a la hora de llevar a cabo un análisis del mundo cultural. Son éstas (mínimas) diferencias las que permiten que ese mundo cultural sea posible.

Las formas de intencionalidad prelingüísticas tienen una estructura, pero carecen de lo que Searle denomina estructuras indefinidamente manipulables con contenido semántico (2007, p. 24) que provee la sintaxis del lenguaje. La percepción se estructura mediante el impacto físico con los objetos percibidos y mediante la fisiología del aparato perceptual. Un perro, por ejemplo, capta que una persona se acerca hacia la puerta gracias a su aparato perceptivo; lo que no puede hacer el perro -ya que no posee elementos sintácticos-, es alcanzar un aparato estructural de elementos que puede manipular a voluntad de un modo indefinido. De este modo,

The beauty of human languages is not just that they have compositionality and generativity but the user can freely manipulate the semantically loaded syntactical elements at will (2007, p. 25. Los destacados le pertenecen al autor). 
$Y$ aquí Searle toca un punto interesante. Si, junto con Davidson, estimamos que sin lenguaje no hay estado intencional posible, estaríamos aceptando que los animales no tienen deseos e intenciones; también le estaríamos negando esa posibilidad a los infantes humanos prelingüísticos. Tendemos a suponer aquí que el resto de los animales también tienen estados intencionales diferenciados pero, ciertamente, cuando los humanos adquieren el lenguaje, todo cambia; y ello ocurre de un modo radical ${ }^{51}$. Searle sostiene que los animales tienen percepciones, intenciones, creencias, deseos, a pesar de que no posean un lenguaje con una estructura sintáctica que puedan manejar libremente.

En el lenguaje, a diferencia de otras formas pre-lingüísticas, encontramos lo que Searle denomina actos de habla declarativos. Estos tienen doble dirección de ajuste, palabra-amundo y mundo-a-palabra en el mismo acto de habla. Si consideramos declaraciones lingüísticas tales como "Se declara la guerra", "La reunión se suspende", o bien se declara una promesa mediante, "Yo prometo", o una orden mediante el acto, "Te ordeno", observamos que se trata de expresiones performativas (es preciso tener en cuenta que todas las expresiones performativas son actos declarativos, pero no todos los declarativos son performativos). La dirección de ajuste es doble porque al realizar el acto de habla produzco una modificación en el estado de cosas exterior a mi conciencia y, por otro lado, ese estado de cosas sólo puede ser modificado al llevar a cabo mi representación (expresión). La capacidad de modificar o crear la realidad al declararla como existente, es la capacidad más poderosa del lenguaje. Nada similar encontramos en las formas de intencionalidad prelingüísticas. Los seres humanos son la única especie animal que tiene la capacidad de crear un mundo social e institucional -gracias a una capacidad colectiva y lingüística-, al representarlo como existente. A continuación nos centraremos en esta vinculación, que hemos dejado entrever, entre representación, por un lado; y expresión, por otro.

\section{Representación y expresión}

A continuación, Searle analiza los siguientes elementos; nos referimos a, i) las características que son comunes a la conciencia y al lenguaje, ii) las características especiales del lenguaje y, iii) las características especiales de la conciencia. La función

\footnotetext{
${ }^{51}$ Según Searle, sin embargo, no hay cambio alguno al apropiarse del lenguaje. No da cuenta de la revolución de los dieciocho meses.
} 
primaria del lenguaje es proveer a nuestra especie animal la posibilidad de comunicarse entre sí. Podríamos preguntarnos inmediatamente, ¿qué significa "comunicarse"?, y ¿qué se comunica? Suele decirse que aquello que los seres humanos comunican es información. Pero éste término, según Searle, es completamente confuso y, de hecho, es uno de los conceptos peores definidos y mal interpretados en la vida intelectual contemporánea (2007, p. 28). Searle cree conveniente hablar, más que de información, de estados intencionales. En filosofía existen ciertos conceptos que aparentan una completa falta de complejidad pero, al observarlos con cierto detalle logramos advertir su complejidad. No creemos que la noción de información sea un caso tal. Cuando decimos que los seres humanos transmiten información, nos referimos a una generalidad, a cualquier cosa que queramos expresar. Pero Searle entiende que esto es una vaguedad y por ello propone la noción filosóficamente más adecuada de estados intencionales pero, ¿qué son los estados intencionales? Son estados mentales que están dirigidos a otras entidades o estados de cosas; son los deseos, creencias, intenciones, miedos, alegrías. También sin embargo, transmitimos acciones tales como, "Estoy entrenando" o, "Ayer fui al cine". Pero, ¿qué más podríamos transmitir? Nada más. El término información es vago y general porque expresa perfectamente la acción de informar, una acción por completo general pues no hay nada, en principio, que nos sea imposible comunicar. De todos modos, la réplica de Searle es válida puesto que en filosofía siempre se pretende aclarar las cosas; indudablemente, la noción de estados intencionales es más transparente que la noción de información.

Los primates también tienen percepción y acción intencional y, según Searle, procesos prelingüísticos de pensamiento. Todos ellos son estados intencionales con contenidos proposicionales concretos ${ }^{52}$. Cuando una criatura se comunica intencionalmente con otra, trata de reproducirle su propio contenido intencional en la cabeza de esa otra persona; cuando por ejemplo se comunica, "Allí hay peligro", es porque quien enuncia la sentencia tiene la creencia de que allí hay un peligro y busca transmitírselo al otro.

Según Searle, el modo más simple de comunicación se da cuando un animal comunica información sobre el mundo mediante una proposición no estructurada a otro animal. Por "proposición no estructurada" Searle entiende una proposición sin sintaxis interna y aclara

\footnotetext{
${ }^{52}$ En lo que se refiere a contenidos proposicionales concretos, podríamos estar de acuerdo con Searle pero, lamentablemente, aún no he visto a un simio ni a ningún otro animal de nivel superior leer el diario o escribir un libro. Como ya hemos aclarado, podríamos asumir que los animales poseen estados intencionales y un lenguaje guiado por el instinto (tal como Apel afirma), pero no existe, at all, contenidos proposicionales en los animales no humanos.
} 
que ese tipo de comunicación es muy frecuente entre los animales (2007, p. 29). Ejemplos de ello son el chillido de las aves cuando ven en peligro a sus crías y ciertos ladridos de los perros; a éste tipo de comunicación, en la Stanford (1959) Peter Strawson la denominó, "feature placing". Se trata, simplemente, de la comunicación de una característica del ambiente. Searle aclara que,

\section{“¡Peligro!”, “jlluvia!”, “jfuego!” Y cuando expandimos una de ellas hacia una oración completa, las otras partes de la oración se encuentran a veces semánticamente vacías, como cuando decimos "Está lloviendo" debido a que "está" no se refiere a nada $\left(2007\right.$, p. 29. La traducción es propia $\left.{ }^{53}\right)$.}

Este tipo de comunicación, sin embargo, no es todavía lingüística; el paso que es preciso dar para pasar de éste tipo de comunicación a una comunicación de tipo lingüística es, según Searle, bastante corto. Veamos.

Quizás podríamos sugerir, prosigue Searle, que el primer escalón hacia la ruta del lenguaje sería introducir las convenciones lingüísticas que permiten comunicar los contenidos intencionales (creencias, deseos, intenciones) de un animal a otro. En la mayoría de los casos, los animales cuentan con dispositivos naturales de comunicación. So far so good, el punto es que para Searle no hay por qué suponer que los homínidos no hayan desarrollado dispositivos convencionales para los estados intencionales que no tienen una expresión natural externa. Un perro, por ejemplo, no tiene un dispositivo convencional para comunicar agresión; basta con que ladre de un modo particular, con agresividad por ejemplo. Lo seres humanos, por su parte, carecen de un modo natural para transmitir el hecho de que está lloviendo. Esta diferenciación entre modos naturales de comunicar los estados intencionales y formas convencionales evolucionadas nos fuerzan a realizar una nueva distinción entre representación y expresión. Según Searle, es preciso distinguir ente aquellos actos comunicativos que involucran intencionalidad representando un estado de cosas en el mundo de aquellos que simplemente expresan el estado interno del animal, donde esa expresión puede ser portadora de información sobre el mundo pero no es capaz de representar que algo es el caso. Si decimos “iLlueve!" estamos representando el clima,

\footnotetext{
${ }^{53}$ Por nuestra parte entendemos que esa otra parte de la oración es completamente plena; nos ubica espacio-temporalmente. Y eso no es poco. Fue necesario un largo y complejo proceso evolutivo. Baste recordar que, según Frege, la unidad mínima del lenguaje no son las palabras, sino la oración elemental.
} 
sin importar que la expresión sea inestructurada; si, por otro lado, decimos "¡Ouch!" como una expresión espontánea de dolor, transmitimos información pero no representamos nada. Searle aclara este punto del siguiente modo,

\begin{abstract}
Simples actos de habla expresivos, incluso cuando se realizan intencionalmente, no son "lingüísticos" en el sentido en que tratamos de hacer explícito, y las palabras correspondientes de los lenguajes actuales no son "palabras" en nuestro sentido. "Ouch!" "Damn!" "Yuck!" "Wow!" son todas usadas para expresar estados mentales, tanto intencionales como no intencionales, pero no son el tipo de fenómeno lingüístico que estamos tratando de explicar (2007, p. 30).
\end{abstract}

Pero, ¿por qué no pertenecen al tipo de fenómeno lingüístico que a Searle le interesa? Porque si bien hacen referencia a ciertos estados intencionales o mentales de los hablantes, no representan; y el problema de Searle aquí es, ¿cómo han evolucionado en los homínidos las representaciones lingüísticas?; ¿cuál es la diferencia entre representación y expresión?

Cuando por ejemplo digo, "iLlueve!", mi afirmación tiene valor veritativo, es decir, puede o bien ser verdadera o bien ser falsa porque lo que esa afirmación hace es representar ${ }^{54}$ el estado del clima. Nada impide, de todos modos, que yo mienta al hacer esa afirmación. Si por el contrario digo, "jOuch!", lo que hago es transmitir una información respecto de mí mismo pero, según Searle, no digo nada que sea literalmente verdadero o falso; cuando digo, "¡Ouch!" sin sentir dolor yo puedo engañar y desinformar, pero nunca mentir. No resulta claro cuál es el sentido de emitir una expresión de dolor (cualquiera sea) sin que haya dolor. Tendemos a suponer, junto con la teoría de los juegos de lenguaje, que si alguien expresa el dolor, sin sentir dolor, o bien pretende engañar a otro, o bien no entiende el significado de la expresión.

Lo primero que tuvieron que crear los homínidos han sido unos dispositivos convencionales para representar los mismos estados de cosas que existen en el mundo y

\footnotetext{
${ }^{54}$ Como vemos, Searle -a diferencia de Husserl y Frege-, no tiene ninguna intención de evitar el psicologismo. Las oraciones, por el contrario sostenemos, no representan un estado de cosas sino más bien, se refieren a un estado de cosas. De todos modos, lo que aquí nos interesa es reconstruir el argumento naturalista de Searle.
} 
son representados por sus estados intencionales internos. Mediante lo que se suele llamar "una oración", una persona puede transmitirle a otra sus estados intencionales existentes; por ejemplo, su creencia de que está lloviendo, de que allí hay comida o un posible peligro. A partir de allí, Searle da un paso más y asume que las personas prelingüísticas pueden conocer las mismas señales. Pero, estás personas prelingüísticas (los bebes humanos hasta los dieciocho meses son el ejemplo típico), ¿qué agregan exactamente cuando comienzan a pronunciar aquello que pretenden comunicar? Searle sostiene que las personas prelingüísticas ya tienen estados intencionales y, es más, pueden comunicarlos (cualquiera que haya tenido un cierto contacto con los bebes humanos puede darse cuenta de ello rápidamente). De este modo, Searle concluye que,

\section{Entonces lo que hace [el hablante] es imponer intencionalmente esas condiciones de satisfacción en las expresiones. Las expresiones ahora tienen las mismas condiciones de satisfacción que sus creencias, y ya que estamos suponiendo que él y sus oyentes conocen la convención por usar el símbolo en cuestión, él puede realizar la expresión confiando en que el oyente reconocerá que tiene aquellas condiciones de satisfacción (2007, p. 31).}

Como vemos, no existe un salto relevante, ni en términos cualitativos ni cuantitativos, cuando se produce la adquisición del lenguaje o, para expresarlo en los términos de Searle, cuando se poseen los dispositivos de convención. Los homínidos prelingüísticos tienen los mismos estados intencionales que aquellos que han adquirido el lenguaje, la única diferencia es que no pueden comunicarlos -o al menos no tan fácilmente como lo hacen los hablantes-. Para Searle, la introducción de dispositivos de convención para representar estados de cosas presupone ya la noción de significado del hablante ${ }^{55}$. A continuación nos detendremos en éste punto.

\section{Condiciones de satisfacción}

\footnotetext{
${ }^{55}$ A diferencia Davidson, por ejemplo, Searle plantea que existen estados mentales internos que no sólo no son lingüísticos (en el sentido usual) sino que además son intraducibles puesto que son incomunicables.
} 
Respecto al significado, Searle establece una distinción entre el significado convencional de las palabras, oraciones y símbolos por un lado; y, por el otro, el significado con el que el hablante se expresa al realizar una expresión intencional. En los casos que hemos tratado, el símbolo en cuestión tiene un significado convencional: "está lloviendo". Cuando el hablante realiza una expresión con su símbolo, expresa un significado, el significado de un acto de habla: "está lloviendo". Cuando el hablante profiere intencionalmente una muestra de un símbolo, la producción de esa muestra es la condición de satisfacción de su intención de pronunciarlo; cuando lo pronuncia significativamente está imponiendo otra condición de satisfacción a la muestra expresada. La condición de satisfacción es que está lloviendo. Esa imposición intencional de condiciones de satisfacción sobre condiciones de satisfacción es, según Searle, la esencia del significado del hablante (2007, p. 31).

La capacidad de realizar esto, es un elemento crucial de la capacidad cognitiva humana. Ello requiere pensar los dos niveles de una vez. En un nivel, la intencionalidad del hablante produce una pronunciación física, pero en otro nivel, la pronunciación representa algo. La misma dualidad afecta al símbolo mismo. En el primer nivel se trata de una muestra física como cualquier otra; en el segundo, ella tiene un significado que representa un tipo de estado de cosas. Intencionalmente el hablante realiza una pronunciación; él pretende que la pronunciación debe tener ella misma condiciones de satisfacción como, por ejemplo, condiciones de verdad. Pero, prosigue Searle, el hablante debe tener éxito en una base regular, debe darse lo que denomina socially recognized conventional device (2007, p. 32). Estos dispositivos convencionales socialmente reconocidos, son tomados regular y convencionalmente por sus interlocutores para transmitir diversos mensajes.

Como hemos visto, Searle desdobla el problema del lenguaje; por un lado tenemos el significado del hablante y; por otro lado tenemos la convención. ¿Qué está primero? En términos de dependencia lógica, la intencionalidad de hablante deber tener prioridad Según este Searle II-, porque esas convenciones de proposiciones inestructuradas codifican, a su entender, significados preexistentes del hablante. Searle entiende, sin embargo que, sin lenguaje y sus convenciones, existen significados de los hablantes, pero éstos son muy simples; es posible pensar y significar por ejemplo, "Aquí está lloviendo". Lo que no es posible es pensar -mucho menos decir y significar-, por ejemplo, "Sería grandioso dar un paseo por la playa el próximo fin de semana, siempre y cuando no llueva y haya cobrado mi salario". Por eso mismo, es preciso remarcar lo siguiente, 
Si los hablantes y oyentes evolucionan hacia un sistema donde pueden comunicarse efectivamente, tendrán que desarrollar un conjunto de dispositivos convencionales para transmitir el significado del hablante (Searle, 2007, p. 32).

En términos evolutivos, cuando los animales humanos desarrollaron un lenguaje, desarrollaron a la vez, un conjunto de dispositivos para lograr una representación pública, social. Se han impuesto condiciones de adecuación sobre condiciones de adecuación mediante convenciones. Esto debe ser entendido como el primer paso en el camino del lenguaje; pero hasta aquí, los humanos no contaban con una sintaxis.

\section{Composición sintáctica}

El análisis de Searle, recordemos, no es histórico o empírico sino lógico; de éste modo, reconoce un nuevo paso "en el camino hacia el lenguaje": se trata de la introducción de dispositivos sintácticos simples que pueden ser combinados con otros dispositivos sintácticos para producir dispositivos sintácticos complejos. Cada uno de los dispositivos complejos, por su parte, sirve para transmitir un estado intencional completo. Para nosotros los humanos, la unidad mínima del lenguaje es la oración elemental. El principio que guía la selección de los dispositivos sintácticos dentro de la oración es que deben realizar una función semántica. Además,

Debe haber mecanismos repetibles cada uno de los cuales puede funcionar como una unidad posible de comunicación (oración) y ella debe estar compuesta de elementos (palabras) que son tales que el contenido comunicativo del todo está determinado por los elementos y por los principios de su combinación en la oración (2007, p. 33).

Searle, fiel a su naturalismo, entiende que el análisis debe construirse a partir de los recursos que los animales ya tienen -y ellos son muy ricos-. El resto de los animales (los animales no humanos) tienen la capacidad de identificar y re-identificar objetos; nosotros, los animales humanos, tenemos la capacidad de nombrar esos objetos; porque ellos tienen 
la capacidad de identificar distintas muestras del mismo tipo, nosotros podemos introducir ciertos nombres generales tales como "perro", "gato", "hombre"; y es porque los objetos tienen ciertas características, que nosotros podemos introducir algo correspondiente a verbos y adjetivos. Con todo, Searle no sugiere que la referencia y la predicación sean elementos independientemente simples; más bien, una vez que tenemos el acto de habla completo podemos abstraer los elementos que lo componen. En éste punto, Searle sigue a Frege puesto que sostiene que tanto las frases sustantivas como las frases verbales se derivan de la oración completa y no que la oración completa se deriva de combinar las frases sustantivas y las frases verbales.

La función semántica viene gratis porque nosotros ya hemos introducido el significado. Searle le asigna a los animales la capacidad perceptual y los contenidos de conciencia, pero la diferencia con los animales humanos es que aquellos no poseen una estructura sintáctica. Los animales no humanos, ven, tienen creencias pero no pueden comunicarlas $^{56}$; no pueden representarse algo así como "está viniendo detrás de mí". Desde el punto de vista del animal, la representación tendría la forma: "viene-detrás-micosa-ahora" (2007, p. 34). Esta construcción tendría que ser representada como si fuera una sola palabra, sin elementos repetibles.

Si bien los animales no humanos poseen feature placing, carecen de referencia y predicación; para tenerlas, necesitarían dispositivos simbólicos. Los animales no humanos pueden observar que algo se les acerca, y creer que algo se les acerca. Nosotros, además, tenemos la capacidad de agregar reglas o procedimientos para organizar los dispositivos (las palabras) en las estructuras complejas resultantes (las oraciones). Searle asume que la construcción pre-sintáctica, "viene-detrás-mi-cosa-ahora" se disuelve en un dispositivo que se refiere a un objeto específicamente contextualizado, tal como un hombre, y la predicación de que viene ahora detrás de mí, como en castellano, "El hombre está viniendo detrás de mí ahora".

En este punto, Searle observa la siguiente paradoja: ¿cómo podemos lograr la unidad de la oración cuando la oración está enteramente compuesta por entidades diversas, por una cadena de palabras y morfemas que la constituyen? Debido a la naturaleza del significado del hablante, se requiere que aquello que sea considerado como una oración sea capaz de

\footnotetext{
${ }^{56}$ Aquí se podría objetar lo siguiente: si es cierto que tienen creencias, ¿̇por qué no pueden comunicarlas? Si no pueden comunicar una creencia, ¿̇por qué habríamos de suponer que sí la tienen? La explicación, la respuesta a esos interrogantes se encuentra, según Searle, en el plano evolutivo. Los animales no humanos no han evolucionado del mismo modo que nosotros; del hecho de no poder expresar una creencia, no se sigue necesariamente que no exista una creencia tal.
} 
codificar el significado del hablante, el cual debe ser capaz a su vez, de codificar un estado intencional completo. Toda intencionalidad -y aquí parece haber un viraje en el planteo de Searle respecto a su obra Intencionalidad-, nos llega proposicionalmente ${ }^{57}$ debido a que cada estado intencional discriminable tiene condiciones de satisfacción y una condición es siempre que tal y tal sea el caso. La oración codifica el contenido proposicional del estado intencional; la unidad de la proposición se edifica en la estructura lógica de la intencionalidad biológica. El viraje que creíamos había dado Searle respecto a su obra Intencionalidad no es tal; aunque es un poco más cauto, sigue otorgándole una prioridad metodológica a los contenidos intencionales. De éste modo afirma,

Entonces la unidad proposicional expresada por la oración completa está ya provista por la intencionalidad prelingüística, y la estructura interna sujeto-predicado está provista por el modo en que nuestra fenomenología nos presenta el contenido proposicional $(2007$, p. 35).

Hasta aquí Searle ha dado tres pasos en el "camino hacia el lenguaje": en primer lugar, identificó la creación del significado del hablante; es decir, la imposición de condiciones de satisfacción sobre condiciones de satisfacción. En segundo lugar, la creación de dispositivos convencionales para realizar los actos del significado del hablante, lo cual nos da algo similar al significado de las oraciones; el significado de las oraciones es asunto de convención. El significado del hablante es típicamente el empleo o uso de esas convenciones en la ejecución de un acto de habla. Finalmente, Searle agregó una estructura interna al acto de habla; hizo referencia a elementos sintácticos discriminables que poseen significados, contenido semántico, pero no pueden valerse por sí mismos en expresiones. Se trata de partes de oraciones, que corresponden a palabras pero que no son aún oraciones completas. Es necesario aún aplicar reglas dentro de la oración completa y distinguir entre cadenas gramaticales y no gramaticales. Las oraciones están compuestas por elementos significativos y esos elementos junto a las reglas de combinación nos permiten crear nuevas oraciones y descifrar los significados de oraciones y expresiones que nunca antes hemos escuchado.

\footnotetext{
${ }^{57}$ Para el Searle de Intencionalidad, la intencionalidad no era, necesariamente, proposicional, era prelingüística, era mental.
} 
Todavía no hemos llegado a la generatividad, la cual refiere a la capacidad que poseen los hablantes de producir y comprender un número potencialmente infinito de oraciones. Para lograr la generatividad, Searle entiende que es necesario agregar algunas reglas recursivas que se aplican una y otra vez sin fin. Las expresiones que proveen generatividad son del tipo, "María cree que", "Es posible que", o reglas para formar oraciones relativas. Al agregar la sintaxis lingüística a la intencionalidad propiamente animal, los hablantes pueden hacer algo que los animales no-lingüísticos no pueden. Los hablantes pueden construir arbitrariamente (dentro de cierto uso de reglas) distintas representaciones de estados de cosas en el mundo, sean éstos posibles, actuales e incluso imposibles.

El aparato que han desarrollado los homínidos (aquí nos referimos específicamente a los seres humanos) les ha permitido extender el vocabulario, tener pensamientos y producir actos de habla que no podrían existir sin el lenguaje. He ahí una de las mayores diferencias (más adelante veremos otras) respecto al resto de los animales de nivel superior. Son éstas diferencias, precisamente, las que nos permiten crear un mundo que el resto de los animales no tiene.

\section{Deontología}

Con lo que hemos visto hasta aquí continuamos en "el camino hacia el lenguaje", no lo hemos alcanzado aún; la tarea se encuentra incompleta. En el análisis que hemos venido desarrollando en el presente apartado, está implícito que el hablante utiliza dispositivos convencionalizados en un escenario social con (al menos) un propósito. Los dispositivos del lenguaje involucran al mundo social porque la comunicación humana tiene un carácter social. El lenguaje funda a la sociedad humana en general.

Si un hablante transmite información intencionalmente a un oyente usando convenciones socialmente aceptadas con el propósito de producir una creencia en el oyente respecto de un estado de cosas en el mundo, entonces el hablante se ha comprometido con la verdad de su enunciado (Searle, 2007, p. 37). 
La estructura formal de los estados intencionales según Searle es $S(p)$, la cual se asemeja por completo a la formalización de los actos de habla, $F(p)$. Searle entiende que $F(p)$ representa un estado intencional ${ }^{58}$; su actual análisis del lenguaje -el que despliega en la obra que estamos analizando, What is language (2007)- pretende abarcar además, las convenciones de un lenguaje socialmente aceptado ${ }^{59}$.

Si yo creo que está lloviendo y quiero decir que está lloviendo, expreso mi creencia mediante la enunciación que pretende tener las mismas condiciones de satisfacción que mi creencia anterior. La operación temporal para Searle es la siguiente: primero tengo la creencia y después le imprimo el lenguaje. La pregunta que debemos plantear aquí es, ¿puede haber creencia sin lenguaje? La respuesta es sí y no. Es posible asignarle creencias a los animales de nivel superior ( $y$, como hemos visto con Apel, un lenguaje guiado por el instinto) y a los niños prelingüísticos. Lo notable es que en los seres humanos, a los dieciocho meses aproximadamente, se produce una verdadera revolución cuando adquieren el lenguaje proposicional; a partir de allí las creencias se funden con el lenguaje, a partir de los dieciocho meses los seres humanos no poseen estados intencionales por fuera del lenguaje. Esa es la especificidad de nuestra especie animal. Somos animales, de eso no hay duda, no hay por qué creer que somos más habilidosos que los simios (ellos tienen capacidades que nosotros no tenemos) pero sí es cierto que nos distinguimos en algunos aspectos. En la especificidad de nuestra especie animal radica nuestra capacidad de crear un mundo social. Pero no nos apresuremos, continuemos con el aspecto deóntico.

Searle se concentra en la relación entre el acto de habla y su correspondiente estado intencional. El acto de habla supone un compromiso que va mucho más allá del compromiso expresado por el estado intencional. En el caso de las declaraciones, ordenes, pedidos y promesas, esto es evidente. Al expresar una promesa me comprometo a cumplir su contenido proposicional, al realizar su enunciado me comprometo con una obligación. Cuando realizamos un enunciado -el que fuere-, no sólo expresamos un contenido intencional sino que, además, nos comprometemos con su verdad. Existen reglas

\footnotetext{
${ }^{58}$ La formalización $F(p)$ fue elaborada por Searle en Actos de habla; la preocupación central de dicha obra es comprender el lenguaje en tanto que actividad humana, destacándose así el aspecto pragmático de lenguaje humano más que sus estados intencionales subyacentes.

${ }^{59}$ No veo por qué razón Searle estima que en Actos de habla la problemática de las convenciones sociales queda por fuera de su marco conceptual. Todo análisis del lenguaje (al menos el abordado por la tradición analítica a partir de Frege y Russell) implica un análisis de las relaciones y de las reglas sociales puesto que uno no puede desprenderse del otro. Suponer que los análisis más formales y lógicos no contemplan las reglas sociales es producto de una mala comprensión de la lógica.
} 
constitutivas en la institución de lenguaje; generalmente tienen la forma, " $X$ cuenta como $Y$ en $C^{\prime \prime 60}$. De éste modo, expresar $X$ en un contexto determinado $C$, cuenta como hacer una promesa $Y^{61}$. Searle aclara que es un error común suponer que los requisitos deónticos se encuentran en algún lugar por fuera del acto de habla. De éste modo afirma,

No puedes explicar qué es una declaración o una promesa sin explicar que una declaración compromete a quien la realiza con la verdad y una promesa compromete a quien realiza la promesa a llevarla a cabo. En ambos casos el compromiso es interno al tipo de acto de habla que está siendo realizado, donde por "interno" quiero decir que puede no ser el tipo de acto de habla que es, éste puede no ser ese mismo tipo de acto de habla si no tenía ese compromiso (2007, pp. 38, 39. Los destacados le pertenecen al autor).

Searle entiende que los actos de habla son más que la expresión de una intención o la expresión de una creencia. Se trata, sobre todo, de una realización pública. De éste modo, cuando le digo algo a alguien, no sólo le transmito mis intenciones y mis creencias; además le estoy diciendo algo sobre el mundo que mis intenciones y creencias representan. Cuando hablo, hablo sobre mi mundo. En el próximo apartado nos detendremos específicamente en esa conexión entre el lenguaje y el mundo que construyen los seres humanos.

\section{Lenguaje e instituciones: una aproximación}

Hasta aquí, el argumento de Searle es que los actos intencionales de significado, es decir, la imposición intencional de condiciones de satisfacción sobre condiciones de satisfacción pública y convencionalmente aceptadas, y con una intención acordada, implican necesariamente una deontología. Una vez que esa deontología es creada mediante esas acciones intencionales, se extiende según Searle, inevitablemente a la realidad social en

\footnotetext{
${ }^{60}$ Esto lo veremos con más detalle en los últimos capítulos.

${ }^{61}$ Esta noción de reglas constitutivas Searle la viene trabajando desde Speech Acts (1969), y fue tematizada con mayor profundidad en The construction of social reality (1995). Más adelante abordaremos el tema con mayor detalle.
} 
general. Una vez que los seres humanos tienen la capacidad de representar, pueden crear una realidad que consiste, en parte, en representaciones. En éste punto Searle nos ofrece los siguientes ejemplos. $\mathrm{Si}$, supongamos, tenemos la capacidad de decir, "Pedro es nuestro líder", "Juan es mi marido", "Rita es mi esposa", "aquella es mi casa", y cosas por el estilo, es porque podemos hacer algo más que representar estados de cosas preexistentes; tenemos la capacidad de crear estados de cosas con una nueva deontología. Tenemos la capacidad de crear deberes, derechos y obligaciones al realizar y al hacer que otras personas acepten ciertos actos de habla. Una vez que los otros reconocen a alguien como un líder, reconocen que algo es de su propiedad o que una persona se unió a su vida, entonces ya se ha creado una deontología pública. Se han creado razones públicas para actuar que son independientes de los deseos particulares. Las representaciones que son parte constitutiva de la realidad social -los gobiernos, los estados, los matrimonios, la propiedad privada, el dinero-, son esencialmente lingüísticas. El lenguaje no describe sino que crea y parcialmente constituye esa porción de la realidad. Los actos de habla (o en términos del Searle más reciente, la composicionalidad) son esenciales en lo que a la creación de la realidad social e institucional se refiere. De éste modo y resumiendo,

Con la composicionalidad el animal puede hacer mucho más que representar estados de cosas existentes; puede representar estados de cosas que no existen pero que pueden ser traídos a la existencia teniendo una comunidad que acepte una cierta clase de actos de habla. Entonces, por ejemplo, el hombre que dice "Esta es mi propiedad" o la mujer que dice "Este es mi marido" podrían estar haciendo algo más que sólo reportar un estado de cosas existente con anterioridad; ellos podrían estar creando un estado de cosas mediante la declaración $(2007$, p. 40).

Cuando este tipo de declaraciones son aceptadas por otras personas es cuando se crea una realidad institucional que no existe con anterioridad a esas declaraciones. No estamos aún en presencia de performativos (los performativos requieren del uso de otro tipo de verbos) pero sí nos encontramos ante declaraciones con una doble dirección de ajuste. Si realizo la declaración, "Esta es mi propiedad" entonces yo me represento a mí mismo como 
teniendo derecho a esa propiedad (dirección de ajuste palabra-a-mundo) y si otros aceptan mi representación entonces soy yo quien creo ese derecho porque ese derecho solo existe gracias a una aceptación colectiva (dirección de ajuste mundo-a-palabra). No se trata de momentos independientes, muy por el contrario, yo represento un derecho al representarme a mí mismo como teniendo tal derecho.

Lo que ha hecho Searle es generalizar el hecho de que algún " $X$ cuenta como $Y$ en un contexto $C$ " que aplicaba a los actos de habla individuales. Lo que pensamos como propiedad privada, por ejemplo, se debe a una serie de actos de habla permanentes (standing speech act); estos actos de habla permanentes se fijan a un objeto. Ello permite que una persona $\mathrm{o}$ un grupo de personas tengan ciertos derechos y obligaciones, mientras que otras personas o grupos no tienen esos mismos derechos y obligaciones. Es el lenguaje humano el que nos permite no sólo representarnos una realidad sino crear una nueva realidad al representárnosla como existente; hemos creado estados, dinero, universidades, matrimonios -entre otras miles de cosas-, al representarnos esos fenómenos como existentes.

\section{Conclusiones}

Como buen pragmatista, Searle sostiene que las posiciones semánticas tradicionales no son capaces de captar el aspecto deóntico del lenguaje. A lo largo de los años, Searle se ha distanciado de los semánticos lógicos, principalmente de Frege, Russell y el Wittgenstein del Tractatus. La pretensión de estos lógicos, grosso modo es, por un lado, "contribuir a explicar aspectos centrales de nuestro comportamiento lingüístico 0 de

nuestro lenguaje, en particular la idea de significación o la de comprensión lingüística", y por otro lado, "discriminar las categorías básicas de la más clara y simple teoría (o teorías) acerca del mundo que en nuestro lenguaje se ofrece(n) en un momento dado" (Moretti, 2008 , p. 12). El problema de los lógicos del lenguaje no se refiere a la actitud de los hablantes ni al uso que ellos hacen del lenguaje. El interés por éstos últimos problemas lo despertó, al menos dentro del terreno de la filosofía analítica de lenguaje, el Wittgenstein de las Investigaciones filosóficas. Searle se mueve dentro de este terreno, dentro de lo 
Apel denominó "el giro pragmático al interior del giro lingüístico" y que hemos hecho referencia más arriba ${ }^{62}$.

Quisiéramos enmarcar en esta parte, el problema del lenguaje del modo en que Searle lo hace, es decir, desde el punto de vista del naturalismo. Ello resulta especialmente interesante porque gran parte de los teóricos provenientes de disciplinas tales como la filosofía, la sociología y también la economía, tienden a realizar una marcada separación entre el mundo natural y el mundo que construimos los seres humanos. Sería conveniente quizás, rever esta demarcación y entender que entre los animales de nivel superior y los seres humanos no existe una brecha tan amplia. De hecho, nuestra especie es una especie animal (la más dotada en términos simbólicos, es cierto) y como tal no se ubica por fuera del mundo natural. Lo interesante $-y$ necesario-, es observar cuáles son las especificidades de nuestra especie animal. La gran complejidad de nuestro mundo social, cultural, institucional, no tiene igual en otras especies animales de nivel superior que también poseen una compleja organización social. Por más evolucionada que sea la vida de los chimpancés, las hormigas o los delfines, ellos son incapaces de construir Estados, dinero, universidades, matrimonios y libros de filosofía -entre otras cosas-. Ello se debe en primer lugar pero no únicamente, a que carecen de lenguaje; al menos, carecen de un lenguaje como el nuestro, carecen de un lenguaje proposicional guiado por convenciones lingüísticas.

Al comienzo del capítulo decíamos que Searle lleva a cabo un análisis lógico, conceptual; Searle se rehúsa a desarrollar un análisis empírico. Pero el naturalismo ha sufrido un extenso tratamiento dentro de la filosofía occidental. Por ejemplo, John Dupré, en El legado de Darwin (2006), toma al naturalismo como una interpretación anti-natural. Su posición naturalista coincide con la adoptada por Searle. Más allá de su discusión contra la teología (que aquí no resulta relevante), nos interesa el modo en que establece la demarcación entre los seres humanos y el resto de los animales. Como buen darwinista, Dupré rechaza de plano una distinción absoluta ente unos y otros.

Si bien, Descartes sostenía que aquello que nos separa del resto de los animales es que, mientras éstos son meros mecanismos, los seres humanos poseen una mente inmaterial; Dupré realiza una homologación entre la mente inmaterial cartesiana y el alma de la tradición cristiana; en ambos casos los seres humanos tenemos un plus, tenemos algo que

\footnotetext{
${ }^{62}$ Los pragmatistas suelen decir que a los semanticistas "se les pasa por alto" el problema del uso del lenguaje. Por mi parte, creo que "no se les pasa nada por alto"; muy por el contrario, de los que se trata simplemente, es del tipo de problemas que se abordan y se pretenden resolver. Los semanticistas, no resuelven el problema del uso del lenguaje por parte del hablante porque ese no es su problema a resolver.
} 
el resto de los animales no poseen. Pero no conforme con esta explicación, Dupré sostiene que,

Sean cuales fueren los rasgos únicos de los humanos, hay dominios enteros de la conducta en los que las semejanzas entre nosotros y nuestros parientes cercanos son demasiado grandes como para que resulte creíble que en un caso esa conducta es el reflejo de un alma o de una mente, en tanto en el otro no existe algo semejante y se trata tan sólo del funcionamiento de una maquinaria neural (2006, pp. $100,101)$.

En la obra citada, Dupré sostiene que cada especie animal posee sus rasgos distintivos; el castor es el único mamífero que es capaz de digerir madera, la ballena azul es el animal más grande y los seres humanos poseemos un lenguaje. Nada de ello contraría al pensamiento evolutivo. Nuestro filósofo evolucionista tampoco niega (al igual por ejemplo, que Apel) que el resto de los animales posean un lenguaje ${ }^{63}$. Dupré sostiene que los animales poseen una ineptitud lingüística; pero agrega que un perro, a diferencia de nosotros los humanos, puede detectar el olor de un conejo que acaba de morir (p. 110). De éste modo,

Hasta el momento, el punto (...) es que no hay ninguna buena razón para negar la continuidad evolutiva entre nosotros y otras criaturas. Pero (...) a pesar de esa continuidad, la novedad evolutiva del lenguaje ha ejercido profundos efectos incluso sobre el estatus biológico de la especie a la que pertenece (2006, p. 111).

El lenguaje (y nosotros agregamos, entre otros elementos) crea las condiciones necesarias para la formación de un mundo cultural. Esa es la tesis central del presente trabajo. Tanto

\footnotetext{
${ }^{63}$ A diferencia de Apel, Dupré le asigna la posibilidad de un lenguaje "no natural" al resto de los animales de nivel superior y muestra de ello es la comunicación que mantienen los monos vervet para alertar a sus congéneres de la presencia de diversos predadores potenciales. No nos detendremos en éste punto porque ya lo hemos discutido más arriba. Más allá de ciertos detalles, Dupré no niega los enormes logros de nuestra especie en materia lingüística. Ver 2006, p. 105 y ss.
} 
un análisis filosófico de los seres humanos como un análisis sociológico, debe elaborarse a partir de un análisis antropológico. La filosofía primera (si es que tiene caso una pretensión tal) no sería la filosofía del lenguaje sino la antropología. Más adelante ahondaremos en ello. Por el momento, sólo basta decir que gracias al lenguaje se crean instituciones humanas (los matrimonios, los Estados, las guerras, el dinero), la división del trabajo, de roles o estatus. Dupré advierte que el lenguaje facilita la diversificación de la especie de dos maneras: gracias a los procesos de aprendizaje y por medio de la cooperación entre los agentes que cumplen diversos roles. En nuestra especie, y esto es evidente, un individuo desarrolla las habilidades, el rol social y el estatus de un panadero, mientras otro se convierte en arquitecto por medio de diferencias de entrenamiento y educación. Las sociedades también cuentan con restricciones económicas y de clase o casta pero, en principio, nada impide a un individuo en condiciones biológicas normales realizar una u otra actividad. Es difícil imaginar que exista un sistema de transmisión y entrenamiento de las distintas actividades y capacidades humanas que no requiera el uso del lenguaje. Sin dudas, la vida de una hormiga soldado requiere que se establezcan relaciones de cooperación con otras hormigas a la hora, por ejemplo, de abastecerse de alimentos; la realización de este tipo de actividades requiere algún tipo de comunicación, pero vivir en una sociedad humana como docente, ingeniero o electricista requiere un grado de comunicación considerablemente mayor. De éste modo, y en primer lugar, Dupré sostiene que el lenguaje humano ha evolucionado considerablemente (tal como el cuello de la jirafa, por ejemplo), permitiendo que se lo considere como una clase diferente a los rasgos semejantes de sus parientes. En segundo lugar, afirma que a medida que el lenguaje humano fue evolucionando, posibilitó otros cambios en la vida humana; esos cambios son los que nos han diferenciado aún más de otras especies animales.

Es aquí donde comenzamos a centrarnos en las especificidades de nuestra especie animal. En el próximo capítulo nos detendremos en el terreno antropológico (filosófico), con el objetivo de aclarar lo que líneas más arriba habiamos anticipado respecto de la antropología filosófica entendida como filosofía primera. Estimamos que los análisis de Searle son insuficientes y no nos dejan decir lo que aquí queremos decir; por ello, recurriremos a la obra de un filósofo brillante pero muy poco discutido en éstas latitudes, nos referimos a Ernst Tugendhat. 


\section{Capítulo 5: Un enfoque antropológico}

\section{Introducción}

A lo largo de los años, Searle ha elaborado una serie de diferenciaciones entre los animales humanos y el resto de los animales de nivel superior. Así, en Actos de habla (1969) podemos leer entre líneas (en ningún momento lo hace explícito), que la principal diferencia entre "nosotros" y "ellos", radica en la posesión de un lenguaje proposicional. A partir de Intencionalidad (1983), pasando por La construcción de la realidad social (1995) El misterio de la conciencia (1997), Mente, lenguaje y sociedad (1998), Razones para actuar (2000), Mentes, cerebros y ciencia (2003), La mente (2004) Libertad y neurobiología (2004), hasta su última obra de 2010, Haciendo el mundo social, sólo para nombrar sus obras más destacadas, ha comenzado a otorgarle -como ya lo hemos visto-, una creciente importancia a la intencionalidad de la conciencia. Como hemos aclarado en reiteradas ocasiones, aquí sostendremos que esta perspectiva se encuentra descaminada. En el presente apartado seguiremos analizando el modo en que Searle trata las diferencias entre los animales humanos y el resto de los animales; ese análisis nos permitirá decir otras cosas que son las que aquí queremos manifestar. Para ello, nos será útil el tratamiento que Ernst Tugendhat realiza sobre la antropología entendida como filosofía primera. Recurrimos a este autor porque nos ayudará a aclarar la tesis central del presente trabajo, a saber: todo estudio de las relaciones sociales, toda caracterización de los rasgos fundamentales de los seres humanos descansa, en última instancia, en la pregunta (antropológica) fundamental: ¿qué es el hombre? o ¿qué somos los hombres? Para entender el lenguaje, la intencionalidad, la racionalidad, las instituciones sociales, la religión, la mística, la muerte, las reglas, es preciso en primer lugar, resolver esa pregunta antropológica fundamental.

\section{El enfoque antropológico de Searle}

En la obra donde Searle mejor sistematiza sus ideas al respecto, es en Razones para actuar, obra del año 2000, es decir, mucho después de su retroceso hacia el plano de filosofía de la conciencia que había iniciado en 1983. Allí Searle discute con lo que 
denomina el modelo clásico de la racionalidad humana que se remonta desde la filosofía griega hasta la moderna, y sostiene básicamente que los seres humanos son más inteligentes que los simios.

Wolfgang Köhler, uno de los principales teóricos de la Psicología de la Gestalt, sostenía que los simios eran capaces de tomar decisiones. Hizo un experimento básico. Ubicó a un simio en una situación en la que contaba con una caja, un bastón y un racimo de plátanos a lo alto, fuera de su alcance. Luego de un rato, el simio movió la caja hasta colocarla a la altura de los plátanos, se subió a ella y con ayuda del bastón bajó los plátanos. Pero el problema de Köhler no era la racionalidad sino más bien la psicología de la Gestalt. El experimento sin embargo, le resulta útil a Searle para plantear sus propios problemas. Los simios de Köhler ejemplifican paradigmáticamente las teorías contemporáneas de la racionalidad. Así, la idea central consiste en que la toma racional de decisiones tiene que ver con seleccionar los medios adecuados que nos permitan alcanzar ciertos fines. Los simios son capaces de tomar ciertas decisiones, es cierto; pero hay una vasta cantidad de decisiones que los simios no pueden tomar. Veamos.

Los animales humanos no sólo tomamos decisiones respecto a nuestro presente inmediato, también planificamos nuestro futuro. Gran parte de nuestras decisiones, de hecho, están orientadas a la organización del tiempo más allá del presente inmediato. Searle afirma que,

Además, el simio no puede tomar en consideración grandes períodos de tiempo que terminen con su propia muerte. Gran parte de las decisiones que se toman en el caso de los humanos, de hecho la mayor parte de ellas, y que conciernen a cosas tales como dónde vivir, qué tipo de actividad profesional realizar, qué tipo de familia tener, etc., tienen que ver con la distribución del tiempo antes de la muerte (2000, p. 14).

La reflexión sobre la muerte no está presente en la vida del simio por sus limitaciones conceptuales.

Searle distingue una segunda diferencia entre la racionalidad humana y la de los simios. Los seres humanos están obligados a decidir entre fines incompatibles que, por ello, se 
encuentran en conflicto. Los humanos estamos forzados a elegir permanentemente ${ }^{64}$. Searle distingue una tercera limitación por parte de los simios, ellos no pueden considerar razones para la acción que no sean dependientes de sus deseos; en el experimento de Köhler, el deseo de mover la caja y tomar el bastón parece estar motivado por un deseo previo: tomar los plátanos. Los seres humanos, por nuestra parte, tenemos innumerables razones que no se vinculan con la satisfacción de los deseos ${ }^{65}$. Una cuarta diferencia es la siguiente, el simio tiene una concepción muy limitada de sí mismo en tanto que yo ${ }^{66}$. Finalmente, Searle distingue una quinta diferencia asociada a la anterior, los simios, a diferencia de los animales humanos, no observan sus decisiones como expresiones de, o compromisos con, ciertos principios generales que se aplican por igual a él como a otros yoes (2000, pp. 14-15).

Una vez más, Searle se refiere a la prioridad metodológica de la conciencia por sobre el lenguaje que viene sosteniendo a partir de Intencionalidad (1983). Generalmente, suele afirmarse que aquello que le falta al simio es el lenguaje. Searle II no está de acuerdo con esto porque de ser así, si se le pudiera enseñar a los simios los rudimentos de la comunicación lingüística, entonces serían capaces de tomar decisiones racionales y tendrían las mismas responsabilidades que nosotros, los seres humanos. Searle tiende a pensar que, "la simple capacidad de simbolizar no es por sí misma suficiente para poseer toda la serie de los procesos de pensamiento racionales" (2000, p. 15). De lo anterior se sigue que, de la capacidad de simbolizar, no se deduce la racionalidad humana. Como ya hemos hecho un recorrido de la posición de Searle respecto a la filosofía del lenguaje y a la filosofía de la conciencia, se podrá advertir que el elemento que para éste Searle (Searle II) es fundamental para que exista la racionalidad, es la capacidad de representar. Una vez más, vamos a sostener que esta posición no es adecuada. En todo lo anterior hemos estado de acuerdo con Searle pero, a partir de aquí necesitamos cambiar la

\footnotetext{
${ }^{64}$ Contraejemplos tales como el “asno de Buridán”, básicamente no tienen sentido. Jean Buridán defendió cierto determinismo moral y sostuvo que es necesario que cualquier hombre elija aquello que se presenta ante su razón como el bien mayor. Sus críticos parodiaron sus argumentos mediante el ejemplo de un asno que muere de inanición al no poder elegir entre dos montones de avena (o de paja) de igual tamaño. Sobre esto podemos decir dos cosas, primero, que los animales están motivados por instinto (su nivel de racionalidad como en el caso del simio es muy bajo porque carecen de una estructura simbólica). De tener que decidir elegiría cualquiera de los montones de avena, pero jamás moriría por una indecisión. Segundo, las decisiones a las que se someten los seres humanos son sobre elementos que no son de igual valor; por eso mismo, las elecciones son tan difíciles y nos obligan a reflexionar con profundidad. He ahí el carácter trágico de la vida; para elegir algo, es preciso renunciar a otra cosa.

${ }^{65}$ Este punto lo clarificaremos con mayor precisión más adelante y de la mano de Tugendhat.

${ }^{66}$ Aquí está la clave y Searle lo menciona al pasar. Más adelante, con Tugendhat nos detendremos en éste punto fundamental.
} 
dirección de los argumentos; de aquí en más su posición teórica no nos permite decir lo que nosotros queremos decir. Para seguir avanzando recurriremos a ciertas nociones básicas de Ernst Tugendhat, referidas a la antropología filosófica que iremos desarrollando a lo largo del presente apartado.

\section{La antropología filosófica de Ernst Tugendhat}

La tesis de Tugendhat es que la antropología no es sólo una disciplina filosófica entre otras, sino que se la debería entender como una filosofía primera. Esto es así porque la pregunta, ¿qué somos los seres humanos? No es una pregunta más, sino que tiene en su base todas las otras preguntas y todas las disciplinas filosóficas (Tugendhat, 2001, 2004, 2007).

En otros tiempos se creía que era la metafísica esa disciplina de base. Desde hace ya muchos años, sostiene Tugendhat, se habla del fin de la metafísica (2007, pp. 17 y ss.). No vemos cómo podría ser la metafísica (al margen de su complejidad conceptual) una filosofía primera; el mismo Aristóteles no creía que así fuera. Distinguía entre filosofía teórica y práctica, una distinción que, de otra manera, también se encuentra en Kant y que es usual hasta hoy: la pregunta por lo que es y la pregunta por lo que debe ser.

Así, tanto el ser como el deber ser, parecen remitir a nuestra comprensión; cuando preguntamos qué significa "nuestra" comprensión, se presupone que nos referimos a la comprensión que realizamos nosotros los seres humanos. Al respecto, Tugendhat sostiene lo siguiente,

Podría parecer entonces que el comprender es lo que está en la base tanto de la filosofía teórica como de la filosofía práctica, y también de la ontología (pues el ser es algo que encontramos solamente en nuestro entendimiento) y, si se contempla a la teología desde un ángulo de una necesidad humana, también ella remite al ser y entender humano. Así, el recurso a la comprensión humana se ofrece como el punto de partida natural tanto de la distinción entre lo práctico y lo teórico como también de las diferentes concepciones de la metafísica, y lo mismo parece evidente 
en disciplinas tales como lógica, ética, teoría de la acción, etcétera $(2007$, pp. 18, 19).

Sería difícil, de éste modo, encontrarse con una disciplina filosófica que no se remita a la comprensión humana ${ }^{67}$.

Tugendhat prosigue con una reflexión acerca de un famoso pasaje de la Lógica de Kant donde sostiene que hay tres preguntas fundamentales dentro de la filosofía: ¿qué puedo conocer? (epistemología); ¿qué debo hacer? (ética); ¿qué puedo hacer? (religión). Ahora bien, todas estas remiten a la pregunta, ¿qué es el hombre ${ }^{68}$ Según la apreciación de Tugendhat, en ese pasaje Kant concibió por primera vez la idea de la antropología como filosofía primera. Es llamativo que todas las preguntas anteriores a, ¿qué es el hombre? estén formuladas en primera persona mientras esta última se encuentra en una formulación objetiva. ¿Por qué se produce esa tensión entre el uso de primera y tercera persona? Tugendhat estima que Kant bien podría haber formulado todas las preguntas en primera persona; así la última podría cobrar la siguiente forma: ¿qué somos como seres humanos? (2007, p. 19). Pero si bien Kant habla en primera persona, sus preguntas no se acotan a, ¿qué puedo hacer como ciudadano de la tradición occidental del siglo tal?; más bien sus preguntas son entendidas en el sentido más amplio posible, en el sentido de la humanidad. Según la interpretación de Tugendhat, Kant no entendió a la antropología como una disciplina formal que estuviera por encima de todas las tradiciones culturales (tal como lo hizo la antropología filosófica del siglo XX), sino que hablaba como representante de la llustración: debemos evaluar cómo pensar y qué hacer, sin centrarnos en la historia ni en las tradiciones, sino en el hecho de que somos seres humanos.

La pregunta por la comprensión -tanto del mundo como de nosotros mismos-, que encara la antropología filosófica, parece ser su punto clave y eso explica por qué la investigación tiene que ser llevada a cabo en primera persona. Sólo tenemos acceso a la comprensión en primera persona singular o plural (2007, p. 20). Pero por otro lado, también parece necesaria la formulación objetiva, ¿qué es el ser humano? Cuando, tanto en ética como en teoría de la acción, nos preguntamos cómo es que "nosotros" entendemos el deber, la acción, parece estar sobreentendido que no se trata, por ejemplo, de la comprensión dentro del lenguaje castellano, sino más bien de la comprensión de nosotros como seres

\footnotetext{
${ }^{67}$ Los análisis de sociología sistémica, principalmente los elaborados por Luhmann, que pretenden desinteresarse de la acción y el entendimiento humanos, distan de la perspectiva de una teoría de la acción. ${ }^{68}$ La cita de Tugendhat corresponde a la edición de la Academia Prusiana IX, 25.
} 
humanos. Esta es una razón más para preferir el "nosotros" antes que el "yo". Por otro lado, nuestra comprensión del deber, del ser, la acción, es una comprensión compartida, pero "compartida" no significa "igual”. Y ello es así porque,

En el aprendizaje del lenguaje, pero también ya en la comunicación prelingüística, el niño intenta captar una comprensión compartida, en contraste con lo que se podría llamar sus perspectivas subjetivas. Aprendemos a verlas como subjetivas y como meras perspectivas en la adquisición gradual de la comprensión de los otros, comprensión objetiva, en el sentido de intersubjetiva (Tugendhat, 2007, p. 21).

Nos encontramos aquí, una vez más en presencia de un viejo problema en el terreno de la filosofía y de las ciencias sociales y humanas: la tensión entre lo subjetivo y lo objetivo; una tensión que se repite cuando nos confrontamos con otras culturas e idiomas.

Si la pretensión que tiene la antropología de ser la disciplina básica dentro de las disciplinas filosóficas, se basa en aquello que es objetivo en nuestra comprensión, ello nos va llevando de a poco a embarcar a toda la humanidad. Tugendhat entiende que el aspecto fundamental de la antropología como disciplina de base no es tanto la pertinencia a la especie sino a la comprensión compartida, al hecho de que podamos dialogar los unos con los otros. Esa comprensión es para Tugendhat el núcleo de la antropología, el cual se distingue de otros aspectos que son característicos de nuestra especie, tales como ser bípedos, tener un cerebro de ciertas dimensiones, no tener el cuerpo recubierto de vello (éstos aspectos se encuentran dentro de lo que se denomina antropología física).

\section{Sobre la comprensión humana}

En este punto, Tugendhat se enfrenta al problema de si la antropología tiene, a su vez, una pregunta básica. Si aquello que Tugendhat ha denominado el núcleo de la antropología -la comprensión compartida-, es la base de toda filosofía, la pregunta básica de la antropología tendría que estar estrechamente ligada a la pregunta básica de la filosofía. De lo anterior se infiere que la pregunta básica de la antropología tendría que 
consistir en preguntarse sobre la estructura de nuestro entendimiento. Tugendhat por su parte, se niega a identificar la pregunta básica de la filosofía con lo que se entiende por filosofía primera; lo que busca, mas bien, es algo así como el punto de arranque, la pregunta más básica que podemos plantearnos en cuanto seres humanos. A partir de una reflexión antropológica nos damos cuenta de que los seres humanos tenemos la necesidad de poner en cuestión nuestra propia vida; a diferencia de otras especies no somos de "alambre rígido" sino que podemos dudar de lo que hacemos y de cómo conducir nuestra propia vida (2007, p.23). Las distintas culturas, algunas muy lejanas a la nuestra, han dado cuenta de esta capacidad que los seres humanos tenemos para conducir nuestra vida de un modo u otro, de la posibilidad de decidir sobre la dirección que le damos a nuestras acciones. Tugendhat cita un pasaje del primer libro de la República de Platón (352d) donde Sócrates aclara que una de las preguntas más relevantes es, ¿de qué manera debemos vivir los seres humanos? (Tugendhat, 2007, p.23). La filosofía, en la China medieval, se refería a la pregunta por el Tao, y "tao" significa camino; lo que el tao era en China, en el Japón medieval se lo denominaba "Do"; por esa razón, la práctica de las diferentes artes marciales hacen referencia a un camino a seguir. Ju-Do, Aiki-Do, Karate-Do, lai-Do, etc ${ }^{69}$. Lo característico de los seres humanos es que este camino nunca está dado de antemano, nunca es obvio.

Según Tugendhat esta es la pregunta más fundamental (en el sentido de más básica) que los seres humanos se pueden plantear. Esta pregunta, además, tiene las dos caras a las que habíamos hecho referencia más arriba: en primer lugar, se trata de una pregunta de cada uno, en primera persona y, en segundo lugar, se trata de una pregunta que nos planteamos los unos a los otros, es una pregunta de "nosotros", una pregunta intersubjetiva.

A la pregunta, ¿cómo debemos vivir los seres humanos? que, tal como Platón la entendía, conectada a la pregunta por el bien, se asocia la pregunta por la estructura de nuestra comprensión. Aquí Tugendhat (2007), hace referencia al segundo capítulo de la Política de Aristóteles (al que hemos hecho referencia nosotros también en otro apartado) donde compara al lenguaje humano con el del resto de los animales de nivel superior y aclara que lo específico del lenguaje humano es lo que Aristóteles denominó logos; con esto,

\footnotetext{
${ }^{69}$ Es difícil entender cómo una cultura o una sociedad (como por ejemplo, la nuestra) no ofrezca un camino a seguir. Por esa razón, el Budismo Zen, por ejemplo, estima que actualmente la humanidad en su conjunto está atravesando una época de decadencia. Como sabemos, la crisis de sentido también era advertida por Max Weber.
} 
Tugendhat interpreta que se refiere a la estructura predicativa o proposicional del lenguaje humano (2007, p. 24). Así, aclara,

Los otros animales, dice [Aristóteles], se comunican recíprocamente sus estados sensitivos, dolor y placer, mientras que los hombres pueden hablar de lo bueno. Lo bueno sólo puede entenderse como predicado, se trata siempre de un juicio de que algo es bueno, y comunicarse sobre esto presupone el lenguaje proposicional. Aristóteles quiere demostrar que comunicarse sobre lo justo (y aún pensar tal cosa) es algo que sólo se puede hacer en el lenguaje predicativo (2007, p. 24 . El destacado le pertenece a Tugendhat).

Mientras que los otros animales guían o regulan sus relaciones sociales mediante el instinto o su sistema genético exclusivamente, los animales humanos tenemos la capacidad de reunirnos en agrupaciones sociales a partir de aquello que consideramos bueno para nosotros. Como vemos, ya Aristóteles (como no podía ser de otra manera) había advertido aquello que la filosofía supo ignorar en los siglos venideros. Desarrollando esa concepción de Aristóteles un poco más allá de lo que él decía explícitamente, Tugendhat sostiene que el fenómeno general es el del lenguaje proposicional. Con "lenguaje proposicional", nos referimos a un lenguaje basado en términos singulares, los cuales permiten que el contenido de lo que se dice sea independiente de la situación a la que se refiere; por otro lado, el interlocutor no reacciona simplemente sino que puede contestar de manera implícita o explícita por "Si" o por "No", o con proposiciones tales como pregunta y duda; así, el lenguaje no sólo se independiza de la situación, sino que también puede hacerlo de la comunicación misma. Con ello surge lo que llamamos pensar, y cuando uno piensa, uno mismo puede dudar de aquello que está pensando. Surge así el fenómeno de la deliberación. Hay dos componentes que en los animales no humanos, están presentes pero unidos, el opinar que las cosas son de un modo determinado y el desear algo. En el caso de los seres humanos, el opinar y el desear se encuentran separados en dos formas lingüísticas completamente independientes. Ello tiene como consecuencia, según Tugendhat, que tengamos que distinguir entre una 
deliberación práctica (que tiene como meta lo bueno) y, por otro lado, una deliberación teórica que tiene que ver con lo que se está opinando (y tiene como meta lo verdadero). Al deliberar, no hacemos otra cosa que pedir por razones, éstas pueden estar a favor o en contra de lo que se está diciendo o pensando. Esto significa que la acción no se encuentra dirigida únicamente por los deseos, sino también por aquello que se piensa que es bueno o verdadero; cuando deliberamos tenemos la capacidad de suspender los deseos. Esa capacidad es lo que habitualmente se llama libertad y responsabilidad. De éste modo, Tugendhat sostiene que a nuestra especie anthropos se la podría denominar, tanto animal racional como animal deliberativo $(2007$, p. 26$)$. La racionalidad no es algo sobrenatural, como muchas veces la tradición ha sostenido; se trata simplemente de la capacidad -exclusivamente humana-, de dar y pedir razones. Esta es la consecuencia inmediata del lenguaje proposicional.

En Problemas (2001), Tugendhat se detiene en el problema de la deliberación. argumento es el siguiente. Si los seres humanos poseen la capacidad de deliberar es porque poseen un lenguaje proposicional; por otra parte, deliberar es pedir por razones como ya hemos aclarado-. Poder pedirlas, implica poder decirlas. Lo central aquí es esta relación entre el lenguaje humano y esta capacidad deliberativa. Tugendhat propone el siguiente ejemplo. Cuando un gato se siente acosado por un perro, sube a un árbol. Tiene el deseo de evitar la muerte y la creencia de que el perro no podrá seguirlo hasta la copa del árbol (2001, pp. 143 y ss.). Lo que hemos hecho aquí es explicar la conducta del gato como resultante de un deseo y una creencia. Hizo lo que hizo porque deseaba y pensaba algo; el punto nodal es que en el gato, estos dos elementos no tienen representantes propios. El hecho de que en los seres humanos, por el contrario, se dé una separación entre deseos y creencias es la consecuencia de que cada uno de estos factores puede ser expresado por separado, lingüísticamente. Tugendhat aclara,

El que un individuo opine o quiera algo, significa que tiene la disposición a expresar la frase correspondiente. El que el lenguaje proposicional no sólo tenga una función comunicativa radica en el hecho de que el individuo no pasa sin más un mensaje a otros individuos, sino que se ve confrontado con su deseo (así como con el deseo o la orden del otro), al igual que con su opinión, en el sentido de que él puede ahora tomar posición -lo mismo, naturalmente, que el 
otro- acerca de su opinión o deseo (o bien frente a la orden de otro individuo) en cuanto que puede afirmar o negar la correspondiente oración, teniendo así también la posibilidad de situarse entre la afirmación y la negación al preguntar o deliberar. El objeto de la deliberación son razones (2001, pp. 143 y 144. Los destacados le pertenecen al autor).

Cuando Tugendhat habla de razones, entiende el estar a favor o en contra de algo, sea de una afirmación asertórica o práctica, de una opinión o un deseo. Tan pronto como un individuo es consciente de esa posibilidad de elegir una afirmación asertórica y un deseo, y descartar otros, es consciente de la existencia de una multiplicidad de opciones; de esta manera (como decíamos más arriba) toma conciencia de su libertad. Esta noción de que los seres humanos podemos tomar posición frente a nuestros deseos, opiniones e intenciones, explica la metáfora a la que hace referencia Tugendhat en reiteradas oportunidades cuando dice que los seres humanos no somos de "alambre rígido" (2001, 2004).

Con esa expresión, busca señalar que, al nivel del comportamiento humano, no existe un determinismo causal; el esquema estímulo-respuesta que tan útil es para analizar el comportamiento de los perros jadeantes, no explica el comportamiento humano. Esto es así porque entre percepción e intención, por un lado, y acción, por otro, puede entrar en juego la deliberación, la ponderación de distintas opciones. Tugendhat, sin embargo, no sostiene que el actuar humano no esté causalmente determinado, sólo que no lo está en el nivel del comportamiento (2001, p. 144).

Así, Tugendhat entiende que estos tres elementos: la capacidad de deliberación, la pluralidad de opciones que tienen los seres humanos, y la perspectiva de razones que poseen, van directamente juntos. Estos elementos se basan en la diferenciación de los componentes teóricos y prácticos; esa diferenciación es a su vez posibilitada por la estructura proposicional del lenguaje. La deliberación, precisamente, tiene su punto de apoyo en la separación de los dos componentes del opinar y del querer. La situación de acción como un todo, no es posible de deliberación; si así fuera, la caída en un círculo vicioso sería inevitable e inhibiría a la acción. La deliberación es ya una acción, una acción sobre la que no se delibera.

Llegados a este punto, es preciso aclarar que, hablar en oraciones no es lo mismo que racionalidad, pero sí es la condición necesaria para que podamos dar y pedir razones, 
Las razones son esencialmente justificaciones para proposiciones, asertorias y prácticas, o bien para aquello a lo que estas se refieren (Tugendhat, 2001, p. 145).

Tugendhat considera otra consecuencia del lenguaje proposicional; tal como decía Aristóteles, el hombre es un animal político y, como se podría añadir, un animal social y cultural. El lenguaje y la cultura han sido producto de la evolución bilógica; tanto el lenguaje como la cultura, sin embargo, se han convertido en un mecanismo de transmisión mucho más rápido y dinámico que la transmisión genética, la cual sigue como base. Esta capacidad humana de dar y pedir razones, que se desprende del lenguaje proposicional, implica un nuevo nivel cognitivo. Ello otorga mayor flexibilidad para adaptarse al medio ambiente; no solo eso, el lenguaje proposicional implica un nuevo mecanismo de transmisión y de acumulación del aprendizaje de generación en generación $^{70}$.

Haremos hincapié a continuación, y para seguir profundizando en la particularidad de nuestra especie animal, en un rasgo singular ( $y$ por ello fundamental) de los seres humanos; aunque ya hemos abordado el problema del lenguaje, consideramos necesario abordarlo en los términos en que lo hace Tugendhat. A continuación analizaremos con algún detalle el problema del lenguaje proposicional desde su perspectiva.

\section{El lenguaje proposicional}

Ante todo debemos afirmar que, si bien no es posible entender todo el comportamiento de los seres humanos a partir del su lenguaje -la música y el enamoramiento, por ejemplo, no tienen una estructura proposicional- consideramos que a partir del estudio del lenguaje y del uso de la palabra "yo" podemos explicar bastantes cosas. En Egocentricidad y mística (2004), Tugendhat se centra en lo siguiente, "a partir de cierta edad, los seres humanos dicen "yo", y sólo pueden decir "yo" porque hablan un lenguaje proposicional" (p. 15). El lenguaje proposicional es producto de la evolución social; a través de su análisis es posible comprender ciertos rasgos que consideramos esenciales (distintivos) de nuestra especie animal.

\footnotetext{
${ }^{70}$ Más adelante nos centraremos en este punto que Michael Tomasello denomina trinquete cultural.
} 
Como hemos advertido más arriba, quien ha observado en primer lugar los puntos distintivos entre el lenguaje humano y los lenguajes del resto de los animales de nivel superior, ha sido Aristóteles. Desde una perspectiva contemporánea, podemos desplegar el análisis de Aristóteles del siguiente modo. Cuando el modo en que los miembros de una formación social determinada se agrupan en torno a lo que se representan como lo bueno para ellos, y en consecuencia, en base a normas, entonces el comportamiento social de la especie no está predeterminado genéticamente (como en el caso de los animales de nivel superior), sino condicionado por formas verbales (y consecuentemente culturales $)^{71}$. Si bien Aristóteles no profundizó la perspectiva que tematizó en la Política, porque su visión de la estructura del lenguaje no estaba aún muy desarrollada, tuvo la lucidez de haber tomado como punto de partida la estructura predicativa.

Si le adjudicamos al resto de los animales no humanos un tipo de lenguaje, podemos hablar de lenguajes de señales ligados a una situación determinada. Lo característico del lenguaje humano es su proposicionalidad ${ }^{72}$. Tugendhat (2004) distingue tres aspectos característicos de la proposicionalidad: $i$ ) en primer lugar, las unidades significativas elementales -tal como Frege había observado-, son las oraciones predicativas, las cuales constan de un predicado y de (al menos) un término singular; por otro lado, ii) éstas oraciones aparecen en varios modos (asertórico, imperativo, etc.); y, finalmente, iii) las oraciones pueden ser negadas, de éste modo los interlocutores, tomando posición por un "si" o por un "no", pueden comportarse respecto de ellas y también respecto uno del otro (p. 18). Son los términos singulares los que permiten la independencia de la situación que caracteriza al lenguaje proposicional. Hay que agregar, siguiendo a Tugendhat que,

La oración predicativa y así mismo toda oración de nivel superior hace referencia a algo, a un eventual hecho (Sachverhalt), con el que hablante y oyente pueden relacionarse -afirmándolo o negándolo- como con algo idéntico para los dos, ya sea en el modo de la aserción. Ya sea en el modo del deseo o el imperativo. Hablante y oyente

\footnotetext{
${ }^{71}$ Ello, por otra parte, explica el cambio social. Las formaciones sociales, debido a ciertas contingencias, pueden ser disueltas o reconstruidas; pero no ocurre lo mismo dentro de la genética. Si bien existen variaciones, éstas son temporalmente mucho más lentas.

${ }^{72}$ Ya no hablamos, como lo hacía Aristóteles, de estructura predicativa sino que lo hacemos de un modo más general en tanto que estructura proposicional.
} 
se entienden sobre una y la misma cosa $(2004$, p. 19. Los

destacados le pertenecen a Tugendhat).

En los lenguajes de las demás especies esa cosa común no existe, sólo lo encontramos en la especie animal que ha desarrollado ese particular tipo de lenguaje basado en proposiciones. Para el resto de las especies sólo existe un modo de comunicación basado en el esquema de estímulo-respuesta; la posición "sí"/"no" distintiva del lenguaje proposicional viene a suplir ese esquema estímulo-respuesta.

Con esto podemos entender algunos rasgos centrales de la conducta humana. Se suele llamar racionalidad a la capacidad de reflexionar, lo cual implica el hecho de dar y pedir razones. Mientras que, prosiguiendo con el análisis de Tugendhat, la reflexión teórica se guía por la pregunta, qué es verdadero; la reflexión práctica, por qué es bueno o mejor. La capacidad reflexiva y la toma de posición suponen una conciencia de tener opciones. En ella se basa lo que se denomina libertad humana ${ }^{73}$. La característica central de los seres humanos, y al contrario de lo que sostuvo toda una tradición (aquella que se inició con Descartes) no es la razón; si los seres humanos son capaces de dar y pedir razones es porque poseen un lenguaje proposicional que se los posibilita. Pero, en éste contexto sería lícito preguntar, ¿cómo es posible que hayamos desarrollado nuestra capacidad de aprender un idioma? ¿Todos los fenómenos específicamente humanos son lingüísticos? Al respecto Tugendhat afirma,

\begin{abstract}
Naturalmente, hay fenómenos específicamente humanos piénsese sólo en la sonrisa- que se dan en los niños antes de que aprendan un idioma, entre otros justamente la capacidad de aprender un idioma; sin embargo, este ejemplo nos muestra que hay fenómenos que no dependen del lenguaje, pero que están genéticamente relacionados con él (2004, p. 21. Los destacados le pertenecen a Tugendhat).
\end{abstract}

\footnotetext{
${ }^{73}$ No nos ocuparemos de éstos problemas en el presente trabajo, sólo lo mencionamos para dar cuenta de nuestra idea central: todo lo social es lingüístico. Todo lo que no posea una estructura lingüística obedece al mundo físico o, para utilizar la terminología de Searle a los hechos en bruto.
} 
El estado de la ciencia actual no es capaz de otorgar una explicación respecto al surgimiento de nuestro lenguaje proposicional, pero analizando el producto terminado es evidente que nuestra especie animal ha desarrollado un nivel cognitivo más alto gracias a la racionalidad -la cual es posible gracias a la adquisición del lenguaje proposicional-.

A continuación nos detendremos en otro problema que muestra el rasgo distintivo del lenguaje humano, un rasgo que es central para los seres humanos en la realización de aquello que en última instancia queremos analizar, a saber, la realidad institucional. Este elemento permite independizar al hablante de la situación de habla, nos referimos a los términos singulares.

\section{Los términos singulares}

Tugendhat (1997) señala tres tipos distintos de términos singulares; primero, los nombres propios como "Juan" o "Buenos Aires"; segundo, pronombres como "este", "aquel", "él", "aquí", etcétera, se trata de las denominadas expresiones indexicales o dependientes del contexto, una oración como "él viene" es una oración que depende del contexto, sólo teniendo en cuenta una situación puede hacerse de esa oración una aserción o bien verdadera, o bien falsa; tercero, hay términos singulares como "la capital de Argentina", "el autor de Los miserables", y otros por el estilo, que se llaman descripciones (el $F$ ) porque representan objetos mediante su descripción o al menos alguna de sus características (pp. 118 y ss.). La tradición se orientó principalmente hacia los términos singulares del tipo de los nombres propios porque se los consideró como fundamentales y se estimó que en estos casos se podría entender con mayor claridad la relación entre el término singular y el objeto; fue Frege quien advirtió que los nombres propios tienen la forma de uso más complicada y presuponen los otros tipos de términos singulares ${ }^{74}$.

Los términos singulares, como decíamos más arriba, posibilitan la independencia de la situación de habla, este es el signo distintivo del lenguaje proposicional; sin ellos no sería posible que hablante y oyente pensaran en una y la misma cosa. Lo que ocurre en el lenguaje proposicional es que los signos elementales (lo que se denomina oraciones

\footnotetext{
${ }^{74}$ Frege destacó que los nombres propios tienen tanto una denotación -representan un objeto (Bedeutung)-, como una connotación -tienen un significado (Sinn)-. Así, el nombre "Aristóteles" representa un objeto: Aristóteles, y lo hace de modo tal que la relación entre el nombre y el objeto se establece con ayuda de descripciones tales como "el alumno de Platón". La concepción de que los nombres propios están unidos a descripciones también ha sido defendida por Russell.
} 
predicativas singulares), gracias a los términos singulares, se convierten en oraciones independientes de la situación. En cierto modo, sostiene Tugendhat (1997, 2004 y 2009) que el objeto designado por el término singular ocupa el lugar de la situación. A diferencia del resto de los animales, los seres humanos no reaccionan a su entorno sino que se refieren a objetos singulares que pueden identificar objetivamente en el espacio y en el tiempo para predicar algo sobre ellos. Los seres humanos tienen conciencia del universo, de un mundo plagado de objetos. Pero, ¿qué se entiende aquí por objeto?

Es preciso advertir ante todo que en filosofía, la palabra "objeto" se usa de un modo más amplio que en el lenguaje ordinario. En el uso ordinario caracterizamos a las cosas materiales bajo la denominación "objetos", pero no a todas las cosas materiales; quedan afuera los seres humanos y el resto de los seres vivientes. Pero según el uso filosófico, estos objetos también son tomados como "objetos"; además de los objetos materiales, también lo son los objetos abstractos como números, estados de cosa y conceptos. Así, Tugendhat sostiene que,

Un objeto en este sentido amplio, según es usual en filosofía, es precisamente todo aquello que puede ser representado por términos singulares en aserciones predicativas singulares, $\circ(\ldots)$, todo aquello para to cual se puede usar la palabra "algo" (1997, pp. 117 y 118).

La identificación de cada objeto del mundo es posible gracias a la referencia. Somos capaces de hacer referencia a objetos porque podemos hacer referencia a lugares especio-temporales. Este sistema de referencia es posible gracias a lo que Tugendhat denomina capa básica de términos singulares (2004); ésta capa básica que hace referencia a una situación y, en última instancia, a un hablante, son las expresiones deícticas o indexicales. De éste modo afirma Tugendhat que,

Los términos singulares no podrían realizar su función hacer independiente de la situación la referencia a lugares espacio-temporales y a objetos- si no se apoyaran en expresiones que hacen referencia a lugares espaciotemporales y a objetos designándolos en relación a la 
situación del hablante (2004, p. 23. Los destacados le pertenecen a Tugendhat).

Ello permite que se produzca una no-relatividad respecto de la situación; a esto se debe que los términos deícticos pertenezcan a un sistema de sustitución: al día que hoy lo denominamos "mañana", el día de mañana lo denominaremos "hoy". También se emplean expresiones que localizan objetivamente; también puedo referirme al día de hoy como el 18-02-2014. De éste modo lo integramos a un sistema de coordenadas que posee un punto cero. El punto cero es identificado por el hablante gracias a la relación que tiene con el aquí y ahora. Con ambas -las expresiones deícticas y las que localizan objetivamente-, aquellos que hablan un lenguaje predicativo son capaces de hacer referencia a un universo de lugares especio-temporales y de objetos, sobre el cual es posible volver una y otra vez desde la situación cambiante del hablante porque son lugares y objetos independientes de su situación. También es gracias a ese sistema de sustituciones que los nombres propios pueden ser comprendidos. Por ello, la tesis de Tugendhat es que únicamente podemos referirnos a un individuo si al mismo tiempo nos relacionamos con un mundo $^{75}$.

La referencia a objetos singulares que existen con independencia de una situación es lo que permite el entendimiento al interior de una comunidad de hablantes; es precisamente porque los individuos que integran una comunidad son capaces -dentro de una cantidad de objetos-, de entenderse acerca de a cuál de ellos aluden, es posible que puedan opinar, desear, negar, etc., una y la misma cosa con lo que dicen de él. Tanto la comunidad de hablantes como los individuos que la integran, forman parte de ese universo de objetos. $\mathrm{Y}$ una comunidad de hablantes, vale aclarar, son todos aquellos con los que podemos entendernos sobre algo.

Para que $A$ pueda comprender qué objeto identifica $B$ mediante un deíctico, $A$ no sólo debe ser capaz de identificar al objeto señalado sino que, además, debe identificar a $B$ (en tal y cual lugar). Cuando, por ejemplo, $B$ se refiere a $A$ diciendo, "Este clima es insoportable", $A$ debe identificar especio-temporalmente a $B$; si $B$ se encuentra en un barrio porteño o si se encuentra en la Patagonia, la referencia de "Este clima" no será la misma. Pero estas identificaciones son posibles (comprensibles), agrega Tugendhat (2004, p. 25) si el hablante puede hacer referencia a sí mismo. La referencia al hablante, no obstante, difiere de la referencia a otro individuo u objeto; así, aclara Tugendhat,

\footnotetext{
${ }^{75}$ Ver principalmente, Tugendhat, 2004, pp. 23 y ss.; y 2009, Lecciones 25 y 26.
} 
En algunos casos [el hablante] hace referencia a sí mismo tal como lo hace otra persona, por ejemplo, apuntando a su pecho con el dedo y diciendo "este hombre". ¿Pero cómo sabe el hablante que este pecho es el suyo y no el de otro? ¿Qué significa "el suyo"? Al usar "esto" (o "este", "esta") se remite a la intención del hablante, porque con "esto" se indica un objeto de su entorno. Da igual si el hablante es otro o soy yo. De modo que cuando $B$ dice "este escarabajo", A sabe de qué escarabajo se trata, si puede identificar a B, pero A no se puede referir a sí mismo como si fuera algo que cabe señalar en su entorno (como su pecho). El hablante no es algo en su entorno (2004, pp. 25 y 26. Los destacados le pertenecen a Tugendhat) ${ }^{76}$.

El presente análisis arroja los siguientes resultados: i) para cada hablante que integra la comunidad de hablantes tiene que haber un universo objetivo constituido por objetos singulares especio-temporales; ii) esto sólo es posible si el hablante es capaz de identificar la relación espacio-temporal en la que se encuentran tanto los objetos como él mismo; iii) si él mismo es un objeto espacio-temporal, entonces tiene que poder referirse a sí mismo de una manera que no le permita decir "esto", porque de esta manera sólo puede hacer referencia a algo que se encuentra en su entorno. Tenemos todo el derecho de preguntarnos entonces, ¿cómo puede el hablante hacer referencia a sí mismo? Y la respuesta es, diciendo "yo". Al decir "yo" el hablante no hace referencia desde afuera como cuando dice "esto", "ese", sino que la referencia es desde adentro. Pero, ¿qué significa desde adentro?

\section{El decir "yo"}

\footnotetext{
${ }^{76}$ Para terminar de saldar las discusiones del Capítulo 2, aclaramos una vez más que Tugendhat no se empeña en negar la existencia de la intencionalidad. La diferencia radica en, digamos, el estatus que le otorga; la intencionalidad para Tugendhat es lingüística y esto es así porque nuestra conciencia es proposicional. Y no hay nada más allá de sus límites; de éste modo, no tiene lugar lo que Husserl denominaba $X$ vacía. Ningún objeto se encuentra desprovisto de conceptualización o contenido proposicional.
} 
Para entender a qué regla obedece el uso de "yo" veamos cómo suceden las cosas desde nuestra tierna infancia. Un niño aprende cómo se usa "yo" cuando observa que los adultos hacen referencia a sí mismos mediante el uso de "yo". También, cuando un individuo no quiere ser identificado desde afuera con ciertas características (por ejemplo, una cualidad física o como teniendo un nombre propio tal), tiene que hacer referencia a sí mismo mediante el uso de "yo". La dificultad del niño radica en que debe aprender la diferencia entre el uso de "yo" y el uso de su nombre propio. Tanto él como los distintos miembros de su familia tienen nombres propios mediante los que pueden hacer referencia unos a otros. Así, cuando uno hace referencia a otro mediante su nombre propio, esta referencia es desde afuera precisamente porque los nombres propios hacen referencia a expresiones deícticas y localizadoras. Pero aún queda abierto el problema, ¿qué significa hacer referencia a sí mismo?

Es posible distinguir distintas clases de predicados que complementan los términos singulares formando oraciones completas. Tenemos, en primer lugar, los predicados perceptuales. En este caso, el modo de observar si le corresponde o no al objeto una característica determinada, es mediante la observación; por ejemplo, determinamos que Ignacio se tiñó el cabello de rubio cuando aparece entre nosotros de tal modo que podemos decir: ésta persona (el objeto apareció en nuestro campo perceptual). La observación, por otro lado, no permite constatar ciertos atributos convencionales o por relaciones causales. Por ejemplo, mediante la observación no podemos constatar si Ignacio es el hijo de Hilda o un profesor universitario. Así, es posible distinguir diferentes perspectivas desde las cuales a un objeto le corresponde un predicado. Si se ha verificado desde la perspectiva adecuada que Ignacio es el profesor, entonces también es posible atribuir al objeto este predicado al usar un término singular que no pertenece a esta perspectiva ("esta persona es el profesor"); ello es así porque todos los predicados que le corresponden a un objeto, lo hacen independientemente del término singular que se emplee (Tugendhat, 2004, p. 26 y ss.).

Ahora bien, además de los predicados perceptuales y de los que le corresponden a un objeto en virtud de relaciones causales o convencionales, Tugendhat (2004) distingue una tercera clase en la que no vale ni lo uno ni lo otro. Se trata de los predicados que se refieren a los estados de conciencia y a acciones y estados corporales de los que una persona es consciente. A estos predicados Tugendhat los denomina internos, aunque aclara que la denominación no es del todo clara y puede dar lugar a malos entendidos. La característica central de estos predicados es que se da cierta asimetría entre el modo en 
que esta persona constata que le corresponden y el modo en que lo constatan los demás. Las otras personas saben que alguien está atravesando un determinado estado "interno" por su conducta. Desde afuera constatan que le corresponde un cierto predicado, no por la observación pero sí a partir de la observación. La persona, por otro lado, no lo constata mediante la observación, sino que lo hace inmediatamente. Pero, ¿qué significa aquí "inmediatamente"?

La filosofía que Tugendhat (2009) denomina tradicional (la que comienza con Descarte y finaliza con Husserl como su último gran exponente) sostenía que cada uno es capaz de darse cuenta en qué estado mental se encuentra (sólo se pensaba en estados mentales). Tugendhat -como no podía ser de otra manera-, entiende que esto es falso por tres razones; en primer lugar, sería fenomenológicamente falsa, una percepción interna tal no existe; en segundo lugar, en caso que ese estado existiera, jamás podría ser constatado por fuera; y en tercer lugar, habría un regreso infinito (2004, p. 28). Aclaremos esto mediante un ejemplo. Si digo, "frente a mí hay un auto" y me preguntan, “¿cómo lo sabes?", respondería, "porque lo veo, por observación”. ¿Se me podría preguntar en ese caso, “¿cómo sabes que lo ves?”? Ahora bien, si respondo, "porque veo interiormente que lo veo", con toda justicia se me podría replicar, ¿y cómo sabes que lo ves interiormente? Así sucesivamente. Lo que intenta explicar Tugendhat es que cuando me encuentro en un estado interno, sé también que me encuentro en él. Tugendhat lo explica del siguiente modo,

\footnotetext{
Desde un ángulo lingüístico (...) se ha aprendido a pronunciar la oración correspondiente cuando uno se encuentra en ese estado (no cuando uno percibe que se encuentra en ese estado (2004, p. 28).
}

Si puedo manifestar que veo un auto mediante la observación directa, o si lo sé por ejemplo, porque alguien me lo dice ya que tengo los ojos vendados (la percepción no sería directa en ese caso), si percibo que estoy mareado, que estoy en el colectivo, o que tengo la intención de ir a la Universidad, si puedo manifestar que me encuentro en uno de esos estados mentales es porque estoy en él. Si estoy en él, entonces también sé que estoy en él. 
Lo central aquí es comprender el vínculo entre el uso inmediato de mis estados y el uso del término singular con que hago referencia a mí mismo ("yo"). En palabras de Tugendhat,

Así como se puede decir que las propiedades directamente perceptibles son las que le corresponden a un objeto desde la perspectiva "esto", claramente puede decirse también que aquellas propiedades que el que las tiene no sabe por observación que las tiene son conocidas desde la perspectiva "yo" (2004, p. 29).

Los niños, muchas veces aplican a sí mismos los predicados correspondientes pero sin utilizar "yo" (quizás todavía no han aprendido su uso). Es frecuente entonces, que un niño diga "Juancito quiere chocolate" y no todavía "quiero chocolate". Aunque no pueda usar la palabra yo, tiene sentido decir que el niño cuenta ya con el concepto "yo". Usa predicados desde la perspectiva "yo" y no desde la perspectiva "esto".

Llegados a este punto, es preciso aclarar cómo se debe entender la función referencial de "yo". En primer lugar, con la palabra "yo" no se hace referencia a algo en mí llamado el yo, sino que el hablante hace referencia a sí mismo ${ }^{77}$. Los predicados internos le corresponden al hablante y no a un yo. En segundo lugar, la palabra "yo" hace referencia al hablante, designa a esa persona pero no la identifica. Esa es una de las diferencias entre el uso de "yo" y el resto de las expresiones deícticas; estas últimas, al igual que los otros términos singulares hacen referencia en tanto identifican: indican, tanto directa como indirectamente, cómo encontrar el objeto singular aludido y cómo diferenciarlo de todos los demás. Diciendo, por ejemplo, "este auto" identifico un auto como el auto que señalo; diciendo "el día de mañana", identifico un día determinado como el que le sigue a hoy; diciendo "hoy", identifico al día en el que estamos hablando o estoy hablando. Pero soy yo el que habla. Diciendo "yo" no me identifico ni para mí ni para los demás. A veces, tenemos la impresión de que esto sucede; pero no puedo identificarme para mí diciendo "yo" porque, como sostiene Tugendhat, sólo puedo identificar algo, asignándole un lugar en relación a mí (2004, p. 31). Sin embargo, se puede advertir otro uso de "yo", un uso en

\footnotetext{
77 El uso de la palabra "yo" que aquí manejamos, no debe ser confundido con el usado por el psicoanálisis. Dentro de ese marco conceptual, el "yo" es uno de los tres elementos que conforman la estructura de la personalidad humana (junto al "ello" y el "super yo"); de éste modo y en esa estructura tripartita el "yo" sí hace referencia a algo en mí, algo que media entre mis deseos ("ello") y el deber, la ley ("super yo").
} 
que sí es posible la identificación. Pensemos, por ejemplo, en el profesor de escuela que toma lista de sus alumnos presentes y ausentes; al decir un nombre, y el alumno decir "yo", o "presente" (en éste último caso la oración completa sería, "yo estoy presente en la clase"), pareciera que se produce una identificación, no por parte del sujeto que se autoenuncia -y allí Tugendhat está en lo cierto-, pero ese uso de "yo", ¿no serviría para que un tercero me identifique ${ }^{78}$.

Tugendhat retoma un punto interesante: mediante la palabra "yo", se hace referencia. Todos los predicados que me atribuyo, me los atribuyo como a una persona distinta de todos los demás objetos y de todas las otras personas. Si bien con la sola palabra "yo" no se ha dicho qué individuo soy yo (recordemos que para Tugendhat no tiene una función identificadora), la sola palabra implica que soy un individuo diferente al resto que se encuentra dentro del universo del mundo objetivo; de este modo, todo lo que digo de mí mismo desde la perspectiva "yo", me corresponde como a un individuo que es diferente de todos los demás. Predico mis opiniones, deseos, sentimientos e intenciones como de este individuo y, al hacerlo, las objetivo. Así se produce el traspaso desde la conciencia proposicional a la conciencia yoica. Es así como,

La autoconciencia no es un acto interno, una vuelta sobre el así llamado yo. Se produce cuando, por medio de predicados, me atribuyo a mí mismo mis estados conscientes -intenciones, sentimientos, etcétera- y con ello a una persona que dentro del universo real, objetivo de cosas diferenciables en una entre todas (Tugendhat, 2004, p. 32; los destacados le corresponden al autor).

La filosofía clásica entendía la autoconciencia como conciencia de sí mismo que se contrastaba con la conciencia de objetos. Precisamente esta perspectiva es la que Tugendhat viene a cuestionar; sostiene, por el contrario, que la "mera conciencia" no es una conciencia de objetos sino el fenómeno prelingüístico de los estados mentales que sólo poseen la propiedad de la conciencia que aún no es conciencia de. Con el lenguaje

\footnotetext{
${ }^{78}$ Entiendo que el ejemplo es problemático porque con el uso de "yo" va asociado un nombre propio. A quien dice "yo" cuando se le toma lista, se lo identifica inmediatamente con su nombre propio y, como sabemos, los nombres propios son casos normales de expresiones deícticas y sí son susceptibles de identificación. Si bien es un ejemplo problemático, podría ser tomado, quizás, como un contraejemplo para Tugendhat. De todos modos, nada de esto modifica sustancialmente su argumento.
} 
predicativo aparecen a la vez la conciencia de otros objetos y la conciencia de sí mismo como un objeto entre otros. Ambas se encuentran entretejidas con la conciencia de un mundo objetivo en el que tanto yo como las demás personas ocupamos un lugar. Aquel que habla un lenguaje proposicional no podría tener conciencia de sí mismo, si no tuviera conciencia de todo (un mundo objetivo); a la vez, no podría tener conciencia de un mundo objetivo si no pudiera hacer referencia a sí mismo.

Entender la palabra "yo" implica entender que cualquiera hace referencia a sí mismo diciendo "yo"; nadie puede usar "yo" sólo para él. En cuanto soy capaz de decirme a mí mismo "yo", una multiplicidad de otros que dicen "yo" se vuelven realidad para mí. De ésta manera no sólo se constituye un universo objetivo de seres independientes del que soy una parte, sino que también, dentro de ese universo, se constituye un universo parcial compuesto por seres que dicen "yo" y que se perciben mutuamente como independientes, cada uno con sus correspondientes deseos, sentimientos, intenciones, opiniones, etcétera. Para el que dice "yo", esa rudimentaria forma de estar centrado en sí mismo, se transforma en ego-centricidad; ahora, además de tener intenciones, deseos, etcétera, sabe que le pertenecen a sí mismo (Tugendhat, 2004, pp. 32 y 33).

\section{Observaciones finales}

Al principio del presente apartado analizamos la posición de Searle respecto a la diferencia entre los seres humanos y el resto de los animales; allí citamos un pasaje (Razones para actuar (2000)), donde decía que la capacidad de simbolizar que tenemos los seres humanos no es un elemento suficiente para posibilitar la racionalidad. A partir del recorrido que hemos hecho por algunos de los puntos centrales de la obra de Ernst Tugendhat, tenemos todo el derecho de preguntarle a Searle, ¿qué más necesitamos además del lenguaje proposicional?, ¿qué más hace falta para dar y pedir razones? La respuesta de Searle sería que, ante todo, es necesaria la capacidad estrictamente humana de representar. El desarrollo del segundo y del presente apartado son esfuerzos por demostrar que esta concepción está equivocada.

La premisa que motiva nuestra reflexión es que somos (casi) idénticos a los simios, nuestro comportamiento y nuestra genética es prácticamente igual. Pero, mientras nosotros construímos un mundo social -Estados, guerras, matrimonios, Universidades-, ellos no pueden hacerlo. ¿Por qué ellos no pueden y nosotros sí?, ¿qué tenemos 
nosotros que a ellos les falta? Un estudio de la ontología humana, implica un estudio de la ontología de la sociedad; y a la inversa. Si podemos identificar con éxito cuáles son los aspectos característicos (en el sentido de exclusivos) de nuestra especie animal, podremos comprender el funcionamiento de nuestras sociedades, no en todos y cada uno de sus aspectos, pero sí en sus lineamientos generales. Se podrá objetar que el presente estudio parte de un naturalismo extremo. Y ello es cierto; no sólo eso, damos un paso más para afirmar que todo estudio de lo social debe partir del naturalismo para no caer en divagues sin sentido, en puntos oscuros. Para edificar un análisis sólido debemos partir de premisas sólidas. Nuestra premisa sólida es la biología; todo análisis cultural que la contradiga estará descaminado. Como dice Searle en algún lugar, desplegar un análisis que parta de una oposición entre cultura y biología no tiene caso, es una batalla perdida porque en la contienda, la biología triunfa siempre.

A partir de aquí nos ocuparemos de otros aspectos que también son señalados por Searle como fundamentales de nuestra especie animal; nos referimos a la intencionalidad colectiva, la asignación de función, y las reglas constitutivas. Estos elementos, posibilitados por el lenguaje proposicional (Searle no estaría de acuerdo en éste punto, pero es una de nuestras tesis centrales), son los que nos permiten a los seres humanos desarrollar un mundo social. Una tesis sobre filosofía de la sociedad -como la presente-, debe preguntarse básicamente, ¿qué es lo social? Para responder esa pregunta básica tuvimos que responder una pregunta más básica aún: ¿qué somos los seres humanos?; y ello es así porque estamos convencidos de que somos los seres humanos los que hacemos la sociedad; y ello es posible gracias a ciertas características que son no sólo fundamentales sino también exclusivas de nuestra especie animal. Los delfines, los simios y las abejas no han sido capaces de crear un mundo social e institucional. Pero así y todo, gran parte de las conductas de los simios son idénticas a las nuestras; entonces, ¿qué plus tenemos?, ¿qué les falta al resto de los animales de nivel superior? Esas son las preguntas que guían nuestro trabajo porque son las preguntas que guían -y debieran guiar-, una reflexión sobre los seres humanos y la sociedad.

Searle tiene la capacidad de visualizar los problemas centrales para presentar una teoría de la sociedad. Nuestras diferencias radican en el tratamiento de algunos de esos problemas, pero, más allá de eso, rescatamos la sencillez y la claridad con la que presenta sus argumentos, y los problemas fundamentales que distingue. Hasta aquí, hemos analizado tanto su realismo externo, como al lenguaje humano; a estos problemas le hemos dedicado estos cinco primeros capítulos, hemos visto sus características 
generales y sus especificidades. Con el objetivo de proseguir este análisis crítico de la obra de Searle, en los siguientes capítulos (seis, siete y ocho), daremos cuenta, como hemos dicho, de la intencionalidad colectiva, de la asignación de función y de las normas constitutivas respectivamente. Comencemos por la intencionalidad colectiva. 


\section{Capítulo 6: La intencionalidad colectiva}

\section{Planteamiento del problema}

Como hemos hecho referencia más arriba, otro de los temas centrales que aborda Searle en su construcción de una teoría de lo social (o una ontología de lo social), es el de la intencionalidad colectiva. Searle desarrolla sus argumentos al respecto, principalmente en The construction of social reality, en el año 1995 (1997); en Mind, Language and Society de $1998(2004)^{79}$ y en su última obra, Making the Social Word de 2010. Principalmente nos centraremos en la primera de éstas obras, La construcción social de la realidad.

Allí (1997), Searle comienza a desplegar su argumento del siguiente modo,

Muchas especies animales, la nuestra señaladamente, poseen una capacidad para la intencionalidad colectiva (1997, p. 41. El destacado nos corresponde).

Como vemos, en primer lugar, Searle señala que esta capacidad -la intencionalidad colectiva-, no es privativa de los seres humanos, sino más bien, muchas especies animales la poseen. Pero veamos, ¿a qué nos referimos específicamente cuando hablamos de intencionalidad colectiva? Este tipo de intencionalidad no debe ser confundida con la intencionalidad desde el punto de vista mentalista, con el estar dirigido a, de nuestra conciencia (en el sentido de Husserl y del propio Searle II). Este tipo de intencionalidad no se emparenta con la problemática analizada en el segundo capítulo. Cuando hablamos de intencionalidad colectiva no damos cuenta de un estado mental, sino que nos referimos a un tipo de conducta cooperativa, y además a la capacidad de compartir creencias, deseos e intenciones. Es posible que los seres humanos hagamos cosas juntos porque, además de la intencionalidad individual, poseemos este otro tipo de intencionalidad; ello hace posible que yo haga algo, sólo en tanto que es parte de nuestro hacer algo. Los ejemplos típicos son los juegos en grupo (fútbol, básquet, etcétera), o la ejecución de un instrumento en una orquesta; así, yo juego al fútbol o toco el violín como un integrante de nuestro equipo, de nuestra orquesta. Hasta en los conflictos bélicos está presente este tipo de intencionalidad; yo voy al frente de batalla porque nosotros (aquí, el

\footnotetext{
${ }^{79}$ Las fechas entre paréntesis corresponden a las traducciones al castellano.
} 
nosotros está representado por nuestro Estado $X$ ) le declaramos la guerra al Estado $Y$. Ambos Estados cooperan con el objetivo de hacer algo en común: en éste caso, desarrollar una guerra. Esto es distinto, por ejemplo, a golpear a un desconocido en la vía pública; en este caso, el agresor no está inmerso en una conducta cooperativa sino que unilateralmente ha decidido agredir. El ejemplo anterior también se diferencia de un combate de boxeo en donde, al agredirse con mutuo consentimiento, ambos contrincantes cooperan colectivamente en una misma actividad. ${ }^{80} \mathrm{~A}$ la hora de comprender los hechos sociales, es esencial -según la perspectiva de Searle-, comprender la intencionalidad colectiva (1997, p. 42).

En Making the Social Word (2010), Searle sostiene que la tradición tiende a naturalizar el fenómeno de la intencionalidad; mediante ese proceso le niegan su existencia real. La tendencia a naturalizar la intencionalidad es porque se supone que pensar es tan natural como "hacer la digestión" (pp. 42 y ss.). Estas afirmaciones son altamente llamativas, en primer lugar porque gran parte de la tradición filosófica de los siglos XIX y XX hasta nuestros días se ha ocupado del problema del lenguaje (y del pensamiento); este problema ha acaparado la atención de los filósofos más destacados de los últimos tiempos. Filósofos no sólo provenientes de la tradición analítica como Frege, Russell y Wittgenstein, sino también los continentales, como Heidegger y Gadamer -por citar sólo a los que más han descollado-. La complejidad de sus análisis del lenguaje descarta cualquier tipo de naturalización, jtodo lo contrario! ${ }^{81}$

Una vez planteada la generalidad del problema, nos detendremos en lo que sigue a analizar ciertos puntos críticos. No conformes con la explicación de Searle respecto a la intencionalidad colectiva, recurriremos a la obra de Tomasello porque entendemos que su andamiaje conceptual y las críticas que le realiza a Searle son completamente pertinentes. Además, Tomasello hace algo que Searle no hace: trabajo de campo, trabajo empírico. Como hemos dicho con anterioridad, la filosofía siempre debe tener un ojo en la ciencia para encaminarse hacia la verdad. A continuación aclararemos la perspectiva de uno y otro y pondremos de relieve nuestro propio punto de vista.

\footnotetext{
${ }^{80}$ Una distinción similar es establecida por Max Weber al analizar la acción social. Weber sostiene que no todo contacto entre dos o más personas implica una relación social. Por ejemplo, un choque entre dos ciclistas no implica una relación social; si, por el contrario, los ciclistas intentan evitar el encontronazo, o si desembocaran en una riña o algo por el estilo, sí sería lícito hablar de acción social. Ver al respecto, Max Weber, "Economía y sociedad", FCE, México, 2002, p. 19.

${ }^{81}$ Esto lo sabe Searle; estimo que sus comentarios tienden, en algunas ocasiones, a generar algún tipo de provocación.
} 


\section{¿Intencionalidad colectiva versus Intencionalidad individual?}

¿Cuál es la relación (si es que la hay) entre la intencionalidad individual y la intencionalidad colectiva? ¿Qué relación existe, por ejemplo, entre "yo intento" y "nosotros intentamos"? Hay una tendencia generalizada a considerar las formas de intencionalidad formuladas en primera persona del singular, expresiones tales como, "yo creo", "yo quiero", como fundamentales; sin embargo, en el presente apartado nos detendremos con especial atención en las expresiones formuladas en primera persona del plural, expresiones tales como, "nosotros creemos", "nosotros realizaremos", "nosotros queremos". Estas últimas expresiones reflejan el tipo de intencionalidad que analizaremos con algún detalle, nos referimos a la intencionalidad colectiva. Lo que aquí haremos es, de la mano de Searle, analizar la estructura lógica de la intencionalidad porque sostenemos que es uno de los elementos centrales de toda ontología humana, de toda sociedad en general.

La tradición filosófica -según entiende Searle (1997)-, ha supuesto que el segundo tipo de intencionalidad -la intencionalidad colectiva o del "nosotros"- es reductible a la primera -la intencionalidad individual o del "yo"-. Por ejemplo, para que juguemos un partido de fútbol es preciso, ante todo, que yo tenga la intención, el deseo, la voluntad de jugarlo. Si los veintidós "yo" no tuvieran la intención de jugar el partido, no habría partido posible. La idea es que, si intentamos hacer algo juntos es porque yo lo intento en la creencia de que tú también lo intentarás; lo mismo ocurre contigo: tú lo intentas en la creencia de que yo también lo intentaré. De ésta manera, todos tienen esas creencias. Pero, si la intencionalidad está en la cabeza de cada uno de nosotros, ¿cómo es posible algo así como la intencionalidad colectiva? Gran parte de la tradición entiende a la intencionalidad individual o del "yo" como una intención primaria; Searle, por el contrario sostiene que la intencionalidad primitiva no es la individual o del "yo", sino la colectiva o del "nosotros". La mayoría de los filósofos reducen el "tenemos la intención de", "creemos", "esperamos", a "tengo la intención de", "creo", "espero". Suponen que cuando dos personas tienen intencionalidad colectiva, es decir, cuando intentan hacer algo juntas (o lo hacen efectivamente), cada una de ellas tiene la intencionalidad del tipo, "tengo la intencionalidad de hacer tal y tal cosa" y a la vez, "creo que tú también tienes esa misma intención". Además, tengo que creer que tú crees que yo creo que tú tienes esa intención; eso a su vez, genera una regresión no viciosa del tipo, "creo que tú crees que yo creo que 
tú crees que yo creo", etcétera; mientras que por tu parte, "tú crees que yo creo que tú crees que yo creo que tú crees", etcétera. A estas creencias iterativas sobre creencias de dos o más personas, se las denomina "creencias mutuas". Searle sostiene que todo este enfoque, que reduce la intencionalidad colectiva a la intencionalidad individual más la creencia mutua, está equivocado. En nuestras cabezas existe la intencionalidad colectiva de un modo primitivo. Así, y en palabras de Searle,

\section{La intencionalidad colectiva es un fenómeno biológico primitivo que no puede ser reducido a, o eliminado a favor de, otra cosa. Todos los intentos que yo he visto de reducir la "Nosotros-intencionalidad" a la "Yo-intencionalidad" están plagados de contraejemplos (Searle, 1997, p. 42; los destacados nos pertenecen).}

En esta cita se observa una vez más la posición naturalista de Searle; se entiende a este tipo de intencionalidad como un fenómeno biológico primitivo; así, los seres humanos tenemos la capacidad de hacer cosas juntos, no porque a una cierta edad se nos enseñe que eso es correcto o preferible; es más, no elegimos -en el sentido en el que Tugendhat se refiere a un proceso deliberativo de toma de decisiones posibilitado gracias a la adquisición del lenguaje proposicional- hacer cosas juntos. Simplemente las hacemos. No se trata de una conducta adquirida sino de una determinación biológica.

La razón por la cual la intencionalidad colectiva no puede ser reducida a la intencionalidad individual es que, caer en una explicación circular, a partir de la cual yo creo que tú crees que yo creo, etcétera, no consigue una agregación suficiente para dar cuenta del sentido de colectividad. Una sumatoria de "Yo-conciencias" no constituye, no conforma un "Nosotros-conciencia"; el camino, según el punto de vista de Searle, es inverso. La sumatoria de creencias, deseos, intenciones individuales no crea deseos, creencias e intenciones colectivas; muy por el contrario, las creencias, etcétera, colectivas son las que generan las creencias, etcétera, individuales. La prioridad metodológica, como vemos, es de la intencionalidad colectiva antes que de la intencionalidad individual. Para graficarlo con un ejemplo, yo tengo la intención singular de anotar un gol en un partido de fútbol, pero tengo tal intención como parte de nuestra intención colectiva de anotar goles para ganar el partido. 
Una conducta como la del ejemplo anterior es una conducta genuinamente cooperativa, la cual se diferencia de la conducta de dos personas (o más) que por mero azar están sincronizadas. Si, por ejemplo, en éste mismo momento, en alguna parte del mundo se encontrara un becario (o investigador) confeccionando un trabajo sobre Searle, planteándose los mismos objetivos que nosotros nos hemos planteado, mi conducta y la del becario $X$ no serían conductas cooperativas. Fue el azar y no la decisión conjunta de abordar ciertas problemáticas, el responsable de la escritura de "la misma" tesis sobre Searle.

Searle advierte un rechazo por parte de la tradición a reconocer en la intencionalidad colectiva un fenómeno primitivo. Generalmente se sostiene que toda intencionalidad existe en la cabeza individual de las personas, de ahí se sigue que la forma de esa intencionalidad sólo puede referirse a los individuos en cuyas cabezas existe. Esta manera de ver las cosas, continúa Searle, parece comprometer a quienes reconocen el carácter colectivo de la intencionalidad, con un elemento supra-natural o místico que se ubica por fuera y por sobre las mentes individuales (1997, p. 43). Searle sostiene que este argumento es falaz e inscribe un falso dilema. Para suplir esta falla, propone el siguiente argumento,

Es verdad que toda mi vida mental está dentro de mi cerebro, y que toda la vida mental de ustedes está dentro de su cerebro, y lo mismo vale para todo el mundo. Pero de aquí no se sigue que toda mi vida mental tenga que ser expresada en la forma de una frase nominal singular referida a mí. La forma que mi intencionalidad colectiva puede tomar es simplemente ésta: "nosotros intentamos", o "estamos haciendo esto y lo otro", etc. En esos casos, yo intento sólo como parte de nuestro intento. La intencionalidad que existe en cada cabeza individual tiene la forma "nosotros intentamos" (1997, p. 43).

Cuando Searle escribió La construcción de la realidad social en el año 1995, ya se encontraba sólidamente situado dentro del enfoque mentalista o internista. Ya hemos dejado en claro en los capítulos anteriores, que no es ésta la posición que aquí adoptaremos. Para aquel que asuma como prioritario y fundamental la función del 
lenguaje proposicional, le resultan extrañas ciertas expresiones tales como, "mi vida mental esta dentro de mi cerebro". Esto sólo puede ser concebido como una metáfora porque dentro de mi cerebro no hay más que tejido neuronal; si bien el cerebro -como todo órgano-, tiene sus funciones específicas, nos resulta difícil sostener la idea de que dentro de nuestras cabezas individuales existe tal y tal cosa. Hay intencionalidad colectiva, de eso no hay dudas; hacemos cosas juntos, generamos acuerdos y renunciamos a nuestro ego al emprender tareas colectivas o cooperativas. Todo eso es cierto pero, ¿cómo es posible? Esa es nuestra pregunta, es la pregunta de Searle; pero entendemos que sus argumentos deberían reverse. Searle deja muy en claro lo que quiere decir. En La construcción de la realidad social (1997, p. 44) grafica las dos posiciones referidas a la existencia de la intencionalidad colectiva.

El siguiente gráfico muestra la posición tradicional de las "Nosotros-intenciones":

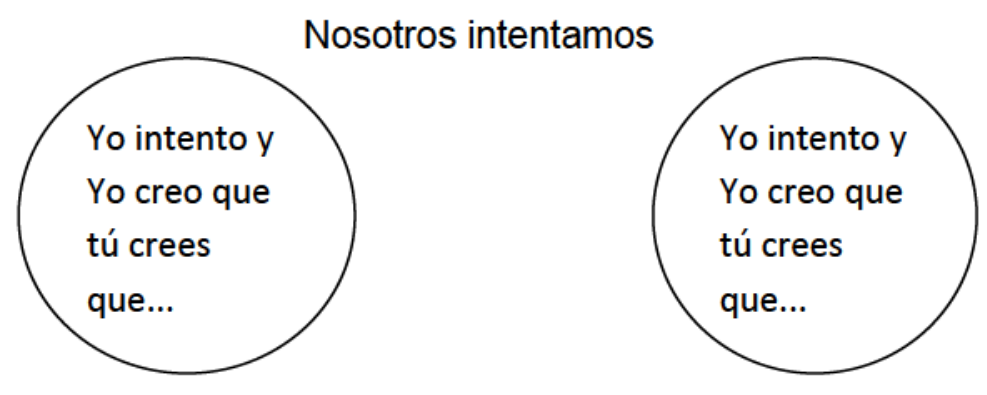

La alternativa de Searle es la siguiente:
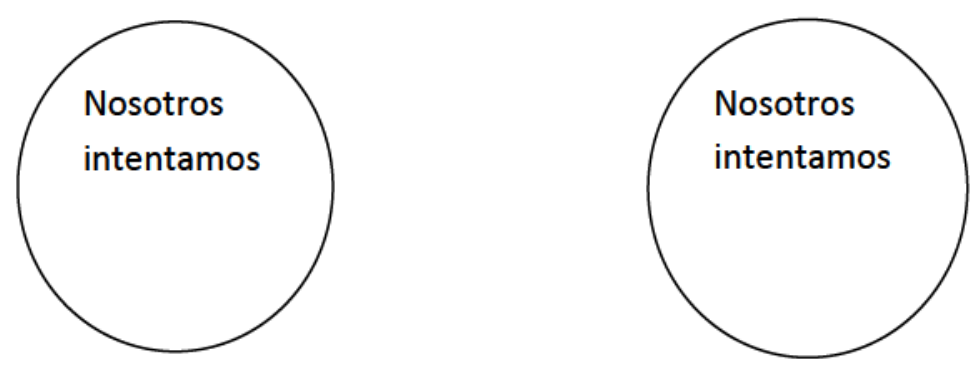

Observamos que Searle entiende que la intencionalidad del nosotros no es el resultado de la sumatoria de intencionalidades individuales sino que aquella ya existe de un modo primigenio en nuestras cabezas. Pero, ¿Qué significa que algo existe dentro de nuestras cabezas? Para aclarar éste punto oscuro recurriremos al análisis de los lineamientos centrales que Tomasello desarrolla al respecto. 


\section{El cooperativismo en Tomasello. Una aproximación}

Tomasello, desde el punto de vista de la psicología cognitiva, despliega tanto un análisis ontogenético como filogenético de nuestra especie. Con el objetivo de abarcar una mejor comprensión del problema de la intencionalidad colectiva, analizaremos algunos de sus argumentos principales. Searle vio el problema, pero el modo en que lo aborda nos resulta un tanto insuficiente porque decir que la "Nosotros-intencionalidad" existe porque está dentro de nuestras cabezas, nos resulta, por lo menos, un tanto vago.

En ¿Por qué cooperamos? (2010), Tomasello, inspirado tanto en el propio Searle, como en Michael Bratman (1992), Margaret Gilbert (1989) y Raimo Tuomela (2007), sostiene que con el concepto Intencionalidad compartida o del nosotros se hace referencia a ciertos fenómenos psicológicos que posibilitan ciertas formas de cooperación; en palabras de Tomasello,

\section{Básicamente, la intencionalidad compartida comprende la capacidad de generar con otros intenciones y compromisos conjuntos para las empresas cooperativas (2010, p. 15).}

Podemos comprometernos e intentar hacer actividades con otros por medio de procesos de atención conjunta y conocimiento mutuo, los cuales, a su vez, son posibles gracias a las motivaciones cooperativas de ayudar a otros y compartir cosas con ellos (2010, p. 15 y 16). La capacidad de cooperación -a diferencia de lo que plantea Searle-, es exclusivamente humana; recordemos que al comienzo del presente apartado citábamos a Searle cuando afirmaba que la intencionalidad colectiva era común a muchas especies animales. Tomasello $\left(2007,2010\right.$ y $\left.2010^{a}\right)$ no está de acuerdo con el planteo de Searle, puesto que sostiene que las formas de vida de otras especies animales (a ello Tomasello lo denomina culturas) se basan exclusivamente en la imitación y otros procesos de aprovechamiento, pero las culturas humanas tienen un plus: la cooperación. La intencionalidad colectiva (el cooperativismo) es, tanto para Searle como para Tomasello, el fundamento de todas las actividades sociales. Y ello es así porque, 
Los Homo sapiens están adaptados para actuar y pensar cooperativamente en grupos culturales hasta un grado desconocido en otras especies. De hecho, las hazañas cognitivas más formidables de nuestra especie, sin excepción, no son producto de individuos que obraron solos sino de individuos que interactuaban entre sí (...) (Tomasello, 2010, p. 17. El destacado le corresponde a Tomasello).

Nuestra especie cuenta con habilidades exclusivas para colaborar, comunicarnos y aprender socialmente; ese tipo especial de inteligencia cultural los niños la van desarrollando a medida que crecen. De este modo se va construyendo la capacidad humana de participar en lo que Tomasello $(2007,2010)$ denomina el pensar grupal cooperativo. Ello sólo fue posible gracias a la enorme capacidad de adaptación a distintas formas culturales que poseen los seres humanos.

Con el objetivo de echar luz sobre los orígenes de la cognición humana, Tomasello, en sus distintas investigaciones $(2007,2010$ y 2010 $)$, desarrolla una serie de comparaciones entre los niños y sus parientes más próximos dentro de los primates, los chimpancés. Sus conclusiones, por lo tanto, no sólo cubren los aspectos ontogenéticos, sino también -al desplegar una historia evolutiva de la especie humana-, los filogenéticos. Las investigaciones empíricas que Tomasello desarrolla se focalizan en dos fenómenos fundamentales, el altruismo (el individuo que se sacrifica por otro) y la colaboración (cuando varios individuos trabajan juntos para beneficio mutuo).

Una de las tesis centrales de Tomasello en, ¿Por qué cooperamos? (2010) es la siguiente,

...a partir del primer año de vida -cuando empiezan a caminar y a hablar y se van transformando en seres culturales-, los niños ya muestran inclinación a cooperar y hacerse útiles en muchas situaciones, aunque no en todas. Además, no aprenden esa actitud de los adultos: es algo que les nace (p. 24. El destacado es mío). 
Tomasello deja en claro que el cooperativismo en los infantes no se adquiere, no se aprende sino que a los niños les nace, es decir, es producto del desarrollo ontogenético de los seres humanos. Los niños tienen una predisposición prácticamente indiscriminada por cooperar que, con el paso de los años se va viendo afectada por el juicio de otros niños y por la preocupación por la opinión de otros miembros del grupo. Paulatinamente los niños comienzan a internalizar normas sociales y reglas de conducta que van prefigurando qué hacer y cómo dirigirse en la vida con otros ${ }^{82}$.

Tras realizar una serie de experimentos con infantes, Tomasello destaca cinco razones para suponer que ayudar a otros en la resolución de problemas físicos simples, surge naturalmente en la conducta de los seres humanos, i) La primer razón es que ese tipo de comportamiento aparece a una edad temprana: entre los 14 y los 18 meses; ii) la segunda, es que los premios y los elogios de los padres parecen no influir en la conducta de los infantes. En los experimentos de Tomasello, el aliento de los padres no influía en la conducta de los niños; se mostraban o no dispuestos a ayudar cuando los incitaban a hacerlo o no. Lo que ocurre es que la motivación intrínseca determina el comportamiento, más que los premios e incentivos que los adultos pueden ofrecerles. Es más, ciertos experimentos desplegados por el psicólogo de Stanford, Mark Lepper, y por Félix Warneken -colega de Tomasello en el Instituto Max Planck-, demuestran que cuanto más se recompensa a los infantes por sus tareas, su capacidades de colaboración se ven afectadas y hasta se reducen; iii) la tercer razón para demostrar que los infantes no brindan ayuda para obtener una recompensa o congraciarse con sus padres es que los chimpancés muestran el mismo comportamiento. Así lo demuestra un experimento que Warneken y Tomasello han realizado en conjunto ${ }^{83}$; allí tres chimpancés criados por humanos ayudaron a individuos humanos acercándoles objetos que se encontraban fuera de su alcance. Este estudio puede generar algún tipo de dudas porque los simios fueron criados por humanos; sin embargo en otros experimentos, los mismos investigadores han observado conductas cooperativas en simios criados en su hábitat natural. Lo que Tomasello pretende demostrar es que si los chimpancés, que son nuestros parientes más cercanos, tienen actitudes de colaboración similares a las nuestras es porque,

\footnotetext{
${ }^{82}$ Esto no significa que no haya lugar para el egoísmo (también en los niños). La preocupación por la propia supervivencia es necesaria para dejar descendencia y que el grupo no se extinga. Tanto la cooperación como el afán por ser útiles a otros miembros, descansan sobre una base de necesario egoísmo.

${ }^{83}$ Warneken, F. y M. Tomasello, "Altruistic helping in human infants and young chimpanzees", Science 311 (5765): 1301-1303. Citado en M. Tomasello, ¿Por qué cooperamos?, editorial Katz, Bs. As., 2010. Hay videos que registran este comportamiento en <bostonreview.net/whywecooperate>.
} 
...el comportamiento altruista de los seres humanos no es producto del ambiente cultural que nos caracteriza (2010, $p$. $32)$.

Poner esto de relieve al intentar abordar un estudio de la ontología de lo social es altamente renovador; y lo es porque generalmente se buscan causas y explicaciones que nada tienen que ver con la ontogénesis y filogénesis. Pero así se deja afuera gran parte del problema. La vida humana es tanto cultural como biológica y todo estudio que no contemple alguno de los dos aspectos estará incompleto. iv) La cuarta razón se fundamenta en un estudio embrionario de Tomasello y su equipo del Instituto Max Planck; allí se comprobó que los niños de culturas más tradicionales (donde la intervención paterna es mucho menor) brindan ayuda en las mismas situaciones y a la misma edad que los niños criados en las clases medias occidentales; $v$ ) la quinta y última razón muestra que la actitud de ayuda de los niños está mediada por el interés empático. Ciertos estudios han demostrado que ante una situación en la que un adulto era injusto con un infante, el resto de los niños presentes se mostraban "preocupados" y ayudaban a la víctima (Tomasello, 2010, pp. 32 y 33). Lo anterior demuestra que los niños no necesitan incentivos externos para ayudar, sino que tienen un interés por el otro. Un interés que, como decíamos más arriba, les nace. Con todo lo anterior, Tomasello concluye que,

$$
\begin{aligned}
& \text { Por estas cinco razones (...) creemos que la temprana } \\
& \text { inclinación por ayudar que muestran los niños no es } \\
& \text { producto de la cultura ni de las prácticas de socialización } \\
& \text { paternas. Por el contrario, es una inclinación natural por } \\
& \text { comprender la situación de otros cuando están en } \\
& \text { dificultades (2010, pp. } 33 \text { y } 34 \text {. El destacado me pertenece). }
\end{aligned}
$$

Esta inclinación natural temprana por ayudar, que muestran los infantes de nuestra especie, también es compartida por nuestros parientes más cercanos pero, sin embargo, hay una forma específica de ayudar que sólo los niños humanos practican: brindar información que es necesaria para otro (Tomasello, 2010, p. 34). Esto lo hacen los niños antes de la revolución de los dieciocho meses, es decir, antes de haber adquirido el lenguaje proposicional. A los doce meses de edad los seres humanos brindan 
información prelingüística señalando. Lo significativo es que ni los chimpancés ni otros grandes simios señalan cosas para brindar información a otro, ni para llamar la atención de sus compañeros, no utilizan ningún medio de comunicación para ofrecer datos que le puedan llegar a servir a otros. Esta práctica, por lo tanto, es específicamente humana y se desarrolla a temprana edad ${ }^{84}$.

Tras una serie de experimentos llevados a cabo por Liszkowski, Carpenter, Striano y Tomasello (2006), realizado con niños de doce a dieciocho meses ${ }^{85}$, quedó claro que los infantes de esa edad comprenden claramente la acción de señalar para brindar información, sin embargo, no ocurre lo mismo con los simios. Cuando los simios se comunican con seres humanos, generalmente lo hacen para que les alcancen alimentos; el móvil de sus gestos siempre es dirigir sus actos, se trata de gestos imperativos. Los simios que han sido criados por seres humanos y han aprendido alguna clase de comunicación similar a la nuestra, usan ciertos gestos para comunicarse con humanos (sólo para dirigir sus actos), pero jamás los emplean para comunicarse con otros simios ${ }^{86}$. A ello, Tomasello agrega,

Tal vez sorprenda saber que los grandes simios ni siquiera comprenden el acto de señalar cuando se lo utiliza con fines informativos. Siguen la mirada y los gestos que apuntan a objetos visibles, pero aparentemente no comprenden la intención comunicativa $(2010$, p. 38).

Los simios no comprenden por qué un humano les señala un objeto determinado, no entienden el por qué de la acción ni su pertinencia; por supuesto que ello es esperable porque en el mundo de los simios ningún individuo le señala a otro un objeto con el fin de llamar su atención. En el mundo de los simios no se da aquello que Tomasello denomina

\footnotetext{
${ }^{84}$ Este elemento podría ser algo así como el requisito para adquirir, posteriormente, el lenguaje proposicional.

${ }^{85}$ Liszkowski, Carpenter, Striano y Tomasello, Journal of Cognition and Development 7 (2), 173-187, 2006. Citado por Tomasello, 2010, p. 35-36.

${ }^{86}$ Ver al respecto la investigación con niños de doce a dieciocho meses antes mencionada, como así también la realizada por Leavens, Hopkins y Bards, “Understanding the point of chimpanzee pointing: Epigenesis and ecological validity", Current Directions in Psychological Science 14 (4): 185-189, 2005. Citado por Tomasello, 2010, p. 36; Call y Tomasello, "The production and comprehension of referential pointing by orangutans", Journal of Comparative Psychology 108 (4) 307-317, 1994; así también, Bullinger, Kaminski, Zimmerman y Tomasello, "Different social motives in the gestural communication on chimpanzees and human children", artículo presentado para su publicación.
} 
atención conjunta [joint attention], y que más adelante analizaremos. Los humanos, por su parte, comprenden los señalamientos con fines informativos y realizan inferencias entre los doce y los catorce meses de edad, es decir, antes de saber hablar. Esa comprensión prelingüística es la necesaria para que, posteriormente, los infantes sean capaces de incorporar el lenguaje proposicional.

Volviendo al problema de la cooperación, los estudios de Tomasello confirman empíricamente que los seres humanos intentan ayudar brindando información que es pertinente para sus interlocutores y no para sí mismos; esto es la confirmación científica del principio de cooperación enunciado por Paul Grice ${ }^{87}$. En el mundo de los simios, no existe nada parecido a la cooperación griceana. Cuando los simios descubren alimento $o$ a un predador, lanzan gritos, esos gritos no tienen por finalidad informales al resto del grupo una situación determinada, porque esos gritos se lanzan aún cuando el resto de los integrantes del grupo se encuentran presentes. El objetivo de esas situaciones, evidentemente, no es brindar información puesto que el resto de los individuos ya están enterados. Lo que hacen, lo hacen en beneficio propio o de sus parientes. Los infantes de nuestra especie, muy por el contrario, brindan información con la intención de brindar ayuda e interpretan con exactitud las intenciones informativas de aquellos que los rodean. En un estudio reciente de Grosse, Moll y Tomasello, un investigador le pidió a un grupo de niños de veinte meses que le alcanzasen "la batería"; en la habitación se encontraban dos baterías, una frente al investigador y la otra en el otro extremo. Si los niños hubieran interpretado la orden de una manera simple y llana, lo mismo hubiera dado alcanzarle una u otra, sin embargo le alcanzaron la que se encontraba en el otro extremo de la habitación porque interpretaron la orden como un pedido de ayuda; ello implica que, muchas veces, el modo imperativo conlleva un pedido de ayuda que se fundamenta en la lógica cooperativa de la colaboración ${ }^{88}$.

Como vemos, la actitud de ayudar y brindar información aparece en los niños a muy temprana edad y de un modo natural. Por supuesto, también a una temprana edad los niños aprenden a mentir. La mentira sólo puede aparecer, sin embargo, luego y porque ya existe previamente la confianza y la cooperación. Si los seres humanos no fuéramos proclives a confiar, la mentira no tendría asidero alguno. Mentimos porque tendemos a creer en lo que hacen y dicen los otros.

\footnotetext{
${ }^{87}$ Consideramos que siempre es necesaria una contrastación empírica; la última palabra no la tiene la filosofía sino la ciencia. Así, se evitan teorías y supuestos que no se verifican en la realidad.

${ }^{88}$ Grosse, Moll y Tomasello, "21-month-olds understand the co-operative logic of request", artículo presentado para su publicación. Citado por Tomasello, 2010, pp. 41 y ss.
} 
Si bien los animales humanos son proclives al altruismo, no ocurre lo mismo con el resto de los monos antropoideos; éstos se muestran muy poco altruistas cuando se trata de compartir recursos escasos como los alimentos. Si bien es cierto que la generosidad de los seres humanos también depende de la situación (si por ejemplo, yo me encontrara en el desierto con una botella de gaseosa sería muy poco generoso y difícilmente la compartiría), los distintos estudios levados a cabo por Tomasello y su equipo demuestran que,

...los niños son más generosos que sus parientes antropoides con los alimentos y los objetos que valoran (2010, p. 44).

Esta generosidad humana también se observa en el modo en que comparten el alimento las madres con sus crías. Ciertos estudios citados por Tomasello demuestran que la mayoría de las madres chimpancé no colaboran en la obtención de alimento de sus crías; ellos deben arreglárselas solos. Las pocas veces que las madres les brindaban alimentos a sus crías, se trataba de las porciones menos apetitosas, cáscaras de frutos, desperdicios o cortezas. Ceder alimentos demuestra que está presente en los simios cierto instinto maternal. La diferencia entre ellos y nosotros los humanos, es únicamente de grado. Los humanos hambrientos tampoco comparten su alimento; los chimpancés actúan como humanos siempre hambrientos.

En lo que sigue, nos detendremos en ciertos aspectos de la ontogenia humana que consideramos importantes. Para cooperar con, y hacer algo con otro debo, en primer lugar, reconocer a ese otro como un sujeto intencional con las mismas capacidades cognitivas que yo poseo. Esta aptitud cognitiva no surge una vez de repente en la ontogenia humana y se mantiene inmutable a lo largo del tiempo; muy por el contrario, la comprensión humana de que los otros son seres con los mismos estados intencionales surge hacia los nueve meses de edad y comienza a manifestarse paulatinamente a medida que el niño va incorporando en forma activa las distintas herramientas culturales que su comprensión le permite emplear. La herramienta más importante, como venimos analizando, es el lenguaje orientado por convenciones.

\section{La cognición y la comprensión del infante}


No es casual que un filósofo tan lúcido como Williams James, describiera el mundo de los infantes como "una tremenda y ruidosa confusión". Solía creerse que el mundo de los bebes humanos poseía un bajo nivel perceptivo. Debido a que los sistemas visuales y auditivos (entre otros) se encontraban en pleno desarrollo, sus capacidades eran reducidas y las probabilidades de captar el entorno cultural, extremadamente bajas. Sin embargo, a partir de la década del ochenta, los psicólogos evolutivos descubrieron que los infantes de pocos meses poseen una serie (nada desdeñable) de habilidades cognitivas. Estas habilidades o aptitudes se relacionan con la comprensión de otros objetos, de las otras personas y de sí mismos.

En su obra clásica sobre la infancia, The origins of intelligence in children (1952), Piaget sostenía que los infantes humanos no tienen comprensión alguna de la existencia de un mundo físico independiente, a una edad que no coincide con las primeras manipulaciones de objetos. Ciertos investigadores que han cuestionado fuertemente la posición piagetiana han sostenido lo contrario; tanto los trabajos de Baillargeon $\left(1995^{89}\right)$, como los de Spelke $\left(1990,1992,1997^{90}\right)$, Haith y Benson $\left(1997^{91}\right)$, tienden a sostener, entre otras cosas, que los niños hacia los tres o cuatro meses aproximadamente, exhiben una comprensión de los objetos como entidades independientes, como entidades que existen aún cuando no están siendo observadas; también comprenden ciertas propiedades básicas de los objetos como, por ejemplo, que no pueden ocupar dos espacios distintos a la vez. De éste modo, y siguiendo a Tomasello $\left(2007,2010\right.$ y $\left.2010^{a}\right)$, observamos que los infantes humanos, a una temprana edad, poseen habilidades en lo que se refiere a la permanencia de los objetos, los mapas cognitivos, la categorización perceptual, la estimación de pequeñas cantidades y la rotación mental de objetos; poseen estas capacidades, se supone, porque su comprensión representacional de objetos en el espacio es idéntica a la de los humanos adultos. Los bebes humanos ponen en práctica lo que han heredado de los primates pero, ponerlo en práctica les lleva algún tiempo (Tomasello, 2007, pp. 79-80).

\footnotetext{
${ }^{89}$ Baillargeon, R, (1995), "Physical reasoning in infancy", en M. Gazzaniga, ed., The cognitive neurosciences, pp. 181-204, Cambridge, MA: MIT Press.

${ }_{90}^{90}$ Spelke, E., (1990), “Principles of object perception”, Cognitive Science 14, pp. 29-56. Spelke, E., Breinliger, K., Macomber, J. y Jacobson, K., (1992), “Origins of knowledge”, Psychological Review 99, pp. 605-632.

Spelke, E. y Newport, E. (1997), "Nativism, empiricism, and the development of knowledge", en R. Lerner, ed., Handbook of child psychology, vol. 1, Nueva York: Wiley.

${ }^{91}$ Haith, M. y Benson, J. (1997), "Infant cognition”, en D. Kuhn y R. Siegler, eds., Handbook of child psychology, vol. 2, Nueva York: Wiley.
} 
Ahora bien, es muy distinta la comprensión que los infantes humanos tienen de los objetos físicos, de aquella que se vincula a otras personas, a objetos animados. Si bien contamos con poca información al respecto, sabemos que los humanos, a pocas horas de haber nacido, dirigen selectivamente la mirada hacia rostros humanos y reconocen en las otras personas a seres animados, distintos de los objetos físicos. Todo ello también es realizado por los primates no humanos. Sin embargo, Tomasello (2007), distingue dos tipos de conductas que se diferencian de las conductas sociales que también poseen los primates. Estas conductas humanas son conductas "ultrasociales". Veamos.

En primer lugar, poco después del nacimiento, los infantes humanos comienzan a entablar "protoconversaciones" con quienes los cuidan. Estas protoconversaciones son interacciones sociales en las que los progenitores concentran su atención en el infante y éste en aquéllos. En éste tipo de interacción social, por otro lado, las partes actúan por turnos. Este modo embrionario de "conversar" parece constituir un tipo universal de vinculación entre adultos e infantes. Estas interacciones, a pesar que Tomasello no las considera intersubjetivas porque los sujetos humanos no llegan a concebir a los otros como sujetos de experiencia, sino hasta los nueve meses, son profundamente sociales no sólo porque las partes intervienen por turno, sino también porque poseen un alto contenido emocional.

En segundo lugar, durante estas interacciones sociales los humanos neonatos imitan ciertos movimientos corporales de los adultos -en especial los de la boca y la cabeza-. Estas imitaciones, quizás no signifiquen una mera reproducción de movimientos conocidos, sino una "identificación" con los otros miembros de la especie. De este modo, Tomasello (2007) alcanza la siguiente hipótesis,

A poco de nacer, los infantes humanos manifiestan una fuerte sintonía social con sus cuidadores, que se refleja en su tendencia a interactuar de una manera recíprocamente sensible en protoconversaciones y que requiere operaciones de igualación cuando tratan de reproducir conductas de los adultos (p. 82).

Al interactuar con su entorno físico y social, los neonatos humanos se percatan de la propia existencia; al dirigir su atención a entidades externas, tienen conciencia de sus propias metas conductuales y del resultado de sus acciones en esas entidades, logrando 
advertir si sus acciones son consentidas o rechazadas. Así, por ejemplo, los infantes humanos se rehúsan a asir un objeto que se encuentra demasiado lejos o que requiere un cambio desestabilizador de la posición corporal. A ello se lo denomina "self-ecológico". De todos modos, es posible que los infantes humanos compartan esta habilidad con los primates no humanos; la cantidad de estudios al respecto no es abundante y se torna difícil establecer cuál es, a temprana edad, el significado de un self-social.

En un momento del desarrollo evolutivo, los seres humanos experimentan una verdadera revolución en su manera de entender el mundo, especialmente el mundo social. Ese momento es alrededor de los nueve meses de edad. Es en este momento cuando ya no quedan dudas de la enorme brecha que separa a los primates humanos de los no humanos; es aquí cuando las diferencias se agudizan. Se trata del momento nodal que, tras años de aprendizaje, permitirá establecer una serie de diferencias respecto a nuestros ancestros más cercanos, los chimpancés. A partir de los nueve meses, los primates humanos comienzan a formar parte de aquello que Michael Tomasello denomina, conductas de atención conjunta [“joint attention”] (2007, 2010, 2010). Lo fundamental en este proceso es que los infantes,

Han comenzado a comprender que, al igual que ellos, las otras personas son agentes intencionales cuyas relaciones con entidades externas se pueden acompañar, dirigir o compartir (Tomasello, 2010, pp. 83-84).

Entre los nueve y los doce meses de edad, las conductas de los niños pasan de ser diádicas a triádicas. Hasta ese momento los infantes humanos, cuando interactuaban con un objeto, y un adulto se encontraba a su alrededor, lo ignoraban por completo, dedicándose exclusivamente a interactuar con el objeto en cuestión; del mismo modo, si se encontraban interactuando con un adulto y se encontraba un objeto cerca, también lo ignoraban por completo. Pero a partir de los nueve meses aproximadamente, comienzan a incluir la coordinación entre los objetos y los adultos que se encuentran a su alrededor; ello da por resultado un triángulo referencial entre el niño, el adulto y el objeto o acontecimiento que concita su atención. Las conductas pasan de ser diádicas a ser triádicas. A este nuevo tipo de relaciones sociales que el infante es capaz de entablar, se lo denomina atención conjunta. A esta edad, y en palabras de Tomasello, los niños 
comienzan a "estar en sintonía" con los adultos y con los objetos con los que los adultos se relacionan $\left(2007,2010^{a}\right)$.

También a esa misma edad, los infantes humanos comienzan a emplear gestos deícticos para dirigir la atención y la conducta de los adultos. Estas conductas comunicativas, le permiten al niño que los adultos dirijan la mirada hacia una entidad externa a la que ellos le están prestando atención. Observamos cómo, además de las conductas diádicas (por ejemplo, levantar los brazos para que un adulto los alce, conducta que es idéntica a la de los chimpancés), comienzan a establecer conductas triádicas, en las que logran conjugar la propia atención y la del adulto hacia un objeto o situación externa. De éste modo, Tomasello afirma que,

... el simple acto de señalar un objeto a alguien con el único propósito de atraer la atención sobre él es una conducta comunicativa exclusivamente humana... (2007, p. 85).

En este punto cabe preguntarse por qué ocurre esta revolución a los nueve meses. Si bien es cierto que los infantes humanos son ampliamente más sociales que los no humanos -y muestra de ello son las protoconversaciones y la imitación neonatal-, estas actividades no implican la atención conjunta ni ninguna otra forma de comprensión de los demás como agentes intencionales. Es preciso entonces analizar la relación (si es que la hay) entre estos procesos cognitivos tempranos y otros posteriores, y por qué culminan en los nueve meses, al comprender que los demás también son agentes intencionales. Lo primero que debemos aclarar es que el proceso en el cual surgen las habilidades para la atención conjunta entre los nueve y los doce meses es un proceso evolutivo coherente que requiere una explicación evolutiva coherente. Pero la presente no es una tesis sobre los procesos cognitivos tempranos sino más bien una tesis sobre la ontología de lo social. La referencia a la ontogénesis y a la filogénesis no es un objeto en sí mismo para nuestro trabajo, sino que es un elemento (muy importante por cierto) a tener en cuenta; por eso mismo lo abordamos. Por el contrario, sí buscamos claridad en un punto que consideramos central para el presente estudio; nos referimos a la construcción del nosotros en los seres humanos, y sus diferencias con el resto de los animales de nivel superior. Con tal fin, a continuación abordaremos una vez más dicha problemática contrastando la posición de Searle con la de Tomasello. Veamos. 


\section{Sobre el "nosotros"}

A diferencia de Searle, Tomasello $(2007,2010)$ sostiene que el resto de los animales de nivel superior no poseen un sentido del nosotros; no hay, por lo tanto, intencionalidad colectiva. El sentido exclusivamente humano del nosotros puede ser observado, no sólo en el mundo institucional de los supermercados, las tarjetas de crédito y los gobiernos; está presente en ejemplos mucho más simples. Tomasello (2010, pp. 77 y 78$)$ presenta la siguiente situación. Supongamos que dos personas acuerdan ir juntas a una tienda. En un punto del trayecto, y sin advertencia previa, uno de ellos decide apartarse y tomar arbitrariamente otro camino. Sin dudas, el sujeto "abandonado" se sentirá sorprendido, disgustado, y, al llegar a su hogar, comentará el hecho a sus amigos y parientes. Les dirá que iba caminando junto a un conocido rumbo a la tienda y que "unilateralmente quebró el acuerdo", que ha abandonado el "nosotros" por puro egoísmo o porque la otra persona esta trastornada. Lo interesante del ejemplo es que todo se hubiera solucionado si el acompañante simplemente se hubiera "despedido", si hubiera dado una excusa, una explicación para quebrar el "nosotros".

Se le podría replicar a Tomasello que sí existen actividades mutualistas y de cooperación dentro del mundo animal no-humano; ello se observa cuando, por ejemplo, los chimpancés salen a cazar en grupo a los monos colobos en los árboles del bosque Tai, en Costa de Marfil. En ese caso, los chimpancés tienen las dos características fundamentales en toda cooperación, i) los participantes poseen una meta común y, ii) los participantes coordinan sus roles respectivos. Sin embargo, según Tomasello, nada de ello ocurre, puesto que en la caza cada animal ocupa el lugar que más le conviene,

Durante ese proceso [la caza], cada participante intenta optimizar sus probabilidades de agarrar la presa, sin que exista ninguna meta preestablecida, ningún plan previo ni asignación de roles (...) Cada uno de los monos antropoides participa de la actividad grupal como "yo", no como "nosotros" (2010, pp. 82 y 83).

A diferencia de los chimpancés, los humanos delinean metas conjuntas con sus compañeros y lo hacen a temprana edad, muy poco después de cumplir un año. 


\section{Palabras finales}

Searle, no realiza la precedente distinción conceptual y sostiene que cuando dos o más agentes "hacen algo juntos", tienen ya intencionalidad colectiva; cuando ello ocurre, Searle habla de hecho social. Los hechos sociales, dentro de su esquema conceptual, y como podemos suponer, no son privativos de los seres humanos; los animales que cazan juntos, los pájaros que se agrupan para confeccionar sus nidos, las hormigas y las abejas que trabajan conjuntamente, también poseen intencionalidad colectiva. Searle, sin embargo, no deja de suponer que los seres humanos tienen una notable y específica capacidad que les permite pasar de los hechos sociales a los hechos institucionales. Los seres humanos hacen algo más que la mera participación física; también hablan entre sí, se casan, crean estados, poseen propiedades, utilizan dinero.

Aquí, por nuestra parte, nos encontramos más cercanos a la posición de Tomasello puesto que sostenemos que no sólo los hechos institucionales son privativos de los seres humanos, sino que también los hechos sociales lo son. En cuanto a la escala de importancia se refiere, sin embargo, estamos de acuerdo con Searle; los hechos sociales son más básicos que los hechos institucionales; éstos suponen la existencia de aquellos para poder desarrollarse. Para decirlo de otro modo, si los seres humanos no fueran sociales serían incapaces de construir las instituciones de los estados, el dinero, los matrimonios, etcétera. Pero la capacidad de separase de la postura estrictamente yoica, y adoptar la posición del nosotros, estableciendo actividades y roles diferenciados, junto con metas específicas y planificadas es una capacidad exclusiva de los seres humanos y no se encuentra en el resto de los animales de nivel superior. Esta característica, junto al lenguaje, la asignación de función y las reglas constitutivas (como veremos en los próximos capítulos), forman parte de ese mínimo porcentaje conductual que nos diferencia a los seres humanos de los primates no humanos. Esa pequeña diferencia es la causa de la ontología social que construimos día a día nosotros, los seres humanos. 


\section{Capítulo 7: Asignación de función}

\section{Introducción}

Hace ya unas décadas Searle viene remarcando una importante distinción a la que ya hemos hecho referencia, pero vale la perna traerla a colación una vez más. En el mundo existen ciertos rasgos que dependen del observador, y otros que existen con total independencia de nuestras representaciones. Mientras que a los primeros los denomina hechos en bruto, a los segundos, hechos sociales e institucionales. Fácilmente es posible caer en el error de establecer una tajante distinción entre naturaleza y cultura. Los hechos en bruto serían los ríos y las montañas (naturaleza), y los hechos institucionales, las universidades y los estados modernos (cultura). No existe en Searle, como bien lo observa Shaeffer (2009), tal oposición porque si la hubiera, "la biología saldría ganando siempre" (Searle, 1997, p. 231). Los hechos institucionales, argumenta Searle, suponen a los hechos en bruto. Pero no nos adelantemos en el análisis. Aclaremos mejor qué entiende Searle por hechos en bruto y hechos institucionales porque la realidad social sólo puede entenderse a partir de esta distinción.

Nuestra ontología fundamental está constituida por elementos que son independientes de nuestras representaciones, no tenemos dudas de eso y por ello hemos defendido el realismo externo en el primer capítulo. Ejemplos de hechos independientes de nuestras representaciones son las montañas y las moléculas. Pero veámoslo del siguiente modo, en este preciso momento tengo frente a mí un trozo de madera y fibras de celulosa con una determinada masa y una determinada composición química. Tanto la madera como las fibras de celulosa no son creaciones humanas, sino que son rasgos intrínsecos a la naturaleza, y los seres humanos nada tienen que ver en su creación. Sin embargo, ese trozo de madera que tengo frente a mí, es una mesa. $Y$ es una mesa porque la gente lo usa como mesa. Que un trozo de madera no sea un mero "trozo de madera", sino una "mesa" se debe a que sus rasgos son relativos al observador, existe en relación con la intencionalidad de los usuarios, observadores, etc. La distinción de la que aquí se trata es puramente epistémica. En nuestro ejemplo, la mesa es un rasgo del mundo epistémicamente objetivo (ningún hablante competente del castellano llamaría "perro" a una "mesa"); sin embargo, y a la vez, se trata de un rasgo ontológicamente subjetivo porque existe sólo en relación con los usuarios, observadores, fabricantes, propietarios, 
etc. Aclaremos un poco este punto. La existencia de un objeto externo no depende en absoluto de la actitud que tengamos hacia él. El objeto mesa tiene una masa y una composición química determinada que existen intrínsecamente al objeto, en el sentido de que no dependen de ninguna actitud de los observadores, usuarios. Por otro lado, posee otros rasgos que sí dependen de la intencionalidad de los actores: se trata de una mesa. A estos rasgos Searle los denomina relativos al observador, los cuales son ontológicamente subjetivos. Algunos de esos rasgos ontológicamente subjetivos son epistémicamente objetivos. En nuestro ejemplo vemos que no es sólo mi parecer u opinión que este objeto sea una mesa; por el contrario, se trata de un hecho objetivamente apreciable. Pensar, tratar, usar un objeto como mesa es, a la vez, intrínseco a los que así piensan, tratan, usan. Ser una mesa es un rasgo extrínseco al observador, pero los rasgos que les permiten a los observadores crear tales rasgos del mundo son ellos mismos intrínsecos a los observadores (Searle, 1997, p. 30).

Ahora bien, uno podría preguntarse con todo derecho, ¿cómo saber cuándo un rasgo es intrínseco y cuándo es relativo al observador? ¿Cómo es posible clarificar la diferencia entre uno y otro? Una manera sencilla, sostiene Searle, es preguntarse,

¿Podría el rasgo existir si no hubiera habido nunca seres humanos u otras clases de seres sintientes? $(1997$, p. 30).

Mientras que los rasgos relativos al observador sólo existen en relación a las actitudes de los observadores, a los rasgos intrínsecos les tiene sin cuidado los observadores y existen independientemente de ellos. No debemos olvidar, por otro lado, y como hemos hecho referencia más arriba, que las actitudes de usar y observar son ellas mismas intrínsecas. Para decirlo de otro modo, los rasgos intrínsecos de la realidad son aquellos que existen independientemente de todos los estados mentales; los estados mentales también son rasgos intrínsecos de la realidad. Los siguientes son ejemplos de enunciados verdaderos que formulamos para atribuir al mundo rasgos que existen con independencia de nuestras actitudes o perspectivas, y aquellos enunciados que atribuyen rasgos que sólo existen en relación con nuestros intereses, perspectivas, propósitos, actitudes, etcétera. De éste modo,

1a. Este objeto es una vaca.

1b. Este objeto es un animal sagrado. 
2a. La luna altera el flujo de los mares.

2b. Esta es una hermosa noche de luna.

3a. Los tornados ocurren por el choque de dos frentes, el cálido y el húmedo.

3b. Los tornados son malos para la economía de los estados.

En éstos pares observamos que los primeros términos (los a), enuncian un hecho intrínseco acerca de un objeto; mientras que los segundos pares (los $b$ ), enuncian un hecho relativo al observador acerca del mismo objeto. La distinción entre hechos intrínsecos y hechos relativos al observador, por trivial que parezca, es fundamental a la hora de entender la realidad social.

\section{Asignación de función. Sus tipos}

Los seres humanos tienen una notable capacidad para imponer funciones a objetos, sean objetos naturales u objetos creados para ejecutar una función determinada. Para nosotros, las cosas no se presentan como un conjunto de objetos materiales o moléculas; nuestro mundo, por el contrario, está plagado de sillas, mesas, autos, casas, jardines, plazas, etc. Todos los términos mencionados con anterioridad actúan como criterios de evaluación que son aplicables también a fenómenos naturales tales como los ríos, los mares y las montañas. Así, evaluamos a los objetos como buenos y malos según las funciones que les asignemos. Es evidente que construimos objetos que nos sirven para cumplir con una determinada función, tal es el caso de las sillas, las bañeras y el transporte público. En el caso de los fenómenos naturales como los ríos y los árboles, decimos que "este es un buen río para la pesca" o, "este es un árbol noble". Gracias a estos pocos ejemplos observamos que la asignación de función nunca es intrínseca a los objetos mismos sino que, por el contrario, siempre es asignada externamente por los observadores, usuarios. La tesis de Searle al respecto es que, las funciones nunca son intrínsecas sino relativas al observador (1997, p. 33).

El término función es muy utilizado en disciplinas tales como la biología y la aritmética. En biología, por ejemplo, se tiende a hablar de funciones como si fueran intrínsecas a la naturaleza. Searle asegura que la naturaleza nada sabe de funciones pero, paradójicamente, grafica el enunciado con un ejemplo proveniente de un hecho en bruto. Tal ejemplo es que el corazón tiene por función bombear la sangre hacia el resto del 
organismo; afirma que es un hecho intrínseco a la naturaleza decir que "el corazón bombea sangre" pero, en cambio, cuando decimos algo así como "la función del corazón es bombear sangre", no sólo registramos el hecho empírico sino que estamos haciendo algo más que registrar un hecho empírico. En este último caso estamos dando cuenta de un sistema de valores albergado por una cultura en particular: la positiva valoración de la vida. Ello nos permite hablar de "disfunciones", de corazones "mejores" o "peores". El ejemplo parece endeble, ¿por qué? Si sustituimos "la función del corazón..." por "aquello que hace el corazón", no vemos diferencia entre un enunciado y otro. Distinto es lo que ocurre con los enunciados anteriores del tipo "éste es un buen río para la pesca" o "éste es un árbol noble"; aquí es el hombre el que asigna la buena condición para la pesca y la nobleza de la madera en la construcción de determinados objetos. Los seres humanos son los que le asignan una función determinada al río y al árbol pero, ¿ocurre lo mismo con la sangre? Pareciera que no. No importa si valoramos positiva o negativamente nuestra propia vida, de todas formas, aquello que hace el corazón (es decir, su función) es bombear sangre al resto del organismo. Pero si esto fuera así, ¿por qué hablamos de corazones mejores o peores, pero no de agua mejor o peor? (Salvo que le hayamos asignado al agua una función previa, por ejemplo, que tenga determinados nutrientes necesarios para nuestra alimentación). Al respecto, Searle aclara que,

"Descubrimos", en efecto, funciones en la naturaleza. Mas el descubrimiento de una función natural puede tener lugar sólo en el marco de un conjunto de asignaciones previas de valor (incluyendo propósitos, teleología y otras funciones). (1997: 34).

Y es porque le otorgamos un valor supremo a la vida y al correcto funcionamiento de los organismos, que podemos "descubrir" que la función del corazón es bombear sangre; si nuestra valoración fuera inversa, si valoráramos la muerte y la extinción de los organismos, "descubriríamos" que la disfunción del corazón es bombear sangre. Larry Wright, en su artículo Functions (1973), pretende otorgar una explicación que abarque tanto a las funciones de la naturaleza como a las de la conciencia; para ello, define la función del siguiente modo:

La función de $X$ es $Z$ significa: 


\section{X existe porque existe $Z$.}

2. Z es una consecuencia o un resultado de la existencia de X.

Así, Wright elimina el punto de vista del observador, otorgando una explicación de la "función" en términos estrictamente causales ${ }^{92}$. A partir de esta explicación, por ejemplo, el corazón existe porque tiene por función bombear sangre; bombear sangre es una consecuencia de que existan los corazones. Como vemos, se trata de una explicación naturalista e intrínseca de "función". Este tipo de explicaciones no le satisfacen a Searle (y tampoco a nosotros), básica y principalmente porque deja afuera el elemento normativo implícito en la noción de "función". Si no tenemos en cuenta este elemento, ¿cómo podemos dar cuenta de corazones mejores o peores, de cardiopatías, de disfunciones cardíacas? Los hechos de la naturaleza no pueden ser explicados del mismo modo que los hechos que dependen del lenguaje o, para utilizar el vocabulario de Searle, no es posible concebir a los hechos en bruto del mismo modo que a los hechos institucionales. Esta distinción es fundamental en la obra de Searle y se halla en todos y cada uno de los problemas abordados. Las funciones no son meras causas; hay algo más. Aquello que está de más es que las funciones son relativas al observador.

Las atribuciones de funciones se distinguen de las atribuciones de causas, además, porque aquellas son intensionales-con-una-s. No es posible substituir términos en contextos funcionales sin modificar los valores de verdad. Así, de "La función de A es hacer $X$ " $\mathrm{y}$ "Hacer $X$ es idéntico a hacer $Y$ ", no se sigue, "La función de A es hacer Y". Por ejemplo, la función del corazón es lograr que la sangre circule por todo el cuerpo, y una buena circulación sanguínea evita que se adormezcan nuestras extremidades; pero no es el caso que la función del corazón sea que no se nos adormezcan nuestras extremidades. Ahora bien, esta caracterización de las funciones, que siempre dependen del punto de vista del actor, puede resultar vaga o prestarse a confusión. En este punto podemos preguntarnos si es posible equiparar un corazón humano con, por ejemplo, una silla. $\mathrm{Si}$ bien le asignamos funciones a los dos objetos, no hay duda de que la silla es una creación humana para un fin determinado, a saber, brindar confort; pero, ¿podemos decir lo mismo respecto a los corazones?, ¿se trata de una creación humana para un fin determinado? La diferencia es evidente. Para aclarar esta problemática Searle introduce una distinción entre funciones agentivas y no agentivas. En ciertas ocasiones, la

\footnotetext{
${ }^{92}$ Ver al respecto, Larry Wright, Functions en The Philosophical Review, Vol. 82, No. 2, Abril 1973.
} 
asignación de funciones tiene que ver con nuestros propósitos inmediatos, ya sean gastronómicos, estéticos, prácticos o de otro tipo. Cuando decimos "esto es una silla", "el agua quita la suciedad", o "esto es un serrucho", señalamos usos que le otorgamos a ciertos objetos. Estas funciones son asignadas en función de los propósitos específicos de los agentes; no ocurren naturalmente. Sin embargo, no todas las funciones de este tipo tienen fines prácticos; tal es el caso del enunciado "hace un frío espantoso". Lo que este tipo de enunciados tiene en común es que son los agentes los que otorgan una función de modo intencional y consciente; por ello las denominamos funciones agentivas. Ciertos objetos cumplen funciones agentivas de modo natural, tal es el caso del agua que usamos para los riegos; otros objetos son fabricados específicamente para cumplir una función determinada, tal es el caso de las sillas y los serruchos. Nada obsta, sin embargo, que utilicemos un objeto construido con un objetivo específico, para cumplir con otro; tal es el caso del enunciado, "uso la silla para mantener la puerta cerrada". La función no es intrínseca al objeto (tal como ocurría en el caso del corazón); en estos casos la función asigna el uso que intencionalmente reservamos para estos objetos (Searle, 1997, p. 38).

Otras funciones, por su parte, se asignan a objetos naturalmente y no se imponen con propósitos prácticos. Muestra de ello es el enunciado, "la función del corazón es bombear sangre", cuando tratamos de dar cuenta del modo en que vive y sobrevive nuestro organismo. Este fenómeno ocurre independientemente de nuestras intenciones y actividades; por ello, Searle las denomina funciones no agentivas. Para clarificar la diferencia entre funciones agentivas y no agentivas basta decir que, mientras las primeras requieren cierto esfuerzo o intencionalidad de nuestra parte, no ocurre lo mismo con las funciones no agentivas. De éste modo, el dinero, las leyes y los termómetros, son dinero, leyes y termómetros porque continuadamente los reconocemos como tales; a los corazones y los pulmones nada les importa nuestro parecer al respecto. Por otra parte, muchas veces usamos un objeto para una función agentiva, desconociendo su funcionamiento por completo. La gran mayoría de los conductores de automóviles, desconocen la totalidad de las piezas que integran un automóvil y, sin embargo, usan los automóviles; en este caso, se trata de una función agentiva.

Las funciones se van agregando a los distintos objetos y todo ello ocurre casi sin darnos cuenta; operan, como sostiene Searle, de un modo "invisible". Así ocurre con la evolución del dinero; puede que nadie haya pensado que estaba imponiendo una nueva función al objeto. Así y todo, la evolución siguió su curso. De todos modos es preciso que alguien en un determinado momento entienda y sepa cómo viene la cosa; si así no ocurriese, la 
función jamás podría ser asignada. Recordemos que las funciones agentivas no escapan de la intencionalidad de los seres humanos; si nadie supiera para qué sirve el dinero o los termómetros, tendrían que caer del lado de las funciones no agentivas. Ciertos autores, como por ejemplo Robert Merton (1987), denominan a las funciones agentivas, manifiestas, y a las no agentivas, latentes. Esta última distinción es inadecuada y carece de sentido pues, ¿qué significa que una función sea latente? Significa que son funciones no queridas $u$ observadas por los miembros de una sociedad. Paradójicamente, el ejemplo paradigmático de Merton respecto a las funciones latentes es el proceso de socialización de los sujetos llevado a cabo en el colegio. Es erróneo suponer que no hay una intencionalidad determinada a la hora de formar y educar a los infantes. Toda formación social inculca en los individuos una serie de elementos deseables e indeseables, valorados y no valorados; todo ello se lleva a cabo a temprana edad y con una intencionalidad precisa. La educación de los niños es, claramente, una función agentiva. Aunque la gran mayoría de las veces no sea del todo clara, toda institución tiene una orientación y sus prácticas distan de ser neutrales, arbitrarias y caprichosas.

Cabe destacar que, en la formación de hechos institucionales Searle siempre ha destacado (a partir de La construcción de la realidad social, 1997) una prioridad metodológica de los hechos en bruto por sobre los hechos institucionales. A continuación nos detendremos en este punto.

\section{La prioridad de los hechos en bruto}

Al respecto Searle es categórico; sostiene que no puede haber hechos institucionales sin hechos en bruto. El ejemplo característico es el del dinero. Cualquier sustancia puede ser dinero -papel, hierro, oro, cobre, plástico-, pero el dinero tiene que existir de cualquier manera física. En los últimos años y de manera casi imperceptiva, el dinero ha sufrido una serie de cambios en su composición física, desde el uso de tintas y celulosas, hasta su formato y aspecto. Pero nada de eso importa porque, para la elaboración de una teoría de la sociedad, la forma es lo de menos mientras pueda funcionar como dinero. Pero así y todo, el dinero debe tener una forma física. De ésta manera Searle establece una jerarquización de los hechos y sostiene que, 
Los hechos institucionales existen, por así decirlo, en la cima de los hechos físicos brutos. A menudo, los hechos brutos no se manifiestan como objetos físicos, sino como sonidos procedentes de las bocas de las personas, o como marcas sobre el papel (o hasta como pensamientos en las cabezas). (1997, p. 52).

Pensemos en otro ejemplo, pensemos en los Estados modernos. Para que exista un Estado tal (pensamos en los Estados modernos por su mayor complejidad) es necesaria una cierta división de poderes -ejecutivo, legislativo y judicial-, una cierta división territorial del poder -nacional, provincial, municipal-, una forma de organizar la propiedad de los medios productivos, un marco legal, una reglamentación de las relaciones económicas, monetarias, bursátiles, de comercialización exterior, entre otras cosas. Todo ello forma parte de los que Searle denomina hechos institucionales pero, para que ello exista, es necesario algo más fundamental (en el sentido de more basic); nos referimos principalmente a dos elementos: un territorio y un grupo de personas. Sin personas ni territorios, no existirían la división de poderes, la propiedad privada de los medios de producción, el dinero, las corridas bancarias, ni los intendentes y presidentes. Para existir, los seres humanos y los territorios, no requieren de la voluntad de nadie ni, de la intencionalidad de un grupo; por eso mismo son hechos en bruto [more basic].

Los hechos institucionales, por su parte, no pueden existir aislados; existen en un conjunto de relaciones sistemáticas con otros hechos. Así, para que un Estado pueda cobrar impuestos, debe existir previamente un tipo generalmente aceptado de intercambio económico. En nuestras sociedades modernas ese rol lo cumple el papel moneda; para que este exista, a su vez en necesario que esa sociedad tenga un sistema de intercambio de bienes y servicios contra dinero. Para que una sociedad disponga de un sistema de intercambio debe contar con un sistema de propiedad y de posesión de la propiedad. En cualquier situación de la vida nos encontramos en medio de una enorme y compleja red de hechos institucionales.

La existencia de los hechos institucionales, las funciones del tipo " $X$ cuenta como $Y$ en $C$ ", no requieren de un mero comportarse de un cierto modo. Muchas veces, por ejemplo, se hace referencia al león como al rey de la selva, también hablamos de abeja reina y abejas soldado, de hormigas esclavas, y cosas por el estilo. Ello no es más que un uso metafórico puesto que para que sea posible que una comunidad cuente verdaderamente 
con reyes, soldados y esclavos es necesario algo más. Pero, ¿qué es ese algo? En La construcción de la realidad social (1997) Searle afirma,

Debería darse, además, cierto conjunto de actitudes, creencias, etc., por parte de los miembros de la comunidad, y esto parecería requerir un sistema de representación como el lenguaje. El lenguaje parece esencial no sólo para representarnos esos hechos a nosotros mismos; (..), las formas lingüísticas en cuestión son parcialmente constitutivas de los hechos ( $p, 54)$.

El papel del lenguaje, tal como lo venimos desarrollando a lo largo de todo este trabajo, es esencial en la formación de la realidad social. Más adelante nos centraremos específicamente en la relación entre lenguaje y hechos institucionales, pero a continuación daremos cuenta de un elemento que explica la variación y la evolución de la realidad social. Este elemento no se encuentra desarrollado en la obra de Searle sino que debemos recurrir, una vez más, a los aportes conceptuales desarrollados por Michael Tomasello; nos referimos a aquello que denomina, trinquete cultural. Veamos.

\section{El trinquete cultural}

Hace unos 200.000 años, en África, un grupo de individuos pertenecientes a la especie Homo siguió un camino evolutivo diferente. Esta nueva especie logró reproducirse y esparcirse por todo el mundo (lo cual es algo inédito); a sus descendientes se los conoce hoy día como Homo Sapiens. Los miembros de esta nueva especie no sólo poseían nuevas características físicas -tales como un cerebro de mayor tamaño-, sino que, y esto es lo más llamativo, contaban con nuevas capacidades cognitivas y productivas. Comenzaron a fabricar herramientas de piedra que se ajustaban a las necesidades que deseaban satisfacer; comenzaron a utilizar símbolos para comunicarse y organizar su vida social. Los símbolos no sólo eran lingüísticos, también se trataba de símbolos artísticos como dibujos y esculturas. Esa capacidad permitió el posterior desarrollo de un lenguaje proposicional, del dinero, el arte, la notación matemática. Por otro lado, comenzaron a adoptar nuevas prácticas organizacionales, tales como ceremonias 
fúnebres y domesticación de plantas y animales. Este tremendo desarrollo evolutivo descansa sobre un enigma básico: el tiempo. Los seis millones de años que separan a los humanos de otros monos antropomorfos es un lapso de tiempo muy corto en términos evolutivos. Prueba de ello es que el $99 \%$ del material genético de los seres humanos modernos es idéntico al de los chimpancés. Hay un solo rasgo biológico capaz de asegurar el desarrollo evolutivo tan acelerado que han tenido los seres humanos. Ese mecanismo biológico es la transmisión social o cultural; el desarrollo social o cultural es mucho más rápido que el biológico y es lo que permite que los seres humanos modifiquen permanentemente su medio ambiente. Si bien para Searle los seres humanos no son los únicos animales que poseen un desarrollo cultural o social (como hemos visto en el capítulo anterior respecto a la intencionalidad colectiva), no deja de admitir que su desarrollo evolutivo específico no tiene igual en el reino animal. El rasgo particular de nuestra especie animal es que, con el tiempo, los seres humanos hemos acumulando modificaciones a las tradiciones y artefactos culturales; este efecto, que se lo denomina evolución cultural acumulativa, no se observa en ninguna otra especie animal. Lo que ocurrió es que un miembro de un grupo -o un grupo-, inventó una herramienta o una práctica $\mathrm{y}$, con el tiempo, otro individuo o grupo la adoptó introduciéndole ciertas modificaciones con el objetivo de mejorarla; más tarde, otros usuarios la adoptaron sin modificaciones hasta que, una generación determinada le introdujo nuevas "mejoras". Así sucesivamente. A este largo y continuo proceso de mejoras y modificaciones de las prácticas y herramientas, Michael Tomasello lo denomina, efecto de trinquete o trinquete cultural $\left(2007,2010,2010^{a}\right)$. Tomasello señala que este proceso evolutivo acumulativo sólo es posible debido a dos factores; por un lado, la invención creativa; por otro, una transmisión social fiel. Ha sido necesaria una importante dosis de imaginación para que el hombre pase de utilizar una roca para excavar la tierra, a fabricar los modernos taladros neumáticos; pero además es necesario que, a medida que se agregue una nueva modificación al "producto original", mejorándolo, no se produzca un deslizamiento hacia atrás (o en otra dirección), para que se mantenga fielmente la finalidad con la que fue creado el objeto original. Por ello mismo, la modificación debe actuar como un trinquete. Es precisamente la ausencia de este elemento lo que les impide al resto de las especies animales -altamente creativas-, que incorporen y continúen agregando nuevas mejoras a sus prácticas y objetos; no poseen el elemento estabilizador, el trinquete. De este modo, 
En el caso de los primates no humanos, muchos individuos producen regularmente innovaciones conductuales inteligentes, pero los miembros de su grupo no realizan el tipo de aprendizaje social que con el tiempo permitiría al trinquete cultural cumplir su misión (Tomasello, 2007, p. 16).

El modo en que los seres humanos desarrollan y transmiten sus recursos cognitivos no tiene comparación con otras especies animales. En Los orígenes culturales de la cognición humana (2007), Tomasello retoma una distinción que ya había realizado en Imitative learning of actions on objects by children, chimpanzees, and enculturated chimpanzees (1993); allí distingue tres tipos de aprendizajes desempeñados por humanos. El aprendizaje imitativo, el aprendizaje impartido y el aprendizaje colaborativo. Existe un elemento característico de nuestra especie animal que hace posible que se den estos distintos tipos de aprendizaje; cada individuo de la especie entiende que los otros miembros son semejantes a él, que poseen los mismos rasgos intencionales y mentales. Esto le permite a cada miembro, no sólo entender del otro, sino a través del otro. Entender que los otros seres son también seres intencionales como uno, es fundamental para el aprendizaje cultural humano porque, tanto los artefactos culturales como las prácticas sociales, remiten a entidades externas. De este modo, las herramientas remiten a los problemas que están destinados a resolver; los símbolos lingüísticos están destinados a las situaciones comunicativas que están destinados a representar. El niño, para entender el uso convencional de la herramienta o el símbolo lingüístico, debe ser capaz de comprender el significado intencional de esa herramienta o símbolo; es central poder entender cuál es la finalidad de aquello que nosotros, los usuarios, hacemos con las herramientas y prácticas sociales. Cuando un ser humano está aprendiendo "a través de otro", se identifica con ese otro y con sus estados intencionales y -en ciertas ocasiones-, mentales. Esa capacidad es estrictamente humana y, si bien los primates no humanos de nivel superior son capaces de comprender que los miembros de su especie son agentes intencionales y de aprender de ellos de un modo muy similar al de los seres humanos, sólo estos últimos entienden que los otros miembros de su especie son, como él, agentes intencionales. Todo ello posibilita que únicamente los seres humanos puedan realizar un aprendizaje cultural.

En esa transmisión (sea de herramientas, de valores y actividades) ocupa un lugar privilegiado el uso del lenguaje que los seres humanos realizan. A continuación nos 
detendremos en la relación que existe entre las formas lingüísticas y la creación de aquello que Searle denomina hechos institucionales.

\section{Lenguaje y realidad institucional}

Para exponerlo llanamente, la tesis de Searle es la siguiente: el lenguaje es esencialmente constitutivo de la realidad institucional (1997, p. 75). En el apartado en el que hemos trabajado los actos de habla (Capítulo 3), hemos aclarado que no es posible tener estructuras tales como los Estados, los matrimonios, el dinero, la propiedad, los gobiernos, sin que haya una forma de lenguaje; éste es constitutivo de los hechos. Searle entiende, por su parte, que aquellos hechos que no necesitan del lenguaje son los hechos sociales puesto que, como hemos visto en el anterior apartado, entiende que los animales de nivel superior, al igual que los infantes humanos pre-lingüísticos, están envueltos en actividades cooperativas pero no poseen lenguaje. Junto con Tomasello, hemos visto que los animales de nivel superior, a diferencia de los humanos, no poseen conductas cooperativas. Más allá de estas diferencias, lo que aquí nos interesa es abordar la relación entre lenguaje e instituciones. En este preciso momento nos topamos con una situación paradojal. Si es cierto que el lenguaje crea instituciones, ¿qué ocurre con el lenguaje mismo? Si las instituciones se crean lingüísticamente, ¿cómo se crea el lenguaje que es él mismo una institución? Estamos aquí frente a una circularidad de tipo viciosa en la cual el lenguaje -en tanto que hecho institucional-, necesita del lenguaje para ser creado.

Es posible sostener que la tesis de Searle tiene una versión débil y una fuerte. La versión débil es como sigue: para que exista un tipo de hecho institucional, la sociedad debe disponer de un tipo de lenguaje (al menos, alguna forma primitiva). De este modo, el lenguaje posee una primacía lógica sobre el resto de las instituciones; justamente por ello, el lenguaje es una institución básica porque las demás suponen el lenguaje pero no a la inversa; el lenguaje no necesita del resto de las instituciones. No podemos tener dinero y matrimonios sin tener lenguaje, pero sí podemos tener lenguaje sin dinero ni matrimonios. La versión fuerte dice que cada institución necesita elementos lingüísticos que se encuentran en los mismos hechos institucionales. Puesto que la versión fuerte implica la débil, a continuación desarrollaremos aquella versión. 
Searle no tiene en cuenta todos los rasgos de los lenguajes naturales plenamente desplegados; para analizar la relación entre lenguaje y hechos institucionales, no se centra en problemas tales como la fuerza ilocucionaria, los conectores lógicos, los cuantificadores: y ello es así porque,

El rasgo del lenguaje esencial para la constitución de los hechos institucionales es la existencia de mecanismos simbólicos, como las palabras, que, por convención, significan, o representan, o simbolizan algo que va más allá de ellos mismos (1997, p. 76. Los destacados le pertenecen a Searle).

Searle sostiene que el lenguaje es parcialmente constitutivo de los hechos institucionales. Hay mecanismos lingüísticos, palabras, símbolos, que significan o expresan algo convencionalmente. Ese algo se encuentra más allá de sus propios límites y es públicamente comprensible. El lenguaje tiene la capacidad de simbolizar; a diferencia de los estados intencionales prelingüísticos, en el lenguaje las capacidades intencionales no son intrínsecas a las entidades; muy por el contrario, los seres humanos las imponen intencionalmente. La sentencia, "Estoy cansado", es lingüística; tiene capacidades representatorias y convencionalmente simbólicas. La sensación de cansancio, sin embargo, no es en absoluto lingüística, a nuestro cuerpo nada le importa las convenciones lingüísticas. En este punto vemos el esfuerzo (atinado) de Searle por distinguir, una vez más, los hechos en bruto de los hechos institucionales. La sensación real de cansancio representa intrínsecamente sus condiciones de satisfacción.

Su esfuerzo se centra en demarcar los límites del lenguaje. Así, distingue los hechos independientes del lenguaje (como el hecho de que el Cerro Aconcagua tenga nieve en su cúspide), de los hechos dependientes del lenguaje (que, "el Cerro Aconcagua tiene nieve en su cúspide", es una sentencia castellana). El principio que genera la demarcación entre un tipo de hechos y otros es muy simple: si un hecho necesita del lenguaje para existir, entonces se trata de un hecho dependiente del lenguaje; si no lo necesita estamos ante un hecho independiente del lenguaje. Saquen todo elemento lingüístico, saquen a todos los seres humanos de la faz de la tierra y, así y todo, el Cerro Aconcagua tendrá nieve en su cúspide. 
Searle establece una segunda distinción entre pensamiento dependientes del lenguaje y pensamientos independientes del lenguaje. Los pensamientos que dependen del lenguaje, son aquellos que sólo ciertos animales poseen, puesto que se requiere de la posesión de un lenguaje proposicional para poder tener pensamientos del tipo, "La cima del Cerro Aconcagua esta nevada". Quien no disponga de este tipo de lenguaje no podría albergar este tipo de pensamiento. Hasta aquí estamos de acuerdo con Searle pero, por lo que hemos venido trabajando a lo largo de todo el presente trabajo, ¿podría ser posible que algún ser sea capaz de albergar pensamientos independientes del lenguaje? El argumento de Searle es como sigue,

Los casos más obvios de pensamientos independientes del lenguaje los ofrecen las inclinaciones y cogniciones no institucionales, primitivas, biológicas, que no necesitan de mecanismos lingüísticos. Por ejemplo, un animal puede tener sensaciones conscientes de hambre y sed, siendo ambas formas un deseo (1997, p. 77).

Estimamos que cuando Searle habla de pensamientos independientes del lenguaje, hace referencia a lo que comúnmente se denomina estados intencionales (creencias, deseos, intenciones). Si negamos la existencia de estados intencionales pre-lingüísticos, no podríamos sostener, no sólo que los animales no humanos no tuvieran creencias, deseos e intenciones, sino que además los bebes humanos tampoco las tuvieran antes de los dieciocho meses de edad. Muchos filósofos sostienen esta posición, Davidson por ejemplo. Aquí nos ubicamos más cerca de la postura de Searle, pero con una diferencia para nada sustancial-; no llamaremos pensamientos a esos estados intencionales. Los animales sienten hambre y sed, son desbordados por el deseo sexual, ¿quién podría negar que se trata de deseos 0 intenciones ${ }^{93}$ ? Hecha la aclaración, volvemos una vez más al problema de la realidad institucional.

\footnotetext{
${ }^{93}$ Parece no haber inconveniente en asumir la existencia de deseos e intenciones que no dependan del lenguaje; como hemos visto, los animales de nivel superior no humano, las tienen, y los bebes humanos también. Pero el caso de las creencias pre-lingüisticas, es un poco más complejo. Searle nos brinda el siguiente ejemplo: “Mi perro puede ver y oler un gato trepando a un árbol y formar la creencia de que el gato está encaramado al árbol. Puede incluso corregir su creencia y formar una nueva creencia cuando ve y huele al gato correr hasta el patio del vecino" (1997, p. 77). Pero, en este caso, ¿el perro tiene una creencia formada respecto a su propio comportamiento y al comportamiento del gato o, por el contrario, se trata de
} 
Searle sostiene (quizás ésta sea su tesis más relevante) que algunos hechos que parecen no depender inmediatamente del lenguaje -hechos tales como el dinero, los Estados y las Universidades-, tienen una dependencia inmediata del lenguaje. ¿Cómo es posible que ello ocurra si ni el dinero, ni los Estados, ni las Universidades son sentencias castellanas? Este es el problema fundamental a resolver a la hora de comprender la realidad institucional. Para que un hecho dependa del lenguaje es preciso que se cumplan dos requisitos. Por un lado, las representaciones mentales -los pensamientos-, deben ser constitutivas del hecho; por otro lado, la representación del hecho debe depender del lenguaje. Vemos cómo Searle desdobla lo que nosotros vemos todo junto; para él, por un lado tenemos la representación de los hechos -el cual es un momento prelingüístico-, y luego tenemos el lenguaje. Así, se le da un contenido lingüístico a una representación mental. Nosotros, por el contrario, sostenemos que, una vez incorporado el lenguaje (lo que ocurre aproximadamente después de los dieciocho meses de edad) no tenemos representaciones pre-lingüísticas. Una vez adquirido el lenguaje, toda representación, todo pensamiento, tiene un contenido proposicional, caso contrario, no podría ser pensable. A partir de los dieciocho meses de edad pensar equivale a hablar. Más allá de esta diferencia entre nuestro planteo y el de Searle (o entre el de Searle I y Searle II), que para lo que aquí nos ocupa no es más que un detalle, lo central es que los hechos institucionales cumplen con ciertos requisitos. Searle afirma que,

Del hecho de que la función de status determinada por el término Y sólo pueda ser cumplida si se reconoce, se acepta y se percibe como tal, o se cree tal, se sigue que el hecho institucional en cuestión sólo puede existir si es representado como existente. Pregúntense ustedes qué tendría que ocurrir para que fuera verdad que el trozo de papel que está en mi mano sea un billete de veinte dólares, o que Tom posee una casa (1997, p. 78$)$.

La realidad institucional, según Searle, puede existir porque la gente se forma ciertas creencias; de este modo, un objeto es dinero, si la gente cree que es dinero; algo es propiedad si la gente cree que es propiedad. De lo anterior se sigue que todos los hechos

un mero instinto. ¿Los animales tienen creencias o actúan únicamente en base a instintos? Dejo el problema abierto porque carecemos de una explicación satisfactoria. 
institucionales son ontológicamente subjetivos y epistémicamente objetivos. La forma lógica de la realidad institucional es, como dijimos, " $X$ cuenta como $Y$ en un contexto $C$ ". Lo que intenta clarificar Searle es que el traspaso de $X$ a $Y$ implica un movimiento lingüístico.

Aquí Searle funde dos de sus nociones básicas; por un lado, los hechos institucionales dependen del lenguaje; por otro lado, los pensamientos que constituyen los hechos institucionales se caracterizan por ser dependientes del lenguaje. Por nuestra parte, creemos innecesario distinguir esos dos momentos porque entendemos que los pensamientos son lenguaje; los pensamientos no son un momento previo al que se le otorga (en un tiempo futuro) un contenido proposicional; no son una cáscara vacía que debemos llenar con proposiciones sino que son siempre ya proposiciones. Sostenemos aquí aquello que Platón afirmaba: pensar es hablar hacia adentro; no es posible pensar por fuera de los límites del lenguaje. Si no hay lenguaje, tampoco hay pensamiento. Pero veamos un poco más en detalle el argumento de Searle.

Searle sostiene, en primer lugar, que no sería posible empíricamente poseer ciertos tipos de pensamientos debido a su complejidad. Tal es el caso de los pensamientos matemáticos; ningún animal -ni siquiera de nivel superior-, sería capaz de resolver un pensamiento aritmético tan sencillo como,

$$
50+50=100
$$

Un caso de dificultad empírica tal, sólo puede ser resuelto mediante el uso de palabras y símbolos. Sin embargo, seguida y curiosamente Searle sostiene lo siguiente,

No veo ninguna imposibilidad lógica en pensar ese pensamiento [la suma aritmética] sin lenguaje. Es fácil imaginar que el curso de la evolución podría producir seres capaces de pensar en relaciones aritméticas complejas sin necesidad de servirse de símbolos (1997, p. 79. El destacado le pertenece al autor.)

No veo cómo esto podría ser posible; no resulta fácil imaginar seres capaces de resolver problemas aritméticos sin servirse de algún tipo convencional de símbolos lingüísticos. Quizás algún día aparezcan pero no hoy; hoy no es posible para los humanos realizar una 
cosa tal. Searle intenta resolver el problema planteando una situación hipotética y ficticia, lo cual no soluciona nada. De lo que se trata tanto en filosofía como en cualquier rama del pensamiento, es de resolver problemas concretos, más que plantear escenarios fantasiosos. Esa no es una manera prudente de argumentar porque los experimentos mentales suelen emplearse para ayudarnos a comprender un problema o un aspecto de la realidad; tienen por función hacer más claro el argumento, pero no tienen la función de negar un argumento. Para rebatir un argumento necesitamos otro argumento (mejor) y no un experimento mental.

Otro caso que Searle expone es aquel donde el lenguaje se involucra como un caso de necesidad lógica porque el pensamiento necesita del lenguaje para poder ser el pensamiento que es. El ejemplo que propone es el del calendario. El pensamiento, "Hoy es miércoles 16 de Abril" requiere un conjunto preciso de palabras porque el contenido del pensamiento ubica temporalmente un día en relación con un sistema verbal específico para identificar días y meses. Si el perro de Searle no puede identificar que "Hoy es miércoles 16 de Abril", se debe a que no posee un lenguaje orientado por convenciones. Lo único fáctico del hecho de que "Hoy es miércoles 16 de Abril", es que ocupa una posición relativa a un sistema lingüístico. A continuación Searle aclara que lo mismo podría ocurrir respecto de las palabras "perro" o "gato"; algo es "perro" o "gato" en relación a un sistema de símbolos lingüísticos. Pero en este punto Searle observa una diferencia notable,

...los rasgos poseídos por un objeto, y en virtud de los cuales la palabra "perro" es verdadera de él, es decir, los rasgos en virtud de los cuales es un perro, son rasgos que existen independientemente del lenguaje. $Y$ en la medida en que uno puede pensar en esos rasgos independientemente del lenguaje, uno puede tener este pensamiento independientemente del lenguaje (1997, p. 80 . Los destacados le pertenecen a Searle.)

Estamos completamente de acuerdo en que ser un perro es un rasgo que no depende del lenguaje; se trata de un hecho en bruto, pero estimamos que de eso no se sigue que nosotros, los humanos, podamos pensar (o representar) a los perros -ni a cualquier otro 
hecho en bruto-, independientemente del lenguaje, porque una vez incorporado el lenguaje proposicional no es posible hacerlo a un lado.

Para cerrar el argumento de Searle es preciso aclarar que él entiende a la realidad institucional como a esos pensamientos acerca de la fecha de hoy; la realidad institucional es dependiente del lenguaje. Si bien nos distanciamos de algunos puntos del desarrollo de su explicación, adscribimos a su tesis central: la realidad institucional no puede ser entendida por fuera de los límites del lenguaje; es el propio lenguaje aquel que constituye ese tipo de realidad.

Al análisis de la realidad institucional que hasta aquí hemos desarrollado, debemos agregarle dos componentes. En primer lugar, la estructura " $X$ cuenta como $Y$ en $C$ " puede ser iterada. Esto funciona de la siguiente manera. El término $X$ de un nivel superior puede convertirse en un término $Y$ de un nivel inferior. Un ciudadano $X$ cualquiera, por ejemplo, puede convertirse en un militante político $Y$ en un contexto $C$ determinado; a su vez, ese mismo militante político (ahora $X$ ) puede ser presidente (ahora $Y$ ) en un contexto $C$. Posteriormente, ese presidente $X$ puede ser galardonado con el Premio Nobel de la Paz $(Y)$ en otro contexto $C$. El sujeto en cuestión -ciudadano, militante político, presidente y Premio Nobel-, siempre ha sido el mismo; lo que sí ha variado es su estatus a medida que ha variado el contexto $C$. Así también, una promesa $X$ puede contar como un casamiento $Y$ en el contexto $C$; el casamiento $X$ equivale a contraer una serie de derechos, deberes y obligaciones $Y$ en $C$; etcétera. Como observamos, los estatus se van encadenando y son esas iteraciones las que ofrecen la estructura lógica de la realidad institucional en las sociedades complejas.

El segundo componente de la realidad institucional se refiere a esas estructuras iteradas que forman sistemas entreverados que operan a lo largo del tiempo. El ejemplo predilecto de Searle es el dinero; así, una persona no sólo se limita a tener dinero, sino que lo tiene en su caja de ahorro y lo gasta haciendo una transferencia para pagar sus impuestos nacionales y municipales por ser un ciudadano de la República Argentina, y residente de CABA y empleado público. Todas las expresiones en cursiva representan conceptos institucionales que operan a lo largo del tiempo. Así también podríamos pensar en las relaciones filiales; por el solo hecho de nacer ya nos convertimos en hijos, hermanos, nietos, sobrinos, con ciertos derechos y obligaciones respecto a nuestros mayores; con el paso de los años nosotros mismos somos padres, tíos y hasta abuelos, contrayendo también una serie de derechos, deberes y obligaciones. Venimos a este mundo -desde el primer minuto-, insertos en una maraña de hechos institucionales que se van iterando y 
complejizando a lo largo del tiempo; no somos nosotros quienes los creamos y, tras nuestra muerte, seguirán existiendo más o menos de la misma manera. ${ }^{94}$

Tras habernos detenido en el traspaso del elemento $X$ hacia el elemento $Y$, traspaso que es posible únicamente gracias al lenguaje, nos centraremos a continuación en el último elemento de la función, " $X$ cuenta como $Y$ en $C$ "; será el turno ahora de analizar el contexto $C$.

\section{Sobre el contexto C}

En Intentional Acts and Institutional Facts (2007), Rakoczy y Tomasello despliegan un análisis que es completamente pertinente a los fines de nuestro trabajo. Como hemos visto en el capítulo anterior, Michael Tomasello, basándose en estudios empíricos, ha demostrado que los animales de nivel superior no poseen intencionalidad colectiva o conjunta ${ }^{95}$. Searle por su parte, sostiene que tanto las hienas como las hormigas desarrollan tareas colectivas en las que hay una diferenciación previa y estructurada de roles y actividad. Nosotros por nuestra parte, sostenemos que nada de eso ocurre en el reino animal (excepto en el caso de los animales humanos) porque no se realizan acuerdos previos a una acción específica. Este distanciamiento de la obra de Searle en lo referido a la intencionalidad colectiva, que Tomasello y Rakoczy proponen $-\mathrm{y}$ a la que nosotros adscribimos-, tiene un impacto directo en otro problema que aquí nos interesa: la asignación de función.

Es preciso aclarar que, tanto Searle como Tomasello y Rakoczy, visualizan una continuidad entre los animales humanos y el resto de los animales de nivel superior. La diferencia radica en que, según Tomasello y Rakoczy, Searle va muy rápido en esa continuidad. La intencionalidad colectiva no está presente en todos los animales -como Searle supone-, sino que es un rasgo distintivo y específico de los seres humanos. Lo cierto es que los animales humanos son los únicos que han sido capaces, tras un período de evolución constante, de crear un mundo institucional tal como los matrimonios, los Estados, las guerras, el dinero y los juegos de ajedrez; la realidad institucional, como

\footnotetext{
${ }^{94}$ Este punto lo ha sabido ver bien Emile Durkheim. Ver principalmente Las reglas del método sociológico (2003).

${ }^{95}$ Hablaré indistintamente de Intencionalidad colectiva o conjunta. El primero de los términos es utilizado por Searle; Tomasello prefiere hablar de Intencionalidad conjunta. A los fines de hacer la lectura más monocorde hablaré en lo siguiente de Intencionalidad colectiva, pero sepa el lector que tanto Searle como Tomasello hacen referencia al mismo hecho, la capacidad de hacer cosas con otros.
} 
hemos vistos, es formalizada por Searle de la siguiente manera, " $X$ cuenta como $Y$ en el contexto C". Así, un trozo de madera cuenta como alfil en el juego de ajedrez. Lo central no es el término $X$, puesto que todos los animales (no sólo los humanos) son capaces de advertir -siguiendo nuestro ejemplo-, un trozo de madera. Lo distintivo de los seres humanos es que somos capaces de advertir el traspaso de un término a otro; lo importante es poder comprender a los dos objetos ( $X$ e $Y$ ) como el mismo, que cuenta como otro. Se trata de un mismo objeto pero en dos niveles. $Y$ esto Searle lo advierte; pero si fuera cierto que el resto de los animales fuesen capaces de tener Intencionalidad colectiva y pudieran actuar en base a un nosotros, pudiendo simbolizar no sólo la primera persona sino también la tercera, se estarían corriendo de los hechos en bruto y estarían dando un paso en el camino a la formación de la realidad institucional. Esto no es posible y Tomasello junto a Rakoczy, lo advierte con razón.

Si bien es cierto que los grandes simios y quizás otros animales de nivel superior pueden ser capaces de percibir objetos en distintos niveles, Tomasello y Rakoczy sostienen lo siguiente,

Por ejemplo, los simios parecen ser capaces de usar objetos tales como réplicas, como maquetas, para estados de cosas en el mundo tal como hacen los infantes humanos (Kuhlmeier y Baisen, 2002). Es cierto, eso probablemente solo involucre apreciar un significado natural (Grice, 1957), pero están fuera de la comprensión de la asignación colectiva de cualquier cosa. Pero puede ser visto como una simple forma de tratar objetos en diferentes niveles, en uno. Pensar objetos en dos niveles es completamente necesario para participar en la asignación de estatus, pero no es suficiente. ¿Qué es lo que no se encuentra entonces en los simios? (Tomasello y Rakoczy, en Tsohatzidis, 2007, p. 125. Traducción propia).

A continuación intentaremos dar respuesta a este interrogante. El término $C$, siguiendo a Tomasello y Rakoczy, tiene un bagaje, un background que debe ser comprendido antes del " $X$ cuenta como $Y$ ". Es en el contexto $C$ donde tienen lugar las prácticas intencionales colectivas. Aquello que no se encuentra en los simios, precisamente, son tales prácticas; 
ello a su vez, les impide crear los estatus que les corresponden a cada función. Este es el punto central de la crítica de Tomasello y Rakoczy -con el que estamos plenamente de acuerdo-. El error de Searle se debe a una extensión de la noción de intencionalidad colectiva hacia el resto de los animales.

La manera de analizar esta imposibilidad que tienen los simios de generar intencionalidad colectiva es echándole un vistazo a la ontogenia humana. Los simios y los niños durante el primer año de edad transitan el mismo camino: ambos comparten formas simples de intencionalidad individual y otras formas muy básicas de comprensión intencional de otros y de sí mismos. Pero a partir del segundo año los seres humanos se bifurcan del camino; los seres humanos paulatinamente ingresan en la intencionalidad-del-nosotros en la forma de colaboración, comunicación pre-verbal y aprendizaje social (Tomasello y Rakoczy, 2007, p. 126). En este punto, el contexto C está aguardando la creación de estatus.

En La construcción de la realidad social (1997, pp. 56 y ss.) Searle da un claro ejemplo de una función de estatus. El ejemplo es el siguiente. Una tribu primitiva construye un muro alrededor de su territorio; el muro tiene funciones gracias a sus propiedades estrictamente físicas: gracias a su altura evita ataques de tribus vecinas. Supongamos ahora que el muro en cuestión, a lo largo del tiempo, pasa de ser una barrera física a ser una barrera simbólica. Imaginemos que nuestro muro se va derrumbando paulatinamente hasta reducirse a una mera línea de piedras. Lo peculiar es que, tanto los pobladores que pertenecen a la tribu como sus vecinos continúan reconociendo esa línea de piedras como una frontera, como un límite. Ese reconocimiento altera sus conductas de tal modo que los moradores no cruzan su límite sino en ocasiones excepcionales y los extranjeros piden permiso para ingresar dentro de sus límites. La función que en esta nueva situación tiene la línea de piedras no está a merced de sus propiedades físicas sino en virtud de la intencionalidad colectiva. La hilera de piedras, a diferencia del muro, no puede prevenir a los pobladores de un posible ataque externo. El resultado es del orden de lo simbólico: se ha delimitado un territorio. A la nueva hilera de piedras se le ha asignado colectivamente un nuevo estatus, es el marcador de una frontera.

Tras exponer su ejemplo del muro, Searle afirma que "los animales pueden imponer funciones a los fenómenos naturales" (1997, p. 57. El destacado me pertenece). Lo que intentamos dejar en claro -de la mano de Tomasello y Rakoczy-, es precisamente, que no todos los animales pueden hacer este tipo de cosas. Lo central aquí es que gracias al contexto $C$ se han constituido las prácticas colectivas de los miembros de la tribu. Del ejemplo del muro, según Tomasello y Rakoczy, se desprende otro elemento que es útil 
para analizar la ontogenia humana. Lo que comienza siendo una práctica colectiva para el infante, sin ningún tipo de estatus, el día de mañana deviene una cuestión institucional. En otro aspecto, la historia del muro de Searle se aleja por completo de la ontogenia humana; mientras que la historia del muro muestra cómo emerge el estatus desde el seno de una comunidad, los infantes se desarrollan en una realidad institucional que existe con anterioridad. Los simios, muy por el contrario, no poseen intencionalidad colectiva y el contexto $C$ nunca alcanza el nivel de una organización institucional (2007, pp. 126 y 127). Los estatus se asemejan a una telaraña; unos se entrelazan con otros y así forman una red de estatus, unos conectados con otros (piénsese por ejemplo en dinero, intercambio externo, pago de deuda pública, bonos bancarios, préstamos financieros). La pregunta central es entonces, ¿cómo es que los infantes ingresan en esa maraña institucional tan compleja? La respuesta que hemos venido ensayando a lo largo del presente trabajo es: a través del lenguaje.

\section{A modo de conclusión}

En el presente capítulo hemos analizado el segundo elemento que constituye y posibilita la creación de hechos institucionales. Este aspecto de la obra de Searle no ha sido muy discutido y, generalmente suele ser aceptado. Es evidente que los seres humanos le asignamos funciones a los distintos elementos del mundo: pero lo que nos interesa remarcar aquí es que esta capacidad es exclusiva de nuestra especie animal porque sólo nosotros, los seres humanos, somos capaces de simbolizar y de tomar al elemento $X$, como un elemento $Y$ en un contexto $C$ en particular. El pasaje de un punto a otro es posible gracias a nuestro lenguaje proposicional y el contexto social e institucional sólo puede ser creado por los animales humanos. Una persona es una persona, pero sólo en ciertos contextos esa persona puede llegar a ser presidente, o diputado, o plomero. La formalización de Searle, " $X$ cuenta como $Y$ en $C$ " permite explicar ese tipo de relaciones institucionales; en verdad, permite explicar todo tipo de relaciones sociales.

Pero aún nos falta analizar un último elemento; aún no hemos analizado el aspecto normativo. Para saldar esa deuda, en el próximo (y último) capítulo nos centraremos en el análisis de las normas constitutivas, cerrando el ciclo explicativo de nuestra ontología de lo social. 


\section{Capítulo 8: El problema de las normas}

\section{Introducción}

Junto con el lenguaje, la intencionalidad colectiva y la asignación de función, Searle identifica un cuarto elemento que constituye la realidad institucional, nos referimos a un tipo particular de normas. Searle distingue dos tipos de normas, unas regulan una actividad existente; otras constituyen, hacen posible el tipo de actividad que regulan. Las primeras son reglas regulativas y las segundas, reglas constitutivas. Su argumento es el siguiente.

El ejemplo típico de Searle para distinguir unas normas de las otras es el de los juegos. Veamos qué ocurre con el juego del ajedrez, por ejemplo. No es el caso que dos personas se enfrentan y comienzan a empujar unos trocitos de madera y llegado un momento acuerdan establecer ciertas normas para evitar que se choquen. Las normas, más bien, están establecidas de antemano porque precisamente, jugar al ajedrez implica actuar en base a ciertas normas: las normas del ajedrez. A éste tipo de normas Searle las denomina normas constitutivas porque hacen posible la realización de la actividad. Las normas constitutivas no solo regulan sino que hacen algo más: constituyen la actividad que regulan. Las normas regulativas por su parte, no hacen más que regular una actividad que existe con anterioridad e independencia de las normas; estas son las normas del tipo, "conduzca de la mano derecha de la calzada". Aquí, la actividad no depende enteramente de la norma porque el hecho de conducir es previo a la regulación de por dónde conducir. A este tipo de normas que regulan actividades que existen con independencia de las normas Searle las denomina reglas regulativas.

Searle ha venido sosteniendo esta diferenciación entre un tipo de reglas y otro, a partir de Actos de habla, obra de $1969^{96}$. A continuación nos detendremos en la específica relación entre las reglas y los actos de habla.

\section{Los actos de habla y sus reglas}

\footnotetext{
${ }^{96}$ En esa época Searle hablaba de reglas regulativas y constitutivas; a partir de La construcción de la realidad social (1995), Searle habla de normas regulativas y constitutivas. Aquí hablaremos indistintamente de reglas y normas porque la referencia en Searle siempre es la misma.
} 
En el uso ordinario estamos acostumbrados a utilizar reglas regulativas imperativas (reglas del tipo, "conduzca por la mano derecha", "no cruce la calle por la mitad de la cuadra", "si conduce no beba", "no grite en la biblioteca" y otras por el estilo); las reglas constitutivas no-imperativas nos sorprenderán, probablemente, por su carácter curioso; tal es así que difícilmente las reconozcamos como reglas. Este último tipo de reglas son, en el uso ordinario, de carácter casi tautológico. Cuando decimos por ejemplo, "se hace jaque-mate cuando el rey es atacado de una manera que en cualquier dirección que se mueva será atacado"; o, "se cuenta un gol cuando el balón atraviesa la línea del arco". En estos casos, la "regla" misma parece ofrecer una definición de jaque-mate o de gol. Searle aclara lo siguiente,

El hecho de que, por ejemplo, se logre un jaque-mate en ajedrez de tal y tal manera puede aparecer bien como una regla, bien como una verdad analítica basada en el significado de "jaque-mate en ajedrez". El que tales enunciados puedan interpretarse como enunciados analíticos es una clave para el hecho de que la regla en cuestión es una regla constitutiva (1994, p. 43).

De este modo, es evidente que las reglas de ajedrez definen ajedrez y las reglas del fútbol definen fútbol. Ello no implica, claro está, que una leve modificación en una regla pueda dar origen a un juego distinto. En todo sistema de reglas constitutivas hay grados de centralidad.

Como hemos aclarado anteriormente, las reglas regulativas suelen ser imperativas, son del tipo "haz esto" o "no hagas esto porque". A este subconjunto de reglas Searle las formaliza del siguiente modo, "Haz $X$ " o "Si $Y$ haz $X$ ". Las reglas constitutivas, por su parte, tienen una forma lógica que ya nos resulta conocida a estas alturas: " $X$ cuenta como Y en el contexto C" (1994, p. 44). La forma lógica de las funciones de estatus y de la realidad institucional es idéntica a la forma lógica de las reglas constitutivas; que un trozo de papel sea dinero tiene la misma forma lógica que el hecho de que un gol pueda crear un tanto en el fútbol: "el papel cuenta como dinero en las economías modernas"; "un gol cuenta como un tanto en el fútbol'. Esto evidencia el carácter normativo de la realidad institucional. 
Con el objetivo de sistematizar y clarificar sus argumentos, Searle aclara (1994, pp. 44 y ss.) que las reglas constitutivas poseen dos fórmulas; en primer lugar, la creación de reglas constitutivas crea la posibilidad de nuevas formas de conducta y, en segundo lugar, las reglas constitutivas tienen la forma " $X$ cuenta como $Y$ en $C$ ". Pero, ¿a qué se refiere Searle cuando sostiene que las reglas constitutivas crean nuevas formas de conducta? Veamos.

Lo que Searle quiere decir es que, cuando la regla es puramente regulativa, la conducta puede recibir una descripción exista o no la regla, con tal de que la descripción no haga referencia explícita a la regla. Pero, por el contrario, cuando la regla es constitutiva, la conducta que está de acuerdo con la regla no podría recibir descripciones o especificaciones si la regla no existiera. Aclararemos esto con algunos ejemplos. Como sabemos, la velocidad máxima para circular en automóvil en las calles de Buenos Aires es de $60 \mathrm{~km} / \mathrm{h}$; ahora bien, si alguien se excede en ese límite de velocidad -lo cual ocurre a menudo-, estaría obviamente transgrediendo esa norma. Podría decirse que esa persona esta transgrediendo una norma, pero no podría decirse que no está conduciendo un automóvil; podría describirse la acción de la manera, "La persona X está conduciendo a una velocidad indebida" pero de todos modos esa persona está conduciendo; es decir, puede realizarse la descripción de la actividad. Si, tomando otro ejemplo, un grupo de veintidós personas hacen movimientos similares a los que se realizan en un partido de fútbol pero siguiendo otras reglas distintas a las del fútbol, no sería posible realizar la descripción, "Ese grupo de personas está jugando un partido de fútbol", porque no habría ningún sentido en el que sus conductas pudiesen ser descriptas como una instancia de jugar al fútbol.

El tipo de reglas que a Searle más le interesa -las reglas constitutivas, que se observan claramente cuando analizamos los juegos-, especifican tipos de conducta que no podrían darse en ausencia de la regla. Nuestro conductor imprudente del ejemplo anterior, así y todo está conduciendo, hay una descripción que se ajusta a la actividad que desarrolla; pero no ocurre lo mismo con nuestro ejemplo de las veintidós personas que se mueven sin seguir las reglas del fútbol porque no se puede decir propiamente que esas personas están jugando al fútbol.

Así y todo, la formalización " $X$ cuenta como $Y$ en el contexto $C$ ", en lo referido a las reglas permanece un poco vaga. Será necesario pues, aclarar un poco este punto. Searle advierte que la formalización no es un criterio para distinguir entre las reglas regulativas y las constitutivas. Una regla regulativa puede caer bajo la formalización; así por ejemplo, 
podemos decir, "El exceder la velocidad máxima en las calles cuenta como una conducta incorrecta del conductor". Pero aquí la frase nominal que sigue a cuenta como se usa como un criterio de apreciación, no de especificación. Por eso mismo, Searle afirma que,

Cuando la regla puede ser parafraseada naturalmente de esta forma y cuando el término $Y$ es una especificación, la regla ha de ser, con toda probabilidad, constitutiva (1994, p.

45).

Acto seguido, Searle realiza dos aclaraciones. La primera emparenta a las reglas constitutivas con todo un sistema. Las reglas constitutivas aparecen generalmente dentro de un sistema; por ello, lo que se ejemplifica no son las reglas individuales dentro del sistema sino el propio sistema (el juego, por ejemplo) en su totalidad. Por ejemplo, aunque la primer regla del fútbol no se cumpla -que cada equipo tenga once jugadores-, si se siguen el resto de las reglas y se actúa conforme a ellas, la actividad cuenta como jugar al fútbol. En segundo lugar, dentro del sistema, la frase que constituye el término $Y$ no suele ser una mera etiqueta. De éste modo, "gol", "posición adelantada", "penal", no son meramente etiquetas para el estado de cosas especificado por el término $\mathrm{X}$ sino que introducen consecuencias adicionales por medio de faltas, puntos, y por el hecho de ganar o perder.

La hipótesis de Actos de habla -como lo hemos aclarado en el capítulo 3-, es que hablar un lenguaje implica realizar actos de a cuerdo con reglas; tras haber analizado el modo en que operan las reglas en la realidad institucional, Searle sostiene que,

...la estructura semántica de un lenguaje es una realización convencional de conjuntos de reglas constitutivas subyacentes, y que los actos de habla son actos realizados característicamente de acuerdo con esos conjuntos de reglas constitutivas (1994, p. 46).

Searle sostiene aquí que existen reglas constitutivas que subyacen a los actos de habla. Podríamos preguntarnos entonces sobre la diferencia, por ejemplo, ente hacer una promesa e ir a dar un paseo; ¿por qué Searle entiende que al hacer una promesa intervienen reglas constitutivas que no subyacen a la hora de salir a dar un paseo? 
Podríamos suponer que no hay ninguna diferencia entre prometer y dar un paseo porque, después de todo, se trata de actividades humanas, actividades que pretenden alcanzar ciertas metas y cumplir ciertos fines. Una parte crucial de la diferencia que Searle observa es que salir a caminar es un acto por completo natural, nuestros miembros se mueven de una manera fisiológicamente normal, que tras años de evolución nos ha permitido a los seres humanos en condiciones normales, trasladarnos de un punto hacia otro con el cuerpo totalmente erguido. Es cierto, de todos modos, que a lo largo de la historia, en determinados pueblos y tribus medievales se han adoptado formas particulares de caminar -quizás un caso conocido sea los "lotos de oro de tres pulgadas" que usaban las mujeres en la antigua China y en el Japón medieval, lo cual consistía en empequeñecer los pies a la fuerza mediante un sistema de vendajes al que eran sometidas las mujeres a partir de la temprana edad; ello era signo de sensualidad y erotismo-; ello indica que hasta un hecho tan natural como caminar se encuentra atravesado por reglas, pero se trata no de reglas constitutivas sino de reglas regulativas. Que bajo tales y cuales condiciones una persona salga a caminar no es asunto de convención alguna. Los actos de habla, por su parte, son asunto de convención. No es un hecho natural que emitir ciertas expresiones en un contexto determinado cuente como hacer una promesa. Un lenguaje no es un hecho natural y eso lo demuestra el caso del niño encontrado en Aveyron, bautizado como Víctor de Aveyron; el niño fue encontrado a la presunta edad de once o doce años y, debido a que había crecido fuera de la sociedad humana, no sabía hablar. Lo que ocurre es que el lenguaje es un hecho social, y si no le enseñamos a hablar a un niño, el infante no hablará; el lenguaje es un sistema de códigos inventado por los seres humanos con fines comunicativos.

Refiriéndose a la relación entre los actos de habla y las reglas constitutivas, Searle distingue tres cuestiones. En primer lugar, se pregunta si los lenguajes (no, el lenguaje) son o no convencionales; en segundo lugar, si los actos ilocucionarios están gobernados por reglas; y en tercer lugar, si el lenguaje está o no gobernado por reglas (1994, p. 47). La respuesta a la primera pregunta, tal como lo hemos analizado más arriba, es sí. Me encuentro escribiendo mi tesis de doctorado bajo las convenciones del idioma castellano, no del inglés o del portugués. Pero la segunda pregunta es más amplia y compleja, no se refiere a un lenguaje en particular (a los lenguajes), sino que se refiere a los actos ilocucionarios en general. Searle responde que, en general, sí tiene que haber convenciones. Para el Searle I, para el Searle que no ha virado hacia el paradigma de la conciencia, los casos que se ubican en los márgenes son las expresiones faciales y los 
actos de señalar con el dedo ${ }^{97}$. Más allá de estos casos extremos -que para Searle I no son definitorios-, los actos ilocucionarios se realizan en general, dentro de un lenguaje en virtud de ciertas reglas. Respecto a esta segunda cuestión Searle hace referencia a las reglas que subyacen a todos los lenguajes humanos; así, Searle sostiene que,

Los diferentes lenguajes humanos, en la medida en que son intertraducibles, pueden considerarse como plasmaciones convencionales de las mismas reglas subyacentes. El hecho de que en francés pueda hacerse una promesa diciendo "Je promets" y que en castellano pueda hacerse diciendo "Yo prometo", es un asunto de convención. Pero el hecho de que una emisión de un dispositivo de prometer cuente como (bajo condiciones apropiadas) la asunción de una obligación, es un asunto de reglas y no un asunto de convenciones del francés o del castellano (1994, p. 48 y 49).

Aquí se puede observar las similitudes ente los juegos y el lenguaje humano; yo podría jugar al ajedrez con una persona de otro país utilizando un antiguo tablero donde las piezas, por ejemplo y utilizando un experimento mental, sean de un tamaño distinto al que estoy acostumbrado, siendo el rey más grande y la reina más pequeña, o donde el tablero tenga otros colores. El hecho de que pueda jugar, así y todo, mi partida de ajedrez, demuestra que hay una serie de reglas que subyacen al juego y, por ello, puedo jugarlo. Lo mismo ocurre con los distintos lenguajes, podemos traducir oraciones de un lenguaje a otro porque las reglas que subyacen en uno y otro son las mismas.

Aquello que está especificado en las reglas no son efectos naturales como, por ejemplo, sentir dolor; por el contrario, no se puede producir independientemente de la invocación de algún tipo de reglas. Por ello mismo Searle aclara que no sólo son convencionales los lenguajes, sino que también cierto género de actos ilocucionarios (la mayor parte de ellos) están gobernados por reglas. Hay una serie de reglas para dar una orden, para pedir disculpas, para hacer promesas, etcétera, y todas ellas deben ubicarse en un contexto determinado.

\footnotetext{
${ }^{97}$ Aquí se observan las limitaciones que surgen a partir de la analogía entre el lenguaje y los juegos. No se puede marcar un gol sin invocar ciertas convenciones (reglas).
} 
Las tres cuestiones planteadas por Searle equivalen a, en primer lugar, ¿tienen convenciones los lenguajes?, al lo que responde sí; en segundo lugar, ¿debe haber reglas (plasmadas de alguna manera) para que sea posible realizar una acto ilocucionario en particular?, a lo cual responde que la mayoría de los actos están gobernados por reglas; y la tercera cuestión es si las convenciones son o no plasmaciones de reglas, a lo que responde que en general, si. El ejemplo del ajedrez resulta útil porque ilustra las convenciones de realización que subyacen a una práctica, cuando las convenciones son plasmaciones de reglas subyacentes, y cuando se requieren reglas, o algún tipo de convención para realizar los actos.

Searle aclara una vez más la relación entre el lenguaje y las reglas, sosteniendo que,

Cuando digo que hablar un lenguaje es participar en una forma de conducta gobernada por reglas, no estoy interesado especialmente en las convenciones particulares que se invocan al hablar este o aquel lenguaje (...), sino en las reglas subyacentes que las convenciones manifiestan o plasman, en el sentido del ejemplo del ajedrez (1994, pp. 49 y 50).

Lo que a Searle le preocupa clarificar, principalmente, es la tercera de las cuestiones planteadas más arriba. Este tercer punto es decisivo porque articula la hipótesis de que hablar un lenguaje es tomar parte de una conducta gobernada por reglas.

Para concluir su análisis sobre la relación entre actos de habla y reglas, Searle despliega dos observaciones finales (1994, pp. 50 y ss.). La primera es de carácter normativo; Searle se pregunta si debe haber una sanción al violarse una regla. Su respuesta es, no. No todas las reglas constitutivas tienen sanciones del mismo modo que en un partido de fútbol no recae una sanción cuando un equipo no cuenta con once jugadores. Este punto es curioso, por lo menos. Toda regla tiene un carácter normativo; las reglas no están hechas para ser violadas sino, por el contrario, para seguirlas. Estimamos que con esta última afirmación Searle echa por la borda el nudo central de su argumento; hasta aquí Searle sostenía que los actos ilocucionarios y las convenciones lingüísticas son (generalmente, es cierto) plasmaciones de reglas, pero ahora sostiene que no hay sanción alguna al romper la regla. Si no la hubiera, esa regla no sería tal. La sanción no es una pena fatal, nadie va a ser decapitado, por ejemplo, por no cumplir con una 
promesa en su forma correcta. El punto es que si una promesa se realiza incorrectamente, sin seguir las reglas que deben seguirse, simplemente no se la tomará por tal, la sentencia no será tomada por una promesa. Si a mi pareja le prometo regalarle un anillo de rubí valuado en ocho millones de dólares, se echará a reír, por lo menos. ¿Por qué? Porque no me creerá; ¿y por qué no me creerá? Porque sabe que se trata de una promesa insincera, porque sabe que no cuento con esa suma de dinero y supondrá (por eso la risa) que se trata de un chiste o algo por el estilo. Al no seguir la regla -0 el conjunto de reglas que subyacen a un acto ilocucionario, o a un acto de habla en general-, ese acto no se comprende. Toda regla no seguida genera algún tipo de sanción, pero no hay que entender la sanción en términos represivos únicamente, la sanción puede llegar a ser que simplemente no se entienda lo que se quiso decir a través del acto de habla.

La segunda cuestión que Searle plantea es si es posible seguir una regla sin conocerla. En este punto sostiene, y apoyamos su punto de vista, que para explicar adecuadamente un fragmento de una conducta humana debemos suponer que fue desplegada, de a cuerdo a una regla; esto es así aún cuando el agente mismo no pueda ser capaz de enunciar esa regla, e incluso puede no ser consciente de que está actuando de acuerdo con la regla. En los términos de la tradición, el hablante posee un saber práctico (know how), pero quizás no posea un saber teórico (know that). Sabe usar la regla porque a partir de su tierna infancia la ha adquirido, aprendido e internalizado, pero en un sentido importante puede no saber que conoce la regla o que actúa conforme a ella ${ }^{98}$. Searle establece dos diferencias entre el hecho de seguir reglas y, la existencia de regularidades que son totalmente pertinentes,

Dos de las marcas distintivas de la conducta gobernada por reglas, en oposición a la conducta meramente regular, consisten en el hecho de que, generalmente, conocemos las desviaciones del patrón como algo erróneo o defectivo en cierto sentido, y que las reglas, a diferencia de las regularidades, cubren, de manera automática, nuevos casos (1994, p. 51).

\footnotetext{
${ }^{98}$ Del mismo modo que no hacen falta sociólogos para que la gente viva en sociedad, tampoco hacen falta filósofos del lenguaje para que la gente haga uso de un lenguaje proposicional.
} 
Ello explica que, ante un caso que jamás ha visto con anterioridad, el agente sabe qué hacer, sabe cómo (know how) actuar.

Como nuestra preocupación en el presente trabajo no es únicamente el problema del lenguaje, es necesario que demos un paso más; un paso que nos dirija hacia una arena más amplia. Así, si es cierto que el lenguaje humano es un elemento constitutivo de la realidad institucional, y si es cierto que hablar un lenguaje implica seguir algún tipo de reglas, entonces debe existir cierto vínculo entre las reglas constitutivas y la realidad institucional. A continuación daremos cuenta de esa relación que es analizada por Searle en The construction of social reality (1995).

\section{La realidad institucional y sus reglas}

Retomando la distinción entre reglas regulativas y reglas constitutivas, sabiendo -como hemos visto más arriba-, que mientras las primeras regulan un tipo de conducta previamente existente como, "conduzca por la mano derecha de la calzada" regula la conducción de autos; pero siendo la conducción misma previa a la instauración de la norma, las reglas constitutivas no sólo regulan una actividad sino que, a la vez, crean la posibilidad misma de realizar esa actividad. Las reglas del ajedrez, del fútbol, del vóley, no regulan una actividad que existe con anterioridad sino que, muy por el contrario, crean la posibilidad de jugar al ajedrez, al fútbol y al vóley. Aquel que no siga las reglas del juego entonces no está jugando el juego. Ese tipo específico de reglas, las constitutivas, como hemos dicho anteriormente, tienen la siguiente forma lógica:

$X$ cuenta como $Y$ en el contexto $C$.

Esta formalización es la misma que, o también se aplica a, las funciones de estatus (tal como hemos visto en el capítulo anterior). La tesis de Searle -y esta es su tesis central-, es que los hechos institucionales existen sólo dentro de sistemas de reglas constitutivas (1997, p. 46). Los sistemas de reglas constitutivas crean los hechos de este tipo; además, ocasiones específicas de hechos tales como que yo anote un gol en fútbol o que Cristina Fernández de Kirchner sea la presidenta del Estado argentino, son el resultado de la aplicación de ciertas reglas específicas, de las reglas para contar un gol o para tomar 
juramento a un jefe de Estado moderno. Esas reglas son, precisamente, reglas constitutivas de la realidad institucional.

Es preciso aclarar, por otro lado, que Searle no habla aquí de convenciones sino de reglas. La diferencia que señala es la siguiente,

Es una regla del ajedrez que se gane la partida haciendo jaque mate al rey. Es una convención que la figura del rey sea mayor que la del peón. "Convención" implica arbitrariedad, pero las reglas constitutivas no son arbitrarias en ese sentido (1997, p. 46. Los destacados le pertenecen a Searle).

Pero, ¿en qué sentido no son "arbitrarias"? El significado que la tradición le otorga a la noción de arbitrariedad, como bien lo observa Searle, es el de una convención. Nosotros, los seres humano -o un grupo de nosotros-, nos hemos puesto de acuerdo (y continuamos haciéndolo) en llamar al objeto que tengo frente a mis ojos, "monitor"; a lo que me permite masticar, "dientes"; al objeto mediante el cual realizo llamadas, "teléfono", y así podríamos seguir ad infinitum. El lenguaje es asunto de convención, es una creación humana, y es por ello que es arbitrario en éste sentido que utiliza la tradición; ello da cuenta del hecho de que podría haber sido de otra manera. Podríamos haber denominado en un punto de la historia (es imposible saber precisamente cuándo y gracias a quién), a los monitores, a los dientes y a los teléfonos, de otra manera; no hay nada que lo impida porque, justamente, nosotros los hemos inventado (nos referimos a los términos). De éste modo, también las reglas constitutivas son convencionales. Que se gane una partida de ajedrez haciendo jaque mate al rey también es una convención, un hombre o un grupo de hombres han creado esas reglas, es un invento humano que podría haber sido de otra manera; para emplear la terminología de Searle, se trata de un hecho social e institucional, no de un hecho en bruto, no es equiparable al agua de los océanos o a las estrellas en el firmamento. Estas últimas no son convencionales porque no las hemos creado nosotros los seres humanos. Entonces, ¿por qué Searle sostiene que las reglas constitutivas no son arbitrarias? Estimo que Searle está aplicando otro sentido de arbitrariedad; un sentido más llano, "arbitrariedad" en el sentido de hacer lo que me venga en gana, hacer algo del modo en que se me antoje. Usando ese sentido de "arbitrariedad" se entiende el punto de Searle. Y está completamente en lo cierto; las reglas constitutivas 
no se usan del modo en que se me antoje porque si no, no se trataría de una regla. No se hace jaque mate del modo en que se me antoje, ni se anota un gol como me venga en gana.

Llegados a este punto, estimamos necesario clarificar la formalización que da cuenta de la realidad institucional, nos referimos a " $X$ cuenta como $Y$ en $C$ ". En el presente capítulo y en los dos anteriores hemos dado cuenta de las tres partes integrantes de la realidad institucional, nos referimos a la intencionalidad colectiva, la asignación de funciones y las reglas constitutivas. Todos estos elementos, junto con el lenguaje -que es el elemento fundamental que distingue a nuestra especie animal-, nos permiten a nosotros, los seres humanos, construir un ambiente que no está únicamente conformado por hechos en bruto. Lo que haremos ahora es analizar el modo en que " $X$ cuenta como $Y$ en $C$ " logra dar cuenta de la vasta realidad institucional y sus tres elementos constitutivos. Solo hemos podido llegar a éste punto tras haber analizado con algún detalle tanto a la intencionalidad colectiva, como a las funciones de estatus y normas constitutivas. Prosigamos.

\section{Sobre "X cuenta como $Y$ en C"}

En el término $Y$ se nombra algo más que los rasgos puramente físicos contenidos en el término $X$. La locución "cuenta como", nombra la imposición de un status al que se vincula una función por medio de intencionalidad colectiva. Lo característico del término $Y$ es que el estatus y la función a él vinculada, van más allá de las funciones meramente físicas (en bruto), que puedan asignarse a objetos físicos. Tal como estamos usando la fórmula, no es un ejemplo de regla constitutiva el enunciado, "objetos $Y$, están diseñados y son usados para que una persona duerma sobre ellos, cuentan como camas", porque satisfacer el término $X$ es ya suficiente para satisfacer el término $Y$, por la mera definición del término "cama". En este caso, la "regla" no añade más que un rótulo y, por ello mismo, no se trata de una regla constitutiva. Tampoco expresa una regla constitutiva decir, "objetos de una determinada forma cuentan como cama"; en este caso, las funciones asignadas pueden asignarse independientemente de cualquier acuerdo humano. Sin importar lo que el resto piense al respecto, podríamos usar un objeto como si fuese una cama. Pero no es esto a lo que Searle se refiere; la clarificación del significado de las 
reglas constitutivas queda claramente representada mediante el ejemplo del dinero. Así, Searle afirma que,

Cuando decimos que tales y tales trozos de papel cuentan como dinero, estamos en presencia de una regla constitutiva genuina, porque satisfacer el término $X$, "tales y tales trozos de papel", no es por sí mismo suficiente para ser dinero, ni determina el término $X$ rasgos causales que hubieran de resultar suficientes para permitir que el material en cuestión funcionara como dinero sin acuerdo humano (1997, p. 61).

Del mismo modo, también podríamos analizar el caso de los matrimonios. Cuando decimos que tales y tales promesas de los novios cuentan como contraer matrimonio, también estamos en presencia de una regla constitutiva; en este caso, satisfacer el término $X$, pronunciar, "Yo $N$, te tomo a ti $N$, por esposa; prometo serte fiel en lo próspero y en lo adverso, en la salud y en la enfermedad. Amarte y respetarte todos los días de mi vida", no es suficiente para estar casados, ni tampoco determina el término $X$ rasgos causales suficientes para permitir que esa promesa funcione como contraer matrimonio sin acuerdo humano. La aplicación de la regla constitutiva introduce los siguientes rasgos: el término $Y$ tiene que asignar un cierto estatus, no poseído previamente por el objeto por la sola circunstancia de satisfacer el término $X$. Además, tiene que haber acuerdo colectivo en dos sentidos; por un lado, respecto a la imposición del nuevo estatus al material al que se refiere el término $X$; por otro lado, respecto de la función que va con ese nuevo estatus. Los rasgos físicos determinados por el término $X$ (en el caso de dinero, el término $X$-el cual siempre es un hecho en bruto ${ }^{99}$-, es papel; en el caso del matrimonio, el término $X$ en cuestión son meros sonidos guturales) no bastan por sí mismos para garantizar el cumplimiento de la función determinada por el término $Y$. El nuevo status y sus funciones correspondientes tienen que tener el tipo de cosas que pueden constituirse por acuerdo o aceptación colectivos. La aceptación y el reconocimiento colectivo, no deben darse una vez y luego quedar en el olvido; debe tratarse, muy por el contrario, de una aceptación o reconocimiento colectivo continuado de la validez de la función asignada. Si así no ocurre, entonces la función no puede

\footnotetext{
${ }^{99}$ Este punto lo hemos analizado en el capítulo anterior cuando hemos discutido la prioridad de los hechos en bruto.
} 
asignarse con éxito. No basta con que estemos de acuerdo con la asignación originaria de que "este material es dinero", o de que "estas promesas sellaron el matrimonio"; tenemos que seguir aceptándolo como dinero o matrimonio o, de lo contrario, perderán su valor, su estatus.

Las mismas críticas [infundadas] que recaían sobre el Searle de Actos de habla y sobre el Austin de Cómo hacer cosas con palabras, podrían recaer en el análisis de la realidad social de Searle. Pareciera que existe un elemento mágico, suprasensible, un truco de conjuro, en la creación de hechos institucionales (y en la creación de actos de habla). Así lo cree, por ejemplo, Ricardo Guastini (1984, p. 306) quien sostiene que la obra de Searle crea una "atmósfera metafísica" innecesaria; esa atmósfera nos conduce a suponer que el mundo "se duplica" mágicamente gracias al lenguaje. Este tipo de suposiciones se deben al carácter no físico, no causal, de la relación entre los términos $X$ e $Y$, gracias al cual simplemente hacemos que las cosas $X$ cuenten como cosas $Y$. No tenemos ninguna duda cuando vemos un lavarropas o un restaurant. ¿Por qué no? Porque los rasgos puramente físicos de los objetos en cuestión les habilitan para funcionar como lavarropas o restaurantes. No renunciamos, sin embargo, a preguntarnos si es realmente $X$ un $Y$. Por ejemplo, ¿son realmente estos trozos de papel, dinero?; ¿es esta porción de territorio, propiedad privada de alguien?; vociferar ciertos ruidos en una ceremonia, ¿es realmente casarse?; hacer una serie de ruidos con la boca, ¿es afirmar o prometer? En estos casos, lo que ocurre es que la función agentiva no es cumplida exclusivamente por los rasgos físicos.

Ahora nos detendremos a analizar la estructura mediante la cual la realidad institucional funciona en las sociedades humanas reales. Nos serviremos del ejemplo del matrimonio para poner a prueba el argumento de Searle. Iremos step by step, destacando las características generales fundamentales. Ciertas clases de promesas circulan a lo largo del mundo, pero solo un grupo reducido de ellas satisfacen ciertas condiciones que encajan en el término $X$. Esas promesas deben tener ingredientes particulares y tienen que casar con un conjunto determinado de patrones. Tienen que ser emitidas, además, por cierto tipo de personas (adultos mayores) con plena conciencia de sus actos y facultades (físicas y mentales). Deben tener un contenido proposicional más o menos como sigue: "Yo $N$, te tomo a ti $N$, por esposa; prometo serte fiel en lo próspero y en lo adverso, en la saludo y en la enfermedad. Amarte y respetarte todos los días de mi vida". A ello la esposa debe responder del mismo modo diciendo, "Yo $N$, te tomo a ti $N$, por esposo..." Esas promesas deben ser emitidas ante un representante del estado (juez de 
paz) o un representante de una institución religiosa (sacerdote, rabino, etcétera). Todo ello debe suceder en un lugar adecuado, sea el registro civil o la iglesia católica, judía, etcétera. Cualquier cosa que satisfaga esas condiciones (el término $X$ ), cuenta como la unión de dos personas, como matrimonio (término Y) en la República Argentina. Describir esas promesas con el término $Y$ “matrimonio" es más que suministrar un rótulo manejable para los rasgos del término $X$; se trata de describir un nuevo estatus, y ese estatus, el matrimonio, tiene una serie de funciones ligadas a él. Algunas de esas cuestiones son el respeto mutuo, la mantención material, moral y espiritual de los hijos, la conformación de un hogar conyugal; tan importante es todo esto que se encuentra claramente expresado en el Código Civil argentino, desde el Artículo 162, hasta el 177. Pero es en virtud de las reglas constitutivas que ese grupo de promesas cuenta como "matrimonio"; la imposición de esa función de estatus por el término $Y$ tiene que ser colectivamente reconocida y aceptada; en caso contrario, la función no se cumplirá.

Los rasgos generalizables más destacados de nuestro ejemplo del matrimonio son los que siguen:

1. La intencionalidad colectiva asigna un nuevo estatus a ciertos fenómenos; ese estatus no puede ser alcanzado por los meros rasgos físicos del fenómeno en cuestión. Esta asignación de función crea un nuevo hecho, un hecho institucional, mediante acuerdo humano. $\mathrm{Y}$ si los seres humanos podemos generar acuerdos es porque poseemos un tipo particular de lenguaje: un lenguaje proposicional guiado por convenciones.

2. La forma de la asignación de la nueva función de estatus se representa mediante la fórmula, " $X$ cuenta como $Y$ en $C$ ". Esta fórmula es una herramienta (muy útil por cierto) para entender la creación de un hecho institucional; la fórmula de la intencionalidad colectiva es imponer ese estatus y su función, determinada por el término $Y$, a un fenómeno nombrado por el término $X$. Debido a que la función en cuestión no puede ser cumplida en virtud de los rasgos físicos del término $X$, y se requiere de nuestra aceptación o acuerdo para ser cumplida, es que la locución "cuenta como" es crucial en este punto. Es así como acordamos contar el objeto nombrado por el término $X$ como un objeto que posee un estatus y una función determinada por el término $Y$. Los distintos tipos de términos $Y$ 
están limitados por la posibilidad de contraer funciones cuyo cumplimiento sea garantizado por la mera aceptación o acuerdo colectivo.

3. El proceso de creación de hechos institucionales transcurren sin que los participantes sean conscientes de que están transcurriendo según esta forma. Al contraer matrimonio, la gente no suele pensar que "mediante estos actos de habla estamos fundando una institución destinada a establecer una serie de derechos y obligaciones a los fines de que no se extinga la especie humana y las sociedades sigan reproduciéndose permanentemente", aún cuando sea eso lo que están haciendo. Y ello es así por dos razones; en primer lugar, nos educamos en una cultura en la cual las instituciones se dan por sentadas, no necesitamos estar atentos o alertas respecto de su ontología; en segundo lugar, en la misma evolución de la institución, los participantes no necesitan ser conscientes de la forma de la intencionalidad colectiva que posibilita la imposición de funciones a los objetos. Es más, pueden aceptar la imposición de función a causa de alguna teoría emparentada como, por ejemplo, creer que algo es matrimonio por el hecho de "estar santificado por Dios", o porque "las bendiciones emanadas por Dios a través del sacerdote (que es un "instrumento de Dios"), insta a los cónyuges a crear un lazo que ningún ser humano puede destruir". A los fines operativos (pragmáticos), lo único que cuenta es que continúa reconociendo en la $X$, la función de estatus $Y$; de éste modo, el hecho institucional se crea y se mantiene. Es eso, más que los reconocimientos individuales, lo que cuenta a los fines de que se cree y se mantenga un hecho institucional.

4. La fórmula adquiere un estatus normativo cuando la imposición de la función de estatus se convierte en un asunto de política (interés) general. Se convierte entonces en una regla constitutiva. Por eso mismo, gracias al carácter normativo de la formula, existe la posibilidad de crear abusos que no existirían si no se tratase de una regla; en el ejemplo del casamiento, son los casos de nulidades -que no tenga la edad necesaria, que haya impedimento de ligamen por cuestiones de parentesco, por tratarse de un 
insano o demente declarado, y cosas por el estilo-; en el caso del dinero, el dinero falsificado. En esos casos, los objetos parecen satisfacer el término $X$, pero no lo satisfacen. La posibilidad de abusos de este tipo es un rasgo característico de los hechos institucionales. El que los médicos, por ejemplo, deban poseer un certificado de título que valide su práctica profesional, crea la posibilidad de que aquellos individuos que no lo posean puedan fingir que lo tengan y fingir ser médicos. Son "falsos" médicos. Incluso una persona cualificada para actuar como médico puede incurrir en prácticas que entran en contradicción con la ética profesional. Estos últimos serían considerados, "malos" médicos.

5. La distinción que Searle establece entre regla y convención es clara. Que los objetos cumplan la función de ser un medio de intercambio es asunto de regla, más que de convención; pero sí es asunto de convención qué objetos cumplen esa función. Mientras que en las sociedades modernas, las funciones de transacción económica, son cumplidas por el papel moneda, otras formaciones sociales han utilizado a esos fines ciertos materiales exóticos poco abundantes -tales como piedras preciosas o café-. Así también, en el ajedrez, las facultades del rey y la reina no son asunto de convención sino de regla; pero utilizar los colores blanco y negro para diferenciar a los jugadores, sí es asunto de convención. A menudo, los rasgos necesarios para que pueda aplicarse el término $X$ resultan esenciales para el cumplimiento del término $Y$. En el caso de la medicina, es necesario que el médico tenga la autorización para ejercer su práctica profesional (término $Y$ ), la cual tiene que fundarse sobre ciertos criterios y conocimientos (término $X$ ). Tras haber estudiado y haber obtenido su título de grado, la persona tiene un determinado estatus, es un médico.

Este juego de funciones y normas también se observa, por ejemplo, en el derecho penal. El derecho penal no es constitutivo sino regulativo; regula actividades que existen con anterioridad como, pongamos por caso, el asesinato. Antes que se cree lo que ahora denominamos derecho penal, la gente se mataba entre sí. Pero para que las regulaciones funcionen, deben 
existir sanciones; ello exige la imposición de sanciones a las personas que violan la ley. De éste modo, la persona que mata a otra (término $X$ ) en ciertas circunstancias (término $C$ ), se le asigna el estatus de "asesino" (término Y). Con este nuevo estatus y la consecuente creación del hecho institucional, vienen las penas y los castigos apropiados. La norma regulativa, "no matarás", genera la correspondiente norma constitutiva "matar, bajo determinadas circunstancias, cuenta como asesinato, y el asesinato cuenta como un crimen punible con la cárcel".

Así las cosas, la diferencia entre los martillos y los médicos, es que los martillos, gracias a su propia estructura física pueden cumplir su función; el estudiante de medicina por su parte, necesita un título que le confiera el estatus de médico. Por ello, Searle afirma que,

El acuerdo colectivo respecto de la posesión del estatus es constitutivo de la posesión del estatus, y poseer el estatus es esencial para cumplir la función asignada a ese estatus (1997, p. 67).

Lo que tiene que hacer el término $Y$ es asignar algún estatus nuevo, un estatus del que carecen las entidades nombradas por el término $X$. Es por eso que los hechos institucionales, a diferencia de los hechos en bruto, se crean. Para que ese nuevo estatus se cree, la aceptación, el acuerdo, y otras formas de intencionalidad colectiva, son razones necesarias y suficientes. Este mecanismo es el que genera la realidad institucional.

6. Existe una íntima relación entre la imposición de esas funciones de estatus $y$ el lenguaje. Los rótulos que conforman las expresiones $Y$, tales como "matrimonios", "dinero", "médico", son constitutivos de los hechos creados.

En este punto, podríamos preguntarnos si el planteo de Searle respecto a la realidad social no provoca un regreso infinito o una circularidad al tratar de explicar los conceptos que conforman la realidad social, nos referimos a conceptos tales como "matrimonio", "dinero" o "médico". En consonancia con Searle, estimamos que su planteo no es circular 
y que, más allá de su propio planteo, es posible entablar una afinidad entre su teoría de los nombres propios, y su teoría de la realidad social. Pero no será sino hasta el próximo Capítulo donde aclararemos con este punto. A continuación nos detendremos a analizar algunas críticas que se le han hecho a Searle referidas al problema de las normas.

\section{Críticas a Searle y conclusión}

En La constitución de la sociedad, obra de 1984, Anthony Giddens discute con la concepción que Searle tiene respecto a las reglas. Giddens dialoga con la formulación de Actos de habla; recordemos que Searle a esas alturas no había publicado aún La construcción de la realidad social, obra que vio la luz en el año 1995. Giddens, básicamente, encuentra sin sentido la diferenciación entre normas regulativas y normas constitutivas porque, en definitiva, ambas hacen algo esencial en términos sociológicos: ambas cumplen un papel en la construcción de un sentido, y ambas poseen un estrecho vínculo con las sanciones (2006, p. 56). En primer lugar, no es claro a qué se refieren los sociólogos cuando hablan tan vagamente sobre el sentido; su supone que se refieren al hecho de direccionar una forma de conducta. Si es así, es cierto que las reglas guían la conducta humana, como también es cierto el segundo punto que Giddens menciona; el incumplimiento de la norma, implica un tipo de sanción que, como dijimos más arriba, no siempre es de tipo represivo. Así y todo, estimamos que Giddens misunderstand the point. Es completamente cierto lo que dice Giddens, pero ello no invalida la distinción de Searle entre ambos tipos de reglas, Searle tiene razón a la hora de distinguir un tipo de reglas que regulan un tipo de realidad previamente existente, de otras que constituyen y posibilitan la existencia misma de una actividad. La distinción no es ociosa; por el contrario, es pertinente para comprender la formalización, " $X$ cuenta como $Y$ en el contexto $C^{\prime \prime}$. El tipo de reglas constitutivas son fundamentales para comprender el funcionamiento de la realidad institucional.

Por otro lado, Joseph Raz, en su obra Razón práctica y normas (1991), sostiene que todas las reglas (tanto las regulativas como las constitutivas) son simultáneamente, regulativas y constitutivas (1991, pp. 126 y ss.). La distinción de Searle, para decirlo de otro modo, es innecesaria. En, Clasificar acciones, Daniel González Lagier se ubica a mitad de camino entre Searle y Raz, sosteniendo que, 
Me parece que esta diferencia existe [entre reglas regulativas y constitutivas], aunque probablemente no sea lo suficientemente marcada como para poder trazar una línea divisoria tajante entre los dos tipos de normas (p. 265).

González Lagier hace pasar su argumento por las descripciones; de este modo, mientras que las reglas regulativas admiten descripciones naturales e institucionales, las reglas constitutivas sólo admiten descripciones institucionales. Por descripciones institucionales González Lagier entiende a las descripciones interpretativas; sostiene, por ejemplo, que no podemos describir los movimientos corporales de una partida de ajedrez, sin haberlos interpretado (p. 273). Pero existen otro tipo de descripciones, las descripciones naturales; éstas últimas pueden ser interpretativas (como por ejemplo, pedir auxilio), o no interpretativas (como agitar los brazos). La tesis de González Lagier es que las reglas regulativas pueden ser descriptas como una conducta no interpretada, como una acción natural interpretada, o como una acción institucional; las reglas constitutivas, por otra parte, pueden ser descriptas como una conducta no interpretada, o como una acción institucional. Debido a que los dos tipos de reglas dan lugar a acciones institucionales, González Lagier concluye que la distinción es puramente de grado, las reglas constitutivas tienen mayor "fuerza constitutiva".

Creemos, por nuestra parte, que la distinción establecida por Searle entre un tipo de normas y otro, permanece en pie. Estimamos que la diferenciación resulta útil en pos de su argumentación porque le permite aclarar aquello que le interesa: que la realidad institucional tiene una estructura normativa, y en esa estructuración, las reglas que mayor relevancia tienen son aquellas que coinciden con la forma lógica del lenguaje y de las funciones de estatus; esa forma lógica es la de las reglas constitutivas, a saber, " $X$ cuenta como $Y$ en el contexto $C^{\prime \prime}$.

A continuación, en el último Capítulo, llevaremos a cabo una revisión del modo en que Searle aborda la comprensión de aquello que hemos convenido en denominar, conceptos institucionales. No conformes con el tratamiento que Searle realiza al respecto, apelaremos al andamiaje conceptual desplegado por Saúl Kripke, específicamente a su teoría de los designadores rígidos, estimando que la comprensión de los conceptos institucionales posee mayor claridad a partir de la teoría de su teoría. Ello posibilitará un avance hacia la clarificación de la teoría de la realidad social que Searle ha desplegado. 


\section{Capítulo 9: Los conceptos institucionales. Una aproximación}

\section{Planteamiento del problema}

En el presente capítulo, plantearemos una última cuestión que nos permitirá acceder a una mayor comprensión de la obra de Searle en particular, y de la realidad institucional en general. Existe cierta vinculación, y el propio Searle la destaca (1997), entre la "teoría cúmulo" de los nombres propios desarrollada en Actos de habla (1968) y en Nombres propios y descripciones $(1958)^{100}$, y su teoría de la realidad social. Veamos.

A la hora de intentar esbozar cualquier definición de la palabra "matrimonio", "dinero" o "médico", no se produce un regreso infinito o circularidad. Las definiciones no son tautológicas; no decimos, por ejemplo, "un matrimonio es un matrimonio", o "dinero es todo aquello que es dinero". Searle entiende los conceptos de la realidad social -que aquí los denominaremos conceptos institucionales, tales como, "matrimonio", "dinero", "modernidad", "capitalismo", "historia", etcétera-, como un nódulo dentro de una gran red de prácticas de derechos, obligaciones, cuidados, satisfacción de necesidades, intercambios (materiales en el caso del dinero, y afectivos en el caso del matrimonio), prácticas de apropiación, compras y ventas, créditos, endeudamientos y cosas por el estilo. En La construcción de la realidad social (1997), el propio Searle sostiene que,

Mientras se conciba al objeto en el desempeño de su papel en las prácticas, no necesitamos realmente que la palabra "dinero" figure en la definición del dinero, de manera que no hay circularidad ni regreso infinito alguno. La palabra "dinero" funciona como una reserva de plaza para la articulación lingüística de todas esas prácticas. Para saber que algo es dinero no se necesita realmente la palabra “dinero" (1997, pp. 68 y 69).

\footnotetext{
${ }^{100}$ Ver J. R. Searle, “Nombres propios y descripciones” (1958), en Luis Valdés Villanueva (ed.), La búsqueda del significado, Tecnos, Madrid, 1991, pp. 83 a 93.
} 
Un concepto refleja toda una serie de relaciones, algo así como una compleja red, un entramado en el cual un concepto se teje con otro y nos permite comprender una enorme maraña institucional. Tras años de entrenamiento en la vida institucional, hemos olvidado lo que tanto nos ha costado comprender aquello que hoy nos parece sumamente sencillo. La enorme complejidad queda al descubierto, por ejemplo, cuando nos interesamos en una problemática que no es de nuestra incumbencia cotidiana y con la cual no estamos familiarizados (por ejemplo, el mercado bursátil, el de la especulación financiera, o los tecnicismos del mundo del derecho). Es allí donde volvemos a vivenciar la complejidad de la realidad institucional y se nos torna evidente la maraña, el entramado altamente complejo que conforman las instituciones humanas. La metáfora del "entramado" es altamente gráfica, y por ello útil; un concepto se relaciona con otro, y éste con otro más, hasta conformar un enorme "tejido". Y es aquí donde aparece la relación entre la teoría del los nombres propios de Searle (la teoría cúmulo, como se la suele denominar) y la teoría de la realidad institucional. A continuación, y en primer lugar, veremos de qué se trata la teoría cúmulo desarrollada por John Searle para, en un segundo momento, esbozar una posición superadora; para ello, nos detendremos en la teoría de Kripke sobre los designadores rígidos.

\section{Teoría cúmulo y realidad institucional}

Searle sostiene (1958) que el problema que ha partido las aguas al interior de la filosofía del lenguaje es si los nombres propios tienen sentido del mismo modo que los adjetivos, nombres comunes y descripciones definidas. A partir de allí, se han establecido dos posiciones bien diferenciadas: las teorías millianas y las teorías descripcionalistas de los nombres propios. Para Mill (1889), un nombre común, como "perro", tiene connotación y denotación. Connota aquellas características específicas en una definición de "perro" (por ejemplo, ladrar, mover la cola al ponerse contento, inhalar y exhalar por la boca sacando la lengua, etcétera); y denota todos los perros. Pero, ¿qué ocurre con los nombres propios? Estos últimos, por su parte, sólo denotan a su portador. Los nombres propios tienen una referencia necesaria y no tienen sentido.

Para Frege (1985) ${ }^{101}$ y Russell (1903), por el contrario, si los nombres propios representan objetos y nada más, ¿cómo podrían, enunciados tales como "a es idéntico a b", transmitir

\footnotetext{
${ }^{101}$ Nos referimos puntualmente a su artículo, Sobre sentido y referencia del año 1892.
} 
información fáctica? Si interpretamos tales enunciados únicamente a partir de la referencia, nos encontramos ante una trivialidad puesto que, si son verdaderos, no hacemos más que decir que un objeto es idéntico a sí mismo. Si, por el contrario, entendemos a los enunciados como dando información acerca de los nombres, parece que deben ser arbitrarios, ya que parece ser posible asignar cualquier nombre que deseemos a un objeto. La solución de Frege consistió en ofrecer un tercer elemento en virtud del cual se refiere un objeto; nos referimos al concepto, sentido. Para utilizar un ejemplo ya clásico y de la propia cosecha de Frege, si decimos "Héspero" y "Fósforo", no hacemos más que utilizar dos sentidos para hacer referencia a un mismo objeto, a saber, el planeta Venus. El sentido proporciona el modo de presentación del objeto. Dentro de este planteo no hay arbitrariedad alguna; todos los nombres propios tienen sentido del mismo modo que "la estrella de la tarde" y "la estrella de la mañana".

Según la teoría clásica (Mill) los nombres propios tienen necesariamente una referencia pero no tienen sentido; según la teoría de Frege, los nombres propios, esencialmente tienen sentido y, contingentemente refieren a algo en el mundo; un nombre propio, adecuadamente utilizado, es una descripción definida abreviada o disfrazada.

Searle, por su parte, encuentra pros y contras dentro de los dos grandes grupos de teorías acerca del significado de los nombres propios. Entiende que los nombres propios no son descripciones definidas porque llamar a un objeto por su nombre no es, en modo alguno, describirlo, como así tampoco, definirlo; por otra parte, no todos conocemos las mismas características del portador de un objeto; además, las propiedades que conocemos de su portador son contingentes. Si bien tales consideraciones pesan a favor de la teoría milleana, ella también presenta serias dificultades. En primer lugar, como hemos aclarado líneas más arriba, no puede dar cuenta de la ocurrencia de nombres propios en enunciados informativos de identidad; en segundo lugar, también es incapaz de explicar la ocurrencia de los nombres propios en enunciados existenciales. Tal es el caso de la afirmación, "El hombre de la bolsa no existe"; aquí negamos la existencia de algo que afirmamos. Otro problema de la teoría milleana es la vacuidad del nombre propio; cuando ello ocurre, no existe el nombre propio. El último problema identificado por Searle respecto a la teoría de Mill, es el referido a la muerte del objeto; si el portador del nombre propio muere, también lo hace el nombre propio; -el último Wittgenstein resolvió el problema estableciendo una distinción ente el portador del nombre propio y el significado del mismo-.

La solución que Searle ofrece al problema del significado de los nombres propios, puede 
ser entendida en los términos de una suerte de compromiso entre Mill y las posiciones descripcionalistas (Frege y Russell). Mill estaba en lo cierto al suponer que los nombres propios no tienen definiciones, pero Frege también lo estaba al suponer que cualquier término singular debía tener un sentido; su error residió en tomar la descripción identificadora que puede sustituirse por el nombre, como una definición.

Si bien puede decirse que los nombres propios tienen un sentido, éste es impreciso, flexible. Las características descriptivas que constituyen la identidad del objeto no funcionan como descripciones, sino más bien como "perchas" (la metáfora es del propio Searle) en las que colgamos las descripciones. El significado de los nombres propios lo otorga, no una descripción, sino un conjunto (un "cúmulo") de descripciones, el cual es disyuntivo, es decir, no es necesario ofrecer todas las descripciones del portador del nombre propio. Tenemos la institución de los nombres propios para realizar el acto de habla de la referencia. Sin descripciones, la referencia es imposible.

Si la propuesta de Searle es, podríamos llamar, descripcionalista crítica, el caso de Kripke (2005) es marcadamente distinto. A continuación nos centraremos en la posición de Kripke debido a que la consideramos una teoría superadora de los nombres propios, y una plataforma a partir de la cual obtenemos un mejor tratamiento del problema que aquí nos ocupa, la comprensión de los conceptos institucionales. Así, según sostiene Kripke (2005), los nombres actúan como designadores rígidos; es decir, un nombre designa al mismo objeto en todo mundo posible. Ahora bien, ¿a qué se refiere Kripke cuando sostiene que los nombres son "designadores rígidos"? ¿Qué es un "mundo posible"? Comenzaremos respondiendo a la segunda de las preguntas.

\section{Designadores rígidos y conceptos institucionales}

\section{I.}

Ante todo, es preciso aclarar que un mundo posible no es un país extraño al que se lo puede alcanzar mediante un telescopio. Un mundo posible, por el contrario, esta dado mediante las condiciones descriptivas que asociamos a él. Cuando decimos, por ejemplo, "En otro mundo posible yo no hubiera escrito mi tesis de 
doctorado", simplemente imaginamos una situación en la cual yo decidí no hacer un doctorado en filosofía. No imaginamos todo aquello que pueda ser verdadero o falso sino, únicamente aquellas cosas relevantes al hecho de hacer $\mathrm{mi}$ correspondiente tesis. Los mundos posibles no se descubren, sino que se estipulan. No hay razón por la cual no podamos estipular que al hablar de mí en cualquier situación contrafáctica, hablamos acerca de mí. Aunque sea cierto que yo podría haber cursado el doctorado en otra Universidad dentro de veinte años; así y todo, nadie más que yo, Ariel Dottori, podría haber sido Ariel Dottori. Este es el test que satisface la prueba intuitiva para establecer que los nombres propios son designadores rígidos. Lo mismo vale para cualquier propiedad que yo pueda o no tener, excepto que algunas de éstas propiedades sean esenciales. Aquello que Kripke niega es que un particular no sea más que un "haz de propiedades".

Kripke adscribe a la teoría de la rigidez de los nombres propios y ello significa que, mientras que los nombres propios son rígidos, las descripciones son flexibles. La fijación de la referencia de un nombre se produce mediante aquello que denomina bautismo inicial, el cual es una ostensión entendida como una descripción primitiva. Luego de ese "bautismo primero" la referencia se transmite causalmente, de hablante a hablante; se trata de una tarea social en la cual hay un compromiso de conservación de la referencia.

Lo que aquí sostenemos es que la comprensión de la realidad institucional -más precisamente aquello que denominamos, conceptos institucionales-, opera de un modo similar a la de los nombres propios. Searle deja entrever que aquello que nosotros hemos denominado conceptos institucionales, se emparentan con su teoría cúmulo de los nombres propios; así sostiene que la realidad institucional se va complejizando cada vez más porque los seres humanos estamos en un proceso permanente de agregación de descripciones identificatorias a la realidad institucional. Para un infante por ejemplo, el dinero, es un medio para comprar golosinas y figuritas en el kiosco; a medida que pasan los años le vamos agregando nuevas descripciones -es el valor de la venta de la fuerza de trabajo, es un medio de compra y venta, es el objeto de una transacción bursátil, un medio de capitalización por medio del ahorro, y cosas por el estilo-. Cuantas más 
descripciones seamos capaces de agregarle al concepto "dinero", lograremos generar una comprensión más amplia, más rica del dinero en tanto que objeto. Por eso mismo, el conocimiento y el manejo de los conceptos es fundamental para la vida de los individuos concretos que viven en sociedad. Cuantas más descripciones identificadoras sea capaz un individuo de vincular a un concepto, mayor capacidad de acción tendrá. A ello hacía referencia Francis Bacon cuando sostenía que el saber es poder. Y esto es más evidente en nuestras sociedades avanzadas. Ser padre es sencillo; cumplir las funciones de padre esperables en nuestras sociedades modernas (Contexto $C$ ), no lo es tanto. Para cumplir con esas funciones debo conocer los deberes, derechos y obligaciones que me ligan a la vida de mi hijo. Desconocer las descripciones identificatorias de la paternidad como institución genera que se active la normatividad social, identificándose a ese padre como un mal padre, o cosas por el estilo.

Cuantas más descripciones seamos capaces de identificar a un concepto, con mayor profundidad conoceremos la realidad institucional a la que se refiere porque, y este es el punto fuerte de la presente tesis, la realidad institucional está constituida por conceptos; todo lo que no sea del orden lingüístico pertenece a otro ámbito, pertenece al mundo de la naturaleza, a los hechos en bruto, para utilizar la terminología de Searle. Si hay una diferencia entre naturaleza y cultura es que la primera está desprovista de lenguaje; pero, sin embargo, no debemos suponer que hay una brecha insalvable entre una y otra; después de todo, los que hacemos la realidad institucional por medio del lenguaje, la intencionalidad colectiva, las funciones de estatus y las reglas constitutivas somos nosotros, los seres humanos; seres bilógicos con "la misma" carga genética que el resto de los animales de nivel superior. Los seres humanos somos una parte de la naturaleza que, gracias a los elementos que antes hemos mencionado, podemos hacer algo más: eso "de más", es el mundo social e institucional. En el siguiente apartado, nos centraremos en el modo en que debemos abordar la comprensión de los conceptos institucionales.

II. 
Aquí plantearemos una última discrepancia con Searle. SI bien nos parece acertada su vinculación entre una teoría de los nombres propios y los conceptos institucionales, estimamos conveniente reemplazar su teoría cúmulo por la posición que Kripke sostiene respecto a los nombres. La tesis que aquí defendemos es que los conceptos institucionales operan como designadores rígidos; así por ejemplo, el concepto dinero, matrimonio, Estado, presidente, y otros por el estilo, son capaces de mantener su significado en otros mundos posibles. No deseamos explayarnos largamente sobre la teoría de los nombres propios desarrollada por Kripke pero, para seguir avanzando en nuestro análisis nos resulta imprescindible analizar parte de su constructo teórico.

Debemos aclarar, en primer lugar, a qué se refiere Kripke cuando habla de un mundo posible. En palabras de Kripke,

\begin{abstract}
Un mundo posible está dado mediante las condiciones descriptivas que asociamos con él. ¿Qué queremos decir cuando decimos: "En otro mundo posible yo podría no haber dado esta conferencia hoy?" Simplemente imaginamos la situación en la que no decidí dar esta conferencia o decidí darla algún otro día $(2005$, p. 47 . Los destacados le pertenecen a Kripke).
\end{abstract}

En este caso, para comprender qué es un mundo posible, no debemos centrarnos en todas las cosas que puedan ser verdaderas o falsas, sino sólo en aquellas que son relevantes al hecho de que Kripke haya dado o no su conferencia. Podemos imaginar que Kripke hubiera dado su conferencia unas horas más tarde o al día siguiente, y cosas por el estilo; eso mismo es un mundo posible. Se trata de una suposición -o una serie de suposiciones-, sobre una situación dada; por eso mismo, Kripke sostiene que los mundos posibles no se descubren sino que se estipulan (2005, p. 47). No hay razón por la cual no podamos estipular una situación contrafáctica al hablar de la conferencia de Kripke; pero así y todo, estaríamos hablando de lo que hubiera -o no-, hecho él. No hay razón que nos impida señalar al hombre y hablar de lo que él hizo o pudiera haber hecho en una situación contrafáctica, hipotética, en la cual los sucesos podrían haber sido diferentes. Lo que se necesita es un criterio de identidad a través de los mundos que nos permita identificar ciertas condiciones (necesarias y suficientes) cualitativas para identificar un 
nombre propio.

De esta manera, Kripke incluye la noción de "identidad a través de mundos posibles". Esta noción refiere a ciertas características que pueden ser modificadas en otro mundo; pero hay ciertas otras características que no pueden ser modificadas en otro mundo posible. Es posible imaginar una situación contrafáctica en la cual Kripke no haya dado su conferencia a las 7 sino a las 9 pm; pero no tiene sentido suponer que en otro mundo el número 7 no sea menor que el número 9. Cuando algo designa al mismo objeto en todo mundo posible, Kripke (2005, pp. 51 y ss.) habla de designador rígido; cuando ocurre lo contrario, lo denomina designador no rígido o accidental. En palabras de Kripke,

Cuando pensamos que una propiedad es esencial al objeto, lo que generalmente queremos decir es que es verdadera del objeto en cualquier caso en el que el objeto hubiese existido. Un designador rígido de algo necesariamente existente puede llamarse rígido en sentido fuerte [strongly rigid]. (2005, p. 51. Los destacados le pertenecen a Kripke).

En, El nombrar y la necesidad (2005), Kripke sostiene la tesis de que los nombres son designadores rígidos. De éste modo, por ejemplo, aunque el hombre (Kripke) podría no haber dado sus conferencias sobre nombres propios, o podría no haberle dedicado su vida a la filosofía y a la lógica modal, no es el caso que pudiera no haber sido Kripke. Lo que sucede es que nos referimos rígidamente a Kripke cuando lo nombramos.

En una obra posterior, Philosophical Troubles (2011), Kripke aplica su noción de designador rígido al uso de la primera persona ${ }^{102}$. La tesis que intentamos defender aquí es que también puede aplicarse el mismo tratamiento para el caso de los conceptos institucionales. Kripke niega explícitamente la posición de Searle y su teoría cúmulo (2005, pp. 63 y ss.) puesto que sostiene que no es cierto que un particular no sea más que un "haz de cualidades" (2005, p. 55). Para identificar, por ejemplo, una mesa no se debe pensar en el conjunto, en el "haz", de sus propiedades; por el contrario, cuando pregunto si la mesa se podría encontrar en otra habitación o si podría ser de otra textura y color, estoy hablando por definición, de ella. Aquello que intenta establecer Kripke es que un nombre no es identificable por sus propiedades, sino que siempre son designadores rígidos; y aquello que fija la referencia es esa posibilidad de ser llamado, y no algún tipo

\footnotetext{
${ }^{102}$ Ver principalmente el Capítulo 10, The First Person, pp. 292-321.
} 
de descripción.

\section{Palabras finales}

Por nuestra parte sostenemos que conceptos tales como guerra, matrimonio, historia, capitalismo, etcétera, también poseen -al igual que los nombres propios-, una referencia rígida. Es cierto que en otro mundo posible, el asesinato del Archiduque de Austria Francisco Fernando podría no haber desatado una guerra en Europa; pero no tendría sentido suponer que una guerra no es un conflicto bélico. Y ello no tiene sentido porque el concepto institucional guerra opera como un designador rígido. En ningún otro mundo posible una guerra puede ser algo distinto a un conflicto armado entre Estados; por ello, estimamos conveniente entender los conceptos institucionales del mismo modo en que Kripke analiza a los nombres y a la primera persona. 


\section{Conclusiones}

El presente puede ser considerado como un estudio crítico de la obra de Searle o, mejor dicho, de algunos de los elementos que consideramos necesarios a la hora de desarrollar una ontología de lo social, un lugar intermedio entre la filosofía del lenguaje y la teoría social. Más arriba hacíamos referencia a un "estudio crítico" porque el presente trabajo no se trata de una mera introducción a la obra de Searle. Si bien consideramos que, grosso modo, su teoría es satisfactoria, nos hemos encontrado con ciertas imprecisiones o perspectivas que, según nuestra posición teórica, debieran ser revisadas. Así, consideramos que si se adopta la perspectiva de Searle, sin su viraje hacia el paradigma de la conciencia, los elementos conceptuales tendrían una potencialidad analítica mucho más rica, y los análisis futuros serían más acertados.

Partiendo de esa premisa, en el Capítulo I, "Sobre el realismo externo", hemos reivindicado el tan criticado realismo externo de Searle. Vale recordar que su posición realista opera como un requisito de trasfondo, algo así como una "petición de principio" que nos permite guiar el análisis de la realidad social e institucional. El realismo externo, para decirlo de otro modo, nos permite demarcar un conjunto de problemas que al teórico de lo social -tanto en el terreno filosófico, como sociológico y antropológico- le resultan pertinentes. La demarcación entre un tipo de hechos (en bruto), y otro tipo de hechos (sociales e institucionales) es adecuada a tales fines; pero no por ello debemos suponer que los teóricos de lo social deben hacer a un lado a los hechos en bruto. En última instancia, quienes construyen a diario el mundo social o, para expresarlo en términos antropológicos, el mundo cultural, son los seres humanos, es decir, seres biológicos (en bruto). Pero la demarcación, según sostiene Searle (y también nosotros), es útil para enfocar el análisis. Por nuestra parte, no hacemos más que defender -al margen de ciertos matices- sus lineamientos generales.

El Capítulo II, "Conciencia y lenguaje", debe entenderse como un esfuerzo por "redireccionar" la posición de Searle; es aquí donde Searle realiza un quiebre y vira hacia el paradigma de la conciencia intencional. Este "retroceso" (en palabras de Apel) que desarrolla Searle al abandonar el punto de vista del linguistic turn, queda evidenciado en el peculiar tratamiento que despliega respecto a la determinación del significado. Si bien, y de la mano de Apel, no desdeñamos -por completo- el rol de la conciencia intencional, consideramos acertado el modo en que el paradigma de la filosofía (analítica) del lenguaje 
aborda el problema de la fijación (lingüística) del significado. Por ello, nuestras reflexiones son guidas, centralmente, por las posiciones de Dummett y Tugendhat. $Y$ ello nos parece acertado, no sólo en lo que a la fijación del significado se refiere, sino que, la perspectiva analítica que se ha venido desarrollando en el mundo anglosajón a partir de los esfuerzos de Frege y Russell, ha sido productiva para abordar problemáticas referidas al problema del lenguaje; pero no únicamente del lenguaje. En un sentido más amplio, sus conceptualizaciones nos permiten abordar problemáticas referidas a la realidad institucional en general.

Pero si pretendemos dar cuenta de la relevancia que tiene el lenguaje para una teoría de la sociedad, es preciso aclarar de qué hablamos cuando hablamos del lenguaje. Esa tarea clarificadora la hemos desarrollado en el Capítulo III, "Los actos de habla", donde nos hemos centrado en el análisis de la teoría de Searle de los actos de habla. Pero no nos hemos detenido allí con gran detalle, y ello no es debido al capricho, o a la falta de pertinencia de la problemática sino, muy por el contrario, porque consideramos que el Searle de Actos de habla ha sido ampliamente revisado y discutido en el mundo de habla hispana. Lo nos interesó desde un primer momento, ha sido desplegar un análisis de ese Searle "desconocido", de ese que ha pasado desapercibido por el mundo académico de nuestro país y del mundo castellano, pues no contamos con una sola tesis sobre la teoría de la realidad institucional de Searle en lengua castellana.

Por su parte, la vinculación entre el lenguaje y el mundo social ha sido tematizada a partir del Capítulo IV, "Lenguaje y sociedad"; en dicho capítulo hemos comenzado a adentrarnos, precisamente, en cuestiones referidas a la realidad institucional en sentido estricto, y al papel que juega el lenguaje en la formación y renovación de esa porción de la realidad. Como sabemos a partir de Austin, el papel de los actos declarativos en la construcción de hechos institucionales -tales como, "los declaro marido y mujer", "le declaramos la guerra al país $X^{\prime \prime}$ - es altamente relevante. En este punto, y de la mano de Searle, hemos observado el papel que tienen las reglas en la realidad institucional; allí radica una de las críticas más sugestivas a los teóricos del contractualismo. Ningún contrato es susceptible de ser celebrado por fuera del lenguaje y, como sabemos a partir del segundo Wittgenstein, dominar un lenguaje implica un seguimiento de reglas. Donde hay reglas, hay lenguaje; y sólo se domina un lenguaje guiado por convenciones lingüísticas cuando los seres humanos interactúan entre sí.

De éste modo, preguntarnos por las relaciones inter-humanas, por el mundo que construyen a partir de esa interacción (los hechos institucionales, para utilizar la 
terminología de Searle), implica la pregunta more basic, “¿qué es el ser humano?” Y ello es así porque, al contrario de aquello que sostienen los teóricos de los sistemas en el ámbito sociológico, el mundo de la cultura se encuentra creado por seres humanos. Por eso mismo, en el Capítulo V, “Un enfoque antropológico", nos hemos centrado en esa pregunta kantiana, relevante no sólo en términos filosóficos y antropológicos, sino también a nivel sociológico. Aquí las problematizaciones de Searle no nos han permitido abordar nuestro problema de un modo adecuado; por ello mismo, hemos analizado el problema antropológico fundamental a partir de las nociones generales desplegadas por Ernst Tugendhat. Su abordaje se centra en la comprensión humana y el lenguaje proposicional. Habiendo advertido, en el Capítulo II, que el lenguaje posee una prioridad metodológica respecto a la conciencia para la fijación del significado, al haber dado cuenta de la teoría de los actos de habla y de su pertinencia a la hora de plantear una relación (fundamental) entre lenguaje y sociedad, estamos en condiciones de plantear nuestro problema del modo en que queremos hacerlo; se trata de elaborar una teoría de la sociedad que no suponga el lenguaje, sino que, muy por el contrario, se edifique a partir del lenguaje guiado por convenciones lingüísticas. Esta tarea sólo puede ser posible a partir de una revisión crítica del retroceso de Searle hacia un enfoque intencionalista, mentalista.

Pero nuestra tarea no concluye en este punto, sino que recién aquí nos encontramos en condiciones de avanzar en nuestro análisis para poder dar cuenta del resto de los elementos que, junto con el lenguaje, nos permiten crear hechos sociales e institucionales. En el Capítulo VI, "La intencionalidad colectiva", hemos analizado el primero de esos elementos fundamentales. En lo referido al problema de la intencionalidad colectiva, estamos de acuerdo con Searle en ciertos puntos, pero no en todos. Consideramos junto con su planteo, que la intencionalidad colectiva no es producto de la sumatoria de creencias individuales más las creencias mutuas ("yo creo que tú crees que yo creo, etcétera"); la intencionalidad colectiva, muy por el contrario, se encuentra siempre ya operando en el ser humano. Pero Searle da un paso más, y sostiene que se trata de un fenómeno biológico primitivo. Biológico, no adquirido. $\mathrm{Y}$ hasta este punto estamos de acuerdo con Searle, pero, de la mano de Tomasello, damos otro paso para sostener que se trata de una característica específica de nuestra especie animal. Esta capacidad estrictamente humana de hacer cosas juntos, es el primer elemento necesario -además del lenguaje, vale aclarar-, para construir un mundo institucional.

El segundo de esos elementos -la asignación de función-, ha sido analizado en el Capítulo VII, que se intitula precisamente, "Asignación de función"; allí nos hemos 
detenido en un aspecto central del presente trabajo. Nos referimos a la formalización de la realidad social, la cual tiene la forma, "Un $X$ cuenta como $Y$ en el contexto $C$ ". Esta formalización tiene la capacidad de dar cuenta de los vastos modos en que los seres humanos creamos muestro mundo institucional. Así, por ejemplo, hacer una promesa en un contexto $C$ determinado (y aquí el contexto es fundamental), cuenta como contraer matrimonio; pronunciar las aserciones en un contexto $C$ preciso, cuenta como iniciar la cesión en la Cámara de Senadores de la Nación. Los ejemplos son variados y evidentes, pero no por ello la formalización deja de ser verdadera; y allí radica la riqueza del planteamiento de Searle: es efectivo. Todo aspecto de la realidad institucional puede ser descrito mediante la formalización, "En un contexto $C$, un $X$ cuenta como $Y$ ".

En el Capítulo VIII, "El problema de las normas", nos hemos detenido en el último elemento que conforma la realidad institucional; nos referimos a las normas constitutivas. Ya hemos retomado (en el Capítulo III) al segundo Wittgenstein para sostener que todo lenguaje implica un seguimiento de reglas; aquí Searle amplía el análisis al sostener que existe cierto tipo de reglas, aquellas que también tienen la forma, " $X$ cuenta como $Y$ en $C$ ", que no sólo regulan la realidad institucional, sino que la constituyen. Por nuestra parte, no hemos hecho más que defender la noción de que la realidad institucional posee una estructura normativa y que el conjunto de la realidad institucional puede ser analizado a partir de la formalización, "Un $X$, en un contexto $C$, cuenta como un $Y$ ".

Finalmente, en el Capítulo XIX, "Los conceptos institucionales. Una aproximación”, nos hemos detenido en el análisis de ciertos conceptos, tales como, "Historia", "clase social", "estado", "dinero", -a los que hemos denominado conceptos institucionales-, y hemos adoptado la teoría de los designadores rígidos elaborada por Kripke en Naming and Necessity (1981) debido a que la consideramos una teoría mucho más satisfactoria y elaborada que aquella desplegada por el propio Searle (nos referimos a su tan conocida "teoría cúmulo" de los nombres propios). Consideramos que la adopción de la teoría de Kripke a la hora de comprender los conceptos institucionales constituye un genuino avance en la comprensión de dichos conceptos. Su desarrollo en el presente trabajo tiene, sin embargo, el carácter de embrionario debido a que no consideramos que el presente sea el lugar para encarar un estudio riguroso al respecto. Preferimos analizar la problemática en trabajos posteriores y con la seriedad y minuciosidad que requiere. Aquí nos hemos contentado con plantear el problema y mostrar, al menos a grandes rasgos, las diferencias entre los planteos de Searle y Kripke. 
Para finalizar, sólo nos resta resaltar lo que decíamos unas cuantas líneas más arriba, los seres humanos tenemos "algo de más" que no se encuentra en el resto de los animales de nivel superior, y precisamente, la obra de Searle debe ser entendida como un esfuerzo por entender eso "de más", ese plus que tenemos los seres humanos que, para bien o para mal, nos permite crear dinero, universidades, presidentes, matrimonios, guerras. $Y$ Searle lo hace bien; su teoría es altamente útil y completa porque -más allá de las discrepancias que hemos planteado-, nos permite comprender cabalmente el modo en que operan (y gracias a qué elementos operan) las instituciones humanas.

Con todo, hemos consideramos relevante poner en discusión la obra de Searle -o una parte de ella al menos, ya que no es posible abordar cincuenta años de producción teórica en un solo trabajo-, debido a lo útil que resulta su andamiaje conceptual a la hora de elaborar una teoría de la realidad social o, como preferimos denominarla, una ontología de lo social. En muchas oportunidades se critica a un autor porque su posición está descaminada en buena medida; en otras ocasiones se lo discute porque ha sabido ver algunos problemas que son centrales. Este segundo caso expresa lo que aquí hemos desarrollado. La crítica es algo natural dentro del ámbito de las ciencias y la filosofía, y no por ello debe suponerse que un autor está descaminado por completo. Dentro del ejercicio del pensamiento no hacemos más que elaborar críticas; si aquí hubiéramos dicho: "vean, lo que dice Searle está muy bien", no habría tesis posible. Lo que se espera es que se valoren los puntos fuertes, y se discutan las debilidades echando mano a otras corrientes, a otras tradiciones, a otros autores. $Y$ eso mismo hemos hecho -o al menos lo hemos intentado-. 


\section{Bibliografía consultada}

- Apel, Karl-Otto, (1972-73) Transformation der Philosophie, Vol 1, Sprachanalytik, Semiotik, Hermeneutik, Suhrkamp Verlag, Frankfurt am Main. (Traducido por Adela Cortina Orts, (1985), La transformación de la filosofía. Tomo l: Análisis del lenguaje, semiótica y hermenéutica, Taurus, Madrid.)

- Apel, Karl-Otto, (1976) Transformation der Philosophie, Vol.2: Das Apriori der Kommunikationsgemeinschaft, Suhrkamp Verlag, Frankfurt am Main. (Traducido por Adela Cortina Orts, (1985ª), La transformación de la filosofía. Tomo II: El a priori de la comunidad de comunicación, Taurus, Madrid.)

- Apel, Karl-Otto (1994), Semiótica filosófica, edición, traducción y estudios introductorios de J. de Zan, R. Mailiandi, D. Michelini, Almagesto, Bs. As.

- Apel, Karl-Otto (2002), Semiótica trascendental y filosofía primera, ed. Síntesis, Madrid. - Aristóteles (2007), Ética Nicomáquea, Gredos, Madrid.

- Aristóteles (2007 $)$, Política, Gredos, Madrid.

- Austin, John (1962), How to do Things with Words, Oxford University Press. (Traducido al castellano por Genaro Carrió y Eduardo Rabossi, (2008), Cómo hacer cosas con palabras. Palabras y acciones, Paidós, Bs. As.)

- Berkeley, George (2013), Obras completas, Gredos, Madrid.

- Blanco Salgueiro, Antonio (2004), Palabras al viento. Ensayo sobre la fuerza ilocucionaria, Trotta, Madrid.

- Bourdieu, Pierre; Chambordeon, Jean-Claude y Passeron, Jean-Claude (2004), El oficio de sociólogo. Presupuestos epistemológicos, Siglo XXI, Bs. As.

- Bourdieu, Pierre (2007), El sentido práctico, Siglo XXI, Bs. As.

- Bourdieu, Pierre (2008), ¿Qué significa hablar? Economía de los intercambios lingüísticos, Akal, Madrid.

- Bratman, Michael (1992), "Shared co-operative activity", Philosophical Review. USA.

- Carnap, Rudolf (1985), Fundamentación lógica de la física, Orbis, Madrid.

- Carnap, Rudolf (1990), Pseudoproblemas en la filosofía, UNAM, México.

- Cassirer, Ernst (1998), Filosofía de las formas simbólicas I, FCE, México.

- Cassirer, Ernst (2013), Filosofía de las formas simbólicas II, FCE, Bs. As.

- Cassirer, Ernst (1998), Filosofía de las formas simbólicas III, FCE, México.

- Descartes, René (2004), Discurso del método, Alianza, Madrid.

- Descartes, René (2010), Reglas para la dirección del espíritu, Alianza, Madrid. 
- Davidson, Donald (1984), Inquiries into Truth and Interpretation, Oxford University Press. (Traducido por Guido Filippi, (2001), De la verdad y de la interpretación. Fundamentales contribuciones a la filosofía del lenguaje, Gedisa, Barcelona.)

- Dummett, Michael (1978), Truth and other enigmas, Gerald Ducnworth \& Company Ltd., Londres. (Traducción de Alfredo Herrera Patiño (1990), La verdad y otros enigmas, FCE, México.

- Dummett, Michael (1993), Origins of Analytical Philosophy, Hardvard University Press, USA.

- Dupré, John (2003), Darwin's Legacy: What Evolution Means Today, Oxford University Press. (Traducido por Mirta Rosenberg, (2007), El legado de Darwin. Qué significa hoy la evolución, Katz, Bs. As.)

- Durkheim, Emile (1982), La división del trabajo social, Akal, Madrid.

- Durkheim, Emile (2003), El suicidio, Losada, Bs. As.

- Durkheim, Emile (2003 $)$, Lecciones de sociología. Física del las costumbres y el Derecho y otros escritos sobre el individualismo, los intelectuales y la democracia, Miño y Dávila, Bs. As.

- Durkheim, Emile (2004), Las reglas del método sociológico y otros escritos, Alianza, Madrid.

- Frege, Gottlob (1985), Estudios sobre semántica, Hyspamerica, Madrid.

- Frege, Gottlob (2007), The Foundations of Arithmetic, Pearson Education, Inc. USA.

- Freud, Sigmund (2001), Obras completas, Amorrortu, Bs. As.

- Gadamer, Hans-Georg (1977), Wahrheit und Methode, J. C. B. Mohr, Tübingen.

(Traducido por Ana Agud Aparicio y Rafael de Agapito, (1993), Verdad y Método, Tomo 1 , Sígueme, Salamanca.)

- Gadamer, Hans-Georg (1986), Wahrheit und Methode, J. C. B. Mohr, Tübingen. (Traducido por Manuel Olasagasti, $\left(1993^{a}\right)$, Verdad y Método, Tomo 2, Sígueme, Salamanca.)

- Giddens, Anthony (1976), New Rules of Sociological Method: A Positive Critique of Interpretative Sociologies, Stanford University Press. (Traducido por Salomón Merener, (2001), Las nuevas reglas del método sociológico. Crítica positiva de las sociologías comprensivas, Amorrortu, Bs. As.)

- Giddens, Anthony (1984), The Constitution of Society. Outline of the Theory of Structuration, Polity Press, Cambridge. (Traducido por José Luis Etcheverry (2006), La constitución de la sociedad. Bases para la teoría de la estructuración, Amorrortu, Bs. As.) 
- Giddens, Anthony (1994), El capitalismo y la moderna teoría social, Labor, Barcelona.

- Gilbert, Margaret (1989), On social facts, Princeton University Press, Princeton.

- Goodman, Nelson (1968), Laguages of Art: An Approach of a Theory of Symbols, Oxford University Press. (Traducido por Jem Cabanes (2011), Los lenguajes del arte:

aproximación a la teoría de los símbolos, Paidós, Bs. As.)

- Goodman, Nelson (1978), Ways of worldmaking, Hackett Publishing Company, USA. (Traducido por Carlos Thiebaut (1990), Maneras de hacer mundos, Visor, Madrid.)

- Goodman, Nelson (1984), Of Mind and Other Matters, Harvard University Press, USA. (Traducido por Rafael Guardiola (1995), De la mente y otras materias, Visor, Madrid.)

- Gonzalez Lagier, Daniel (1993), Clasificar acciones. Sobre la crítica de Raz a las reglas constitutivas de Searle, en "Doxa: Cuadernos de Filosofía del Derecho", No. 13.

- Grice, H. P. (1957), Meaning, en "The Philosophical Review", Vol. 66, N. 3, Cornell University.

- Guastini, Ricardo (1984), Teoría de las reglas constitutivas: Searle, Ross, Carcaterra, en "Alf Ross. Estudios en su homenaje", Revista de Ciencias Sociales, Universidad de Valparaíso.

- Habermas, Jürgen (1981), Theorie des kommunikativen Handelns. Band I, Suhrkamp Verlag, Frankfurt am Main. (Traducido por Manuel Jiménez Redondo (2002), Teoría de la acción comunicativa. Vol. I, ed. Taurus, Mexico.)

- Habermas, Jürgen (1981a), Theorie des kommunikativen Handelns. Band II, Suhrkamp Verlag, Frankfurt am Main. (Traducido por Manuel Jiménez Redondo (1999), Teoría de la acción comunicativa. Vol. II, ed. Taurus, España.)

- Habermas, Jürgen (1985), Der Philosophische Diskurs der Moderne, Suhrkamp Verlag, Frankfurt am Main. (Traducido por Manuel Jiménez Redondo (2008), El discurso filosófico de la modernidad, Katz, Bs. As.)

- Habermas, Jürgen (1988), Nachmetaphysisches Denken, Suhrkamp Verlag, Frankfurt am Main. (Traducido por Manuel Jiménez Redondo (1990), Pensamiento postmetafísico, Taurus, Madrid.)

- Habermas, Jürgen (1999), Vahrheit und Rechtfertigung, Suhrkamp Verlag, Frankfurt am Main. (Traducido por Manuel Jiménez Redondo (2007), Verdad y justificación, Trotta, Madrid.)

- Heidegger, Martín (1927), Sein und Zeit, Max Neimeyer Verlag, Tübingen. (Traducción de José Gaos (2009), El Ser y el Tiempo, FCE, Bs. As.) 
- Husserl, Edmund (1900), Logische Untersuchungen. Erste Teil: Prolegomena zur Reinen Logik, Leipzig, Veit. (Traducido por Manuel G. Morente y José Gaos (1976), Investigaciones lógicas, Revista de Occidente, México.)

- Husserl, Edmund (1913), Ideen zu einer reinen Phänomenologie und phänomenologischen Philosophie, Halle, Alemania. (Traducido por José Gaos (1992), Ideas relativas a una fenomenología pura y una filosofía fenomenológica, FCE, México.) - Husserl, Edmund (1952), Ideen zu einer reinen Phänomenologie und phänomenologischen Philosophie. Zweites Buch: Pänomenologische Untersichungen zur Konstitution, Kluwer Academic Publishers B. V. (Traducido al castellano por Antonio Zirión Q. (2005), Ideas relativas a una fenomenología pura y una filosofía fenomenológica. Libro segundo: Investigaciones fenomenológicas sobre la constitución, FCE. México.)

- Kant, Immanuel (2010), Lógica, Corregidor, Bs. As.

- Kripke, Saúl (1981), Naming and Necessity, Basil Blackwell Publisher, Oxford. (Traducido por Margarita M. Valdés (2005), El nombrar y la necesidad, UNAM, México.) - Kripke, Saúl (1982), Wittgenstein on Rules and Private Language, Blackwell Publishing Ltd, Oxford. (Traducido por Jorge Rodríguez Marqueze (2006), Wittgenstein a propósito de Reglas y Lenguaje privado, Técnos, Madrid.)

- Kripke, Saúl (2011), Philosophical Troubles. Collected Papers, Volume 1, Oxford University Press, Oxford.

- Kuhn, Thomas (2007), La estructura de las revoluciones científicas, FCE, México.

- Lepore, Ernest y Van Gulick, Robert (1993), John Searle and his critics, Blackwell, USA.

- Luhmann, Niklas (1998), Complejidad y Modernidad, Trotta, Madrid.

- Luhmann, Niklas (1998 $\left.{ }^{a}\right)$, Sistemas Sociales: Lineamientos para una Teoría General, Anthropos, Madrid.

- Marx, Karl (1994), La cuestión judía y otros escritos, Planeta-Agostini, Bs. As.

- Marx, Karl (2002), El capital. El proceso de producción del capital, Tomo 1, Vol. 1, Libro primero, Siglo XXI, Bs. As.

- Merton, Robert (1987), La Teoría y Estructuras Sociales, FCE, México.

- Mill, John Stuart (1889), System of Logic. Ratiocinative and Inductive, People's edition, Londres.

- Moretti, Alberto (2008), Interpretar y referir. Ejercicios de análisis filosófico, Grama, Bs. As.

- Navarro Reyes, Jesús (2010), Cómo hacer filosofía con palabras. A propósito del desencuentro entre Searle y Derrida, FCE, Madrid. 
- Peirce, Charles (2012), Obra filosófica reunida, Tomos 1 y 2, FCE, Bs. As.

- Piaget, Jean (1952), The origins of intelligence in children, International Universities Press, New York.

- Popper, Karl (1990), La lógica de la investigación científica, Tecnos, Madrid.

- Putnam, Hilary (1987), The many faces of realism, Open Court Publishing Company, La Salle, Ltd. (Traducido al castellano por Margarita Vázquez Campos y Antonio Manuel Liz Gutiérrez (1994ª), Las mil caras del realismo, Paidós, Barcelona.)

- Putnam, Hilary (1994), Cómo renovar la filosofía, Cátedra, Madrid.

- Raz, Joseph (1991), Razón práctica y normas, Centro de Estudios Constitucionales, Madrid.

- Ruben, David-Hillel (1985), The Metaphysics of the Social World, Routledge \& Kegan Paul, London.

- Ruben, David-Hillel (1997), John Searle's "The Construction of Social Reality", Philosophy and Phenomenological Research, Vol. LVII, № 2, June.

- Russell, Bertrand (1948), Human Knowledge. Its Scope and Limits, Routledge ed. Traducido por Néstor Mínguez (1984), El conocimiento humano, Hyspamerica, Bs. As.)

- Russell, Bertrand (1993), Ensayos filosóficos, Altaya, Bs. As.

- Russell, Bertrand (1905), On denoting, originally printed in Mind, new series, 14 (1905): 479-493; text from Logic and Knowledge, ed. Robert Marsh. (Traducido en (1983), Sobre el denotar.)

- Rust, Joshua (2009), John Searle, Continuum International Publishing Group, New York.

- Roice, Josiah (2009), Lectures on modern idealism, Yale University Press, Yale.

- Roice, Josiah (1961), Principles of Logic, Wisdom Library, California.

- Salgueiro, Antonio Blanco (2004), Palabras al viento: ensayo sobre la fuerza ilocucionaria, Trotta, Madrid.

- Saussure, Ferdinand de (2007), Curso de lingüística general, Tomo 1, Losada, Bs. As.

- Saussure, Ferdinand de $\left(2007^{a}\right)$, Curso de lingüística general, Tomo 2, Losada, Bs. As.

- Schaeffer, Jean-Marie (2009), El fin de la excepción humana, FCE, Bs. As.

- Searle, John (1969), Speech Acts: An Essay in the Philosophy of Language, Cambridge University Press. (Traducido al castellano por Luis M. Valdés Villanueva (1994), Actos de habla, Planeta-Agostini, Bs. As.)

- Searle, John (1979), Expression and Meaning: Study in the Theory of the Speech Acts, Cambridge University Press, Cambridge y New York. 
- Searle, John (1983), Intentionality. An Essay in the Philosophy of Mind, The Syndicate of the Press of the University of Cambridge, England. (Traducido por Enrique Ujaldón Benítez (1993), Intencionalidad. Un ensayo en la filosofía de la mente, Altaya, Bs. As.) - Searle, John \& Vanderveken, Daniel (1985), Fundations of illocutionary logic, Cambridge University Press, Cambridge.

- Searle, John (1995), The construction of social reality, The Free Press, New York.

(Traducido al castellano por Antoni Domenech (1997), La construcción de la realidad social, Paidós, Barcelona.)

- Searle, John (1997 $\left.{ }^{a}\right)$, The Mystery of Consciousness, The New York review of Books, New York.

- Searle, John (1998), Mind, Language and Society. Philosophy in the Real World, The MIT Press, California. (Traducido por Jesús Alborés Rey (2004), Mente, lenguaje y sociedad. La filosofía en el mundo real, Alianza, Madrid.)

- Searle, John (1999), The Rediscovery of the Mind, The MIT Press, USA. - Searle, John (2001), Rationality in Action, The MIT Press, USA. (Traducido por Luis M. Valdes Villanueva, (2001), Razones para actuar. Una teoría del libre albedrío, Nobel, Madrid.)

- Searle, John (2003), Minds, Brains and Science, Harvard University Press, Cambridge, Massachusetts.

- Searle, John (2004), Realism Reconstructed: a Reply, The Philosophical Forum, Volume XXXV, No. 3.

- Searle, John (2004a) Mind: A Brief Introduction, Oxford University Press. (Traducido por Horacio Pons (2007), La mente. Una breve introducción, Norma, Colombia.)

- Searle, John (2007), Freedom \& Neurobiology. Reflections of Free Will, Language and Political Power, Columbia University Press, New York.

- Searle, John (2010), Making the Social World. The Structure of Human Civilization, Oxford University Press, USA.

- Simmel, Georg (1939), Sociología, Espasa-Calpe, Bs. As.

- Simmel, Georg (2003), La ley individual y otros escritos, Paidós, Bs. As.

- Simmel, Georg (2007), De la esencia de la cultura, Prometeo, Bs. As.

- Tarsky, Alfred (1962), Fundamentación de la semántica científica, UBA-FFyL, Bs. As.

- Tarsky, Alfred (1965), La concepción semántica de la verdad, UBA-FFyL, Bs. As.

- The Stanford Encyclopedia of Philosophy (2014), Stanford University Press, United States. 
- Tsohatzidis, Savas (2007), Intentional acts and institutional facts. Essays on John Searle's Social Ontology, Published by Springer, The Netherlands.

- Tsohatzidis, Savas $\left(2007^{a}\right)$, John Searle's Philosophy of Language. Force, Meaning and Mind, Cambridge University Press, Cambridge.

- Tomasello, Michael (1999), The cultural origins of human cognition, Hardvard University Press, Cambridge. (Traducido por Alfredo Negrotto (2007), Los orígenes culturales de la cognición humana, ed. Amorrortu, Bs. As.)

- Tomasello, Michael (2009), Why we cooperate, The MIT Press, USA. (Traducido por Elena Marengo (2010), ¿Por qué cooperamos?, Katz, Bs. As.)

- Tomasello, Michael $\left(2010^{\mathrm{a}}\right)$, Origins of Human Communication, The MIT Press, Cambridge, Massachusetts.

- Tugendhat, Ernst (1979), SelbsbewuBtein und Selbstbestimmung. Sprachanalytische Interpretationen, Suhrkamp Verlag, Frankfurt am Main. (Traducido por Rosa Helena Santos-Ihlau (1993), Autoconciencia y autodeterminación. Una interpretación lingüísticoanalítica, FCE, Madrid.)

- Tugendhat, Ernst (1983), Logisch-semantische Propädeitik, GmbH \& Co., Stuttgart. (Traducido al castellano por Guillermo Hoyos Vásquez (1997), Propedéutica lógicosemántica, Anthropos, Barcelona.)

- Tugendhat, Ernst (1992), Philosophische Aufsätze, Suhrkamp Verlag, Frankfurt am Main. (Traducción, Rosa Helena Santos-Ihlau (1998), Ser, Verdad, Acción. Ensayos filosóficos, Gedisa, Barcelona.)

- Tugendhat, Ernst (1993a), Vorlesungen über Ethik, Shurkamp Verlag, Frankfurt am Main. (Traducido por Luis Román Rabanaque (2010), Lecciones de ética, Gedisa, Barcelona.)

- Tugendhat, Ernst (1997), Egozentrizität und Mystik, Verlag C. H. Beck oHG, München. (Traducido por Mauricio Suárez Crothers (2004), Egocentricidad y mística, Gedisa, Barcelona.)

- Tugendhat, Ernst (2001), Problemas, Gedisa, Barcelona.

- Tugendhat, Ernst (2003), Introducción a la filosofía analítica, Gedisa, Barcelona.

- Tugendhat, Ernst (2007), Anthropologie statt Metaphysic, C. H. Beck. (Traducido al castellano por Daniel Gamper Sachse, Mónica Jaramillo Ocampo, Rafael Sevilla y Mauricio Suárez Crothers (2007), Antropología en vez de metafísica, Gedisa, Barcelona.) 
- Tugendhat, Ernst (2009), Traditional and Analytical Philosophy. Lectures on the philosophy of language, Cambridge University Press, Cambridge.

- Tuomela, Raimo (2007), The philosophy of the sociality: The shared point of view, Oxford University Press, Oxford.

-Valdés Villanueva, Luis Ml. (1991), La búsqueda del significado: lecturas de filosofía del lenguaje, FCE, Madrid.

- Weber, Max (1979), La ética protestante y el espíritu del capitalismo, Península, Barcelona.

- Weber, Max (1996), Economía y sociedad, FCE, México.

- Weber, Max (2001), Ensayos sobre metodología sociológica, Amorrortu, Bs. As.

- Winch, Peter (1990), Ciencia social y filosofía, Amorrortu, Bs. As.

- Wittgenstein, Ludwig (2008), Investigaciones filosóficas, Crítica, Madrid.

- Wittgenstein, Ludwig (2009), Tractatus logico-philosophicus, Alianza, Madrid.

- Wright, Larry (1973), Functions, en "The Philosophical Review", Vol. 82, No. 2, USA. 